\title{
ENHANCING FORM-BASED CODE: A PARAMETRIC APPROACH TO URBAN VOLUMETRIC MORPHOLOGY IN HIGH DENSITY CITIES
}

BY

YINGYI ZHANG

\author{
A thesis \\ submitted to the Victoria University of Wellington \\ in fulfilment of the requirements for the degree of \\ Doctor of Philosophy \\ in \\ Architecture
}

Victoria University of Wellington

2019 


\begin{abstract}
Parametric tools have been broadly implemented in Architecture, Engineering and Construction (AEC) industry. Recently, an increasing volume of research finds that parametric tools also have the capability to facilitate large-scale planning and urban design. Much of this research, however, focuses on parametric representation or environment simulation. There is insufficient research about using parametric tools to enhance urban regulation. Parametric tools can provide smart design procedures by integrating strategies, solutions and expressions in one system. They may allow alternative approaches to urban regulation that conventional tools do not process.
\end{abstract}

This research aims to create a parametric modelling system to aid urban regulation. The system offers a visualised coding interface to manipulate parameters and achieve interactive performance feedback at the early stage of urban regulation. Form-Based Code uses the modelling system in this research. It generates a specific morphology by controlling physical form with less focus on land use. With the rise of New Urbanism, Form-Based Code has been used in various American regulation projects. This research extends the application of Form-Based Code, adopting it for urban-peripheral environments outside of the USA. High-density cities where provide the volumetric morphology context is important for this work. Tsim Sha Tsui area of Hong Kong works as an experimental site.

The feasibility of parametric urban regulation is examined by developing a parametric modelling system for Form-Based Code in Hong Kong. Understanding the site's form characteristics, the transect matrix of Form-Based Code is expanded by incorporating multi-layered zone types and regulating plans. Embedding the zones into parametric modelling software Rhinoceros $3 \mathrm{D}$ and Grasshopper 3D, a regenerative prototype works to create real-time 
scenarios responding to parameters, rules and geometry constraints. The results of parametric urban regulation are evaluated by both Form-Based Code standards and local urban regulation standards to assess its feasibility in context.

This research demonstrates that the parametric modelling system for FormBased Code has both technological and implemental potential to work as an alternative approach to urban regulation, especially in complex developments. Form complexity is a reflection of sophisticated human-society systems and the sequential evolution of a dynamic morphology. Form-Based Code is enhanced by the parametric modelling system to describe and regulate form complexity in a logical manner. Additionally, although parametric Form-Based Code processing is based on the original Form-Based Code, it is not limited to that. Describing urban regulation with visualised models bridges specialists and the public in community demonstrations and code assembling. The parametric modelling system has a positive impact on resolving challenges, predicting outcomes, and applying urban regulation innovation to the volumetric morphology of high-density cities in Asia. 


\section{Acknowledgements}

My $\mathrm{PhD}$ study at Wellington was highly enjoyable and memorable. I owe my sincere appreciation to the people who generously gave me their support and company over the years.

First and foremost, I would like to express my special thanks to my supervisor Prof. Marc Aurel Schnabel, who has given me endless inspiration and encouragement. His dedicated advice and boundless energy always motivate me to keep my research on track. I appreciate all his contributions to making my $\mathrm{PhD}$ experience cool, fun, and productive. I could not have completed this dissertation without him.

I would like to also thank my friends and colleagues: Serdar Aydin, Sky Tian Tian Lo, Harry Yi He, and Shuva Chowdhury. Thank you for sharing your professional viewpoints to help me overcome barriers. And thanks for supporting me to make my research time enjoyable. Thank you too, all of the friends I met in New Zealand. My time was enriched by your company. I will treasure our beautiful memories my whole life.

Lastly, I would like to thank my parents and family. I would not have had the courage to start my $\mathrm{PhD}$ study without them. They taught me to have grace under pressure. They encouraged me to strive forward and prepared a warm harbour for me to return to. Words cannot express how grateful I am.

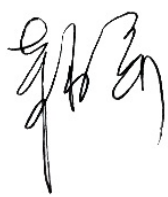




\section{Papers Published During Study}

Y. Zhang and M. A. Schnabel (2019): A use of Form-Based Code for volumetric morphology of high-density cities. Advances in Science, Technology and Engineering Systems Journal, forthcoming.

Y. Zhang and M. A. Schnabel (2018). Parametric thinking in form-based code evaluation. Journal of Environmental Science and Sustainable Development, Vol.3, 2018.12, pp.89-99.

M. A. Schnabel, Y. Zhang, and S. Aydin (2017): Using parametric modelling in Form-Based Code design for high-dense cities, Procedia Engineering, Vol. 18, pp. 1379-1387.

Y. Zhang and M.A. Schnabel (2017): A workflow of data integrating and parametric modelling in urban design regulation. Proceedings of 51st International Conference of the Architectural Science Association (ANZScA), Wellington, New Zealand, pp.139-148.

S. Chowdhury, M. A. Schnabel, and Y. Zhang (2017): Form processing: the regeneration of urban codes towards predictable neighbourhoods. Proceedings of 10th International Urban Design Conference, Queensland, Australia, 17 pgs.

Y. Zhang and M.A. Schnabel (2017): Parametric Modelling in Form-Based Urban Design Code for high-density cities. Proceedings of 2017 Annual Symposium on Simulation for Architecture and Urban Design (SimAUD), Society for Modelling \& Simulation International (SCS), Toronto, Canada, pp. 265-272.

Y. Zhang and M.A. Schnabel (2016): Mapping Volumetric Urban Space: A 
Critical Development Analysis of Multilevel Morphology of High-dense Cities. Proceedings of 11th International Symposium on Architectural Interchanges in Asia (ISAIA), Sendai, Japan, pp. 1785-1790.

M.A. Schnabel, Y.Zhang, and S. Aydin (2016): Using parametric modelling in Form-Based Code design for high-dense cities. Proceedings of International High-Performance Built Environment Conference - A Sustainable Built Environment Conference 2016 Series (SBE16), iHBE 2016, Sydney, Australia, 9 pgs.

Y. Zhang and M. A. Schnabel (2016): Form-based Code (FBC) Modelling for Urban Design of High-dense Cities. Proceedings of 2016 Symposium on Simulation for Architecture and Urban Design (SimAUD), Society for Modelling \& Simulation International (SCS), London, UK, pp. 147-152.

Y. Zhang and M. A. Schnabel (2016): Form-Based Code in Parametric Modelling for Continuous Urban Design. Proceedings of the 21st International Conference of the Association for Computer-Aided Architectural Design Research in Asia CAADRIA 2016, Melbourne, Australia, pp. 33-42. 


\section{Contents}

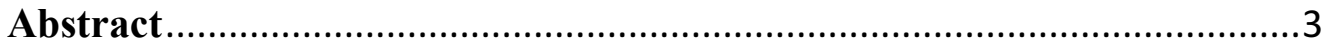

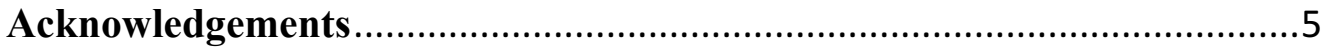

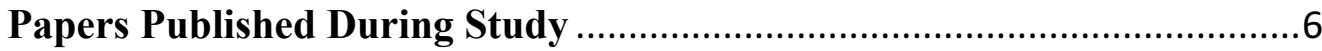

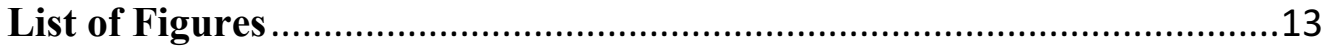

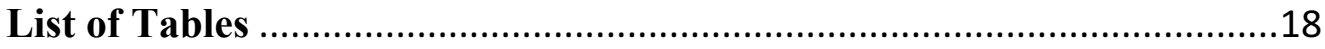

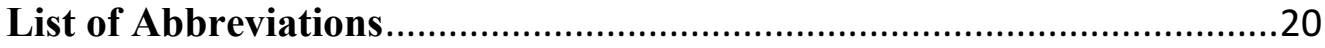

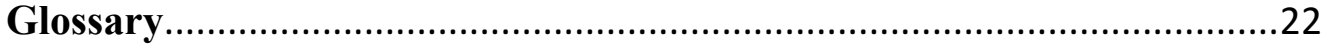

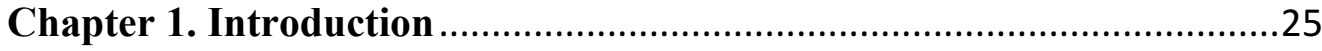

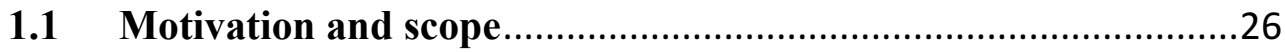

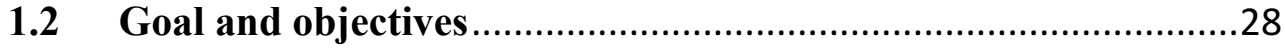

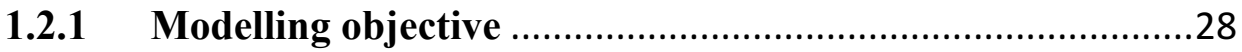

1.2.2 Implementation objective ..............................................29

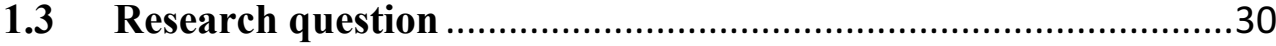

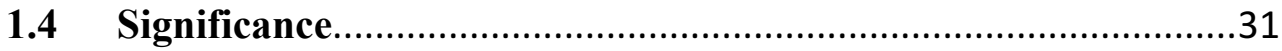

1.4.1 Complex urban regulation .............................................. 31

1.4.2 New approaches to Form-Based Code .................................31

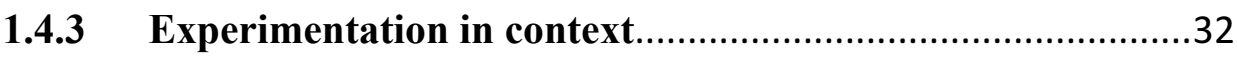

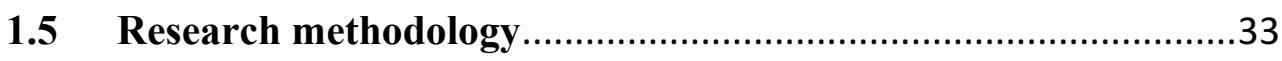

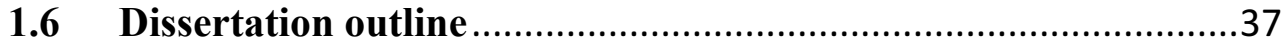

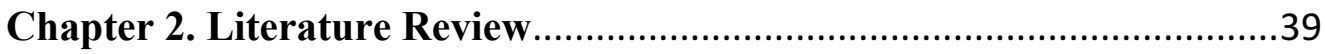

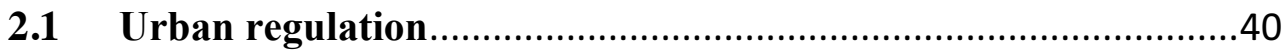

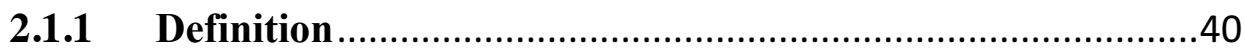

2.1.2 Approach to land use regulation ......................................41

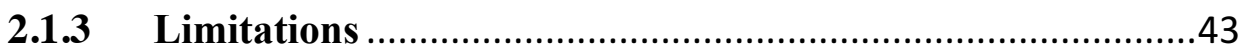

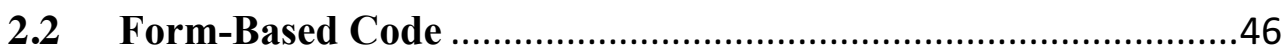

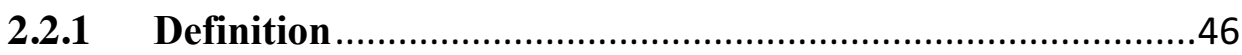

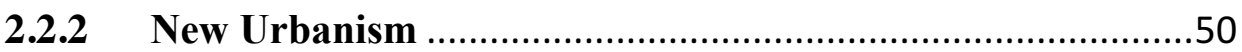

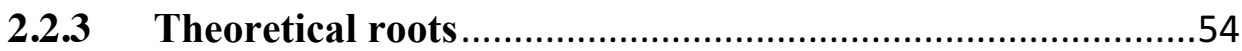

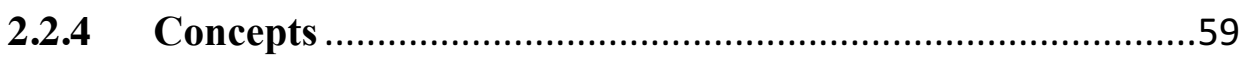

2.3 Challenges of Form-Based Code................................................73 


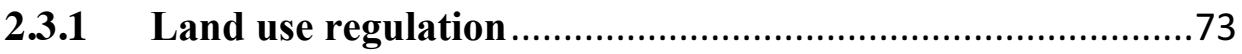

2.3.2 Morphology hierarchy ................................................ 74

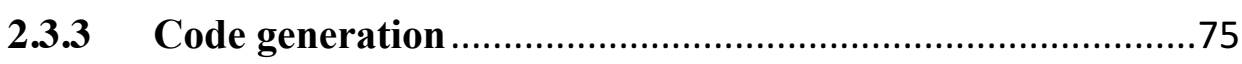

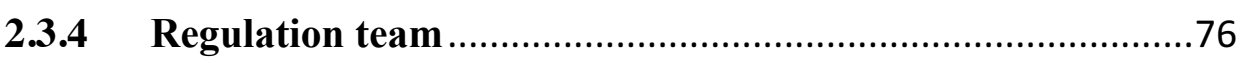

2.4 Phases and tools of Form-Based Code ......................................78

2.4.1 Documenting ..................................................................... 78

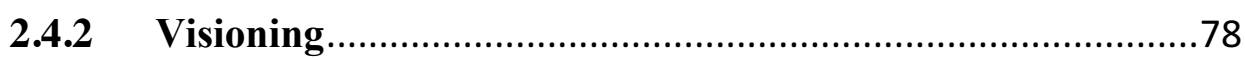

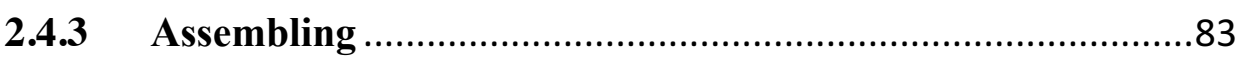

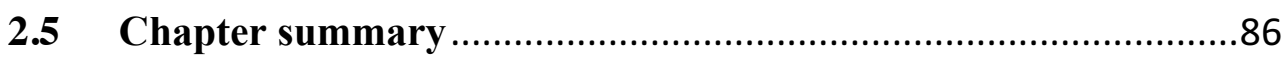

Chapter 3. Examples of Form-Based Code ...............................................87

3.1 Borys, Talen and Lambert's Code Study..................................8

3.2 Review description .................................................................91

3.3 Smart Code Montgomery ....................................................93

3.3.1 Main components .......................................................93

3.3.2 Main parameters ....................................................97

3.3.3 Adoption results...........................................................99

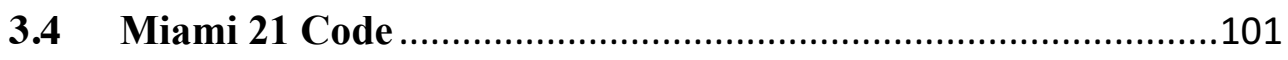

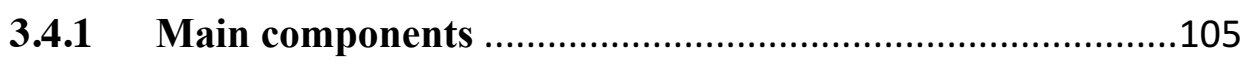

3.4.2 Main parameters .......................................................107

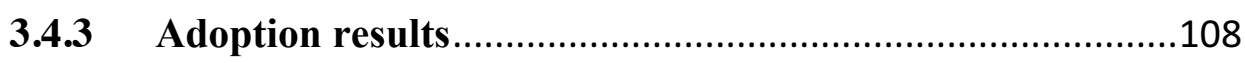

3.5 Downtown Code for Nashville ...................................................110

3.5.1 Main components …...................................................110

3.5.2 Main parameters .......................................................112

3.5.3 Adoption results............................................................114

3.6 East Billings Renewal District Code .......................................116

3.6.1 Main components ........................................................116

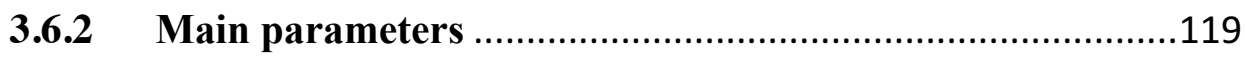

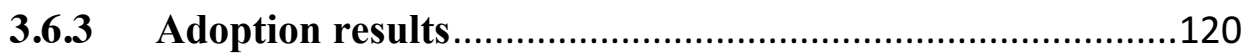

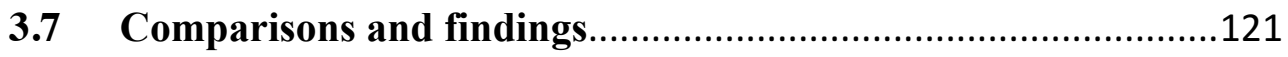

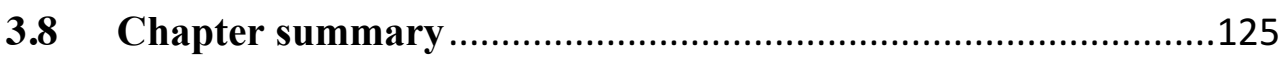

Chapter 4. Form Transecting and Results ...............................................126

4.1 Understand the context ......................................................128 


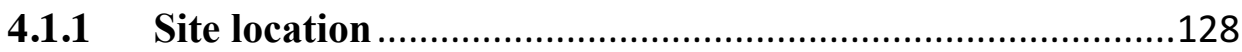

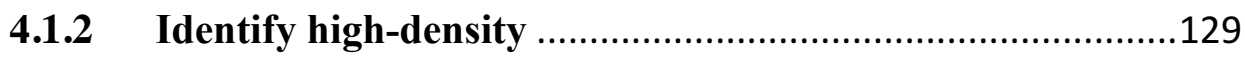

4.1.3 Volumetric morphology ............................................134

4.1.4 Regulation peculiarities in high-density situations .............138

4.2 Field study and physical data collection .................................141

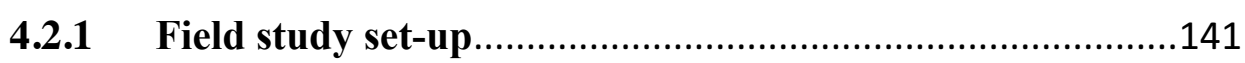

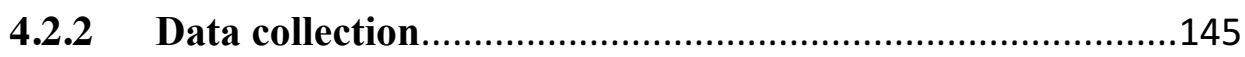

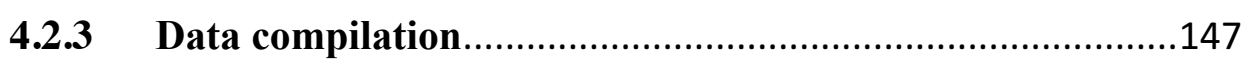

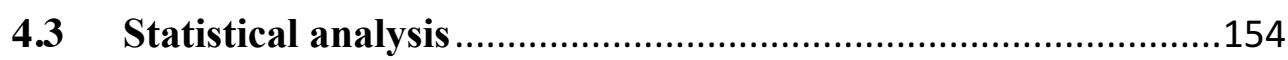

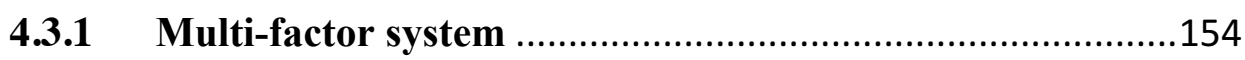

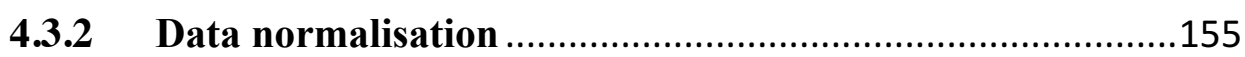

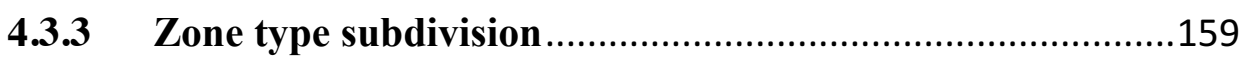

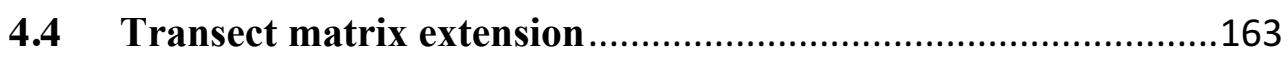

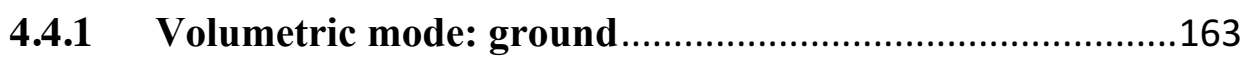

4.4.2 Volumetric mode: underground......................................166

4.4.3 Volumetric mode: upper ground....................................168

4.4.4 Transect descriptions ..................................................171

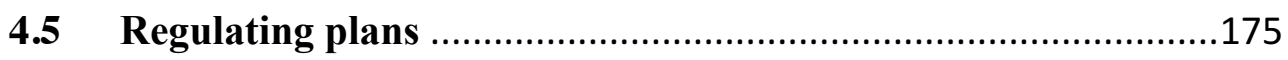

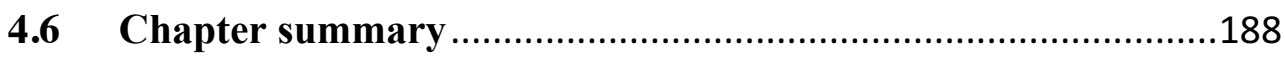

Chapter 5. Parametric modelling and results ....................................189

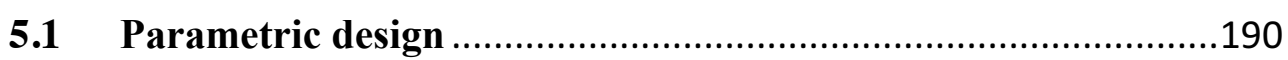

5.1.1 Parametric concepts ........................................................190

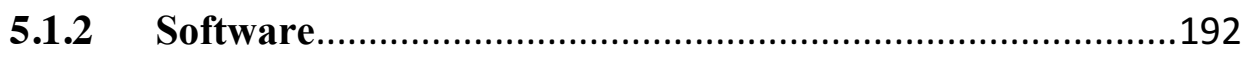

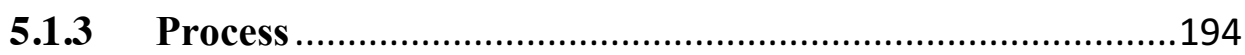

5.1.4 Parametric Form-Based Code .............................................195

5.2 Parametric systems in Form-Based Code frameworks ............197

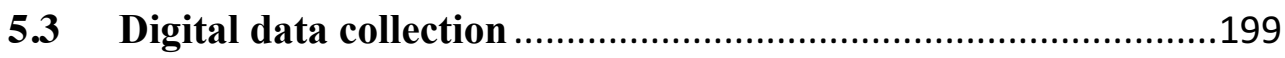

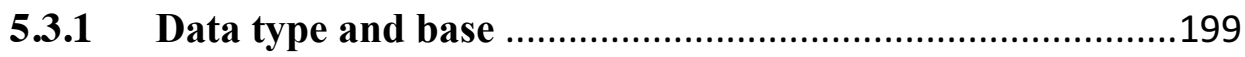

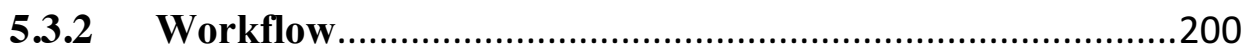

5.3.3 Prototype of clustering geospatial data............................202

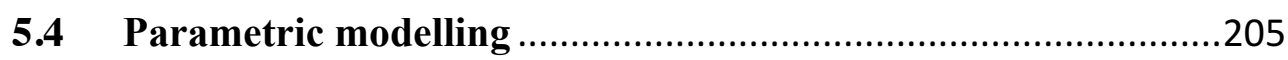

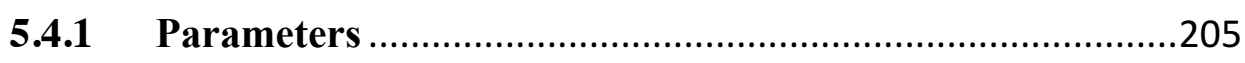


5.4.2 Prototype of parametric modelling ................................208

5.4.3 Modelling layers ..........................................................212

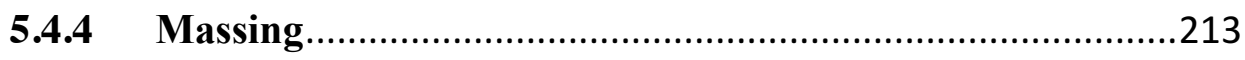

5.4.5 Multi-scenarios ................................................................216

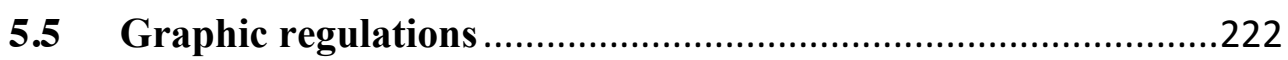

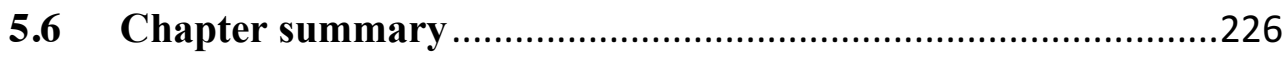

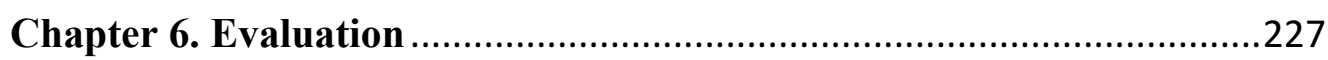

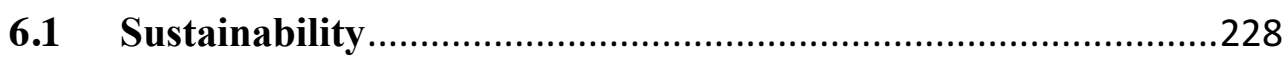

6.1.1 Evaluation system criteria ............................................228

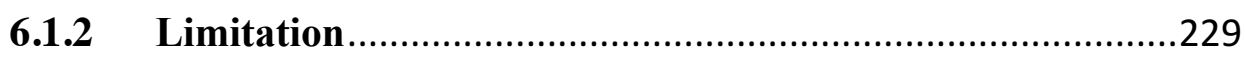

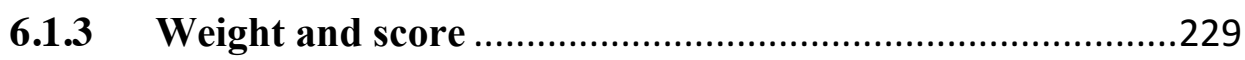

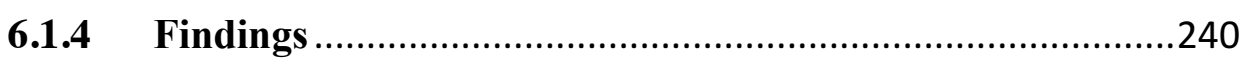

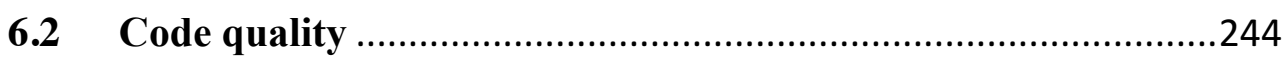

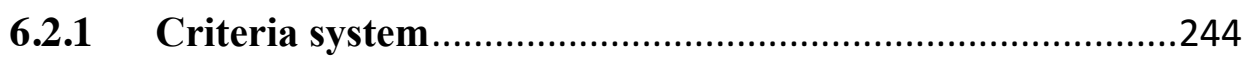

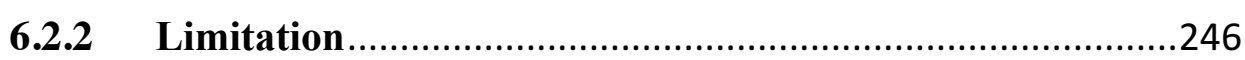

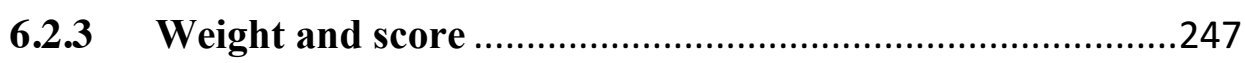

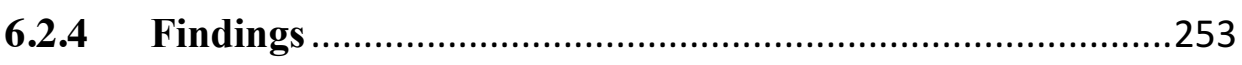

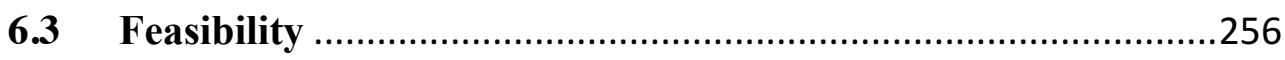

6.3.1 Current urban regulation mechanism ...............................256

6.3.2 Cooperation with established urban regulation.................261

6.3.3 Criteria system................................................................263

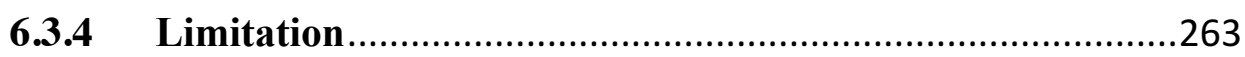

6.3.5 Weight and score ...........................................................264

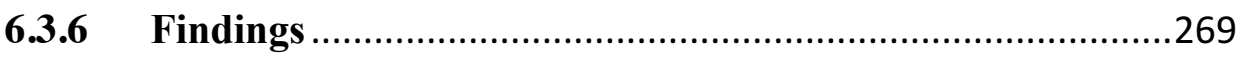

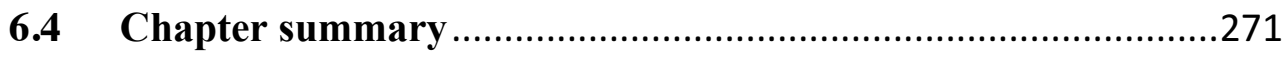

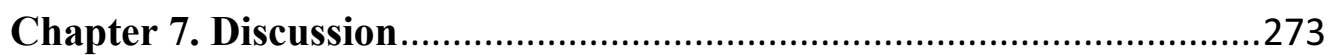

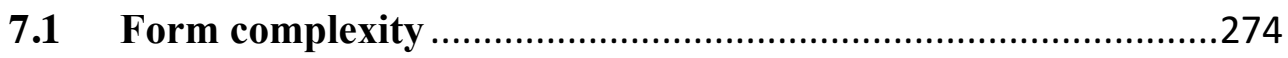

7.2 Parametric system for urban regulation...............................280

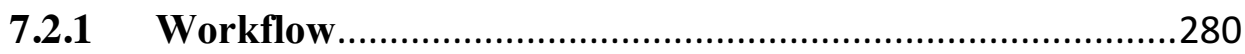

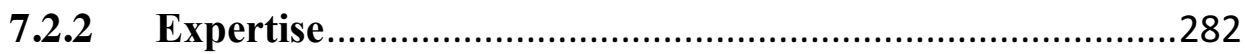

7.2.3 Implementation prospects..................................................284

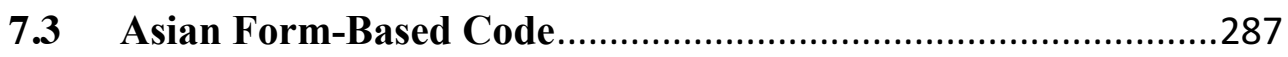




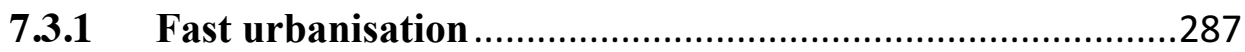

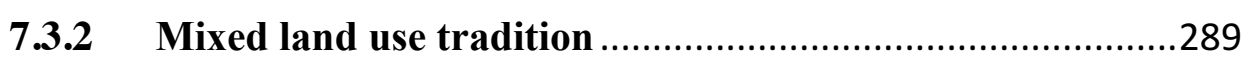

7.3.3 Established urban regulation systems ...........................289

7.3.4 Lack of evaluation principles.........................................290

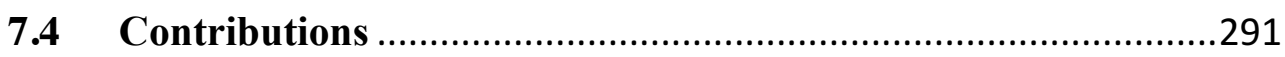

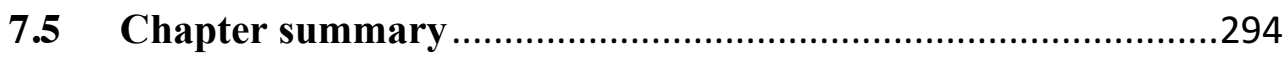

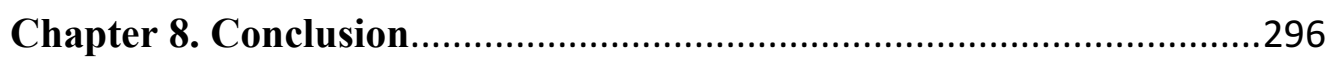

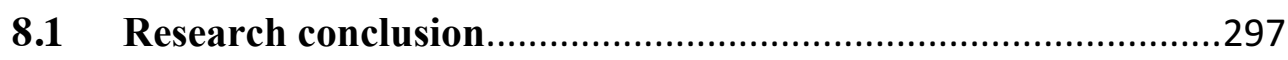

8.2 Implications for urban regulation .........................................299

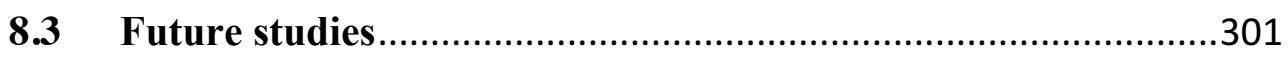

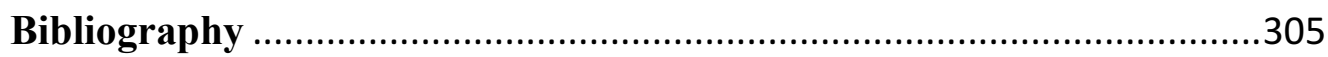




\section{List of Figures}

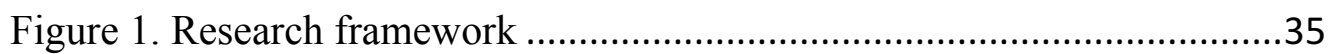

Figure 2. An example of Land Use Map and Zoning Map in Delaware Code,

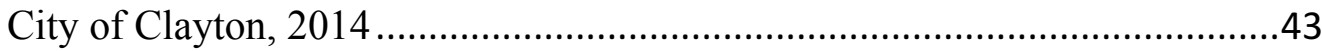

Figure 3. Comparison of four zoning approaches that broadly used currently, including Euclidean zoning, Form-Based zoning, Performance zoning, and Incentive zoning, Rodrigue, 2017

Figure 4. Expressions of different urban regulation approaches, City of Los

Angeles, 2013

Figure 5. Research trends of Form-Based Code and related concepts using data derived form Google Scholar ...................................................................54

Figure 6. Concentric Development Rings, von Thunen, 1826 .....................56

Figure 7. Patrick Geddes Valley Section (1909), Clay, 1980 ..........................56

Figure 8. Transition from rural to downtown in Form-Based Code, FBCI, 2014

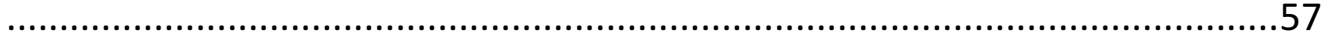

Figure 9. Transition from ocean to base dune in eco-system, DPZ, 2015 .......58

Figure 10. Differences between conventional zoning and Form-Based Codes,

Kan, 2012

Figure 11. Comparisons among conventional zoning, guidelines and Form-

Based Code, FBCI, 2015b...................................................................62

Figure 12. Standard transect matrix of Form-Based Code, DPZ, 2009 ..........64

Figure 13. Regulating plan of Hammonton Form-Based Code, City of

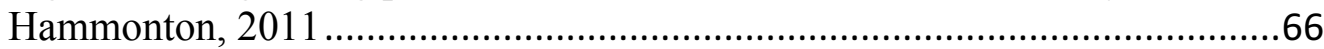

Figure 14. Regulating plan of Flagstaff Downtown Code, City of Flagstaff,

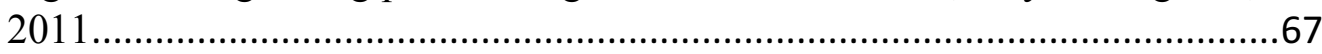

Figure 15. An example page of Form-Based Code of Cincinnati of Ohio, City

of Cincinnati, 2013

Figure 16. Example codes of Form-Based Code of Cincinnati of Ohio, City of

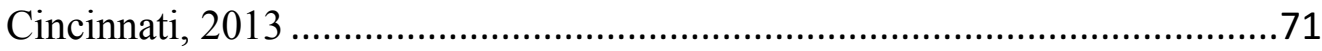

Figure 17. Form-Based Code maintains balance without function and

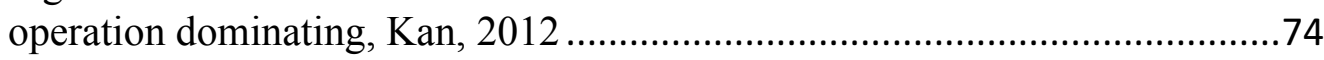

Figure 18. Collaboration among various teams..........................................76

Figure 19. Hand drawn image of Ocean Front Resort District Form-Based

Code of City of Virginia Beach, City of Virginia Beach, 2017......................80

Figure 20. Manual-based modelling for Form-Based Code, Ocean Front

Resort District Form-Based Code of City of Virginia Beach, City of Virginia

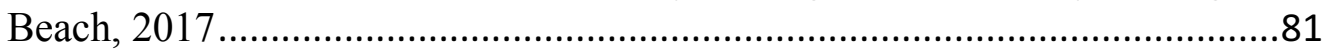

Figure 21. Web-GIS system of Form-Based Code in Bradenton, City of

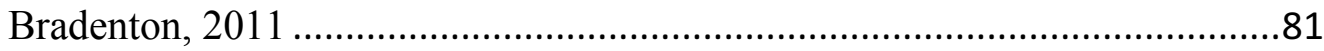

Figure 22. BIM modelling for Form-Based Code, Kim and Clayton, 2010 ....83 
Figure 23. Phases of Form-Based Code, re-edited by author based on Parolek, et al., 2008 .....

Figure 24. Form-Based Cods: Annual adoptions 1981-2016+2017 in progress, Borys, et al., 2017

Figure 25. Code Study: SmartCode and other Form-Based Codes, Borys, et al., 2017

Figure 26. Basic information of Montgomery.....

Figure 27. Downtown Transect Map of Downtown Montgomery Plan, City of

Montgomery, 2007.

Figure 28. Result of conventional zoning of Downtown Montgomery Plan, City of Montgomery, 2007

Figure 29. Result of Form-Based Code of Downtown Montgomery Plan, City

of Montgomery, 2007. 96

Figure 30. Examples of vertical extent buildings in transect zones of

Downtown Montgomery Plan, City of Montgomery, 2007. .96

Figure 31. Examples of transect zone T4 building regulations of Downtown Montgomery Plan, City of Montgomery, 2007.

Figure 32. Illustrations of thoroughfare, frontages, turnings, building disposition, lit layers and lot lines in Smart Code Montgomery, City of Montgomery, 2014

Figure 33. Example models of regulating result of Downtown Montgomery

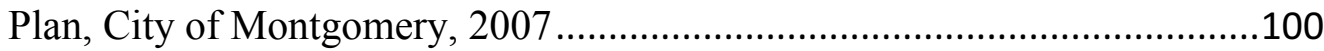

Figure 34. Basic information of Miami ......................................................101

Figure 35. Transect-based regulating map of Miami of Miami 21 Code, City of Miami, 2009

Figure 36. Transect matrix of Miami of Miami 21 Code, City of Miami, 2009

Figure 37. Examples of building standards of Miami 21 Code, City of Miami, 2015. 106

Figure 38. Before-after comparison of adopting Miami 21 Code (modelled),

City of Miami, 2015 .... 108

Figure 39. Basic information of Downtown of Nashville 110

Figure 40. Regulating plan of Downtown Code for Nashville, City of Nashville, 2017

Figure 41. An example of sign standards of Downtown Code for Nashville, City of Nashville, 2017 .112

Figure 42. Existing zoning and results of Downtown Code for Nashville, City of Nashville, 2017 113

Figure 43. Form-Based Code and results of Downtown Code for Nashville, City of Nashville, 2017 113 Figure 44. Regulation result prediction of Downtown Code for Nashville, City of Nashville, 2017 115

Figure 45. Basic information of City of Billings... .116 
Figure 46. Regulating map of EBURD of EBURD Code, City of Billings, 2014

Figure 47. On-street bicycle facilities of EBURD Code, City of Billings, 2014

Figure 48. Revenue trends of year 2007-2016 of EBURD Code, Billings Industrial Revitalization District incorporated, 2014 . 120

Figure 49. Areas of Tsim Sha Tsui, Hong Kong, re-edited by author based on Town Planning Ordinance, Town Planning Board of Hong Kong, 2008 ......129 Figure 50. Population comparison among high-density cities, Burdett, et al., 2011

Figure 51. Population distribution in high-density cities, Burdett, et al., 2011

Figure 52. Underground connections of Tsim Sha Tsui Station, Frampton, et

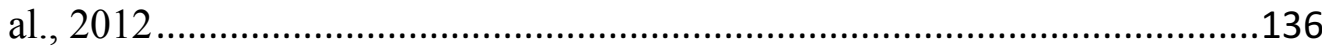

Figure 53. Rooftop space usage, Canham and $\mathrm{Wu}, 2008$..........................137

Figure 54. Housing types in Hong Kong, Esther and Li, 2014...................138

Figure 55. Field study areas in Tsim Sha Tsui ........................................146

Figure 56. Relationships between variables, factors and data index .............155

Figure 57. Method options of data normalisation.....................................155

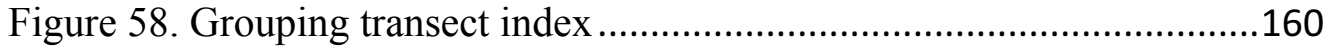

Figure 59. Standard transition from natural to artificial, DPZ, 2015 ............160

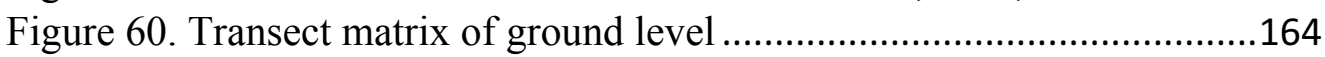

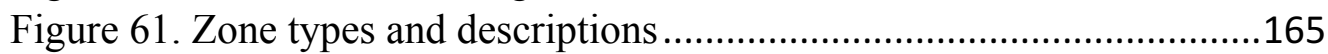

Figure 62. Transect matrix of underground level ........................................167

Figure 63. Example of underground usage................................................168

Figure 64. Transect matrix of upper ground level ......................................169

Figure 65. Examples of upper ground usage ............................................170

Figure 66. Transect matrix of Form-Based Code for Tsim Sha Tsui ............172

Figure 67. Zone descriptions of T6-4 ....................................................173

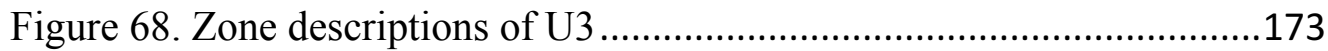

Figure 69. Zone descriptions of V3 ..................................................174

Figure 70. Zoning layers of ground level ...............................................176

Figure 71. Layout example of ground level regulating plan, re-edited by author based on Town Planning Ordinance, Town Planning Board of Hong Kong, 2008.

Figure 72. Underground space organisation of Kowloon Park, Underground Space Development in the Selected Strategic Urban Areas, Planning Department of Hong Kong, 2015.

Figure 73. Underground area of Tsim Sha Tsui, re-edited by author based on the Map of Tsim Sha Tsui Mass Transit Railway (MTR) Station, MTR Cooperation Limited, 2017 
Figure 75. Layout example of underground regulating plan, re-edited by author based on Town Planning Ordinance, Town Planning Board of Hong Kong, 2008

Figure 76. Zoning layers of upper ground level

Figure 77. Layout example of upper ground regulating plan, re-edited by author based on Town Planning Ordinance, Town Planning Board of Hong

Kong, 2008

Figure 78. Existing zoning plan according to the Town Planning Ordinance,

Town Planning Board of Hong Kong, 2008

Figure 79. Comparisons between the existing zoning plan and regulating plans of Form-Based Code ..................................................................................186

Figure 80. Flowchart of Euclid's Algorithm, Tausworthe, 1977..................191

Figure 81. Parametric design process .......................................................195

Figure 82. Structure of merging a parametric system in Form-Based Code..197

Figure 83. Generating an OSM file ..........................................................201

Figure 84. Screenshot of OSM interface, OpenStreetMap Foundation, 2017

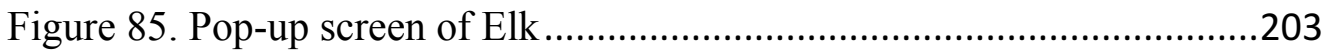

Figure 86. Coordinates of buildings maps on the modelling site .................204

Figure 87. Structure of the prototype of parametric modelling ....................208

Figure 88. Script of the parametric modelling system...................................210

Figure 89. Script unit for modelling of the ground level .............................210

Figure 90. Script unit for modelling of the underground level .....................211

Figure 91. Script unit for modelling the upper ground level .......................211

Figure 92. Modelling layers on the modelling platform of Rhinoceros 3D...213

Figure 93. Structure of generating massing models ...................................214

Figure 94. Massing models of different zones .........................................215

Figure 95. Scenarios of massing for the ground level ................................218

Figure 96. Scenarios of massing for the underground level ........................219

Figure 97. Scenarios of massing for multiple levels...................................220

Figure 98. Scenarios of massing for the upper ground level ......................221

Figure 99. Example page: Conventional Form-Based Code descriptions (T6-4)

.223

Figure 100. Example page: Parametric Form-Based Code descriptions (T6-4)

224

Figure 101. Parametric Form-Based Code descriptions (U3 \& V2)..............225

Figure 102. Example of rating standards in the Smart Scorecard..................245

Figure 103. Score chart of the Smart Scorecard ......................................254

Figure 104. Rates of each weight in different categories ...........................255

Figure 105. Hierarchy of urban planning in Hong Kong, Kan, 2012 ............257

Figure 106. Hong Kong's official development control mechanism, Kan, 2012 
Figure 107. Original transect matrix and the extensions, re-edited by author based on the transect matrix of Form-Based Code, DPZ, 2009 275 Figure 108. Transect matrix for a volumetric morphology, re-edited by author based on the transect matrix of Form-Based Code, DPZ, 2009 .277

Figure 109. Workflow of the original and parametric Form-Based Code .....281

Please note that the figures without marked citations are created by the author. 


\section{List of Tables}

Table 1. Ten principle of New Urbanism, Haas, 2008 ..................................51

Table 2. Theoretical roots of Form-Based Code, Faga, 2014 …....................55

Table 3. Differences between Euclidean zoning and Form-Based Code,

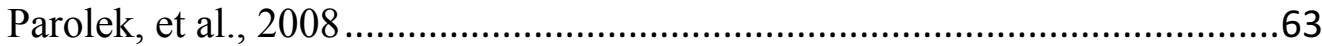

Table 4. Components of Form-Based Code, FBCI, 2015b...........................72

Table 5. Parameters of BIM modelling for Form-Based Code, Kim and

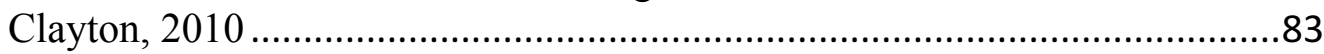

Table 6. Building regulation of transect zone T5 in Smart Code Montgomery,

City of Montgomery, 2014 ......................................................................99

Table 7. An example of the parameters of transect zone T6-12 of Miami 21

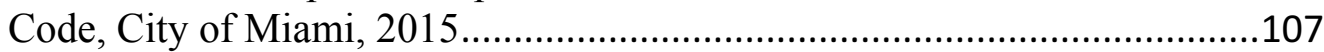

Table 8. Parameters of Downtown Code for Nashville, City of Nashville, 2017

Table 9. Permitted frontage types by district of EBURD Code, City of

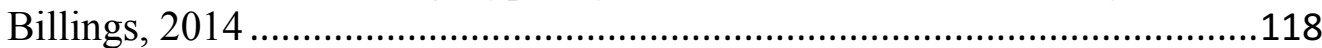

Table 10. Main components of Form-Based Code projects ..........................121

Table 11. Rate of components in Form-Based Code projects .......................122

Table 12. Main parameters of Form-Based Code projects ...........................122

Table 13. Rate of parameters in Form-Based Code projects ........................123

Table 14. Population density description ...............................................130

Table 15. FAR standards for Residential zones in Hong Kong, HKPSG, 2017

Table 16. Example of a physical data collection sheet..............................142

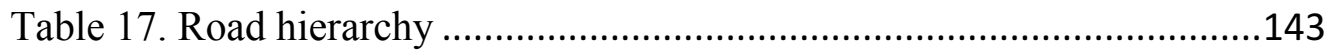

Table 18. Infrastructure descriptions ......................................................144

Table 19. Example of a data collection sheet of Jordan Road Area ..............147

Table 20. Example of a data collection report page ..................................147

Table 21. Data compilation for Jordan Road Area ......................................148

Table 22. Data compilation for Hong Kong Observation Area ....................149

Table 23. Data compilation for Nathan Road East Area ............................150

Table 24. Data compilation for Kowloon Park Area ....................................151

Table 25. Data compilation for Nathan Road West Area .............................152

Table 26. Data compilation for Canton Road Area .....................................152

Table 27. Dara compilation for Hung Hom Area ......................................153

Table 28. Data normalisation ..............................................................159

Table 29. Blocks of Tsim Sha Tsui and the classification of the average

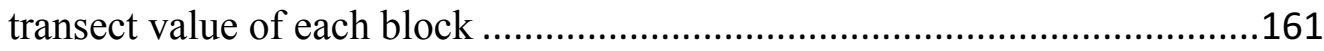

Table 30. Zone types of volumetric grounds in Tsim Sha Tsui...................171 
Table 31. Components and script of clustering digital data .......................202

Table 32. Example of regulation solutions ..............................................217

Table 33. Example of regulation solutions ...............................................217

Table 40. Concordance measurement, Garde, et al., 2015 ..........................233

Table 41. Scoring results of SLL-LEED-ND ............................................236

Table 42. Scoring results of NPD-LEED-ND ..........................................238

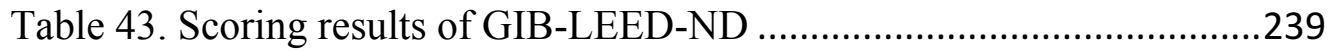

Table 44. Concordance scoring results.........................................................241

Table 45. Evaluation result of LEED-ND ..............................................243

Table 46. Criteria system developed by the FBCI. FBCI, 2015b .................246

Table 47. Example of Smart Scorecard criterion .......................................247

Table 48. Location and Service Provision Scores ........................................248

Table 49. Density and Compactness Scores..............................................249

Table 50. Density of Use Scores ..........................................................250

Table 51. Diversity of Housing Scores....................................................250

Table 52. Accessibility, Mobility and Connectivity Scores .......................251

Table 53. Pedestrian Safety, Streetscapes and Parking Scores ......................252

Table 54. Environmental Protection Scores ..............................................252

Table 55. Community Needs and Local Development Scores .....................253

Table 56. Evaluation result of the Smart Scorecard ....................................255

Table 57. Emphases of the current urban planning in Hong Kong, Lai, 2010

Table 58. Grades and scores of local standards in Hong Kong .....................265

Table 59. Open space and greenery scores..............................................266

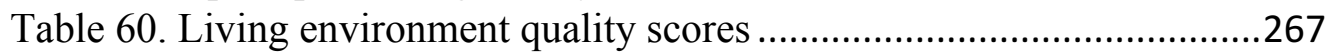

Table 61. Development control scores ......................................................268

Table 62 . Evaluation of the feasibility in context....................................269

Please note that the tables without marked citations are created by the author. 


\section{List of Abbreviations}

AEC

APA

$\mathrm{BCR}$

CAD

CATS

$\mathrm{CNU}$

CMAP

CP\&DR

DPZ

DTC

DWUA

EBURD East Billings Urban Renewal District

EPA

FAR

FBCI

GIB

GIS

HKPSG Hong Kong Planning Standards and Guidelines

IN

LEED Leadership in Energy and Environmental Design

LEED-ND Leadership in Energy and Environmental Design for Neighbourhood Development 


$\begin{array}{ll}\text { MAP } & \text { Michigan Association of Planning } \\ \text { MTR } & \text { Mass Transit Railway of Hong Kong } \\ \text { NPD } & \text { Neighbourhood Pattern and Design of LEED } \\ \text { OSM } & \text { OpenSpaceMap } \\ \text { RP } & \text { Regional Priority of LEED } \\ \text { SGPS } & \text { Smart Growth Project Scorecard } \\ \text { SLL } & \text { Smart Location and Linkage of LEED } \\ \text { TIF } & \text { Tax Increment Finance, Billings City Council, Montana } \\ \text { USGBC } & \text { United States Green Building Council }\end{array}$




\section{Glossary}

Euclidean zoning. A system of zoning whereby a town or community is divided into areas in which specific uses of land are permitted. It is from Village of Euclid, Ohio v. Ambler Realty Co. (1926), case in which the Supreme Court upheld the right of a locality to enforce such a system (MerriamWebster Dictionary).

Form-Based Code. A land development regulation that fosters built results and public realm by using physical form, rather than separation of uses, as the organizing principle for the code (Form-Based Code Institute, 2018). It creates or recreates a specific urban morphology primarily by controlling form through city or country regulation (Parolek, et al., 2008).

Land use regulation. A regulation that ensures alignment of policy standards and the private use of land resources (Black's Law Dictionary, 1995).

New Urbanism. An urban design movement which promotes environmentally friendly habits by creating neighbourhoods containing a wide range of housing and job types (Boeing, et al. 2014).

Smart Code. A unified development ordinance, addressing development at multiple scales of design, from regional planning on down to the building signage. It is based on the rural-to-urban transect rather than land use divisions (Duany Plater-Zyberk and Company, 2015).

Transect. A framework identifies a range of habitats from the most natural to the most urban. Its continuum, when subdivided, lends itself to the creation of zoning categories. A Transect integrates environmental and zoning methodologies, enabling environmentalists to assess the design of social habitats and urbanists to support the viability of natural ones (Duany Plater-Zyberk and Company, 2009).

Transect-Based Code. A code uses transect to define a series of zones that transition from sparse rural farmhouses to the dense urban core. Transectbased code is one description of Form-Based Code. 
Urban regulation. A constituent part of urban planning that control urban development by a local government authority, from which a licence must be obtained to build a new property or change an existing one (Oxford Dictionaries).

Zoning. The action or process of assigning parts of a town or piece of land to categories subject to different restrictions on use and development in the USA (Oxford Dictionaries). 


\section{Chapter 1. Introduction}

This chapter is an overview of a framework for formulating the concepts and challenges of developing parametric urban regulation in high-density cities by using Form-Based Code as the regulating approach. The challenges are described as a goal with specific objectives. A methodology is formulated for the resolution of research questions. The chapter concludes with an outline of the dissertation. 


\subsection{Motivation and scope}

This research explores the usage of parametric tools to support urban regulation in understanding, analysing and developing high-density cities with complex situations. From the first experiment using parametric tools in architecture, it has become clear that these tools could bring similar benefits to urban projects, effective even in higher scale urban cases (Nagy, 2009). Parametric tools have been applied in architecture and urban design for decades, such as a series of urban-scale practices by Zaha Hadid Architects, but rarely attempted in urban regulation. This research facilitates urban regulation for design augmentation with parametric capabilities. Form-Based Code is the specific approach integrated with a view to regulation.

Form-Based Code creates or recreates a specific urban morphology primarily by controlling physical form, with a reduced focus on land use, through city or country regulation (Parolek, et al., 2008). Since the first contemporary FormBased Code was created in Florida in the 1980s, hundreds of projects have been adopted. Adopters include metropolitans, such as Miami and Los Angeles, as well as small neighbourhoods with populations of around 100 people. Different from land use-based regulation, Form-Based Code deals with the forms of streets, street blocks, plots and buildings. Its principles encourage mixed uses in neighbourhoods and communities. The regulatory results of Form-Based Code have the potential to be predicted as the control of specific variables.

This dissertation argues that parametric tools are critical for the enhancement of Form-Based Code, especially in a complex urban development situation. Parametric tools help to combine computational design software with coding. The combination makes design process to be parameterised on computer-aided design (CAD) platforms. The graphical interfaces provided by these platforms may support Form-Based Code designers to manipulate parameters and rules to achieve real-time models. If so, parametric tools can possibly improve Form- 
Based Code, identifying problems and solutions in the same modelling process.

As Parolek, et al. (2008), Miami 21 Code has proved the benefits of applying Form-Based Code in high-density cities. Form-Based Code may result in similar benefits to other metropolitans - not solely those in the USA. Hong Kong, as one of the high-density cities in Asia, works as the experimental site. Generating a parametric Form-Based Code for a high-density city can be a large and complicated project. Manifold parameter types and relations must be embedded. As a result, using parametric tools to create urban regulation layouts for the whole city and assessing the complexity of the parametric system is beyond the scope of this research. The research is limited to exploring:

1. Approaches to using parametric tools to enhance the generation of conceptual models for Form-Based Code

2. The feasibility of manipulating and applying parametric Form-Based Code in the volumetric morphology of high-density cities, using Tsim Sha Tsui, Hong Kong as a sample site

The research explores a parametric approach to urban regulation. Different from the manual methods of hand-drawings and text description, the parametric approach seeks to find out if generation, visualisation and optimisation can fold in one integrated system. It attempts to facilitate the rational analysis of urban regulation and examine optimisation by performance feedbacks at the conceptual stage of regulation. 


\subsection{Goal and objectives}

The goal of the research is to identify the feasibility of parametric instruments in enhancing the urban regulation of volumetric morphology of high-density cities, through developing a parametric modelling system for Form-Based Code in that context. The urban regulation process intends to be facilitated by graphical coding interfaces, generative modelling procedures and interactive optimisation with parametric instruments. The parametric modelling system for Form-Based Code extends the transect matrix, generating massing models and assembling codes in an experimental site. The research will propose a new approach to urban regulation enhancement; one that uses parametric decisionmaking tools to integrate different forces and parameters in a computational system.

To address the goal, the research analyses the challenges of Form-Based Code and posits possible strategies to resolve them. The strategies determine the methodology of developing a parametric modelling system. It has implications for assessing the application of parametric Form-Based Code in the volumetric morphology of high-density cities. The objectives established are distinguished as a modelling objective and an implementation objective.

\subsubsection{Modelling objective}

The modelling objective is to seek approaches to developing a parametric modelling system for Form-Based Code that will improve urban regulation design procedures at the conceptual stage. The approach adopting a parametric Form-Based Code should be:

1. Different from existing applications of Form-Based Code

2. Integrating variables and parameters controlling urban form in one parametric system

3. Re-usable and customisable for further design and regulation

4. Easy to manipulate 
A newly-developed parametric modelling system that meets these principles will provide solutions for improving Form-Based Code. Different projects can choose to work with similar rules and component structure but produce unique scenarios by manipulating parameters.

\subsubsection{Implementation objective}

This research also resolves the challenges of implementing the parametric modelling system of Form-Based Code in context and predicts implications for existing urban regulation. The implementation objective is to examine the parametric modelling system which:

1. Extends the transect matrix in Form-Based Code implementation

2. Has a greater technical capability to regulate urban forms in context

3. Interfaces with the established urban regulation system

Hong Kong is the experimental site of the implementation. Parametric FormBased Code that meets these criteria is expected to deliver feedback at the conceptual stage of urban regulation and improve existing regulation solutions in Hong Kong. 


\subsection{Research question}

This research focuses on two aspects of urban regulation. Namely, a parametric modelling system for urban regulation and the feasibility of parametric FormBased Code in a high-density urban context. The research question is described as:

\section{How parametric Form-Based Code be an alternative to the urban regulation approach in the volumetric morphology of high-density cities?}

The research question is divided into two sub-questions:

1. How to develop a parametric modelling system to enhance the generation of urban regulation and modification logics using FormBased Code as the regulation approach?

2. Can the parametric modelling system applied within Form-Based Code have positive implications for urban regulation in enhancing the volumetric morphology of high-density cities?

To answer these questions, the research is organised into modelling exploration and implementation assessment, each corresponding to the research objectives. Developing the parametric modelling system provides an approach to enhance the conceptual design process of urban regulation. Demonstrating the implications of the parametric modelling system for Form-Based Code enables an assessment of parametric urban regulation implementation in both academia and practice. 


\subsection{Significance}

The parametric modelling system for Form-Based Code in this research addresses the challenges of complex urban regulation, providing alternative instruments to enhance Form-Based Code, and demonstrating experimentation in context.

\subsubsection{Complex urban regulation}

Burgeoning urbanisation in developing counties and regions has resulted in an increasing number of high-density cities with compact urban space and concentrated populations. Urban regulation is more complex than ever before, especially in regions which are experiencing fast changes. The challenges of complex urban regulation stem from the multifarious components, intricate generative phases and aperiodic amendments. Parametric urban regulation work as a novel approach to generation and optimisation in the regulating process. It potentially offers a rational means to facilitate conceptual modelling and optimises design regulation. This research creates a parametric modelling system that integrates parameters, analysis, modelling, and modification in one system to produce morphology configuration and visualised feedback. Significantly, the parametric modelling system aims to assemble complex urban regulation as a whole. It has the potential to efficiently examine and amend regulation scenarios by manipulating parameter types, relationships and parametric components that conventional tools do not process.

\subsubsection{New approaches to Form-Based Code}

Form-Based Code, as the Form-Based Code Institute (FBCI) states, conveys regulation with "generous illustrations and simple diagrams" for "quick and convenient understanding". Arguably, there is a lack of efficient decisionmaking tools to support Form-Based Code generation and implementation. This research provides a parametric modelling system to present Form-Based Code's regulation potential. Conventional graphical descriptions, hand drawings and 
manual models can be supported by parametric methods to resolve expression and optimisation limitations. Additionally, the implementation of the parametric modelling system potentially enables proposing outcomes with real-time performance feedback. This feedback can be described with illustrations and diagrams to allow a multitude of potential solutions.

\subsubsection{Experimentation in context}

Urban regulation in the volumetric morphology of high-density cities is a critical issue of study due to the manifold variables and forces that affect spatial configuration. The experimentation of parametric Form-Based Code in context provides a regenerative regulation schema that can be customised for different projects in high-density cities. It allows analysis and evaluation of possible solutions through the manipulation of parameters and components. This research creatively extends the innovation of urban regulation to the volumetric morphology of the high-density cities of Asia, using Hong Kong as the experimental context. 


\subsection{Research methodology}

This research seeks to develop a parametric modelling system for the enhancement of urban regulation solutions in the volumetric morphology of high-density cities. The methodology supports the generation and examination of the parametric modelling system in the experimental site. The research involves four phases. They are:

1. Study of urban regulation procedures and challenges

2. Extension of the importance and role of transect matrix

3. Generation of a parametric modelling system for Form-Based Code

4. Evaluation of the parametric Form-Based Code in context

To facilitate the research phases and experiments, parametric tools have been developed to interface with Form-Based Code approaches to regulate the building and street forms of the volumetric morphology of high-density cities. The research incorporates phases from framing the conceptual structure to examine the results of parametric Form-Based Code.

Phase One is conducted through a literature review and an analysis of FormBased Code examples in Chapter 2 and Chapter 3, including the theory underpinning Form-Based Code, the process and tools of Form-Based Code generation, challenges of Form-Based Code enhancement, and applications of Form-Based Code. Comparisons are undertaken between Form-Based Code and conventional zoning. Based on the findings of this phase, a series of experiments are conducted to implement the methodology in Phase Two, Phase Three and Phase Four.

Phase Two processes the data collection in field study and analyses the physical data with statistical methods (Experiment 1). It is to extend the importance and role of transect matrix and generate the transect-based regulations of Form- 
Based Code in Chapter 4. This phase standardises the physical data to reorganise urban zone types and extend form hierarchy in an urban-periphery environment. It helps to establish the parameters to be embedded into the parametric modelling system in the following phases.

Phase Three develops Rhinoceros $3 D$ and Grasshopper $3 D$ models on computer-aided platforms, using the established parameters to generate the parametric modelling system (Experiment 2). This merges Form-Based Code regulations with the parametric modelling process; integrates the regulated parameters and components; and achieves multiple performance feedback in Chapter 5. The system produces a regenerative prototype edited in Grasshopper 3D. Implementing the prototype in the experimental urban context, a series of regulation scenarios of Form-Based Code are proposed through the modelling interface.

Phase Four is undertaken using a weigh-score system to examine the results of parametric Form-Based Code (Experiment 3). This is to assess the parametric Form-Based Code against urban regulation evaluation standards to identify its feasibility in context in Chapter 6. It attempts to assess the implementation of the parametric modelling system to augment Form-Based Code in the volumetric morphology of high-density cities. 


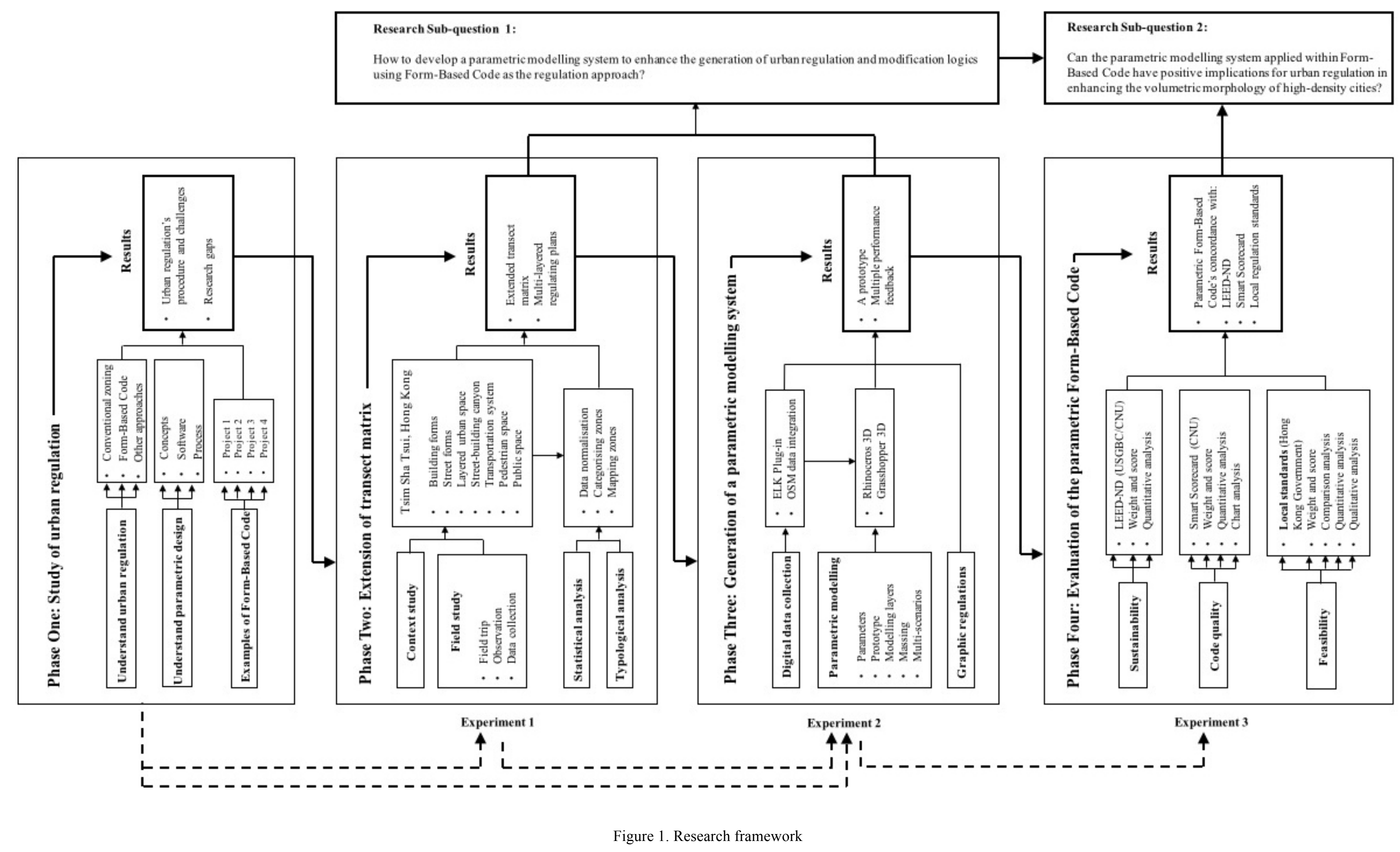




\subsection{Dissertation outline}

The dissertation consists of eight chapters including introduction (Chapter 1), literature review (Chapter 2), examples of Form-Based Code (Chapter 3), two methodology description chapters presenting the pre-modelling analysis (Chapter 4) and modelling system generation (Chapter 5), evaluation of the parametric Form-Based Code (Chapter 6), discussion (Chapter 7) and conclusion (Chapter 8).

Chapter 1 is a general overview of the dissertation and outlines the issues, including motivation and scope, goal and objectives, research questions, significance, research methodology, and dissertation outline.

Chapter 2 builds the foundation of the research with a literature review. Given the target of generating parametric modelling system for Form-Based Code enhancement, it is necessary to understand the concepts and process of urban regulation, the theory underpinning Form-Based Code, and challenges of enhancing Form-Based Code in the aspects of generation and implementation.

Chapter 3 analyses the examples of existing Form-Based Code projects as precedents for generating regulation solutions in cases that exhibit complex urban morphology.

Chapter 4 presents the process of form transecting in Form-Based Code for premodelling analysis. The transect matrix relevant to the volumetric morphology of high-density cities is redefined through form categorisation and an assessment of issues in the original transect matrix modification. According to the redefined transect matrix, a series of layered regulating maps are generated, highlighting the particularity of urban regulation with multiple ground layers. 
Chapter 5 describes the methodology of generating and implementing the parametric modelling system in Form-Based Code. It allows visualised morphology control and real-time performance feedback. Massing models are created through a generative prototype. The prototype consists of parameter selection and editing of scripts for different transect zone types using the software Rhinoceros 3D and Grasshopper 3D.

Chapter 6 presents the evaluation of a parametrically enhanced Form-Based Code in context. The implementation results of the parametric modelling system are assessed by a series of comparisons and measures.

Chapter 7 discusses the contributions to the field and potential relevance beyond the scope of this study.

Chapter 8 draws conclusions from the research. The research outcomes suggest that parametric Form-Based Code can usefully provide alternative approaches to urban regulation by enabling enhanced conceptual modelling, integrated generation and optimisation process, and feasible urban regulation in volumetric morphology of high-density cities. 


\section{Chapter 2. Literature Review}

This chapter presents an overview of urban regulation and Form-Based Code that is the foundation of this research. It covers the review of concepts of urban regulation, comparisons between conventional zoning and Form-Based Code, the theory underpinning Form-Based Code, and challenges of enhancing FormBased Code in the aspects of generation and implementation.

The chapter concludes with an understanding of previous efforts to create urban regulation and Form-Based Code for contemporary cities that capitalise on novel concepts and processes to support complex regulation tasks. 


\subsection{Urban regulation}

The section explores the complexity of urban regulation, reviewing literature about the development of urban regulation and associated concepts and approaches. Euclidean zoning is explained as one broadly used approach to urban regulation. The section concludes with an analysis of the challenges of, and alternatives to, Euclidean zoning.

\subsubsection{Definition}

Urban regulation has broad scope and content. Many types and methods are used globally. Precise definitions of urban regulation that internationally agreed are almost non-existent. Urban regulation developed with the rise of civilised cities and human construction. In antiquity, urban regulation separated religious places, civic living spaces, and undesirable functions usually due to noise and smell (Hirt, 2015).

Urban regulation became complex with the onset of the Industrial Revolution. The definition of home ties to the definition of the economy and this meant a much greater mix of uses within the residential quarters of cities (Arendt, 1958). After a short time of prosperity, mix-use urban regulation declined throughout the industrial era. According to Arendt, the rapid increase of mass production and manufacturing contributed to the re-regulation of industrial cities by rigidly separating overcrowding, pollution, and factory noise from residential areas.

In the late 19th century, modern urban regulation emerged in Germany. It was further developed by the German engineers Reinhard Baumeister and Franz Adicks at the meeting of the German Architectural and Engineering Societies in 1874 (Ben-Joseph and Kiefer, 2005). Baumeister created two zones (city and suburb) and specified bulk regulations for building height, setbacks, and lot area, which influenced urban regulation in the 1890s (Kim, 2014). 
Contemporary interpretations of urban regulation stress the legislative guidance that can determine planning provisions, land use conditions, pattern rules of urban and peripheral places, and building forms in the policy context. Urban regulation is regarded as a process of dividing the municipality land into zones in which certain land uses are permitted or prohibited (Lemar, 2015).

As the leading approach to urban regulation, zoning, is broadly utilised around the world with various names and components. Most governments use zoning as restrictive, indicative, incentive and performance control (Kan, 2012). In 1916, the first American zoning ordinance was adopted in New York City. Because of rapid urbanisation, factories and populations were clustered in the city centre. Public health become a problem. The modernist city began to create a collective society in which everyone would have housing with minimum standards for sanitation, light, and air (Barnett, 2016). Zoning in this context is a primitive system that could keep residences away from noisy and dirty factories and protect neighbourhoods from tall buildings (Kim, 2014).

It is believed that urban regulation contributes to ordered development and a common purpose for the whole society. The definitions of contemporary urban regulation are various, but commonly work to protect property values, exclude dangerous nuisance uses, prevent exploitation, and foster service delivery (Taylor, 1973; Zack and Silverman, 2007). As a tool of regulation, zoning helps prevent over-intensive development (Bassett, 1922), a spread-out of the city (Bettman, 1925), and unconscious neighbourhood development (Hall, 2002).

\subsubsection{Approach to land use regulation}

According to Lamar (2015), land use regulation is one main regulatory target in urban regulation. Land use regulation intents to ensure alignment of policy standards and the private use of land resources as Black's Law Dictionary explained (Black, 1995). In the USA, land use regulation regards zoning as the 
major approach to bridging regulation strategies and real-world constructions. Euclidean zoning, commonly referred to as conventional or traditional zoning, is named for the Village of Euclid where zoning was upheld in 1926 as a legitimate governmental power under the police powers of government (City of Euclid, 2018). It firstly proposed a legal regulating on the land use in the USA. After that, Euclidean zoning has been a broadly used American approach to regulation since the early 20 th century. It indicates the outright and conditional uses of land, size, location, and dimensions of different zones, and the form and scale of buildings.

From its beginning, Euclidean zoning aimed to address the public health problems associated with the poor living environments in heavy industrial areas. These problems were addressed by dividing land uses into incompatible categories. Land use is the priority consideration of Euclidean zoning. Figure 2 explains an example of the relationships between the Land Use Map and Zoning Map in a real zoning code. The Land Use Map divides a site into zones, such as open space, residential and town centre. Accordingly, the Zoning Map further specifies land uses by creating zone sub-types. For example, residential land use consists of residential suburban, one-family and townhouse, multiple-family, and manufactured housing.

The process of Euclidean zoning contains some main components based on Garvin and Jourdan (2008), Emerson (2006) and Woodward (2013). One is preparing the Land Use Plan. Different zoning projects contain different zone types. But land use falls largely into five categories; including residential, mixed residential-commercial, commercial, industrial, and spatial. These categories present two-dimensional zoning schemes using different colour such as the Land Use Map presented in Figure 2. Each geographical district has a particular land use type or subtype. For instance, industrial subtypes include heavy manufacturing and warehousing. Commercial subtypes may include small retail 
or office use. Another component includes drafting a Zoning Ordinance. A typical Zoning Ordinance includes chapters that describe various districts by use (either as a list or a matrix), provides a map of multiple use zones, and then represents height, bulk, and density controls, standards, and definitions of terms (Garvin and Jourdan, 2008; Emerson, 2006; Woodward, 2013).

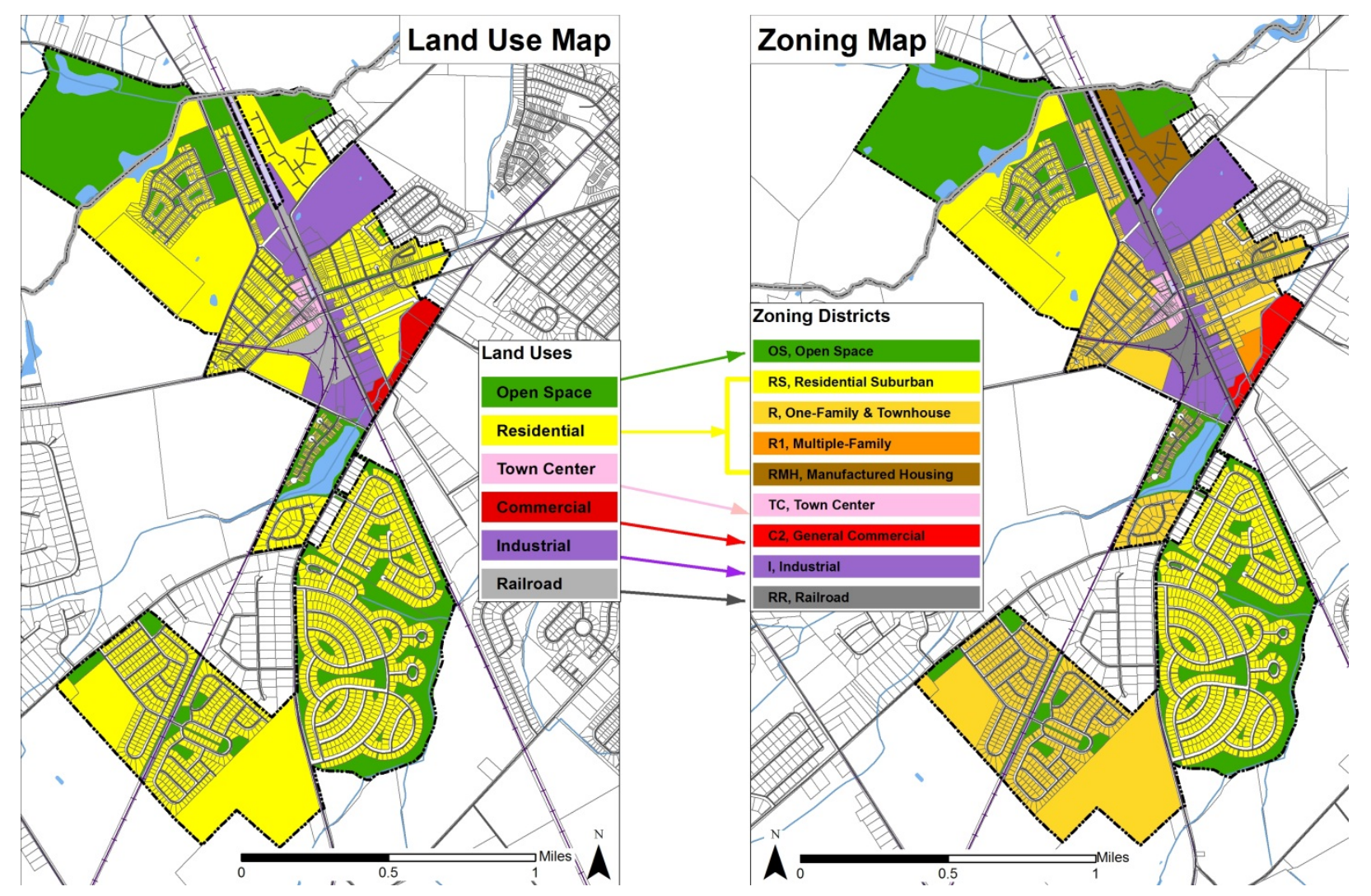

Figure 2. An example of Land Use Map and Zoning Map in Delaware Code, City of Clayton, 2014

\subsubsection{Limitations}

As analysed, Euclidean zoning has relative effectiveness, a mature legal precedent, and ease of management. A wide range of zone types have evolved over the years with shifting political, social, and economic priorities (Holm, 2006). However, Michigan Association of Planning (MAP) argues that Euclidean zoning alongside rapid suburbanisation has created issues (MAP, 
2007). Directly or indirectly, it results in issues in aspects of urban sprawl, physical performance control and land use mixing.

\subsubsection{Urban sprawl}

In tandem with the dislike of sprawl, Euclidean zoning has been despised by planners for more than 50 years now (Talen, 2013). It is argued that because of the separation of land use and scale of zones, it is inconvenient to walk to the corner store or for children to walk to school (MAP, 2007). Although separating heavy industry from housing areas is a valid consideration, people who do not work in heavy industry must also commute by vehicle during weekdays. Some researchers state that the relationship between Euclidean zoning and sprawl is ambiguous (Bruegmann, 2005); that urban sprawl is the inexorable product of car-based living (Glaeser and Kahn, 2003), growing populations, rising incomes and falling community costs (Brueckner, 2000) rather than Euclidean zoning. These conclusions miss a large point: that zoning has a significant, detrimental impact on urban pattern and form at the local scale (Talen, 2013). Sprawl may occur in anywhere in a low-density, non-contiguous and automobile dependent city (Bengston, et al., 2004). Euclidean zoning facilitates sprawl, and sprawl contributes to serious problems such as global warming (Gonzalez, 2009), social inequity (Squires, 2002; Pendall, 2000), environmental degradation (Benfield, et al., 2001; Ewing, 2005), and public health problems (Frumkin, 2004).

\subsubsection{Physical performance control}

Euclidean zoning is not designed to achieve specific physical forms (Garde, et al., 2015). It typically specifies generic measures such as density, floor-area ratio (FAR), and maximum building height (Garde, et al., 2015). These regulations are adopted to ensure certain minimum levels of performance and to reduce the adverse impacts of development to an acceptable level (BenJoseph and Kiefer, 2005; Kayden, 2011). Although urban planners and 
developers have attempted to revitalise old areas, they were increasingly frustrated by the limitations of Euclidian zoning. These included the division of land use and application of standardised minimum requirements without accommodating inherent physical or social site limitations (Kendig, et al., 1980). Zoning approaches and outcomes affect on the subsequent urban design guidelines and building projects. According to the MAP (2007), rigid land use may result in monotonous building forms. Increasing car parking spaces requires considerable setbacks, to which many cherished buildings and urban spaces do not conform (MAP, 2007). Conventional urban regulation approaches contribute to the production of featureless urban-scapes comprised of similar buildings and unfriendly pedestrian space.

\subsubsection{Land use mixing}

Euclidean zoning was initially used to segregate pollution and noise from neighbourhoods. But today's urban regulation must balance use, form, location, safety and public process (Gunder, 2011). Diverse zonings sometimes are incompatible with conventional zoning method which separates zones to ensure quality living and working. However, this ignores, for example, that my residential neighbour playing his drum set at 1:00 am is less compatible with my sleep than the quiet office next door, which closed at 5:00 pm (Russell, 1994). Russell argues that Euclidean zoning prevents the harmonious mixing of use that historically characterised every lively village, city, or rural area (Russell, 1994). The use-based regulation approaches may overlook the requirements of land use mixing in communities and neighbourhoods.

This research focuses on the application and enhancement of Form-Based Code, which has the potential to extend Euclidean zoning by using form, rather than land use, as the primary consideration. The following section analyses recent urban regulation with a Form-Based Code approach. 


\subsection{Form-Based Code}

Form-Based Code is the approach to the application of parametric urban regulation of this research. This section provides a detailed understanding of Form-Based code. It defines Form-Based Code and traces its development through reviewing its New Urbanism background and theoretical roots. The section then explores the key concepts of Form-Based Code, critical for adopting the parametric modelling system.

\subsubsection{Definition}

Form-Based Code is an approach to urban regulation that creates or recreates a specific urban morphology primarily by controlling physical form, with less focus on land use, through city or country regulation (Parolek, et al., 2008). It fosters predictable built results and a quality public realm by using form as the organising principle for the code (FBCI, 2015a). FBCI explains Form-Based Code as:

“... address[ing] the relationship between building facades and the public realm, the form and mass of buildings in relation to one another, and the scale and types of streets and blocks. The regulations and standards in form-based codes are presented in both words and clearly drawn diagrams and other visuals. They are keyed to a regulating plan that designates the appropriate form and scale (and therefore, character) of development, rather than only distinctions in land-use types."

After the first Form-Based Code implementation in Seaside Florida in the 1980s, new regulations were created for zoning reform (Kim, 2014). Form-Based Code templates can be applied at a variety of scales. Examples include sub-areas within a municipality, counties or regions that encompass both urban areas and countryside, areas that are undergoing changes in land ownership, or are the location of planned infrastructure improvements (Chicago Metropolitan 
Agency for Planning (CMAP), 2012). Sub-areas may contain downtowns, commercial corridors, shopping centres, or historical neighbourhoods. Dealing with the spatial features of block typology, streetscape, open space, and building façade, Form-Based Code is scoped in Borys, Talen and Lambert's Code Study:

- Focusing primarily on regulating urban form and less on land use

- Regulatory rather than advisory

- Emphasising standards and parameters for forms with predictable physical outcomes (build-to lines, frontage type requirements, etc.) rather than relying on generalised parameters (plot ratio, density, etc.) whose outcomes are impossible to predict

- Requiring private buildings to shape public space by using building form standards with specific requirements for building placement

- Comprising regulations and standards keyed to specific locations on a regulation plan

- Providing unambiguous diagrams in the code, clearly labelled, and accurate in their presentation of spatial configurations (Borys, et al., 2014)

In Form-Based Code, form is the regulating priority while land use becomes a secondary consideration. Urban form generally consists of streets, street blocks, plots and buildings (Oliveira, 2016). From as far back as Roman times, form has been a primary concern in issues such as city layout, public and private buildings, and building materials as Vitruvius' Ten Books on Architecture records. Nowadays urban is described as an organic whole that can be seen according to different levels of resolution (Kropf, 1996; Oliveira, 2016). The higher the level of resolution, the greater the detail of what is shown and the greater the specificity of form description (Oliveira, 2016). Form-Based Code extends the use-based regulatory system taking form codes into consideration. 
Due to its flexible framework, Form-Based Code has potential to permit compact development and mixed use, thus bringing destinations closer to housing, making neighbourhoods walkable, supporting active transportation, permitting a variety of housing types to facilitate inclusionary housing and mitigate social and spatial inequities, and emphasising physical form standards to improve the quality of public realm and enhance a sense of place (Garde, et al., 2015; Elliott, et al., 2012; Hansen, 2014; Parolek, et al., 2008; Talen, 2009).

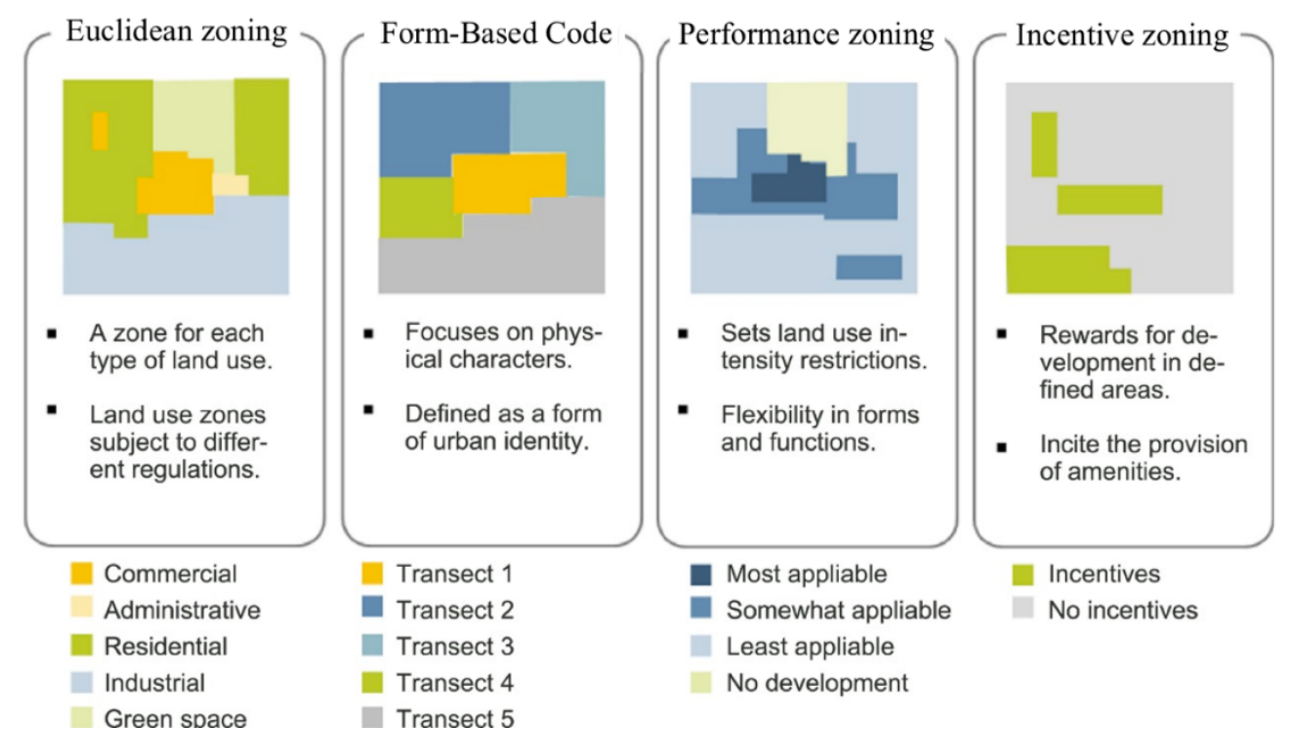

Figure 3. Comparison of four zoning approaches that broadly used currently, including Euclidean zoning, Form-Based zoning, Performance zoning, and Incentive zoning, Rodrigue, 2017

Form-Based Code has been accepted and adopted by official planning organisations, such as Planning and Zoning Department of the City of Miami, and builders' associations (Sullivan, 2005) as it is believed to have potential to aid the zoning development. Figure 3 compares Euclidean zoning with alternative approaches. Quantity resolutions, such as Form-Based Code, specify variables to control building performance and urban morphology. Zones are defined as forms of urban identity. Quality resolutions, such as performance zoning and incentive zoning, facilitate measuring impacts or merits. 


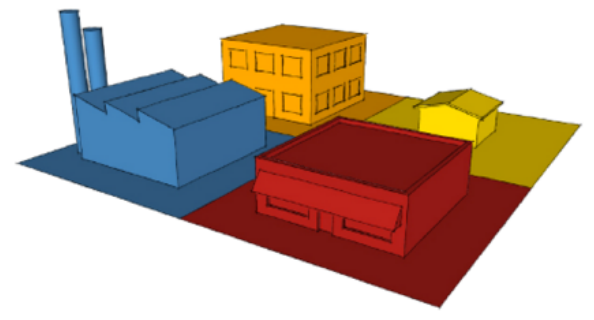

Euclidean zoning

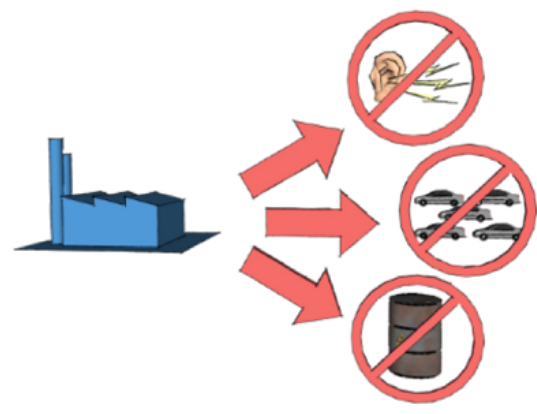

Performance zoning

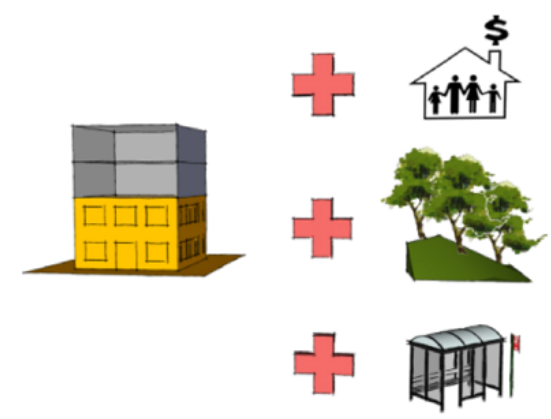

Incentive zoning

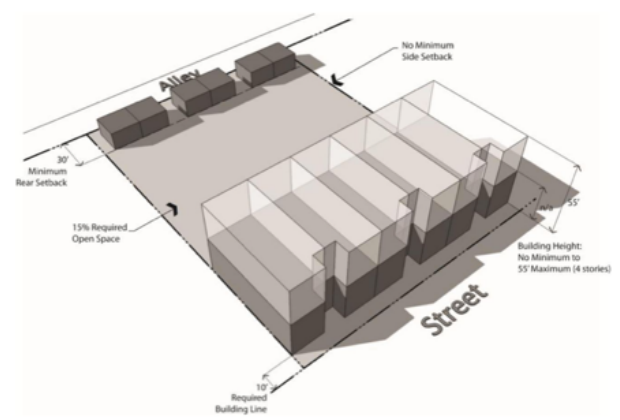

Form-Based Code

Figure 4. Expressions of different urban regulation approaches, City of Los Angeles, 2013

As analysed in former sections, Form-Based Code principles regard form as the primary regulation targets to shape urban morphology in zoning process. Compared with Form-Based Code, Performance zoning principles do not require planners and community officials to predict what the future should look like (Hassinger, et al., 2001). Performance zoning provides performance standards for development proposals, which have roots in building codes. Any building forms can be built, allowing some flexibility in design and administration (Ben-Joseph and Kiefer, 2005). Performance zoning manages regulations and building plans with perceptive description, rather than abstract values and numbers. While in Incentive zoning framework, the regulation provides a reward-based system to control projects to fulfil urban development goals. It requires a series of revisions to maintain the balance between incentive magnitude and the value given to developers (Hascic and $\mathrm{Wu}, 2004)$. When new 
development bonuses attract more construction stakeholders, community infrastructure may fail to serve the increasing population. Figure 4 describes an example of differences in code expression between Euclidean zoning, Performance zoning, Incentive zoning, and Form-Based Code.

\subsubsection{New Urbanism}

New Urbanism is an ideological trend that emerged in the 1980s in the field of urban planning, regulation and urban design. Form-Based Code works as a tool that provides a means of putting New Urbanism into practice through offering a visual representation of its concepts.

The Congress for the New Urbanism (CNU) describes New Urbanism as encouraging urban planning based on the principles on which cities and towns have been built for the last several centuries: walkable blocks and streets, housing and shopping in close proximity, and accessible public spaces; in other words, New Urbanism is focusing on human-scaled urban regulation and design (CNU, 2015a). The core concept of New Urbanism is the Ten-Principles (Table 1). According to the Miami 21 Amended Codes, the principles appeal for the re-establishment of mixed-use urban neighbourhoods, the efficient use of existing infrastructure, and the preservation of natural habitats (City of Miami, 2015). Supporters state that the principles of New Urbanism contribute to building a sense of community and the development of green practices (Haas, 2008) and promoting environmentally friendly habits by walkable neighbourhoods containing a wide range of housing and job types (Boeing, et al., 2014).

\begin{tabular}{l|l}
\hline New Urbanism Principles & \multicolumn{1}{c}{ Details } \\
\hline \multirow{3}{*}{ Walkability } & $\begin{array}{l}\text { Most things an individual need should be within a 10-minute } \\
\text { walk of home and work; } \\
\end{array}$ \\
& Pedestrian-friendly street design. \\
\hline
\end{tabular}




\begin{tabular}{|c|c|}
\hline Connectivity & $\begin{array}{l}\text { An interconnected street grid network disperses traffic and } \\
\text { eases walking; } \\
\text { A hierarchy of boulevards, streets, and alleys. }\end{array}$ \\
\hline Mixed-use and diversity & $\begin{array}{l}\text { A mix of shops, offices, apartments, and homes on site; } \\
\text { Promote safer neighbourhoods with a diversity of people. }\end{array}$ \\
\hline Mixed housing & Provide a range of types, sizes and prices in close proximity. \\
\hline $\begin{array}{l}\text { Quality architecture and } \\
\text { urban design }\end{array}$ & $\begin{array}{l}\text { Emphasis on quality in workmanship, aesthetics, human } \\
\text { comfort, and creating a sense of place; } \\
\text { Human scale architecture and beautiful surroundings. }\end{array}$ \\
\hline $\begin{array}{l}\text { Traditional neighbourhood } \\
\text { structure }\end{array}$ & $\begin{array}{l}\text { Discernible centre and edge, Public space and activity } \\
\text { located at the centre of town or neighbourhood. }\end{array}$ \\
\hline Increased density & $\begin{array}{l}\text { More buildings, residences, shops, and services are arranged } \\
\text { closely together for the ease of walking, to enable a more } \\
\text { efficient use of services and resources, and to create a more } \\
\text { convenient, enjoyable place to live. }\end{array}$ \\
\hline Smart transportation & $\begin{array}{l}\text { A network of high-quality transit alternatives connecting } \\
\text { cities, towns, and neighbourhoods together; } \\
\text { Pedestrian-friendly design that encourages a greater use of } \\
\text { bicycles and walking as daily transportation. }\end{array}$ \\
\hline Sustainability & $\begin{array}{l}\text { Minimal environmental impact of development and its } \\
\text { operations; } \\
\text { Eco-friendly technologies, respect for ecology and value of } \\
\text { natural systems; } \\
\text { Energy efficiency. }\end{array}$ \\
\hline Quality of life & - \\
\hline
\end{tabular}

Table 1. Ten principle of New Urbanism, Haas, 2008

New Urbanism is a controversial alternative to conventional patterns of urban development (Ellis, 2002). The principles of New Urbanism are criticised by scholars. Marshall argues that New Urbanism is advocated as essentially a marketing scheme that repackages conventional suburban sprawl behind a façade of nostalgic imagery and empty slogans (Marshall, 1999). As the 
complex background and situation of different cities, historical or newly developed, New Urbanism cannot address different urban issues by just mixing houses and creating walkable streets. As Boeing argues, the "human-scaled urban regulation" that is proposed in New Urbanism is asserting universal principles of design instead of attending to local conditions (Boeing, 2014). Centrally planned development following New Urbanism concepts obstructs the "initiative for construction to be taken by the finial users themselves" (Salingaros and Mena-Quintero, 2010). New Urbanism may solve the issues in the aspects of shaping urban morphology or streetscape but not all problems of urban regulation.

New Urbanism is considered as following Jacobs' idea of urban development in response to conventional urban regulation (Wickersham, 2001). Jacobs identified four preconditions for the creation and preservation of vibrant and diverse cities: Accommodating the activities of high-density populations, a mixture of primary uses, small-scale pedestrian-friendly blocks and streets, and retaining old buildings alongside new (Jacobs, 1961; Wickersham, 2001). Where Jacobs favours a mixture of primary uses, Euclidean urban development patterns separate, or quarantine, uses so that they do not infect one another (Wickersham, 2001). New Urbanists argue for the restructuring of zoning approaches to support their principles:

- Neighbourhoods should be diverse in use and population

- Communities should be designed for the pedestrian

- Cities and towns should be shaped by physically defined and universally accessible public spaces and community institutions

- Urban places should be framed by architecture and landscape design that celebrate local history, climate, ecology, and building practice (CNU, 2015b)

These principles of New Urbanism were developed to offer alternatives to the sprawling, single-use, low-density patterns typical of post-World War II 
development, which have been shown to inflict negative economic, health, and environmental consequences on communities (CNU, 2015b). New Urbanism aims to re-establish mixed-use urban neighbourhoods, yet critics argue it may fail in its objective. According to Talen, although New Urbanists advocate to mixing divergent groups, it is not known whether the effect on social interaction, of such design, works well in reality. Specific site designs may promote some aspect of social interaction, and social interaction may eventually lead to some dimension of community (Talen, 2002). But along the way, there are likely to be interactions with indirect effects that are beyond the designer's control (Talen, 2002). Besides, DeWolf argues that New Urbanists feign urbanity without making an effort to be urban (DeWolf, 2002). Within the principles of New Urbanism, communities and neighbourhoods may be separated into small segments with one central focus such as squares and stores (DeWolf, 2002). It overlooks the complexity of establishing communities and neighbourhoods. Kan also proposed that New Urbanism does not accommodate practical considerations (Kan, 2012) in different situations in contemporary cities and heritage cities. Mixing divergent communities relates to multiple elements of society, culture and ideology. The concepts and approaches of New Urbanism cannot address all issues to mix communities in every region.

Although controversial, New Urbanism draws increasing attention to FormBased Code and its related codes (such as Transect-Based Code and SmartCode) as new urban regulation tools. There has been broad research in Form-Based Code with the arise of New Urbanism. As of March 2018, there are more than 100 million results if searching the keyword "Form-Based Code" through Google Search. On Google Scholar, researches using "Form-Based Code", "Form-Based Zoning", "SmartCode", and "Transect Code Zoning" as keywords keep increasing from 1980 to 2015. As Figure 5 shows, between year 19811985, the research outputs, such as papers, books and academic reports, using Form-Based Code as the key words are much lower than 2000 according to 
Google Scholar. While between year 2011-2015, the research outputs using Form-Based Code as the key words nearly reach to 14,000 with the same search engine. "Form-Based Code", "Form-Based Zoning", "SmartCode", and "Transect Code Zoning" are all New Urbanism tools with similar zoning concepts. Form-Based Zoning presents the zones using form rather than land use. It equals with Form-Based Code in majority projects and researches. SmartCode is a unified development ordinance, addressing development at multiple scales of design, from regional planning on down to the building signage. As Duany Plater-Zyberk and Company (DPZ) describes, SmartCode is based on the rural-to-urban transect rather than land use divisions (DPZ, 2009). Transect Code Zoning is a zoning type that contains transect zones in a conventional zoning framework. In this research, Form-Based Code is a broad term encompassing all of these parlances.

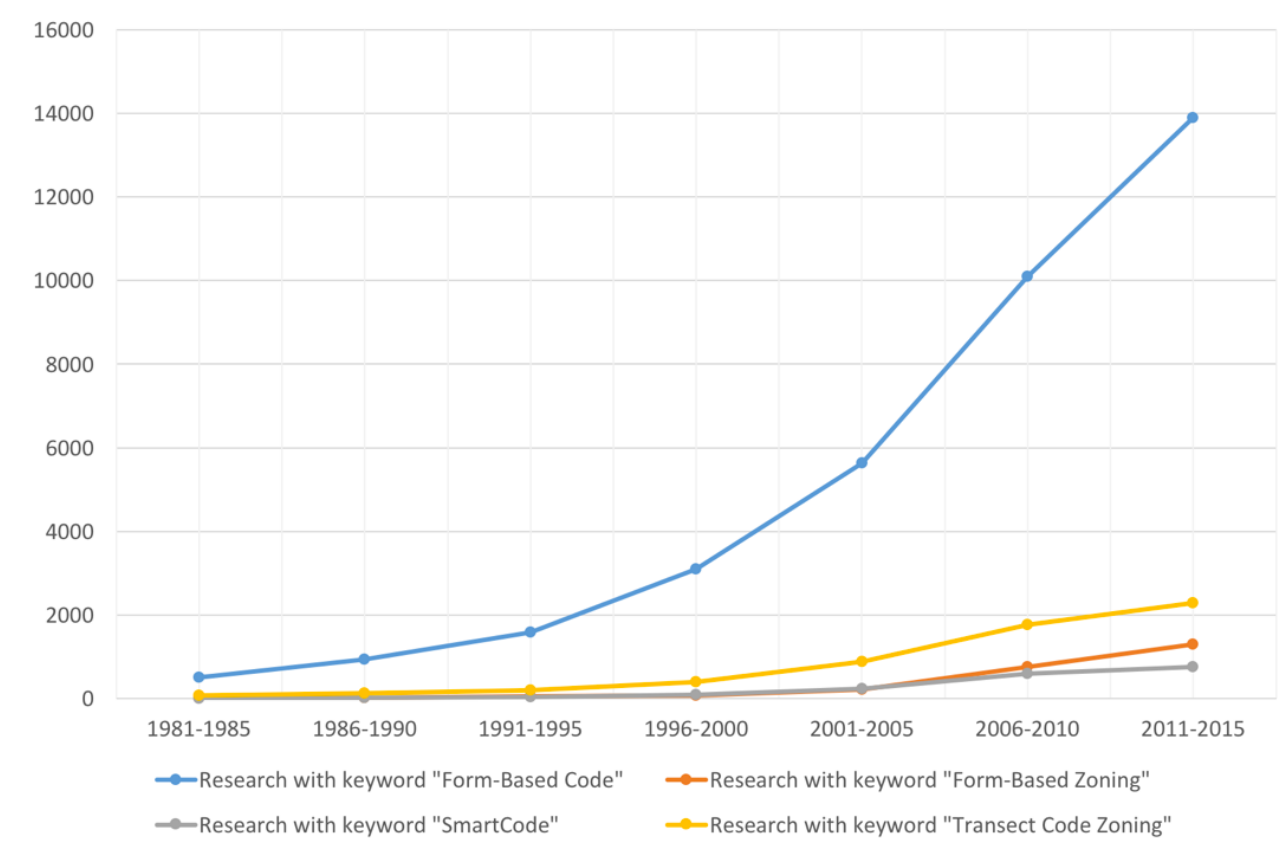

Figure 5. Research trends of Form-Based Code and related concepts using data derived form Google Scholar

\subsubsection{Theoretical roots}

Although Form-Based Code is a newer regulatory approach than conventional zoning, it is not a 21 st- or even 20 th-century concept, but one that has evolved 
from earlier centuries (Faga, 2014). Reaching back at least 3,000 years, much of what current code reformers are trying to do when they regulate urban dimensions like street width, building height, and frontage, connects to a long history of urban design (Talen, 2009). Not solely regulation; urban design theories are also the foundation of Form-Based Code (

Table 2).

\begin{tabular}{|c|c|c|c|c|c|c|c|c|}
\hline & $\begin{array}{c}\text { Central Place } \\
\text { Theory }\end{array}$ & The Ideal City & Zoning & $\begin{array}{c}\text { Growth } \\
\text { Machines and } \\
\text { Agglomeration }\end{array}$ & $\begin{array}{l}\text { Regional } \\
\text { Impact }\end{array}$ & $\begin{array}{l}\text { Power and } \\
\text { Practice }\end{array}$ & Sustainability & FBC \\
\hline 1850 & Thunen (1826) & \begin{tabular}{|l|} 
Haussmann \\
$(1855)$ \\
Burnham (1893) \\
Howard \\
$(1898,1902)$ \\
\end{tabular} & & & & & & \\
\hline 1900 & $\begin{array}{l}\text { Christaller } \\
\text { (1933) }\end{array}$ & $\begin{array}{l}\text { Hessell (1922) } \\
\text { Mumford (1938) }\end{array}$ & Williams (1992) & $\begin{array}{l}\text { Ohin (1933) } \\
\text { Hoover (1937) }\end{array}$ & Geddes (1909) & & & \\
\hline 1950 & Losch (1954) & \begin{tabular}{|l|} 
Jacobs $(1961)$ \\
De Certeau \\
$(1980)$ \\
Whyte $(1980)$ \\
Foucault $(1984)$ \\
Kostof $(1991)$
\end{tabular} & $\begin{array}{l}\text { Colean (1953) } \\
\text { Reps (1964) } \\
\text { Scott (1969) } \\
\text { Clawson (1971) } \\
\text { Barnett (1974) } \\
\text { Jacobs, A. (1980) } \\
\text { Boyer (1983) } \\
\text { Willis (1986) } \\
\end{array}$ & $\begin{array}{l}\text { Molotch (1976) } \\
\text { Logan and } \\
\text { Molotch (1987) }\end{array}$ & \begin{tabular}{|l|} 
Clay $(1980)$ \\
Cronon $(1991)$ \\
Bolton (1992) \\
Krugman \\
$(1993,1999)$
\end{tabular} & \begin{tabular}{|l} 
Friedmann \\
$(2012)$ \\
Legates and \\
Stout (1998) \\
Forrester \\
$(1999)$
\end{tabular} & $\begin{array}{l}\text { Lynch (1984) } \\
\text { McHarg } \\
\text { (1992) } \\
\text { Thompson and } \\
\text { Steiner (1997) }\end{array}$ & \\
\hline 2000 & & $\begin{array}{l}\text { Gehl (2010) } \\
\text { Rybczynski } \\
\text { (2010) }\end{array}$ & $\begin{array}{l}\text { Birch (2001) } \\
\text { Ben-Joseph (2005) } \\
\text { Sitkowski (2007) } \\
\text { Hirt (2007) } \\
\text { Inniss (2007) } \\
\text { Wolf (2008) } \\
\text { Cullingworth and } \\
\text { Caves (2009, 2014) } \\
\text { Qian (2011) }\end{array}$ & & $\begin{array}{l}\text { Calthorpe and } \\
\text { Fulton (2001) } \\
\text { Ross (2009) } \\
\text { Christopherson } \\
(2010) \\
\text { Glaeser (2011) }\end{array}$ & \begin{tabular}{|l} 
Beauregard \\
$(2012)$
\end{tabular} & $\begin{array}{l}\text { Norton (2004) } \\
\text { Farr (2008) } \\
\text { Palazzo and } \\
\text { Steiner (2012) } \\
\text { Duany and } \\
\text { Talen (2013) } \\
\\
=\mid\end{array}$ & $\begin{array}{l}\text { Duany, Plater- } \\
\text { Zyberk and Speck } \\
(2000) \\
\text { Langdon (2006) } \\
\text { Parolek, Parolek } \\
\text { and Crawford } \\
\text { (2008) } \\
\text { Talen (2009, } \\
2012,2013) \\
\text { Elloitt, Goebel } \\
\text { and Meadows } \\
\text { (2012) } \\
\text { Leigh and } \\
\text { Hoelzel (2012) } \\
\text { Diaz (2013) }\end{array}$ \\
\hline & & & & & & & & $\begin{array}{l}\text { Garnett (2013) } \\
\text { Rangwala (2013) }\end{array}$ \\
\hline
\end{tabular}

Table 2. Theoretical roots of Form-Based Code, Faga, 2014

Form-Based Code regards cities as continuous sections. The idea of crosssections corresponds with the theories of Concentric Development Rings by von Thunen (1826), Valley Section by Geddes (1909) and Central Place Theory by Christaller (1933). The Concentric Development Rings concept describes the relationships between agriculture costs and urban-periphery hierarchy. If the city centre is the circle centre, layered agriculture lands surround the circle from horticulture and dairying to grazing. When a river interweaves the built environment, the circle model becomes a belt pattern ( 
Figure 6). Von Thunen's graphical illustration influenced the model of Valley Section (Figure 7) where the sectioned urban and landscape, mode of life, density and society are also layered and cut transversely. The Valley Section is regarded as a rudimentary theory of Form-Based Code. As FBCI, if the urbanperiphery system also can be represented by continuous sections as the Valley Section, the transition from rural to downtown in Form-Based Code should move from natural, to rural, to sub-urban, to general urban, to urban centre, and to urban core according to the appropriate level (Figure 8).

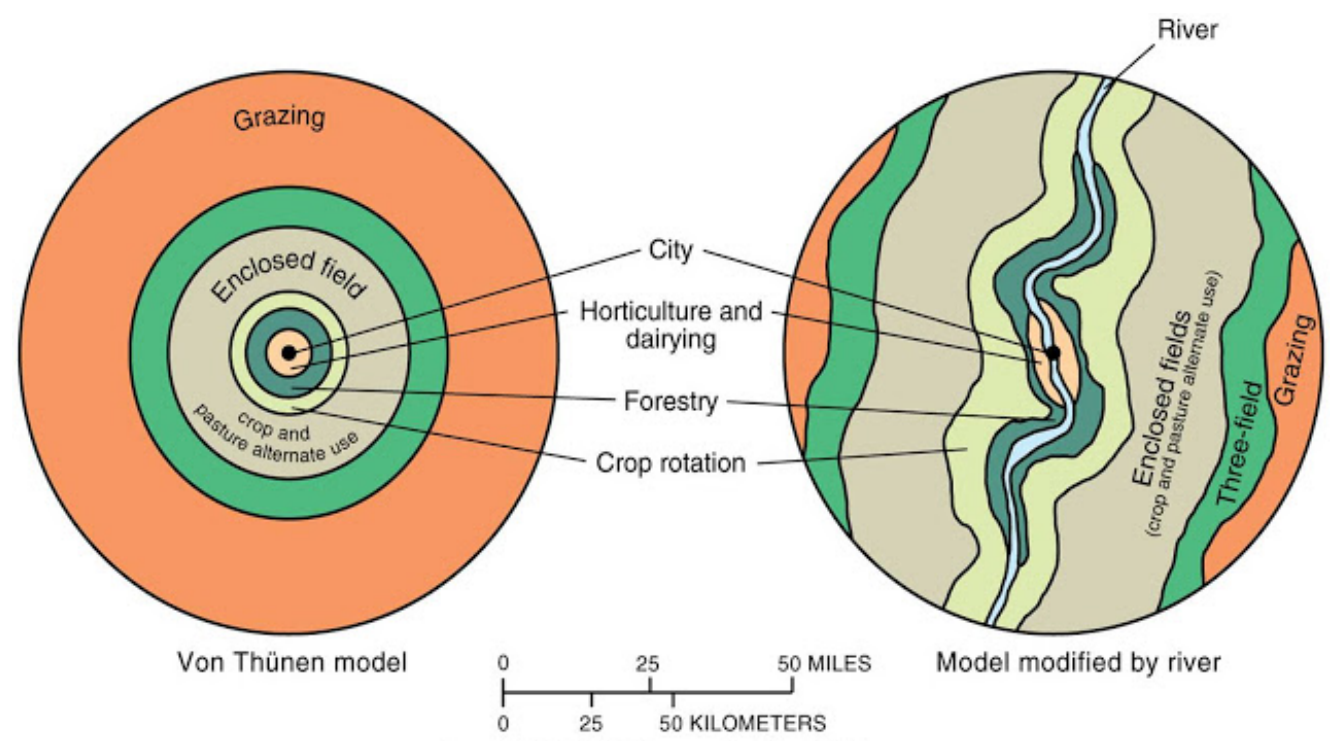

Figure 6. Concentric Development Rings, von Thunen, 1826

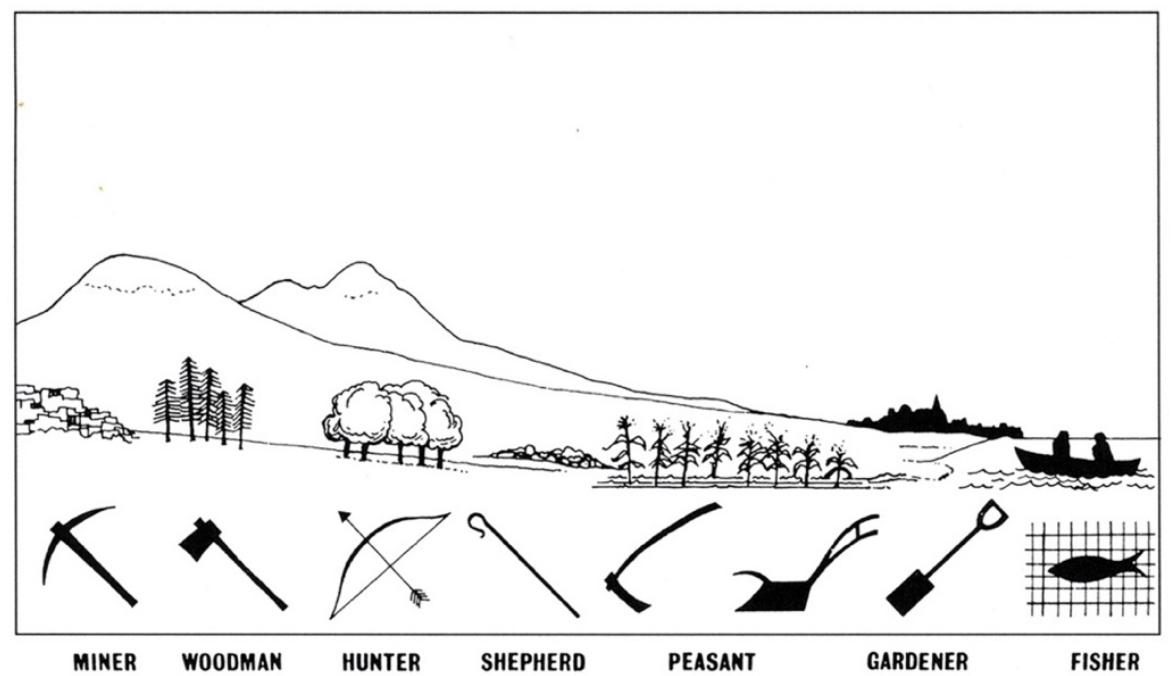

Figure 7. Patrick Geddes Valley Section (1909), Clay, 1980 


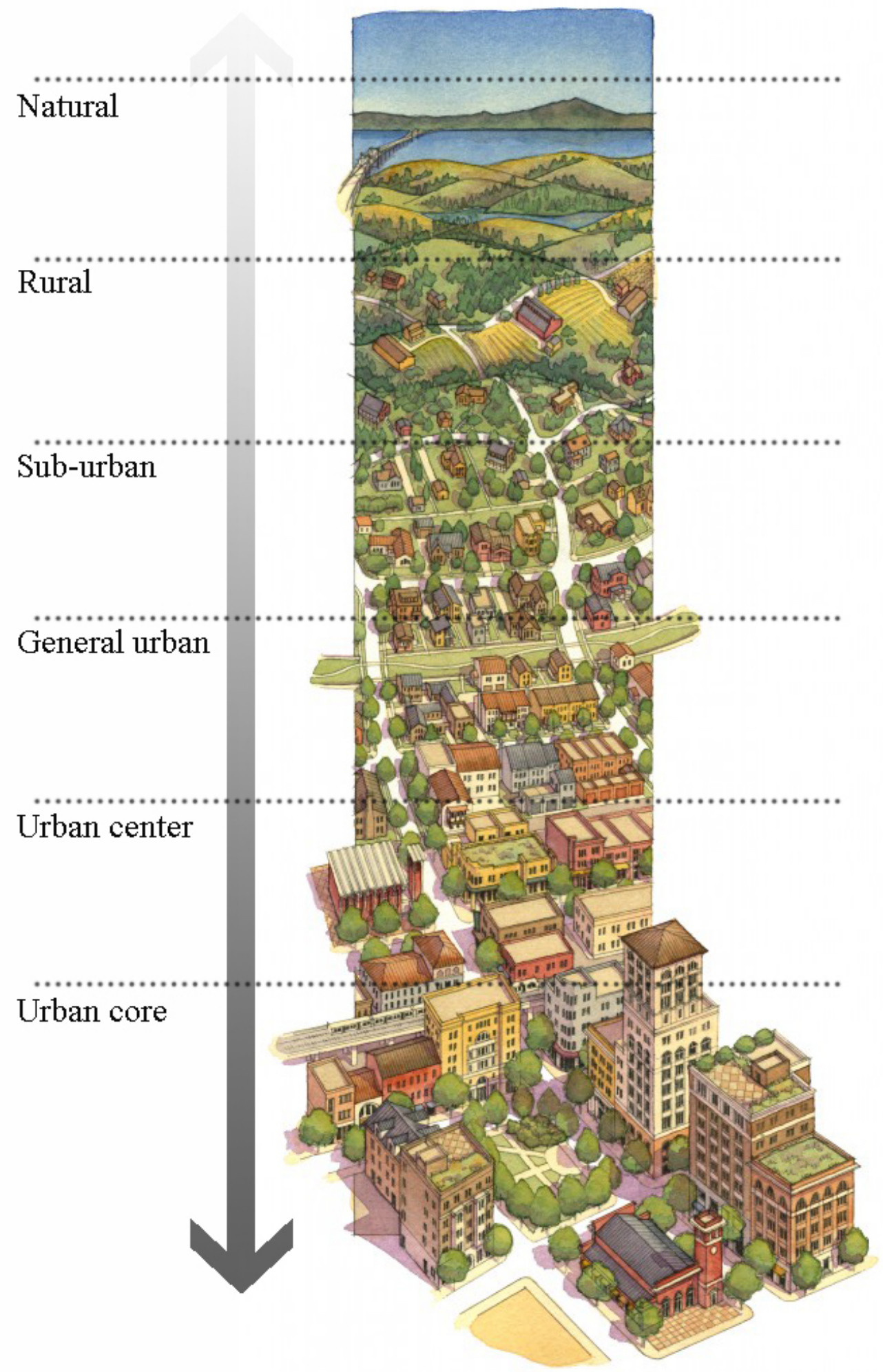

Figure 8. Transition from rural to downtown in Form-Based Code, FBCI, 2014 
In his attempt to organize German land conquests before and during World War II, Christaller (1933) expanded von Thunen's ideas with a central place theory that included an imposed structure (Franzman, 2010). Christaller's theory revolved around threshold and range, where threshold included the minimum market required for selling a good, and the range was the maximum distance customers would go to obtain the good or service (Faga, 2014). The urban structure of Central Place Theory evolved into Form-Based Code.

Form-Based Code's mode of expression comes from the model of ecosystem transections. Naturalists use different sections to describe the hierarchy of ecosystems from one sub-ecosystem to another (Figure 9). This method of analysis and graphical pattern are used in Form-Based Code for reference. Duany has applied this idea to human settlements, and from about 2000 the idea has permeated the thinking of New Urbanists (CNU, 2015c). Accordingly, it is more appropriate to say that the concept of Form-Based Code is a consequence of multiple studies accumulating in different disciplines.

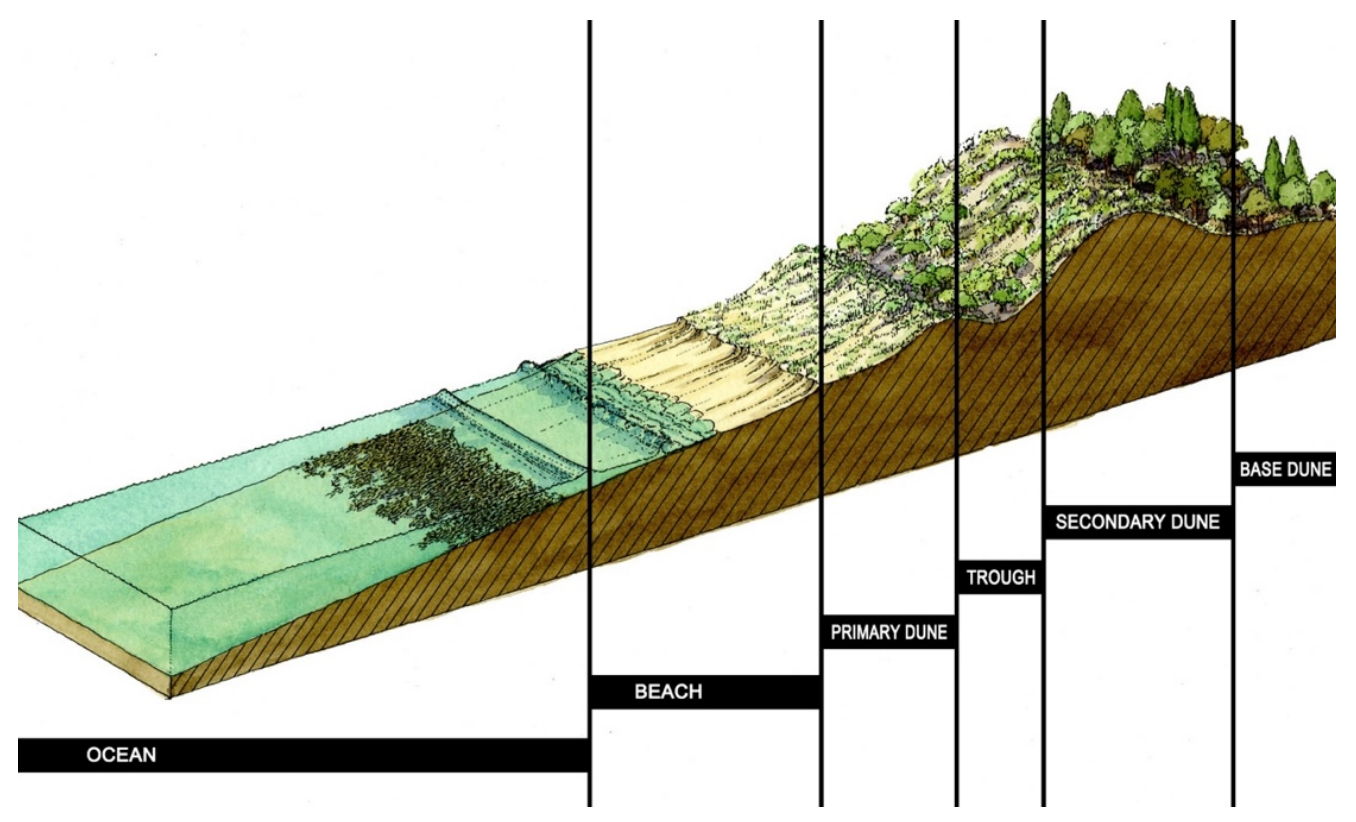

Figure 9. Transition from ocean to base dune in eco-system, DPZ, 2015 


\subsubsection{Concepts}

Form-Based Code has three key concepts: The form-based principle, transect matrix, and visualised manifestation. The form-based principle is a critical response to the land use-based principle. A transect matrix reorganises urbanperiphery environments from natural zone to urban core zone. Visualised manifestation provides understandable codes with illustrations and graphics. The following paragraphs explain the details of these concepts.

\subsubsection{Form-based principle}

Urban form describes the performance of buildings and streets. In Form-Based Code, the forms of buildings and streets are regulated before functions, arrangements, and activities in a certain land type are designated. After controlling performance, land use is embedded into buildings or public spaces and can be mixed flexibly according to regulation strategies.

The form-based idea is analysed through comparison with conventional urban regulation. Differences between conventional regulation and Form-Based Code have been heavily studied. According to Parolek, et al. (2008), Talen (2013), Ben-Joseph (2005), Kayden (2011), and Kan (2012), the differences stem from conventional regulation being land use-based, while Form-Based Code is formbased (Figure 10). In conventional zoning, land use is the primary consideration; in Form-Based Code, physical form and character are the primary considerations (Kan, 2012). The former divides the land into segregated districts. The latter divides the land by prioritising consistent building forms, street corridors, characters and atmosphere, while allowing a mixture of functions. Generally, urban form is not an essential element in urban regulation. But in Form-Based Code, forms serve as the necessary regulating objectives. Spatial performance is more significant than functional division. 
Conventional Zoning

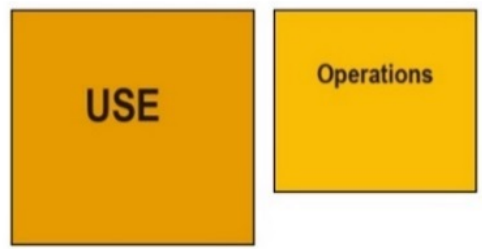

Focused on use
Form-Based Codes

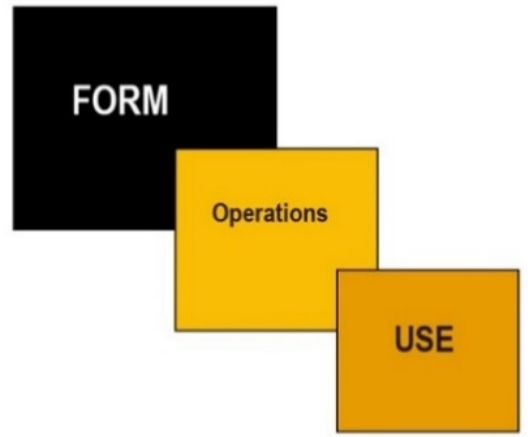

More focus on design and form

Figure 10. Differences between conventional zoning and Form-Based Codes, Kan, 2012

Inniss (2007) argues Form-Based Code is "back to the future" because it reuses the urban design ideas of gardening and beautifying from before the Industrial Revolution. In 1898, the garden city movement was initiated by Ebenezer Howard in UK. His idealised garden city would be planned on a concentric pattern with open spaces, public parks and radial boulevards in his book Tomorrow: A Peaceful Path to Real Reform (which was reissued in 1902 as Garden Cities of To-morrow). The garden city concept influenced New Urbanism and its application in Form-Based Code. Form-Based Code principles encourage mixed land use, pedestrian space and green canopy.

Because of the different regulation concepts, Euclidean zoning and Form-Based Code's regulatory plans present in different ways. For example, Miami Urban Planning Regulation (2012) by Euclidean zoning defines the context with land uses of residential, commercial, open space, government, and industrial. While in Miami 21 Code (2015) by Form-Based Code, the city is defined with form zones of natural, sub-urban, general urban, urban centre, and urban core with specific zone names. Land use becomes the secondary consideration. FormBased Code (Miami 21 Code) can be regarded as an extension of the existing 
Miami Urban Planning Regulation by taking form as the primary consideration.

The form-based principle is believed that it has the capability to allow urban design details in zoning. FBCI uses Figure 11 to compare graphic examples of Euclidean zoning, design guidance and Form-Based Code. Euclidean zoning regulates setbacks to create envelopes. The building results are potentially approved no matter what shape the final product takes (Woodward, 2013). Dimensional demands are considered with specific functions. Katz (2004) state that Euclidean zoning defines a one-block parcel in large scales. It does not describe what the place looks like, nor does it generate a walkable environment in detail. Design guidelines extend zoning to more details such as building façade, street trees, building heights, the frequency of openings, and surface articulation - even though land use is the guiding foundation. The guideline is in line with land use-based regulation ideas whilst incorporating some urban design elements into the regulation. Form-Based Code provides more urban design objects with parameters and figured guidance, such as street and building types, build-to lines, building heights, number of floors, and percentage of built site frontage. These regulations help to prescribe where buildings are required to be set a specific distance from the front lot line (MAP, 2007) and what the streetscape looks like. Land use is not directly reflected.

According to the comparison, Euclidean zoning macroscopically controls land use. Form-Based Code, as part of a land-use regulatory system, extends conventional zoning by regulating and creating places, focusing on both buildings and streetscapes on various scales. As a result, conventional zoning may generate more uniformity and Form-Based Code more diversity (Kan, 2012). Parolek, et al. (2008) thoroughly tabulated the differences between Euclidean zoning and Form-Based Code (Table 3). He describes Euclidean zoning as proscriptive and Form-Based Code as prescriptive. However, "proscriptive" is more about forbidding or inhibitory and "prescriptive" is more 
about application of normative approaches or regulations. Considering the analysis above, Euclidean zoning is suitable to be described as "prescriptive" and Form-Based Code as "descriptive".

\section{How zoning defines a one-block parcel}

Density, use, FAR, setbacks, parking requirements, and maximum building height(s) specified.

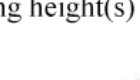

How design guidelines define a one-block parcel

Density, use, FAR, setbacks, parking requirements, maximum building height(s), frequency of opening, and surface articulation specified.

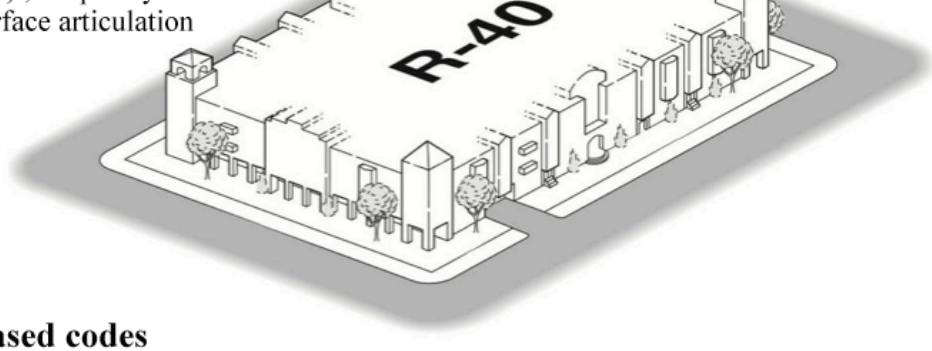

How form-based codes define a one-block parcel

Street and building types (or mix of types), build-to lines, number of floors, and percentage of built site frontage specified.

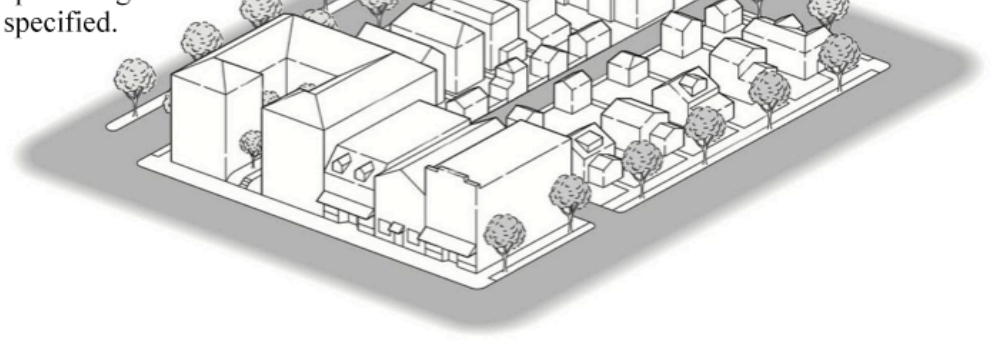

Figure 11. Comparisons among conventional zoning, guidelines and Form-Based Code, FBCI, 2015b 


\begin{tabular}{|c|c|}
\hline Euclidean zoning & Form-Based Code \\
\hline Land use is primary consideration & $\begin{array}{l}\text { Physical form and character are primary, } \\
\text { with secondary consideration to use }\end{array}$ \\
\hline $\begin{array}{l}\text { Segregated land-use planning } \\
\text { principles }\end{array}$ & $\begin{array}{l}\text { Mixed use, walkable, compact } \\
\text { development-oriented principles }\end{array}$ \\
\hline Districts & Neighbourhoods/streets \\
\hline Organized around land use zone & $\begin{array}{l}\text { Used spatial organizing principles to } \\
\text { reinforce urban hierarchy }\end{array}$ \\
\hline $\begin{array}{l}\text { Reactive to individual development } \\
\text { proposals }\end{array}$ & Proactive community visioning \\
\hline $\begin{array}{l}\text { Proscriptive, regulating by numeric } \\
\text { parameters } \\
\text { e.g. Plot ratio, setbacks, parking ratios }\end{array}$ & Prescriptive, describe the requirement \\
\hline $\begin{array}{l}\text { Regulate to create buildings } \\
\text { Focus on sites, right-of-way }\end{array}$ & $\begin{array}{l}\text { Regulate to create places } \\
\text { Attention on street and streetscape }\end{array}$ \\
\hline Uniformity in neighbourhoods & Diversity in neighbourhoods \\
\hline
\end{tabular}

Table 3. Differences between Euclidean zoning and Form-Based Code, Parolek, et al., 2008

\subsubsection{Transect matrix}

The transect matrix is another concept representative within Form-Based Code. The role of transect matrix is to provide zone types in the framework of FormBased Code. The definitions of zone types in the transect matrix mode are based on urban features. The mode of transect matrix presents a continuous development from natural to urban. Duany describes the transect matrix as:

“... [arranging] in useful order the elements of urbanism by classifying them from rural to urban. Every urban element finds a 
place within its continuum. For example, a street is more urban than a road, a curb more urban than a swale, a brick wall more urban than a wooden one, and an alley of trees more urban than a cluster. Even the character of streetlights can be assigned in the transect according to the fabrication from cast iron (most urban), extruded pipe, or wood post (most rural)" (DPZ, 2009).

The transect matrix defines the hierarchical development scale from sparse suburban to dense urban cores (Forsyth, 2003a; Hascic, 2006; LignannZielinska, 2008; Stephenson, 2002; Kim, 2014). A standard transect matrix is divided into zones from rural to urban (DPZ, 2015; Figure 12). The zone types are natural zone (T1), rural zone (T2), sub-urban zone (T3), general urban zone (T4), urban center zone (T5), urban core zone (T6), and special districts (SD).

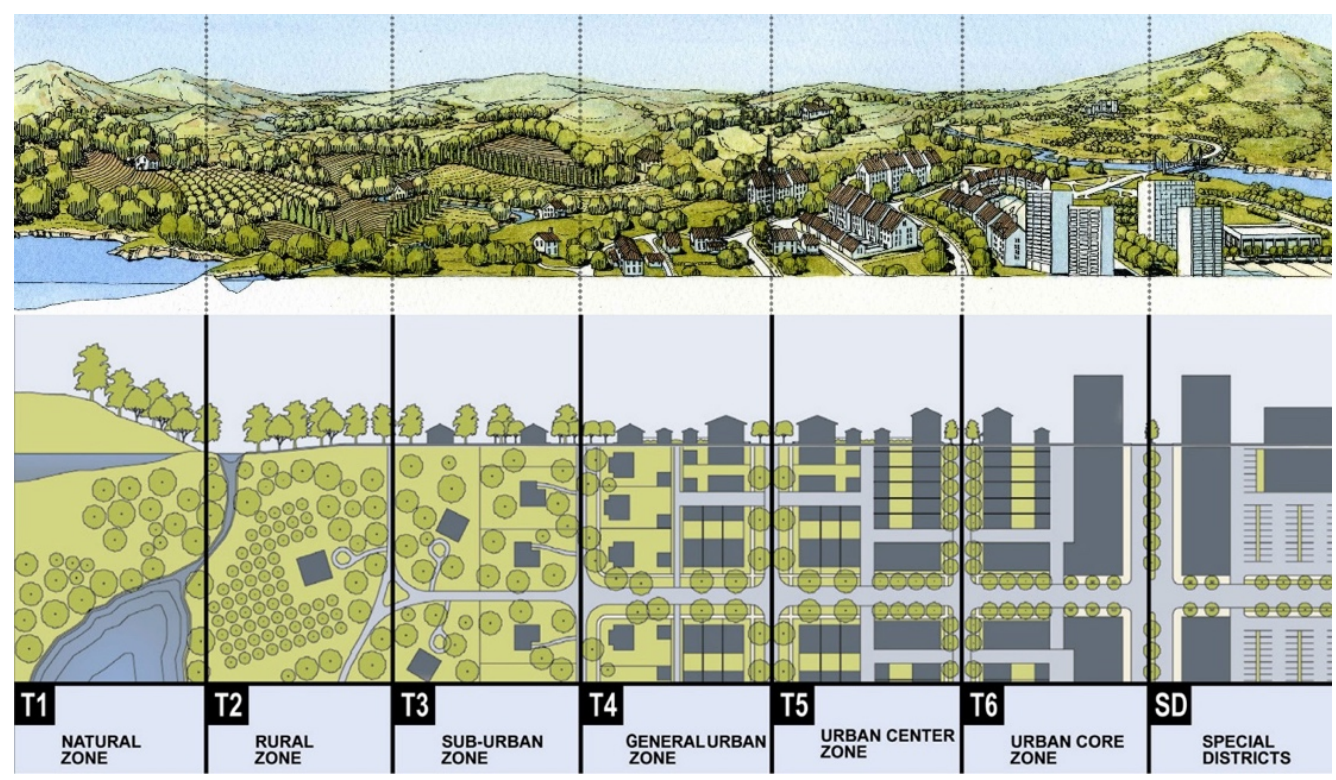

Figure 12. Standard transect matrix of Form-Based Code, DPZ, 2009

The left side of the transect matrix tends to be natural; the right side tends to be artificial. Each zone's placement in the matrix depends on the role and nature of the urban space, such as its degree of density, open space forms, building forms, and facilities. If an area contains a high-density of buildings and paved 
streets, or a large percentage of road and highways, it is defined as "more urban" than the area containing large-scale greenery, natural water systems or smallscale residential buildings. The standard transect matrix experimentally describes a universal urban morphology transitioning from natural to artificial. Identifying the transect matrix and zone descriptions, Form-Based Codes will be identified. Generally, land uses are mapped on a land use plan in Euclidean zoning and the development of each land use type are regulated in Euclidean zoning ordinances. While in Form-Based Code, transect types in the transect matrix are mapped on form-based plan and the development of each transect type are regulated in Form-Based Code ordinances.

Transect matrix has been used in the Form-Based Code framework to enhance the zoning process. However, according to Garnett, the morphology hierarchy in the transect matrix seems to indicate that inhabitants have to cluster at the city centres rather than live in suburbs (Garnett, 2013). Or, to put the challenge into social-science terminology, Form-Based Code principles make cities generate social capital by drawing together strangers who would not otherwise connect, while suburbs inhibit social capital by further privatising the readyatomized culture (Garnett, 2013). But from the perspective of spatial analysis, the transect matrix in Form-Based Code framework proposes a method to recognise the physical characteristics of a built environment. It extends the zone types of Euclidean zoning by using form as an essential consideration. Transect matrix focuses on form analysis. Other urban issues, such as land use division, cannot be solved by the method proposed in transect matrix.

The standard transect matrix can be used directly or customised according to different regulation strategies and existing circumstances in real-world projects. The natural-artificial transition in the standard transect matrix describes an ideal development model. Urban planners and designers who make the specific FormBased Code can choose to adjust the matrix to make it suitable for specific sites. 
For instance, in the Hammonton Form-Based Code (2011) in New Jersey, designers redefined the transect matrix and changed the descriptions of each zone. They used Zone Gateway Crossroads (G3), Gateway Boulevard (G2), Gateway Avenue (G1), Near Town (D1), In Town Railway (D2), In Town (D3), and "Main Street" (D4) to instead natural zone (T1), rural zone (T2) to urban core zone (T6). These zones are coloured and mapped on the site ( Figure 13). In the Flagstaff downtown regulating plan (Figure 14), the transect types consist of zones T3, T4, T5, and T6. T3 and T4 represent neighbourhoods and neighbourhood open. T5 represents the main streets and the main street open. T6 represents downtown. By incorporating the zone types into a sitemap, a regulating map is generated with transect types and sub-types. Whilst the transect diagram is based on American urbanism, other countries have applied the new zoning method in urban regulation projects. Centre for Applied Transect Studies (CATS) presents that the examples exist in England, Scotland, Mexico, the Bahamas, Spain, Russia, and Romania (CATS, 2017). More reviews of transect matrix implementation are presented in Chapter 3.

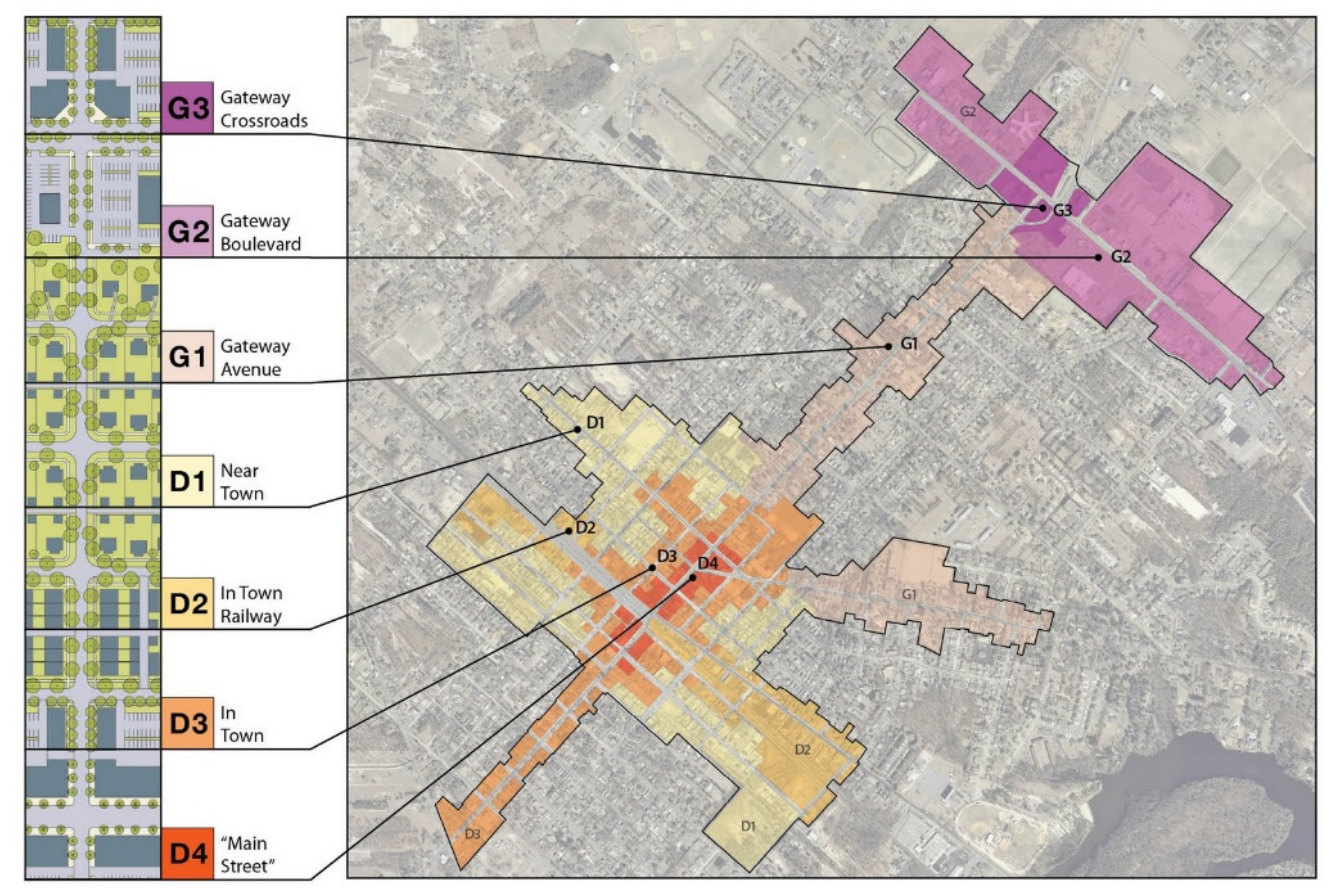

Figure 13. Regulating plan of Hammonton Form-Based Code, City of Hammonton, 2011 


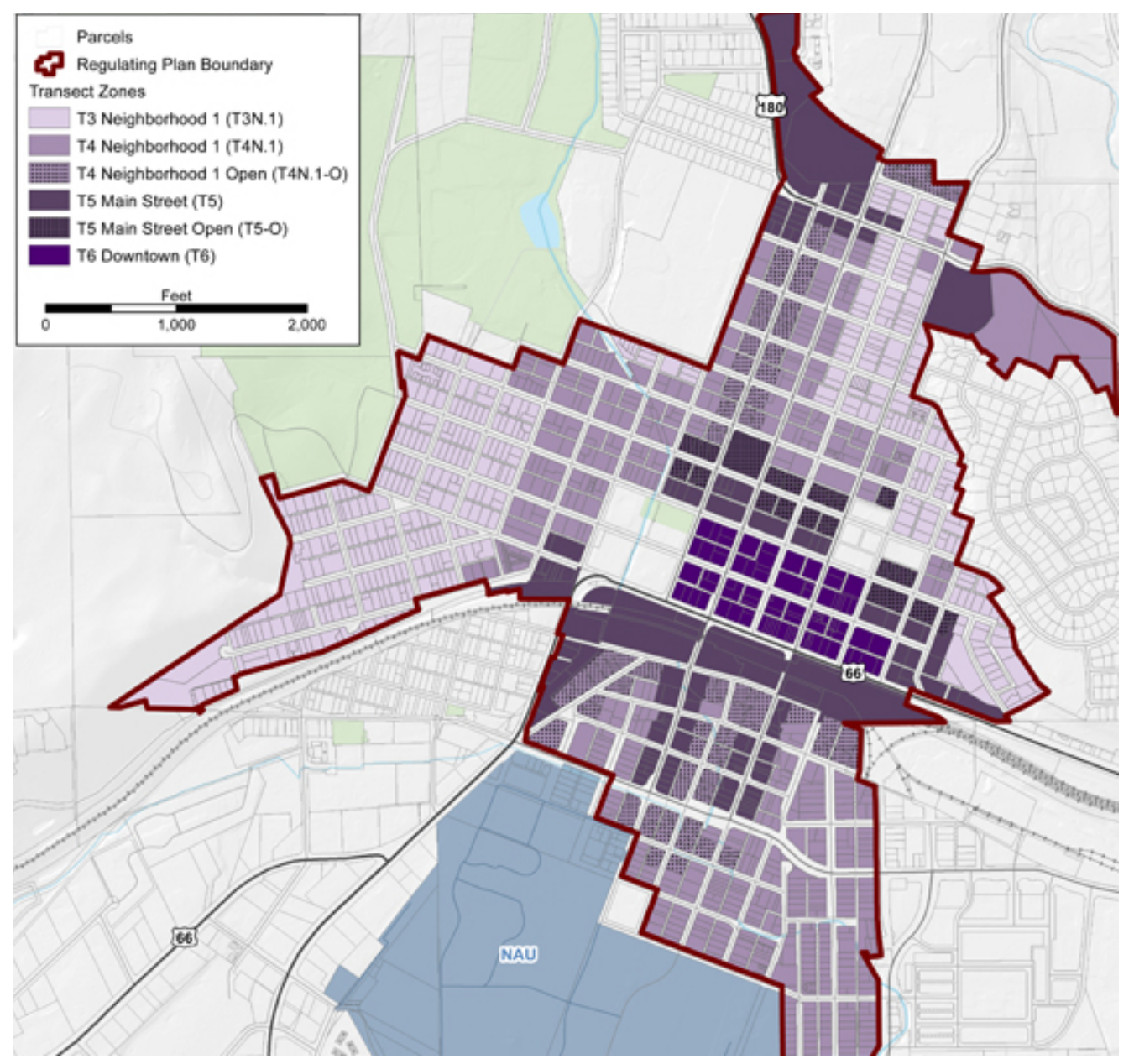

Figure 14. Regulating plan of Flagstaff Downtown Code, City of Flagstaff, 2011

\subsubsection{Visualised regulation}

Conventional expressions of urban regulation are mainly text-based, with most codes found as text documents with supporting graphics and tables. Form-Based Code presents regulations by using illustrations and models, providing visual aids with variables for code description. Regulation outcomes beyond land usebased Euclidean zoning can be predicted with relatively detailed models.

Figure 15 presents a typical page of Form-Based Code standards. It describes part of the regulation of T4 Neighbourhood Small Footprint (T4N.SF) in the Form-Based Code of City of Cincinnati (2013). The information on this page 
includes intent, zone categories, allowed building types, and building forms. Specific parameters and their values are expressed by words, illustrations and renders.

Visualised regulations are embedded in different components of Form-Based Code standards. Normally, Form-Based Code contains five major components: a regulating plan, a public space standard, a building form standard, administration, and definition. A regulating plan is essentially a fine-grained zoning map combined with a street plan and an open space plan, keyed to a set of development standards (Russell and Madden, 2015). Making the regulating plan depends on design intentions and the physical environment's characteristics (FBCI, 2015b). Each district type must be designated a specific physical location with the representative colour. The public space standard regulates streets, blocks, envelops and building lots in the city-wide or specific area following the regulating plan. It is a series of codes for the public realm, such as sidewalks, travel lanes, on-street parking, street trees, and street furniture, etc. (FBCI, 2014). The building form standard regulates a building's configurations, features, and architectural details as a part of the public realm ( Figure 16). The primary codes of a building form standard include placement, form, allowed encroachments, and parking placement. Administration acts as a streamlined application and project review process. Definition is a glossary to ensure the precise use of technical terms (FBCI, 2014).

Regulating plans, public space standards and building form standards are primary components described by illustrations and models. Administration and definition are supplementary components with word-based interpretations (Table 4). According to Parolek, et al. (2008), many Form-Based Code projects choose further optional components, such as architectural standards, landscape standards, thoroughfare standards, signage standards and annotation, to assist its description and implementation. 
T4 Neighborhood Small Footprint (T4N.SF)
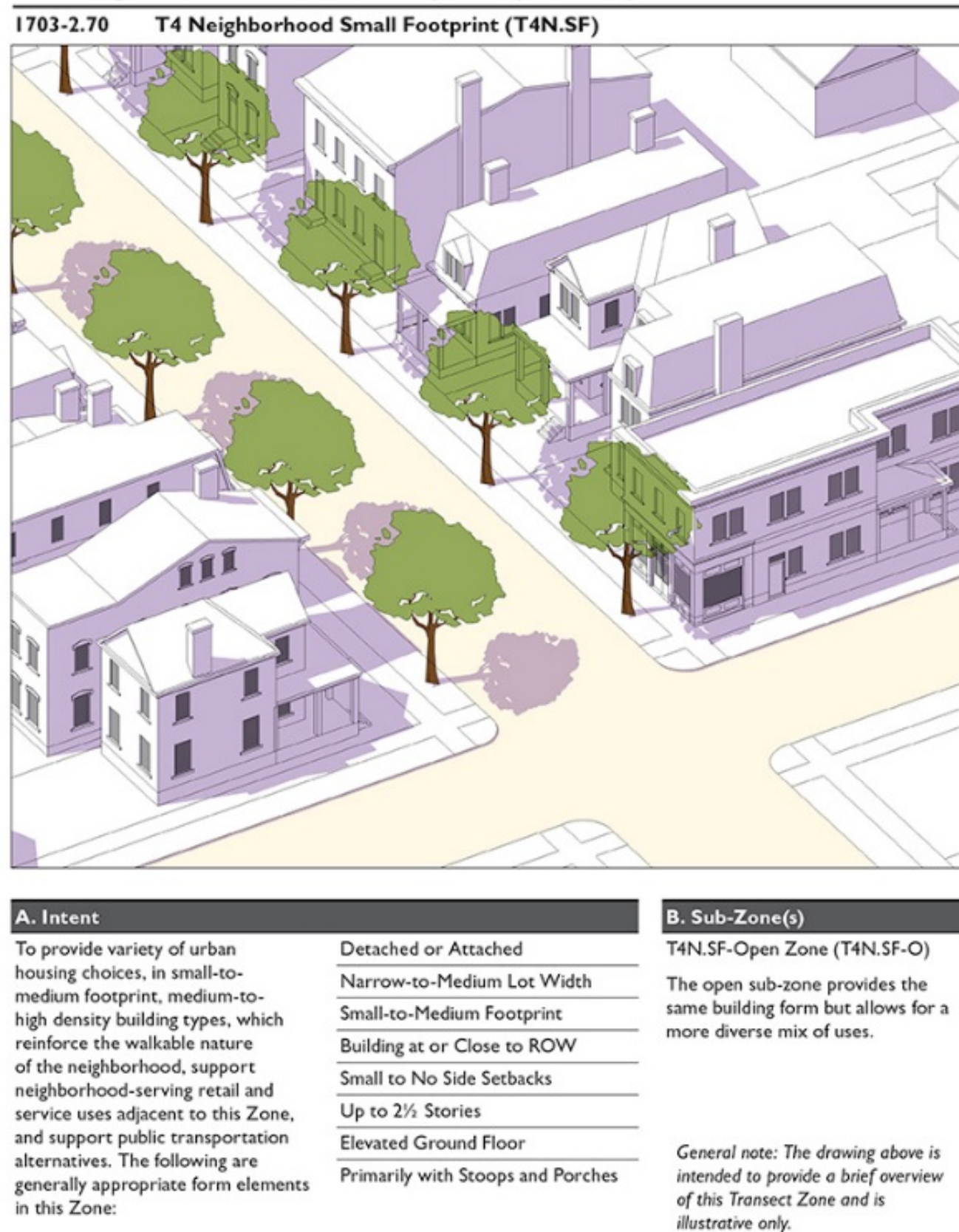

City of Cincinnati Form-Based Code

Final Draft 2/15/13

$2-23 \quad 2-24$
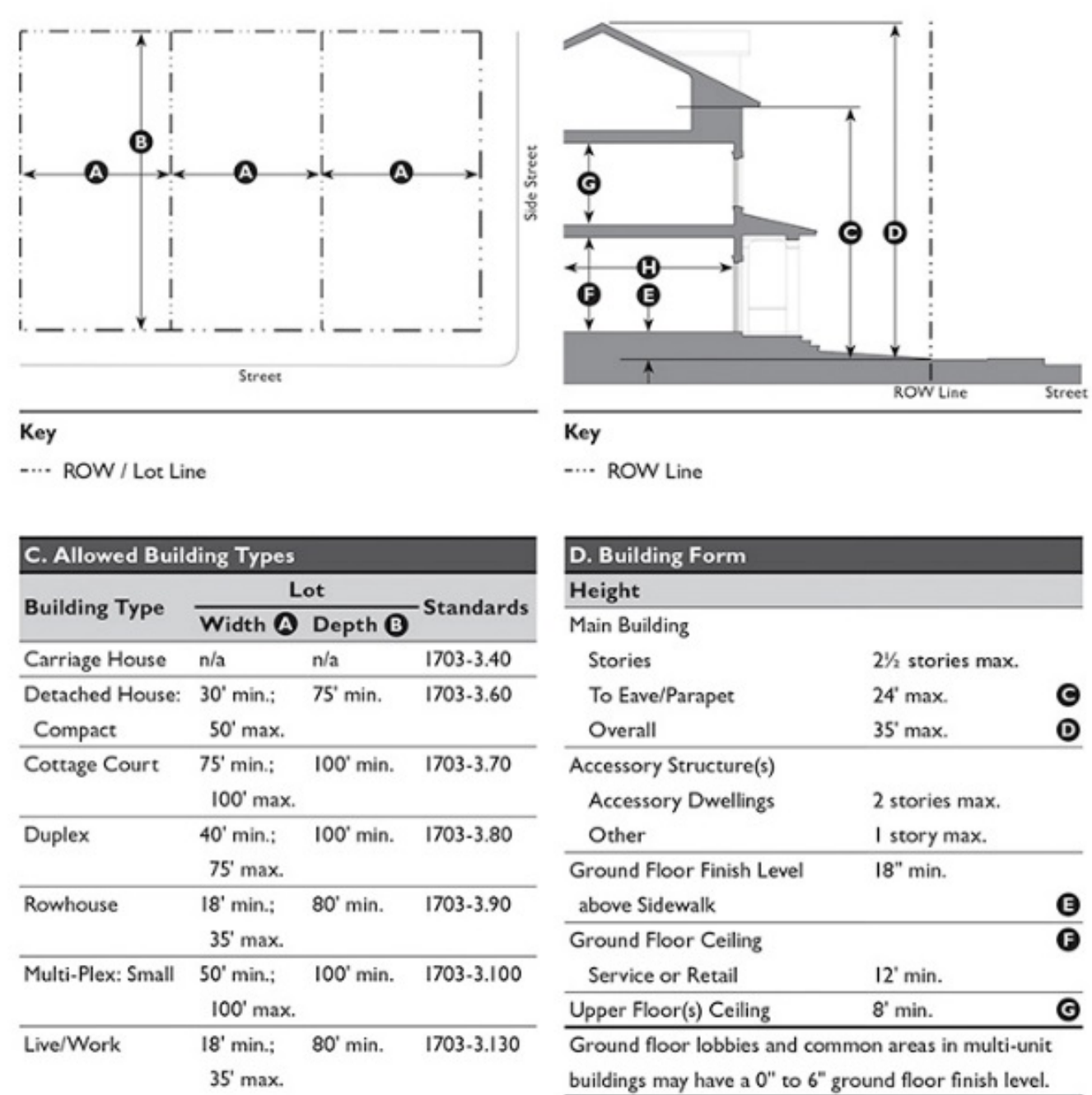

D. Building Form

Main Building

Stories

To Eave/Parapet $\quad 21 / 2$ stories max.

Overall $35 \mathrm{max}$

Accessory Structure(s)

Accessory Dwellings 2 stories max.

Other I story max.

Ground Floor Ceiling

\begin{tabular}{lll} 
& \\
\hline & & \\
\hline
\end{tabular}

Ground floor lobbies and common areas in multi-unit

buildings may have a 0 " to 6 " ground floor finish level.

Footprint

Depth, Ground-Floor Space 24

Accessory Structure(s)

Width

$24^{\prime} \max$

Miscellaneous

Loading docks, overhead doors, and other service

entries shall be screened and not be located on primary street facades.

Final Draft 2/15/13

City of Cincinnati Form-Based Code

Figure 15. An example page of Form-Based Code of Cincinnati of Ohio, City of Cincinnati, 2013 

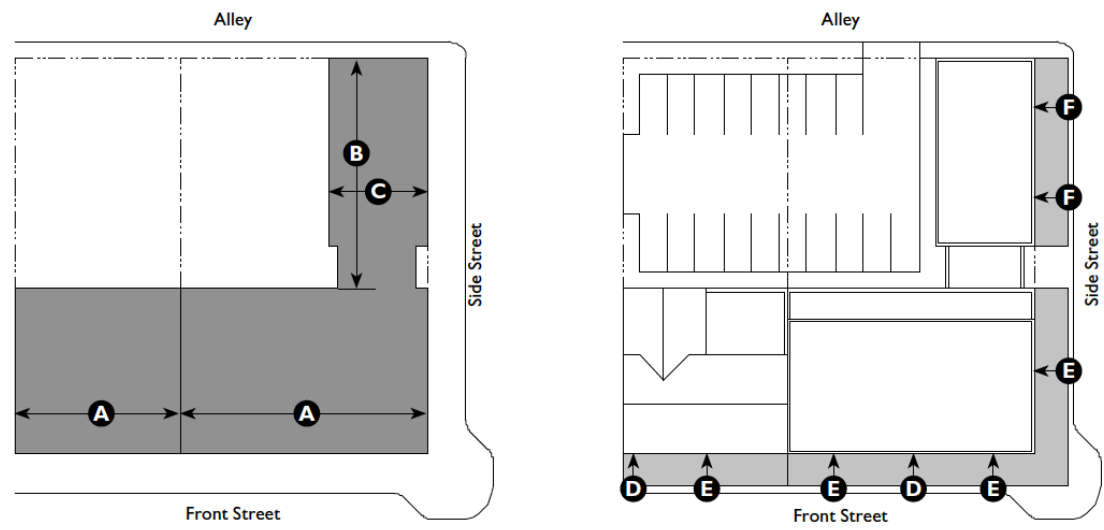

\begin{tabular}{|c|c|}
\hline $\begin{array}{l}\text { Key } \\
-\cdots-\text { ROW / Lot Line } \\
\cdots-- \text { Setback Line }\end{array}$ & $\square$ Building \\
\hline B. Number of Unit & \\
\hline Units per Building & $2 \mathrm{~min}$. \\
\hline C. Building Size an & sing \\
\hline Height & \\
\hline Height & $\begin{array}{l}2 \text { stories min.; } \\
4 \text { stories max. }{ }^{1}\end{array}$ \\
\hline $\begin{array}{l}{ }^{1} \text { Height shall also com } \\
\text { in Section } 1703-2\left(S_{p}\right.\end{array}$ & $\begin{array}{l}\text { th transect zone standards } \\
\text { o Transect Zones). }\end{array}$ \\
\hline Main Body & \\
\hline Width & I50' max. \\
\hline Secondary Wing(s) & \\
\hline Width & $100^{\prime} \max$. \\
\hline Depth & $65^{\prime} \max$. \\
\hline
\end{tabular}

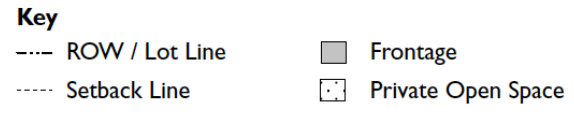

D. Allowed Frontage Types

Forecourt I703-2.80

Dooryard $\quad 1703-4.90$

Lightwell 1703-4.100

Shopfront 1703-2.110

Terrace 1703-4.120

E. Pedestrian Access

Upper floor units located in the main building shall D

be accessed by a common entry along the front

street.

Ground floor units may have individual entries

along the front street or side street.

On corner lots, units in a secondary wing/accessory $\mathbf{F}$

structure may enter from the side street.

\section{F. Private Open Space}

No private open space requirement.

Figure 16. Example codes of Form-Based Code of Cincinnati of Ohio, City of Cincinnati, 2013

Arguably, Form-Based Code has the potential to resolve the issues created by conventional approaches to urban regulation, with the aims of mixed land-use and reviving urban centres (Parolek, et al., 2008; Duany and Talen, 2001; Talen. 2002, 2009; Geller, 2010). Form-Based Code presents an approach to regulation. Embedding this approach into existing regulatory systems may have challenges both in academia and practice. The following section explores the challenges of achieving the regulation aims of Form-Based Code. 


\begin{tabular}{|c|c|c|c|}
\hline Type & Components & Description & Graphic solution \\
\hline \multirow{3}{*}{ 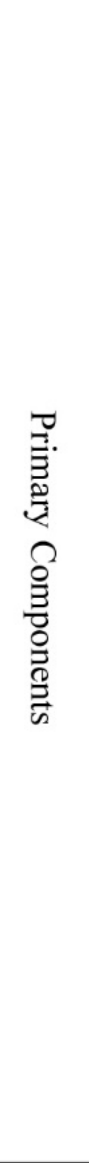 } & Regulating plan & $\begin{array}{l}\text { A plan or map of the } \\
\text { regulated area designating } \\
\text { the locations where different } \\
\text { building form standards } \\
\text { apply. }\end{array}$ & 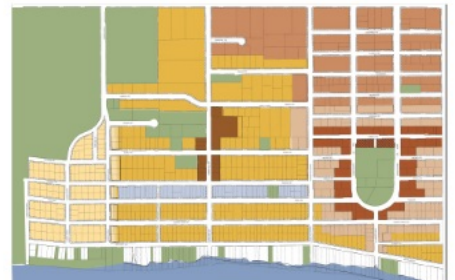 \\
\hline & Public space standard & $\begin{array}{l}\text { Specifies elements in the } \\
\text { public realm: sidewalk, } \\
\text { travel lanes, on-street } \\
\text { parking, street trees and } \\
\text { furniture, etc. }\end{array}$ & 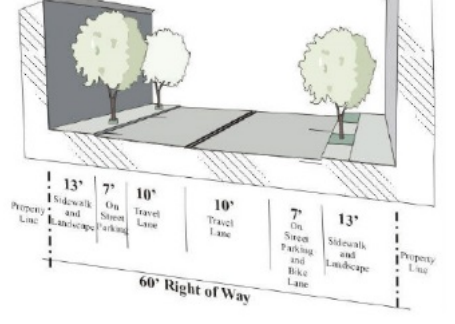 \\
\hline & Building form standard & $\begin{array}{l}\text { Regulations controlling the } \\
\text { features, configurations, and } \\
\text { functions of buildings that } \\
\text { define and shape the public } \\
\text { realm. }\end{array}$ & 0 \\
\hline \multirow{4}{*}{ 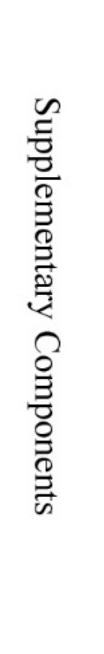 } & Administration & $\begin{array}{l}\text { A clearly defined and } \\
\text { streamlined application and } \\
\text { project review process. }\end{array}$ & \\
\hline & \multirow{3}{*}{ Definition } & \multirow{3}{*}{$\begin{array}{l}\text { A glossary to ensure the } \\
\text { precise use of technical } \\
\text { terms. }\end{array}$} & $\begin{array}{l}\text { Building Elements } \\
\text { Encroachments }\end{array}$ \\
\hline & & & $\begin{array}{ll}\text { Front, Areas II, III, IV } & \text { To ROW } \\
\text { Front, Areas V, VI } & 10^{\prime} \text { beyond } \\
\text { Front, recessed } & 3^{\prime} \\
\text { Ci }\end{array}$ \\
\hline & & & $\begin{array}{l}\text { Notes } \\
\text { Bay windows, balconies, stoops and } 1 \\
\text { the encroachment areas. }\end{array}$ \\
\hline
\end{tabular}

Table 4. Components of Form-Based Code, FBCI, 2015b 


\subsection{Challenges of Form-Based Code}

This section explores the challenges of, and proposes solutions for, using FormBased Code to achieve specific regulation aims are also analysed. The critiques and challenges are associated with aspects of land use regulation, morphology hierarchy, code generation, and regulation teams. The section concludes with a deeper understanding of Form-Based Code and a criticism of Form-Based Code's regulation system.

\subsubsection{Land use regulation}

Euclidean zoning, as analysed in former sections, is criticised for its rigid landuse division (Russell, 1994) and overlooks of form in the zoning process (Kan, 2012), yet land use remains one of the most important elements for contemporary urban regulation. Form-Based Code may have the capability to work as an extension or supplement of the Euclidean zoning framework, but it has weak consideration of land use. According to the California Planning \& Development Report (CP\&DR) in 2010, it is easy to focus too little on land use in a Form-Based Code, so that areas of use with a big impact on the community get overlooked (City of California, 2010).

The secondary consideration of land use does not mean land use is unimportant in urban regulation. As Figure 17 shows, a balanced approach of urban regulation contains balanced consideration of operation, function and form. Conventional zoning approach is argued as overlooking form, however, the form-dominating approach is neither a good approach to urban regulation (Kan, 2012). Form-Based Code extends Euclidean zoning by improving the form consideration. According to Parolek, in the principles of Form-Based Code, land use simply becomes tertiary to the form standards instead of being the primary consideration, and they are simplified and vetted so as not to compromise the intent of the Form-Based Code (Parolek, et al., 2013). Land use codes also need to be included in the coding layouts. For instance, Miami 21 Code defines land 
use, such as industrial and civic institution health districts, as special zone types of the transect matrix.

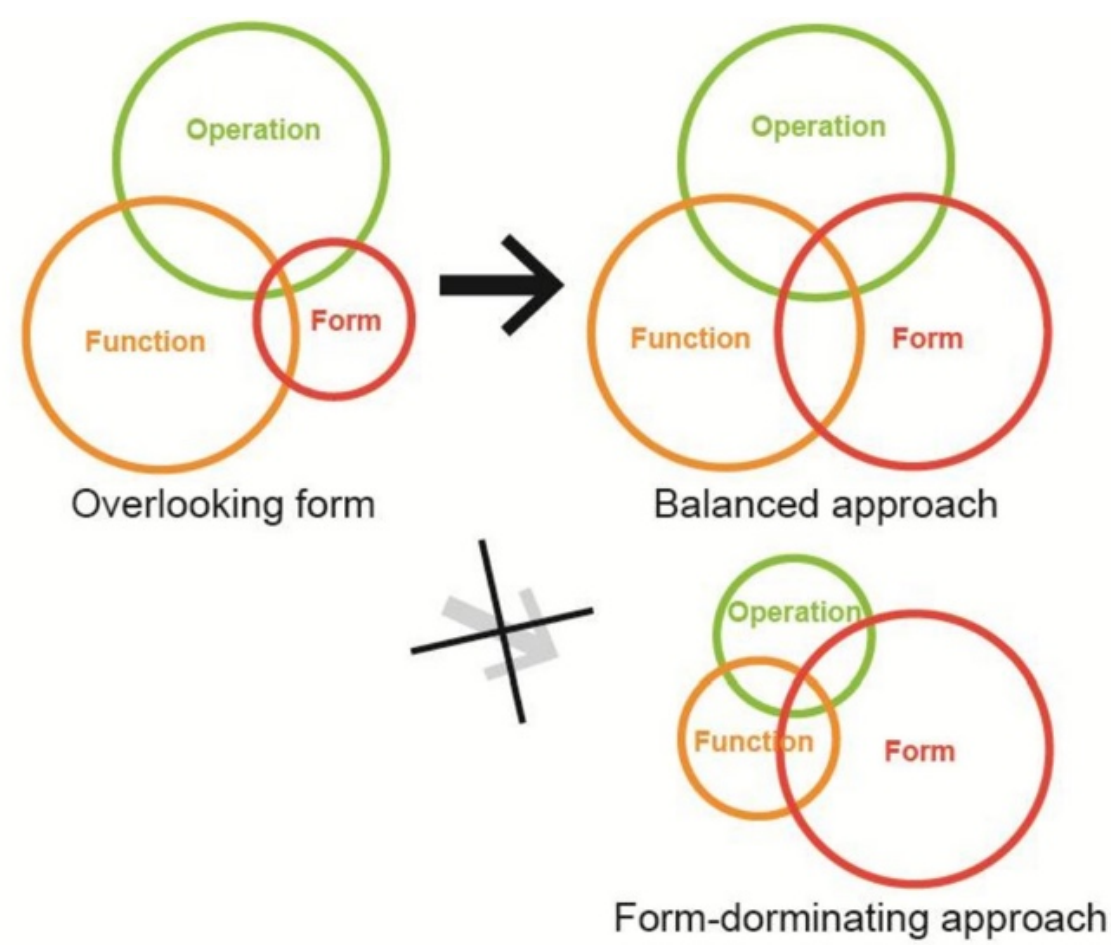

Figure 17. Form-Based Code maintains balance without function and operation dominating, Kan, 2012

\subsubsection{Morphology hierarchy}

Form-Based Code's transect matrix contains a hierarchy from natural to urban core. The zone categories include rural, suburban and urban in general. It is argued that the New Urbanists' case against Euclidean zoning is part antisuburban polemic and part pro-urban philosophy (CNU, 2011; Frug, 1999). If Form-Based Code follows Euclidean zoning laws that mandate a single-land use, the suburban zone ought to be scrapped (Garnett, 2013). Although FormBased Code supports intensive development in urban centres and avoids suburban sprawl, this does not mean that urban is better than suburban. Urban and suburban are both necessary morphology types in the urban development 
process. Intensive not only describes urban; sprawl is not specific to suburban. Sprawl can happen in any place that is low density, non-contiguous and automobile dependent (Bengston, et al., 2004). Form-Based Codes in Birmingham, Alabama, and Beaufort have illustrated the complexity and effectiveness of the morphology hierarchy system (including both "urban" and "suburban") and its ability to reinforce the unique characteristics and patterns of a wide range of places (Parolek, et al., 2013).

\subsubsection{Code generation}

From a planner's perspective, Form-Based Code is a tool developed by architects for planners -two groups long separated by the universities; their differences reinforced by professional organisations (Rangwala, 2013). Zoning and urban design are two separated parts, conducted by different disciplines. But for Form-Based Code, form and pattern act as an integral element of zoning. The regulation designers must engage with the unique building characteristics of communities, urban space features, and code documents together so that Form-Based Code can be generated.

Garnett (2013) argues that Form-Based Code can be overly complex. The complexity results from the components required to regulate, and is reflected in the code documents. For example, the Seaside Code in the 1980s was a single page; the Miami 21 Code as amended April 11, 2013 comprises almost 700 pages in two volumes: Volume 1 of the code is over 383 pages and Volume 2 (Appendices) is over 300 pages and growing (Faga, 2014). Provisions and principles are described in a complicated way - hundreds of pages long for one little town or even a neighbourhood (Faga, 2014). Considerable elements are evolved to control the urban morphology and building forms. Large-scale FormBased Code often requires a long time to set up, design, edit, discuss, assess, and amend. Code generation can be inefficient, especially during the amendment process. One regulation item always relates to others, so changing 
one existing code means subsequent work. Code generation is arguably too complex, especially in large-scale projects (Carmona, 2009; Imrie and Street, 2006).

In addition, as a result of the cross-disciplinary nature of Form-Based Code, regulation designers require sufficient knowledge of architecture, urban design, cityscape, project programming, even marketing and management. MAP (2007) summarises the challenges of Form-Based Code generation as "the cost is two to four times more than conventional zoning plans; and the regulating plan is more complicated, definitive, and expensive than the standard zoning map" (Purdy, 2007). Thus, establishing an effective approach may require generating code on a small scale before extending to a large one.

We use GIS Data

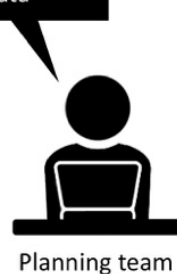

Planning team

\section{We provide text-based regulation}

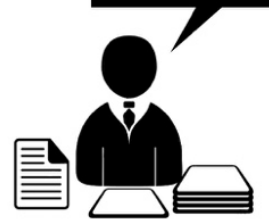

Regulating team

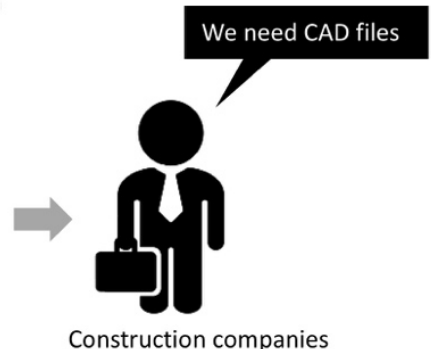

Figure 18. Collaboration among various teams

\subsubsection{Regulation team}

Form-Based Code requires multiple disciplines, professionals and management departments to cooperate. Efficient design sharing platforms are crucial to the generation and implementation process. The challenge here, is that the current cooperation mechanism of Form-Based Code regulation leads to inefficient 
design sharing between regulatory team members. For example, to format the regulatory plan, urban planners and architects using the geographic data from the Geographic Information System (GIS) database. Government departments provide text-based regulations. Engineers from the construction companies use Computer-Aided Design (CAD) documents. Design exchange has become an issue due to the various requirements and products of different teams (Figure $18)$.

Form-Based Code combines regulation, zoning and urban design in one project. As a result, Form-Based Code has no standard evaluation system. Most scholars and professional organisations use Euclidean zoning principles as the regulation review standard. Switching the standards from Euclidean zoning to Form-Based Code is going against their established knowledge system. It results in a shortage of reliable evaluation principles for Form-Based Code projects. 


\subsection{Phases and tools of Form-Based Code}

This section explores the original phases and tools of Form-Based Code. Workflow and tools are analysed following a synopsis of the development phases defined by Parolek. The phases consist of documenting, visioning and assembling. The following paragraphs review the details of each phase and the challenges of processing tools. It provides a foundation for creating and implementing a parametric modelling system in Form-Based Code.

\subsubsection{Documenting}

Documenting identifies the building and the street forms of the target site. The site can be a neighbourhood, a community, an area of public urban space, or a whole city. Form-Based Code strengthens the unique spatial performance and form characteristics of the site. Before the regulation is created, documenting provides a thorough understanding of the existing situation, from the urban morphology to the architectural details. This phase provides a basis for the creation of Form-Based Code (Parolek, et al., 2008).

The documenting phase requires a Form-Based Code team to work on two scales: macro and micro. On a macro scale, the framework diagram of existing urban regulations should be reviewed to understand the established regulation system, identify the area of the site to adopt Form-Based Code, and the extent to which Form-Based Codes interact with existing regulations (Parolek, et al., 2008). On the micro scale, the documenting sheets for transect types and formbased elements work together to collect physical data, identify spatial characteristics, and find the challenges of the existing built environment. The common tools of this phase are the manual review, sketch, hand-drawing, and text-/sheet-description.

\subsubsection{Visioning}

Visioning defines the community's vision for its future (Parolek, et al., 2008). 
Form-Based Code attempts to predict the urban regulation outcome. Vision is the desired regulatory outcome as defined by both the community and the FormBased Code designers. This phase provides opportunities for exchanging regulation thinking between the community and Form-Based Code designers through public hearing or survey in neighbourhoods. When the vision is addressed, the team creates regulations aimed towards the desired outcome.

Form-Based Code operates interactively in the visioning phase. The community offers its desired results in part or in whole. The regulation team offers an illustrative plan and graphics to reprocess the regulation's intentions and present to the community. The community's vision informs the Form-Based Code at the early stage of urban regulation. There is usually a kick-off meeting between the regulation team and community stakeholders (including the general public) before processing Form-Based Code. Sometimes the community already has a clear vision; other times it can only provide fuzzy intentions - they need more green areas for family leisure time, for example. In this situation, designers may collect the information and translate ideas into imagery. After the kick-off meeting, a summary is often paired with a written vision description and an illustration of the district on a single page or two, which may be presented to the public as a poster for feedback and eventually serve as the main explanation of the district in the final Form-Based Code document (Parolek, et al., 2008).

The products of the visioning phase contain illustrative regulations, the transect matrix, and the regulating plan. Illustrative regulations provide imaginary communities and neighbourhoods. Considering the regulation design requirement, regulatory of public space, building forms and pedestrian environments could be components in Form-Based Code framework. The transect matrix defines zone types through graphics and text descriptions. The regulating plan maps the zone types on the target site. Designers may repeatedly amend the transect types and regulatory files to accommodate public feedback. 
Hand drawing is commonly used in this phase for its clear description and easy reading. The method helps people quickly understand what will happen in their community. For example, in the Ocean Front Resort District Form-Based Code of City of Virginia Beach, the regulation team uses a large amount of manually drawn pictures to describe the regulating results with brief text explanations ( Figure 19).
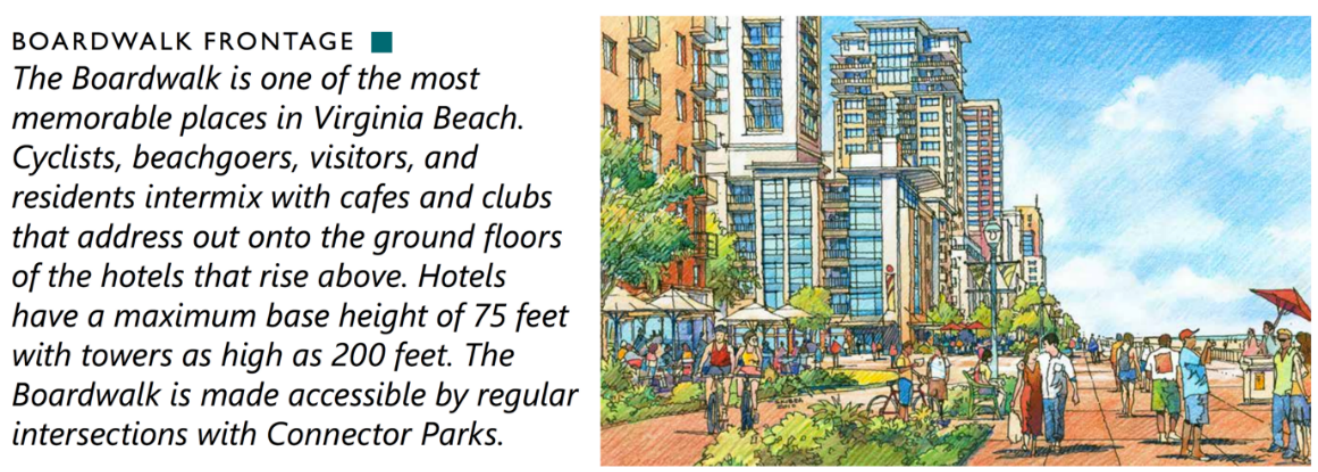

Figure 19. Hand drawn image of Ocean Front Resort District Form-Based Code of City of Virginia Beach, City of Virginia Beach, 2017

Computer-aided drawing and three-dimensional modelling are also tools that support visioning description. As in Error! Reference source not found., the proposed regulations are depicted with models. The models, composed of points, lines and surfaces, are created without topologic relations or rule-constraint processing. If the visions change, the related parts of the models must be recreated.

There have been attempts to embed Form-Based Code regulations into GIS software. Form-Based Code models can potentially combine with big data methods. For example, in the Form-Based Code project in Bradenton, Florida (2011), designers made a web-GIS system for information searching and code visualisation in large-scale regulation (Figure 21). ArcGIS ${ }^{\mathrm{TM}}$ helps to create spatial information maps, compile geographic data, and share regulation online with the community. The geodatabase works as a container to hold datasets, 
topology information and model behaviour of features (Tomlinson, 2003). Visualising Form-Based Code regulations with GIS allows the community to see what will happen where and write comments.

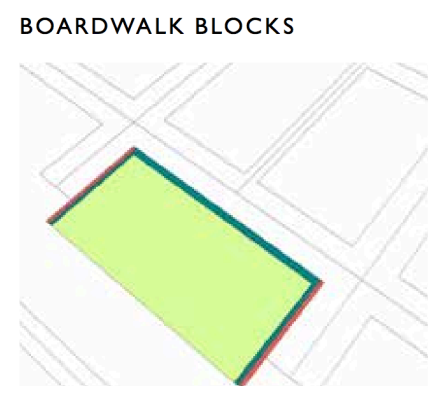

Boardwalk blocks have setbacks and facade locations that animate Atlantic Avenue as well as the Connector Parks that serve as access routes to the beach.

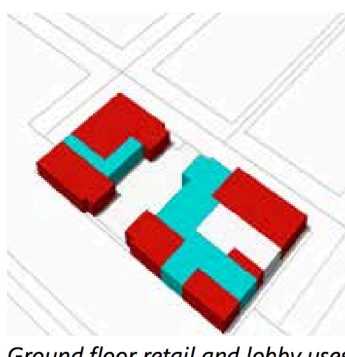

Ground floor retail and lobby uses animate all sides of the blocks.

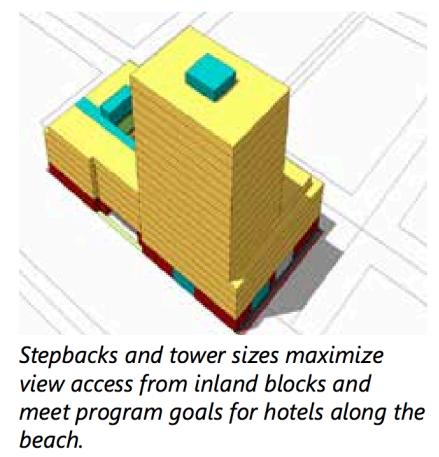

Figure 20. Manual-based modelling for Form-Based Code, Ocean Front Resort District Form-Based Code of City of Virginia Beach, City of Virginia Beach, 2017

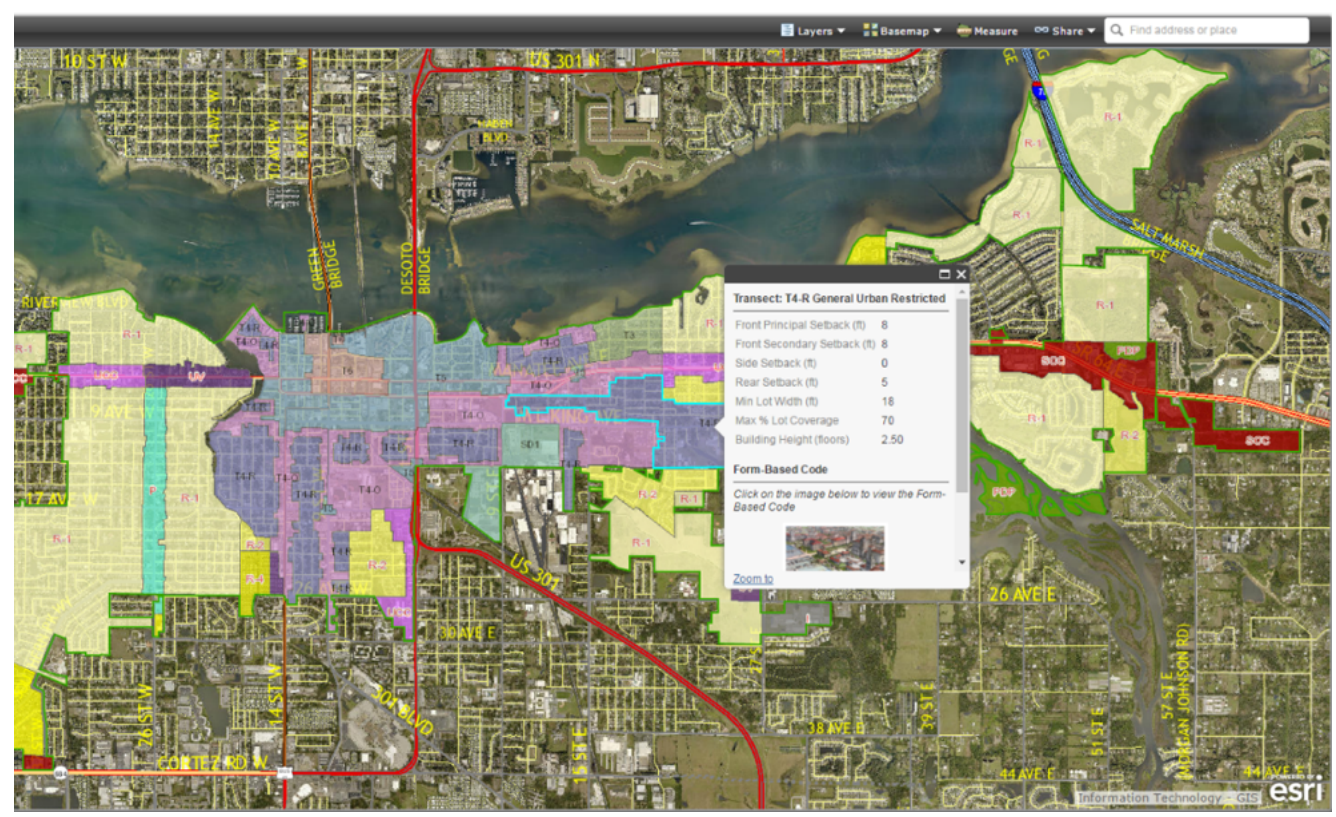

Figure 21. Web-GIS system of Form-Based Code in Bradenton, City of Bradenton, 2011

Parametric software has recently also been used in Form-Based Code. A small group of scholars started to explore the possibility of using parametric tools to 
describe regulations. For example, Kim and Clayton (2010) made Autodesk Revit ${ }^{\mathrm{TM}}$ models (Figure 22) for the regulation description with parameters (Table 5). By creating Revit projects and storing the object information as parameters, elements of Form-Based Code can be regenerated according to any parametric values (Eastman et al., 2008; Smith and Tardif, 2009). In the regulation project of Dallas, Texas, Revit supports testing multiple scenarios by changing settings when the codes need to be modified. The visioning phase of Form-Based Code can be conducted with the tools of hand-drawing, textdescription, manual modelling, GIS software, or parametric software for the regulation designers. Multiple tools cooperate to describe the regulation's purpose and desired outcomes. Manual tools are used broadly during this process. There is limited exploitation of parametric modelling for Form-Based Code in academia and practice. This research argues that parametric tools can possibly enhance the modelling procedure. They have the capability to allow production and experimentation of multiple scenarios by amending parameter values. Further analysis of parametric tools is presented in Section 5.1.
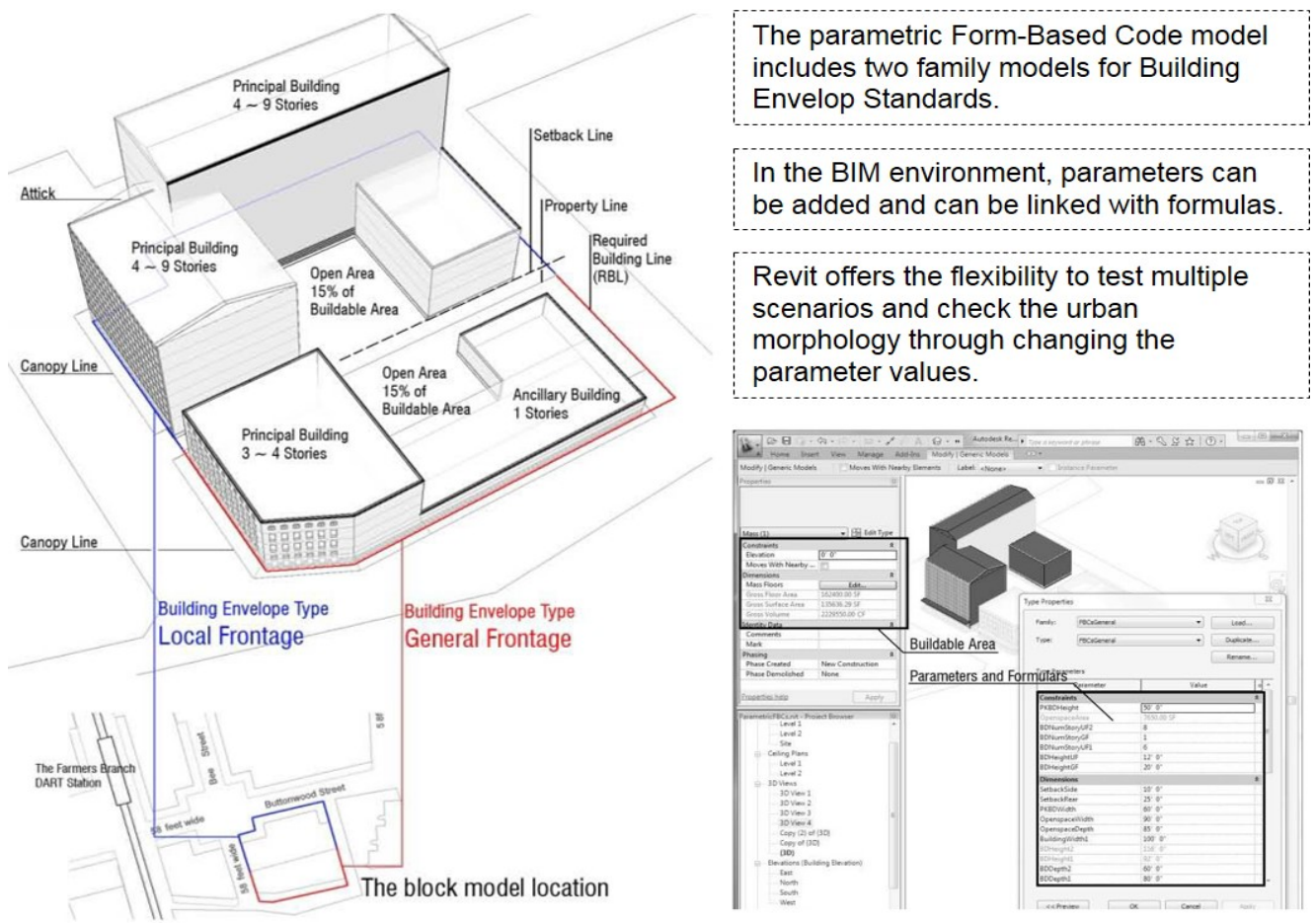
Figure 22. BIM modelling for Form-Based Code, Kim and Clayton, 2010

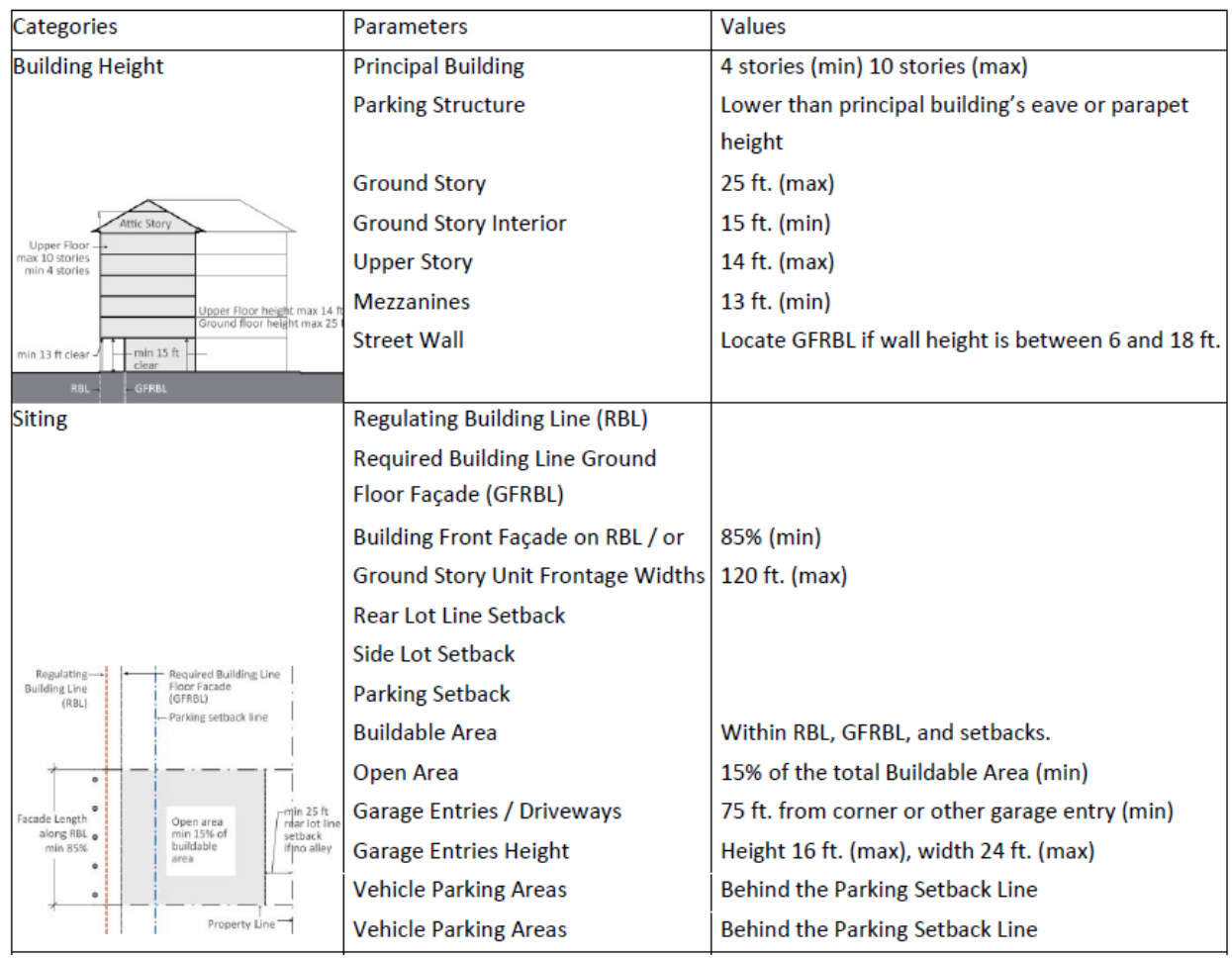

Table 5. Parameters of BIM modelling for Form-Based Code, Kim and Clayton, 2010

\subsubsection{Assembling}

The assembling phase aims to format and splice Form-Based Code. The layouts usually include a regulating plan, building standards, public space standards, additional standards, administration and definitions. The final Form-Based Code documents are ready to implement with text descriptions, sheet descriptions and illustrations. When feedback is received and results evaluated, amendments can start from the documenting or visioning phase.

It is queried whether the amendment process of Form-Based Code is too complicated. Form-Based Code provides detailed design regulation for urban and architecture design. It is possible that in some situations, a single building or a public garden design, for example, it is hard to meet the requirements of Form-Based Code. When unpredictable building results occur, an illustrative 
cue is needed to address the specific issues. The usual amendment is to tinker with the regulations. Tinkering may be a way to make Form-Based Code more practicable. But the result is a code book that becomes thicker and thicker. Too much "clarifying" and too many exceptions make people doubt that FormBased Code is suitable for regulation. An amended code needs additional clarification or an independent section to explain. As time passes, the regulation files become more and more impenetrable and complicated - so much so that even the most highly trained planner, urban designer, or developer can struggle to ascribe meaning to the principles embedded in these codes (Garvin and Jourdan, 2008).

In summary, the framework of Form-Based Code generation is concluded as Figure 23. It provides three phases in the coding process. The workflow is different from conventional zoning, but the major tools are the same - hand drawing, manual modelling, and text descriptions.

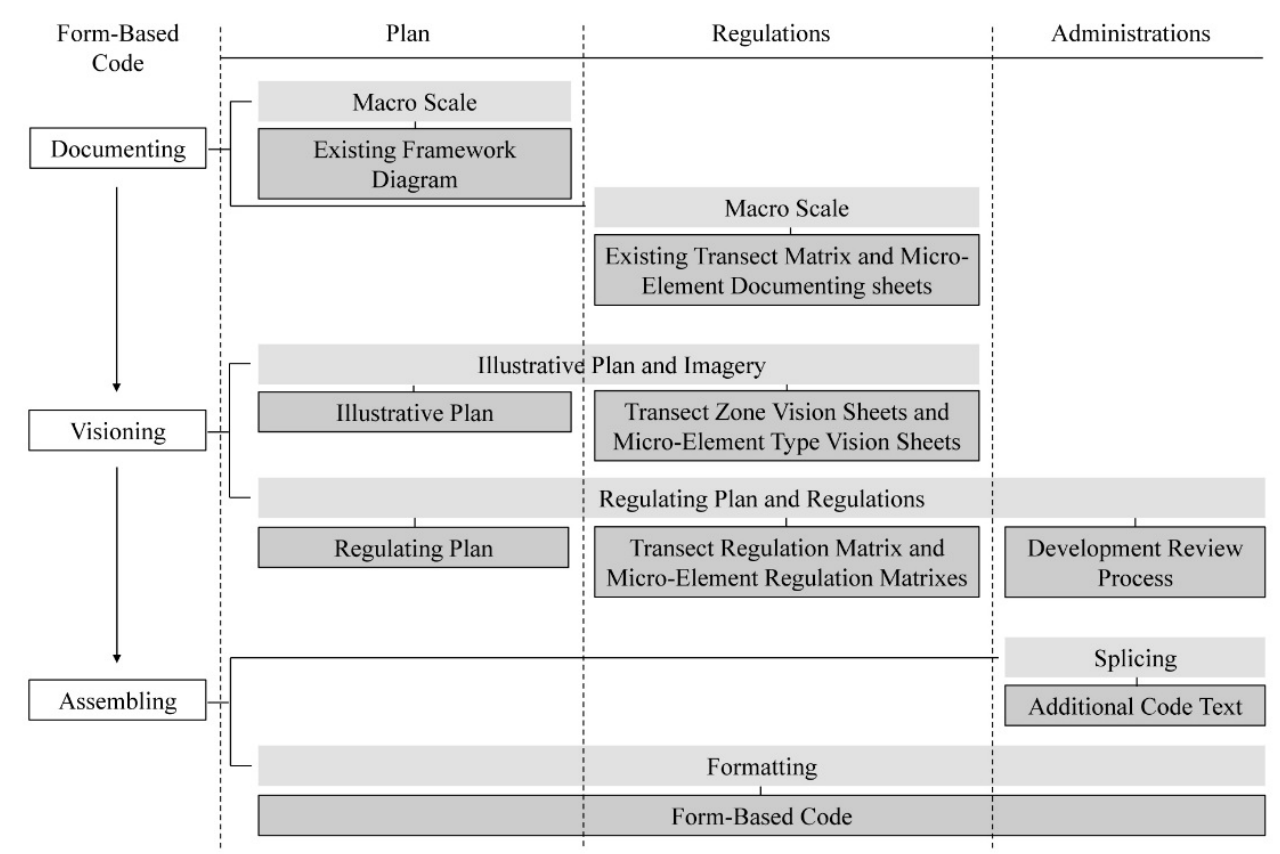


Figure 23. Phases of Form-Based Code, re-edited by author based on Parolek, et al., 2008

The original phases and tools provide both benefits for and challenges to FormBased Code. It provides an opportunity for interactive communication between a regulation team and a community. The community's visions motivate the regulation, which is generated from the early stage of Form-Based Code. Because of public participation, Form-Based Code requires an efficient generation and modification approach which the original regulation framework cannot offer. The following section reviews parametric design for Form-Based Code to resolve the challenges. 


\subsection{Chapter summary}

Urban regulation acts as an essential role in urban planning and management. It has a direct bearing on urban development goals and achievements. With changing political, social and economic priorities, the concepts of urban regulation have been reformed from rigid land use segregation to the harmony of multiple spatial elements. One consensus in regulatory intervention is shaping urban form and scale because code reformers recognise the impact of urban form and scale on the success of sustainable developments (Ben-Joseph, 2009; Carmona and Punter, 1997; Kim, 2014). Urban regulation needs formbased approaches and tools to facilitate the design process.

Euclidean zoning has been the primary approach to regulation for more than one century. It is relatively effective, has a mature legal precedent and ease of management. Issues, however, have been exposed in recent decades due to the excessive usage of this approach. It is argued that Euclidean zoning aggravates sprawl, wastes land resources, and is silent on spatial characteristics protection. In light of the predicament of Euclidean zoning, scholars such as Duany and Talen (2001), Talen (2009), Calthorpe and Fulton (2001), Shigley (2006), and Burdette (2004) have studied Form-Based Code and its novel concepts in regulation decisions. Form-Based Code extends the conventional zoning approaches (Barry, 2008) with different ideas, manners, processes, layouts and expression. The main characteristics of Form-Based Code principles include mixed use, revising central declination, detailed regulation, and comprehensively controlled results. The principles of Form-Based Code work to shape urban morphology or streetscape, but they cannot solve all of the urban issues in every city. The issues such as the land use division and the development of divergent communities are complex in different cities. FormBased Code does not address all of them. The following chapter analyses the existing examples of Form-Based Code application in order to further understand Form-Based Code in real practice. 


\section{Chapter 3. Examples of Form-Based Code}

This chapter analyses a series of existing Form-Based Code examples, including Smart Code Montgomery, Miami 21 Code, Downtown Code for Nashville, and East Billings Renewal District Code. A critical analyse of Borys, Talen and Lambert's Code Study is conducted as the underpinning of the review description. The chapter summaries with a comparison between the Form-Based Code examples. The purpose is to understand the components, parameters and variables of the real-world examples and their outcomes and impacts. 


\subsection{Borys, Talen and Lambert's Code Study}

Today, more than 600 cities and counties worldwide have adopted Form-Based Code in urban planning, regulation and design. Known applications of FormBased Code in alternative land development regulations include Central Petaluma Specific Plan and Central Hercules Plan (Singh, 2010). These FormBased Code examples have similar templates but different goals, problemsolving manners, and implementation results.

Uptake has been increasing rapidly. Borys, Talen and Lambert studied the prevalence of Form-Based Code and conducted a big data statistical analysis of the practices between 1981 and 2017. As of February 2017, they have tracked 670 codes worldwide, including the US, Canada, Brazil, Mexico, UK, and Australia, of which 654 meet the criteria made by FBCI. Even though FormBased Code is 36 years old, $88 \%$ of practical examples have been adopted since 2003 (Borys et al., 2017, Figure 24). Most of these codes are clustered in the USA (Figure 25).

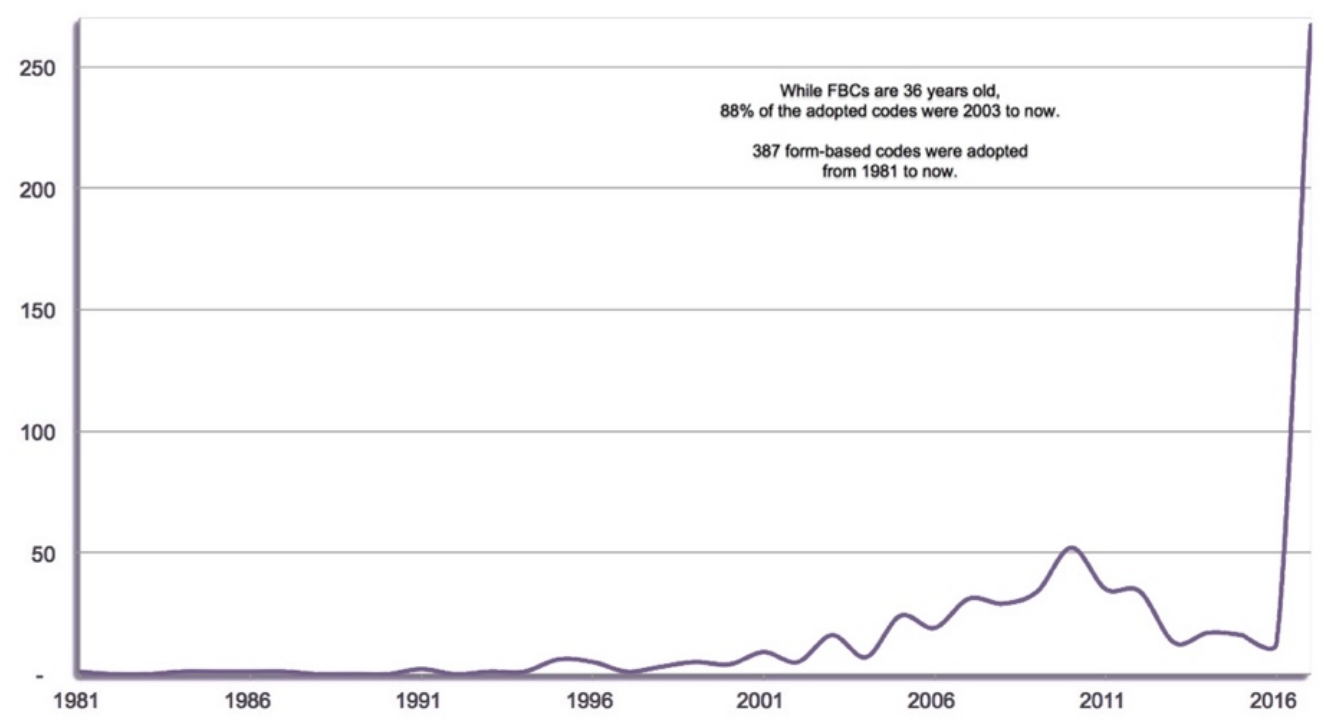

Figure 24. Form-Based Cods: Annual adoptions 1981-2016+2017 in progress, Borys, et al., 2017 


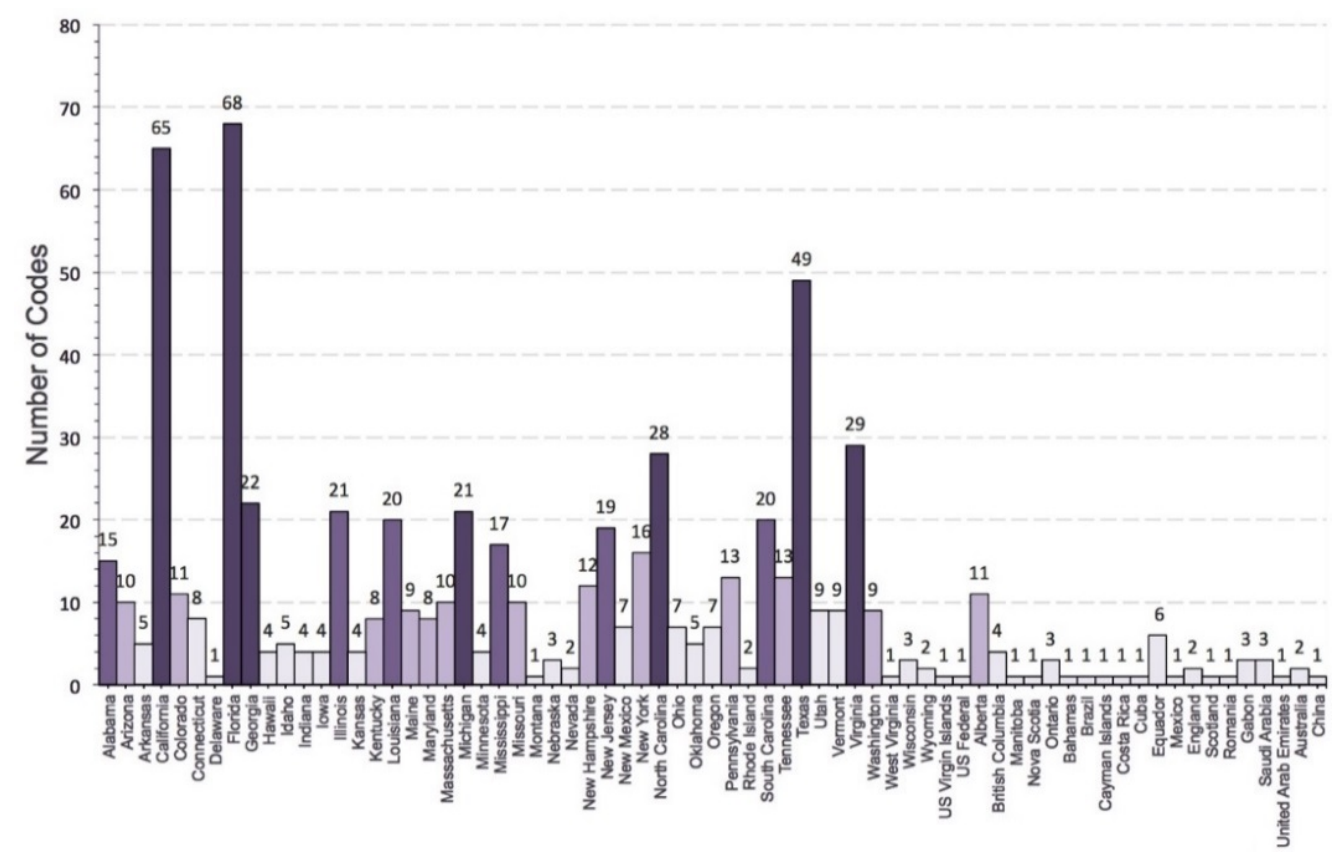

Figure 25. Code Study: SmartCode and other Form-Based Codes, Borys, et al., 2017

The Code Study divides codes into six types: SmartCode Adopted, SmartCode in Process, Transect Form-Based Codes, Other Form-Based Codes, SmartCode \& Form-Based Code Discussion, and Form-Based Guides. This classification method describes the Form-Based Code and its deuterogenic codes. A code is named as SmartCode if it folds zoning, urban design and architectural standards into one compact document, meanwhile it is based on the rural-to-urban transect rather than land use divisions (DPZ, 2009). SmartCode Adopted means the SmartCode already exists. SmartCode in Process means the SmartCode is not finished yet. A code adopting a Transect Form-Based Code approach means it contains a transect matrix and uses the transect types to define zones in context. Other Form-Based Codes are the Form-Based Codes neither contain transect matrix nor belong to SmartCode. SmartCode \& Form-Based Code Discussion means the specific design guidelines are generated with form-based elements. Form-Based Guides mean the form-based reports or guide books, which may not meet Form-Based Code criteria that FBCI proposed and do not count toward SmartCode, Transect-Based Code and Other Form-Based Codes. For example, 
the book Form-Based Codes: A Step-by-Step Guide for Communities by CMAP Planning belongs to Form-Based Guides.

The classification method of the Code Study is not suitable for choosing FormBased Code examples in this chapter. For example, SmartCode and Transect Form-Based Code frequently overlap. Some SmartCodes also need the transect matrix to divide zones. The Form-Based Code reviewed here is a broad concept that contains multiple code types. The next section describes how Form-Based Code projects were selected for review. 


\subsection{Review description}

Given the target of reviewing Form-Based Code examples, this section defines the principles of selecting Form-Based Code cases for analysis:

1. The cases must be form-based. Form-Based Code is broadly defined as a regulation of urban forms and patterns rather than land use control. In this research, appellations like Form-Based Code(s), Transect-Based Code(s) and SmartCode(s) are all regarded as Form-Based Code.

2. The cases must be comparable. They should have differe6nces in location, scale, density, and context morphology. Although they have a similar regulation concept (form-based), they contain distinct components, parameters and manners of adoption.

3. The cases must have sufficient material, including completed zoning documents, design process description and subsequent zoning results (if any).

Although Form-Based Code has been applied around the world, as an American zoning approach, there are relatively mature methodologies for generating and implementing Form-Based Code in the USA. According to the case selecting principles, four representative American Form-Based Code projects are selected for review. They are Smart Code Montgomery (2007), Miami 21 Code (2012), Downtown Code for Nashville (2017), and East Billings Urban Renewal District Code (2014). The case reviews comprise three aspects: the main components, parameters, and adoption results. These aspects are described as follows.

The main component is a review of the code contents and the structure of each project. As FBCI suggests, the general components include a regulating plan, 
building standards, public standards, management and definition. But the components vary with different aims and contexts. Reviewing the main components of each Form-Based Code project helps to understand how to generate components, and why specific components are selected in different urban development situations. These findings support the decision of what components should be included in the parametric Form-Based Code of this research.

Reviewing parameters identifies those parameters used to control forms. The urban designers and architects shape or reshape the urban morphology with parameters, and these parameters directly affect municipal regulation and development.

The adoption results present the outcomes, positive and negative, of the examples. They provide evidence of Form-Based Code's feasibility in practice. 


\subsection{Smart Code Montgomery}

Montgomery locates in the Southeast region of the USA. Smart Code Montgomery is a section of the Downtown Montgomery Plan (2007). In past decades, downtown experienced neglect, demolition, and incompatible infill because of sprawling development. According to the Downtown Montgomery Plan (2007), the city proved that Form-Based Code should replace the city's Zoning Ordinance for downtown (City of Montgomery, 2007).

The key principle of zoning in Montgomery is to plan, preserve, restore, and reuse historic buildings and addresses, and foster an improved environment for private investment and development; mixed land uses, building types and housing options; expand downtown's green and civic spaces; and to promote a better balance of transportation options and designs (Dover, Kohl and Partners, 2007).

\begin{tabular}{c|c}
\hline Basic Information & Description \\
\hline Project Area & 730 acres \\
\hline Client & City of Montgomery \\
\hline Year Adopted & 2007 \\
\hline &
\end{tabular}

Figure 26. Basic information of Montgomery

\subsubsection{Main components}

The Smart Code Montgomery consists of three sections: regional scale plans, community-scale plans, and building scale plans. Transect zones with types of 
civic, T4-reserved, T4-open, and T5 are mapped under the regulation of regional and community unit (Figure 27). According to the standard transect matrix, T4 is the general urban zone. In this project, the designers divided T4 into the reserved general urban zone and the open general urban zone. The civic zone is a zone type newly added to the standard transect matrix. Although the transect matrix has a template, designers redefined the transect zones flexibly to generate a specific transect map.

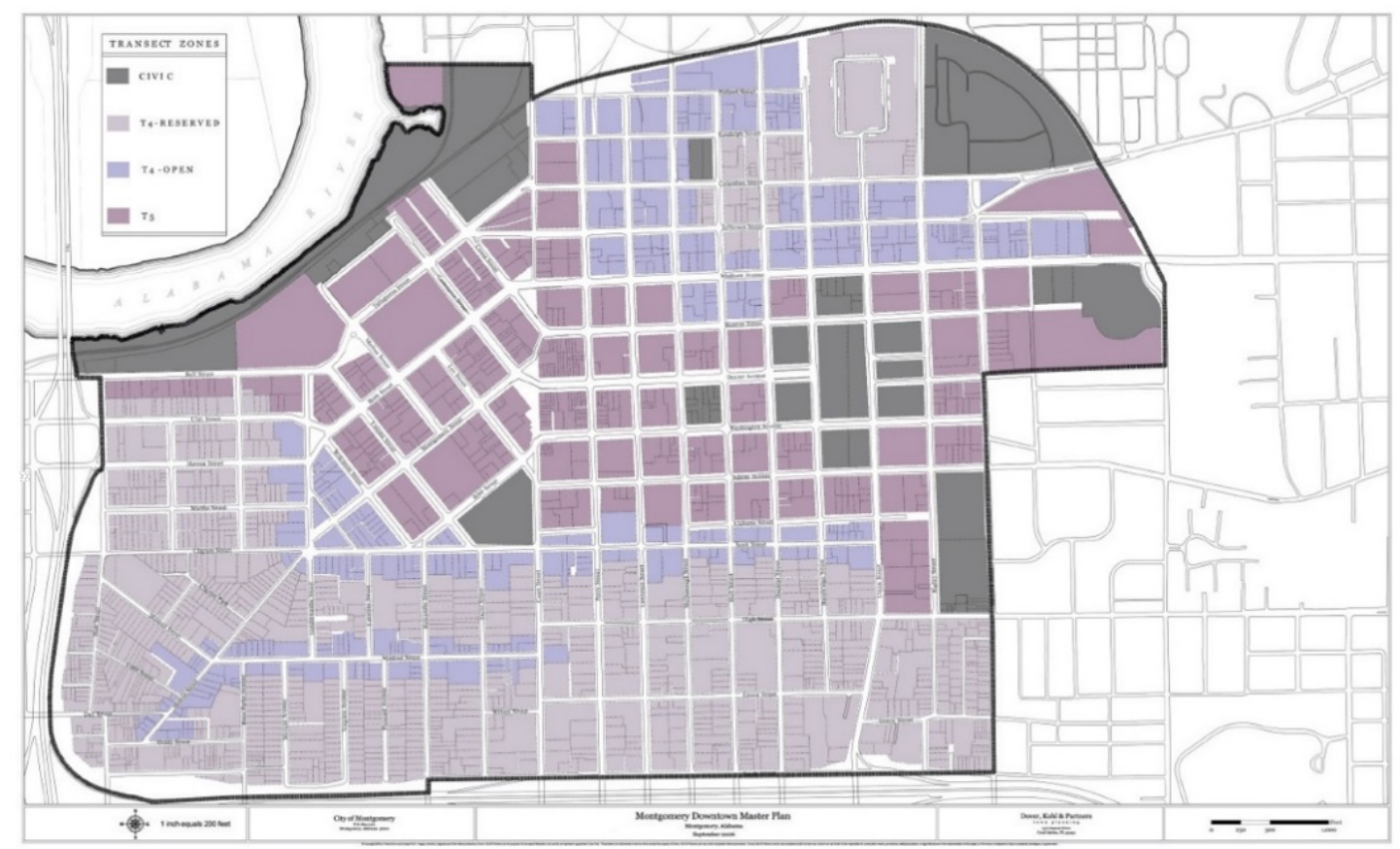

Figure 27. Downtown Transect Map of Downtown Montgomery Plan, City of Montgomery, 2007

The urban growth process and the possible results in Montgomery are described following the approach of conventional zoning and Form-Based Code. These prove that Form-Based Code encourages mixed land use while conventional zoning creates isolated districts. In the existing ordinance ( Figure 28), new office buildings can occur in any commercial zones but are unconnected to each other because of segregated land use. Designers argue that the self-contained commercial tower cannot contribute to the creation of a complete neighbourhood or positively affect city vitality. 

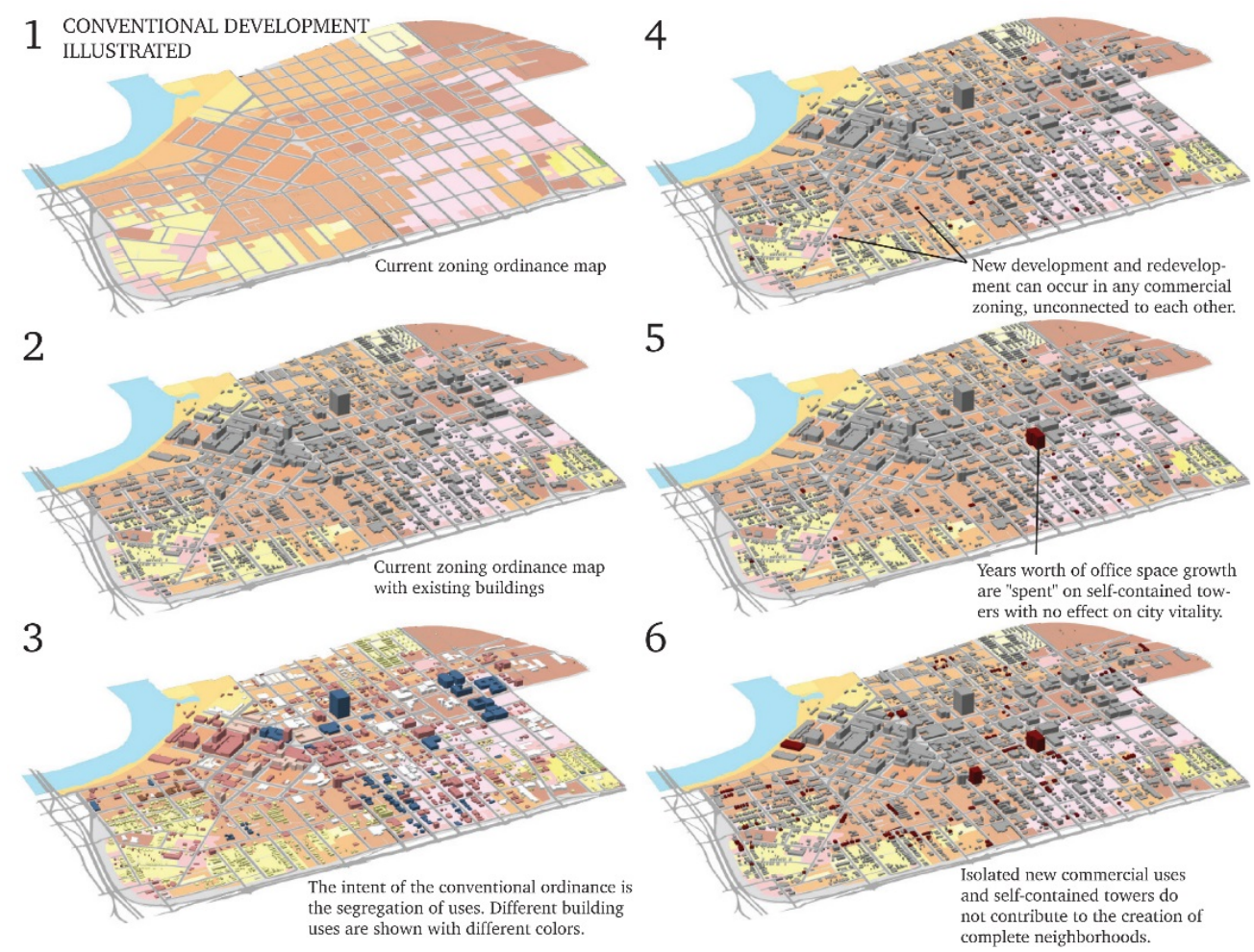

Figure 28. Result of conventional zoning of Downtown Montgomery Plan, City of Montgomery, 2007

In the Form-Based Code, variable land use types become neighbourhoods and urban centres which attract new development. Commercial developers can choose intersections as a building site without land use limitations. Then new residential units located at intersections can connect with corridors in walkable distances. In the Smart Code of Montgomery, intersections work as the core of urban growth. Commercial or residential buildings first cluster around an intersection then extend to inside blocks or plots (

Figure 29).

Building development is controlled by specific parameters and conditions in Smart Code Montgomery. The regulations include building functions, configurations, lot occupations, building disposition, setbacks, and frontage 
(Figure 30, Figure 31). Figures and models assist the illustration of the standards.
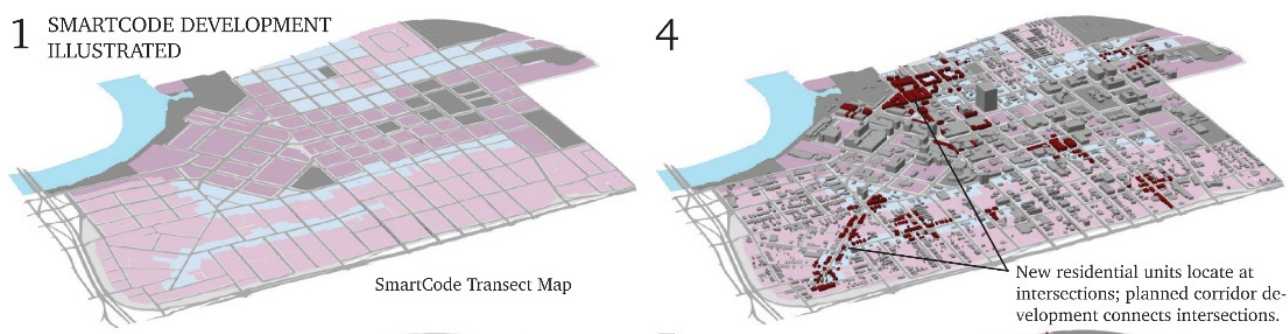

2
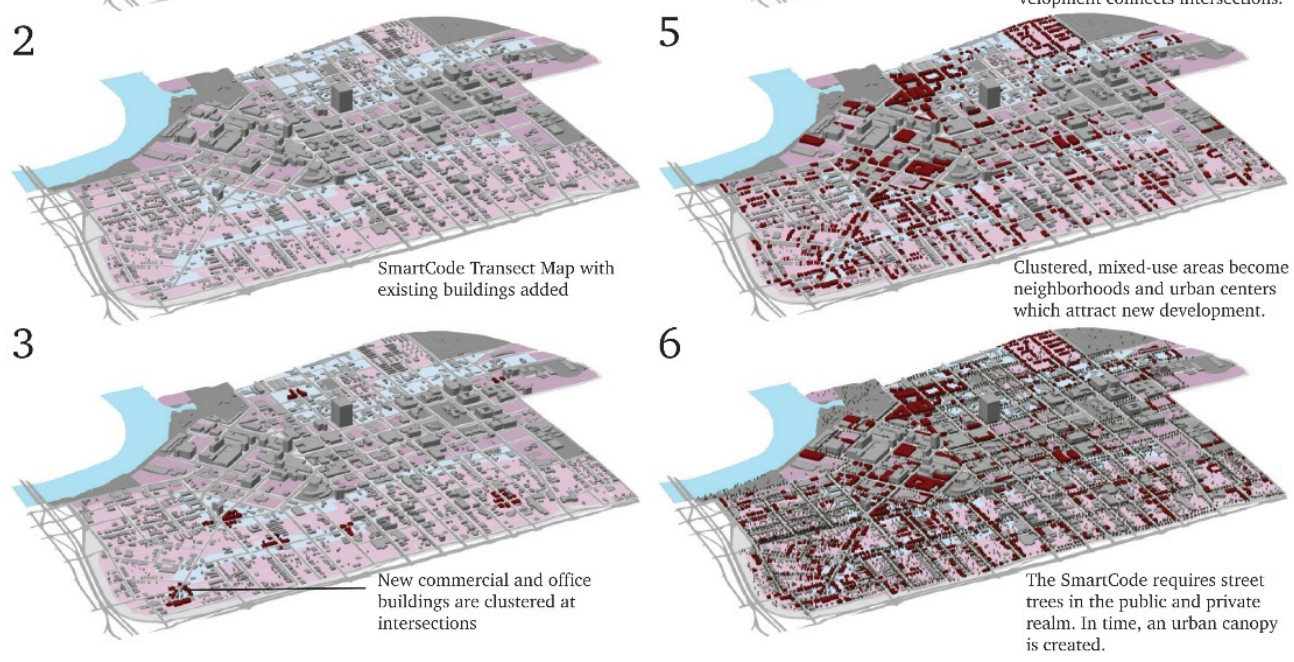

Figure 29. Result of Form-Based Code of Downtown Montgomery Plan, City of Montgomery, 2007
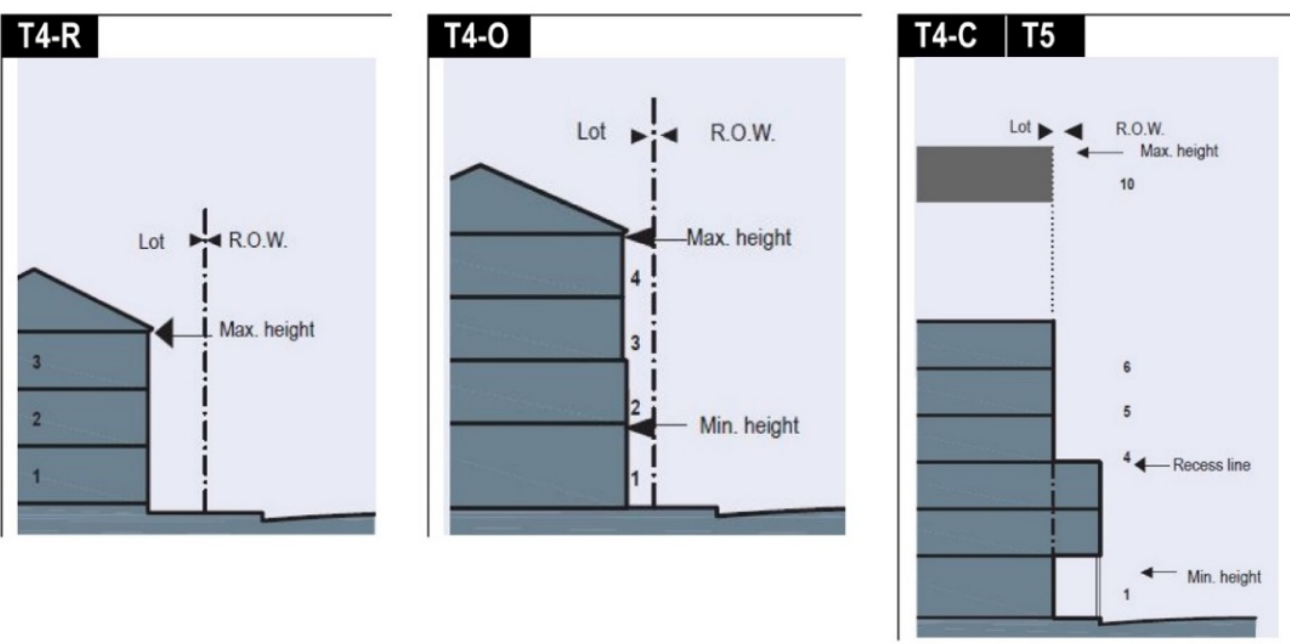

Figure 30. Examples of vertical extent buildings in transect zones of Downtown Montgomery Plan, City of Montgomery, 2007 
SETBACKS - PRINCIPAL BLDG

1. The Facades and Elevations of Principal buildings shall be distanced from the Lot Lines as shown.

2. Facades shall be built along the Principal Frontage to the minimum specified width in the table.

ETBACKS - OUTBUILDING

1. The Elevation of the

Outbuilding shall be

distanced from the Lot Lines

as shown.
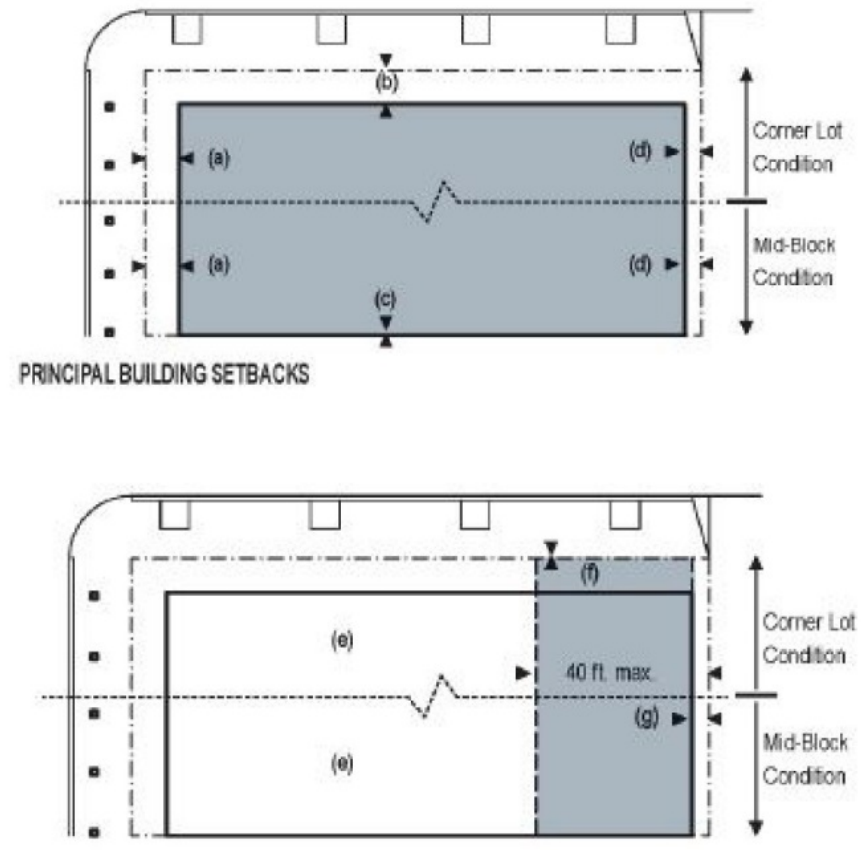

OUTBUILDING SETBACKS

Figure 31. Examples of transect zone $\mathrm{T} 4$ building regulations of Downtown Montgomery Plan, City of Montgomery, 2007

Other regulations like thoroughfare and frontages, lot lines, sign standard, civic space standard are also included in the Smart Code Montgomery (Figure 32). These additional standards help to supplement zoning principles and connect with urban design and architectural design projects.

\subsubsection{Main parameters}

Parameters are used to regulate street and building forms in specific zone types. Table 6 presents a series of parameters in this project. Transect zone T5 works as an example. There are four parameter categories: building configuration, lot occupation, setbacks of principal buildings, and setbacks of outbuildings. Each of the parameters has an interval range. By controlling the building configurations, predicting the zoning result is possible for planners, designers, developers, and communities. 

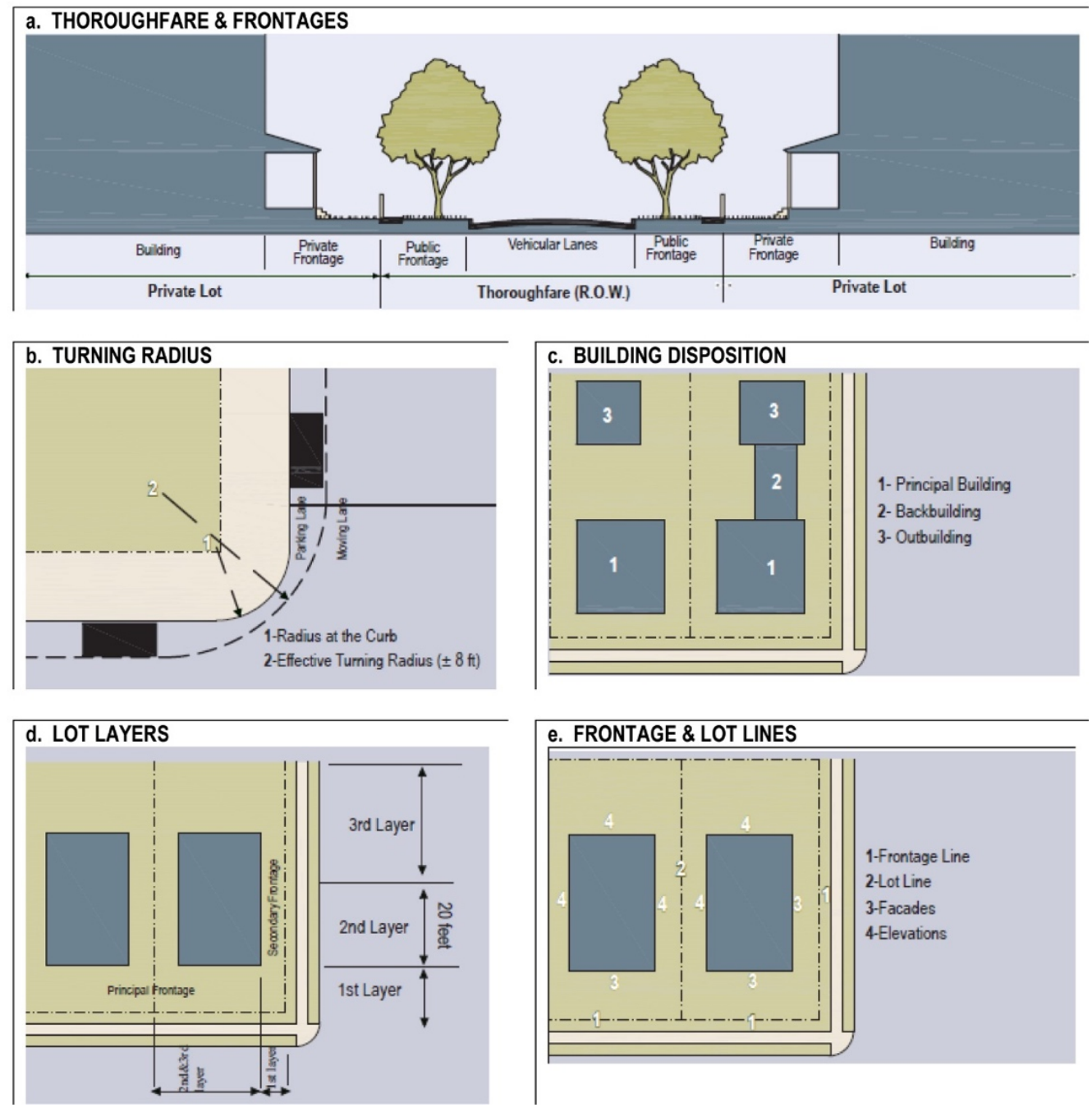

Figure 32. Illustrations of thoroughfare, frontages, turnings, building disposition, lit layers and lot lines in Smart Code Montgomery, City of Montgomery, 2014 


\begin{tabular}{|c|c|c|c|}
\hline Transect zone & Graphical solution & \multicolumn{2}{|c|}{ Regulations } \\
\hline \multirow{6}{*}{ Transect zone T5 } & & \multicolumn{2}{|c|}{ Building configuration } \\
\hline & & Principle building & 6 stories $\max , 2 \min$ \\
\hline & & Outbuilding & No max \\
\hline & & \multicolumn{2}{|c|}{ Lot occupation } \\
\hline & & Lot width & $18 \mathrm{ft} . \min -180 \mathrm{ft} . \max$ \\
\hline & & Lot coverage & $80 \% \max$ \\
\hline \multicolumn{4}{|c|}{ Regulations } \\
\hline \multicolumn{2}{|c|}{ Setbacks - principle building } & Frontage build out & $80 \%$ min at setback \\
\hline Front setback principle & $0 \mathrm{ft} . \min -12 \mathrm{ft} . \max$ & \multicolumn{2}{|c|}{ Setbacks - outbuilding } \\
\hline $\begin{array}{c}\text { Front setback } \\
\text { secondary }\end{array}$ & $2 \mathrm{ft} . \min -12 \mathrm{ft} . \max$ & Front setback & $40 \mathrm{ft} . \max$ \\
\hline Side setback & $0 \mathrm{ft} . \min -24 \mathrm{ft} . \max$ & Side setback & $0 \mathrm{ft}$. min or $2 \mathrm{ft}$. at corner \\
\hline Rear setback & $3 \mathrm{ft} ., \min$ & Rear setback & $3 \mathrm{ft} . \max$ \\
\hline
\end{tabular}

Table 6. Building regulation of transect zone T5 in Smart Code Montgomery, City of Montgomery, 2014

\subsubsection{Adoption results}

By adopting Form-Based Code, the urban morphology of Downtown Montgomery has changed. The Downtown Montgomery Plan (2007) argues that conventional Euclidian zoning requires deep setbacks from the street to encourage the siting of commercial, office and civic buildings in the exact centre of the lot with asphalt parking around (City of Montgomery, 2007). Form-Based Code in Montgomery requires less front setback. It aligns setbacks to create the main street style with shop fronts (

Figure 33).

Urban designers use Form-Based Code of Montgomery to develop pedestrianfriendly streets accommodating new development. Like most American cities, Montgomery's zoning still has as its conceptual basis the Standard State Zoning 
Enabling Act of 1926 (City of Montgomery, 2007). According to Parolek, et al. (2008), the city of Montgomery is now on its way to re-establishing high-quality urban environment patterns by Form-Based Code. The Smart Code Montgomery provides a zoning file mainly for shaping forms and creating walkable streets. Issues on land use division are not addressed by the Smart Code Montgomery.

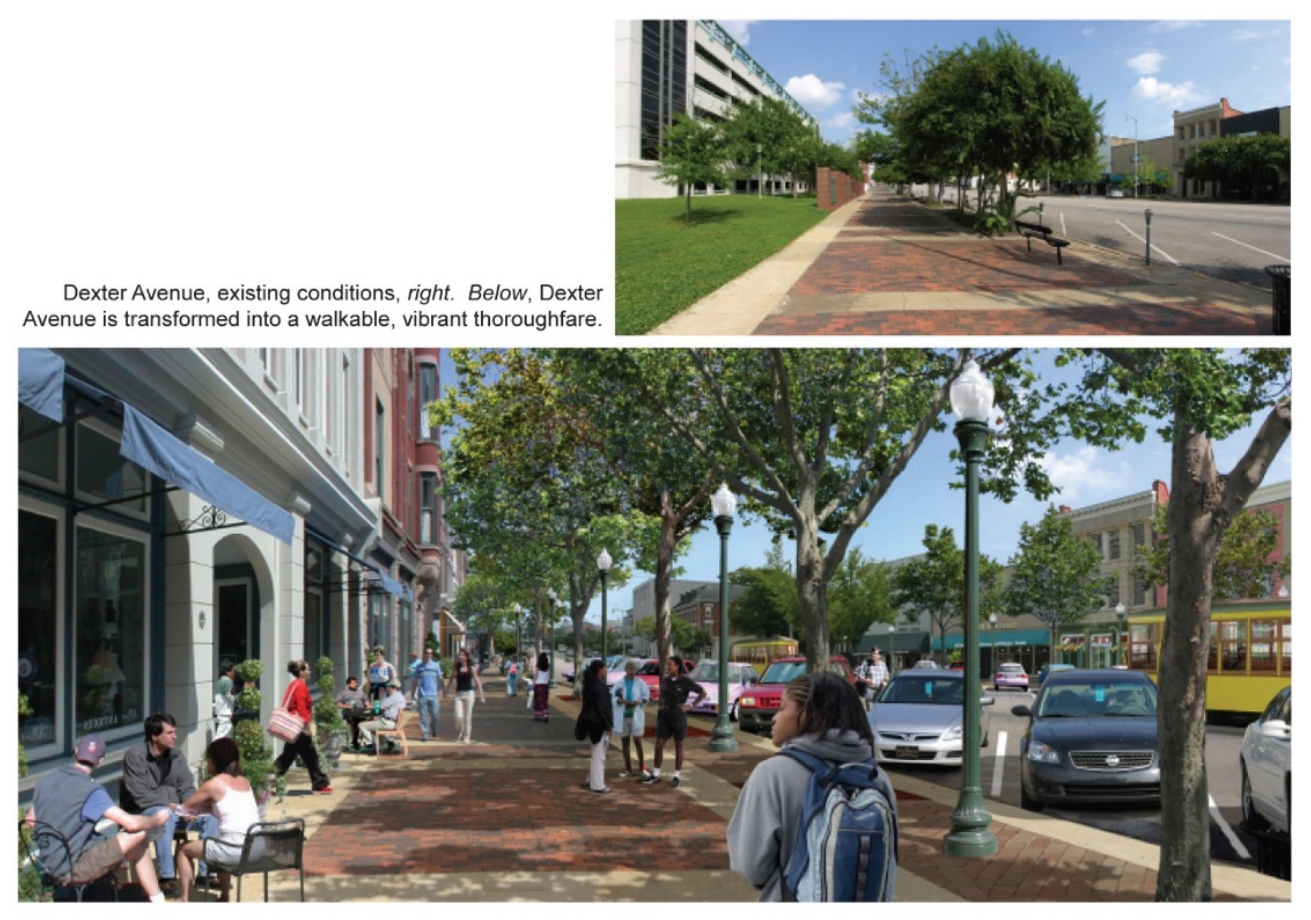

Figure 33. Example models of regulating result of Downtown Montgomery Plan, City of Montgomery, 2007 


\subsection{Miami 21 Code}

By the end of 2015, Miami is the largest city to comprehensively overhaul its old zoning code by replacing it with a mandatory citywide transect-based FormBased Code (Garde et al., 2015). Miami 21 Code creatively extends FormBased Code to a high-density city. The city is in the midst of rewriting its entire code, using form-based techniques on a larger scale than ever before attempted (Madden and Spikowski, 2006). Analysing the Miami 21 Code can offer a practical experience of adopting Form-Based Code framework in a high-density city with complex development situation.

\begin{tabular}{c|c}
\hline Basic Information & Description \\
\hline Project Area & 22,400 acres \\
\hline Client & City of Miami \\
\hline Year Adopted & 2009 \\
\hline &
\end{tabular}

Figure 34. Basic information of Miami

With a target of smart growth and new urbanism, Miami adopted Form-Based Code after hundreds of public hearings and totally replaced the existing Ordinance 11000. Miami 21 Code works as a legal regulatory document published by the city council. While Ordinance 11000 relies primarily on the textual explanation of regulations, Miami 21 Code includes illustrative drawings to describe regulations, making it easier for people to understand the rules and related built-form objectives (Garde et al., 2015). 
(This page is intentionally left blank) 


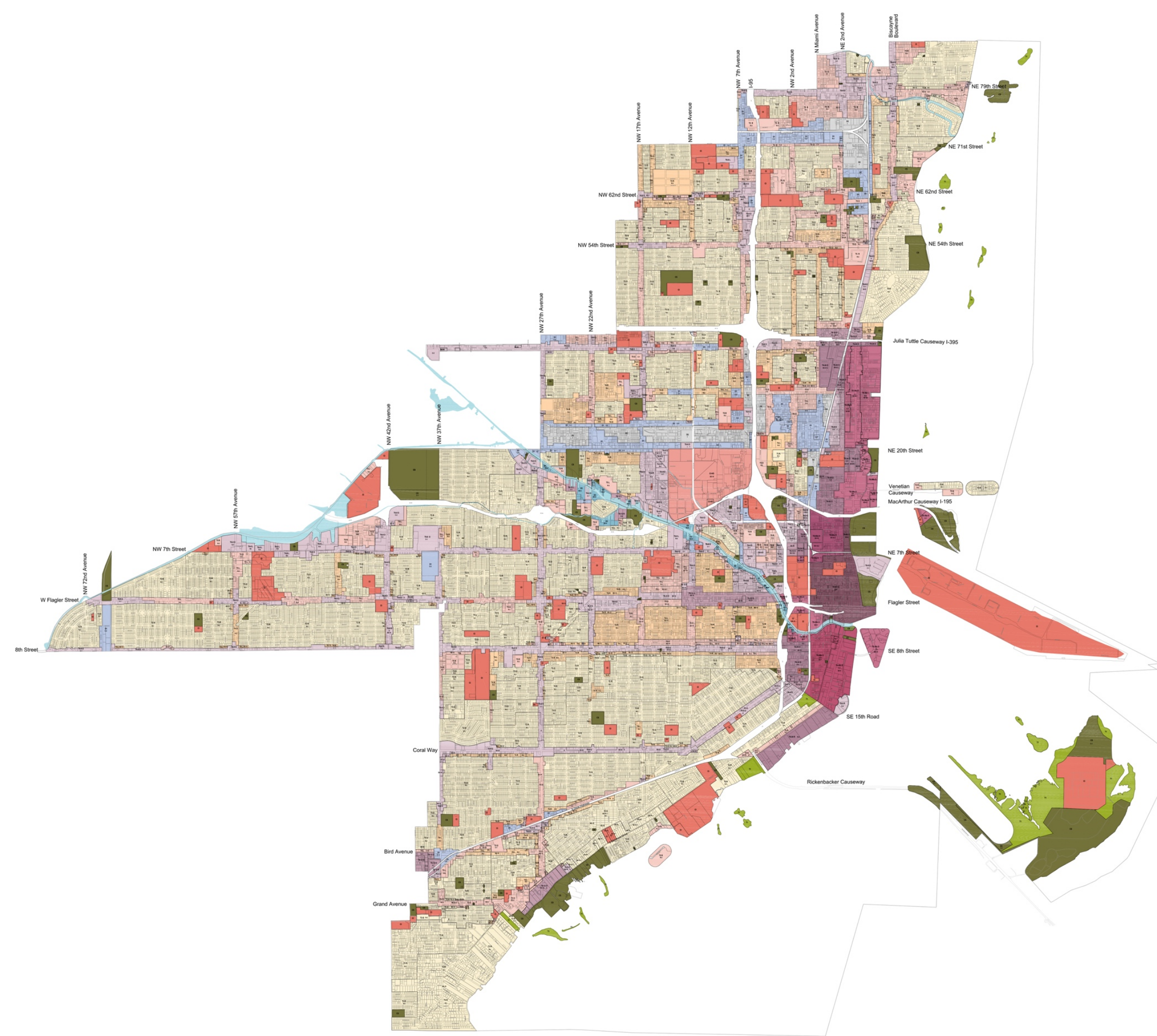

PROPOSED ATLAS

T1 NATURAL

T3 SUB-URBAN

T4 General uRban

T5 URBAN CENTER

T6-8* URBAN CORE

T6-12* URBAN CORE

T6-24* URBAN CORE

T6-48* URBAN CORE

T6-60* URBAN CORE
T6-80* URBAN CORE

D1 WORK PLACE

D2 INDUSTRIAL

D2
D3 MARINE

CS CIVIC SPACEIPARKS

Cl CIVIC INSTITUTION

CI-HD CIVIC INSTITUTION - HEALTH DISTRICT $R$ - RESTRICTED
L - LIMITED L. - OPEN
OPITED

Figure 35. Transect-based regulating map of Miami of Miami 21 Code, City of Miami, 2009 
(This page is intentionally left blank) 


\subsubsection{Main components}

Miami 21 Code consists of a neighbourhood conservation district, waterfront design guidelines, a midtown overlay district, Miami world centre, Brickell city centre, design district, river landing, and ransom everglades. The transect map of the whole city is shown in Figure 35. Different transect types are mapped on the regulatory plan with specific colours. Because of the high-density morphology, the transect matrix of Miami contains more types and subtypes than the standard transect matrix. Designers have extended the urban core zone (T6) with a series of subtypes, such as T6-8, T6-12, and T6-24 (

Figure 36). One general category is insufficient for describing urban forms, especially for large cities. Redefining the transect matrix is necessary to fulfil zoning requirements because of the complex development in different areas.

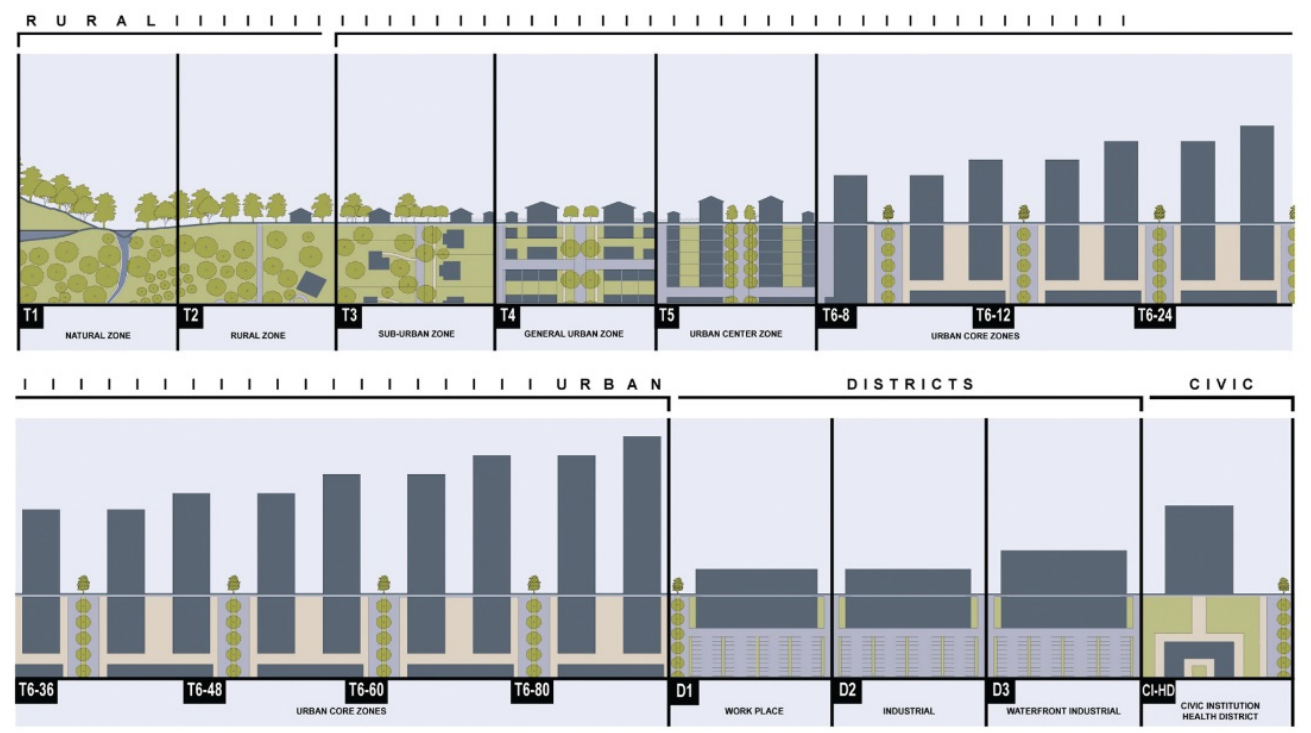

Figure 36. Transect matrix of Miami of Miami 21 Code, City of Miami, 2009

The customised transect matrix also specifies land use. The three land uses are workplace, industrial, and waterfront industrial. This kind of land use division is different from that of Euclidean zoning. Its purpose is to regulate building 
size and parking supply, rather than separate land use. The civic zone is concentrated green space described as the civic institution health district.
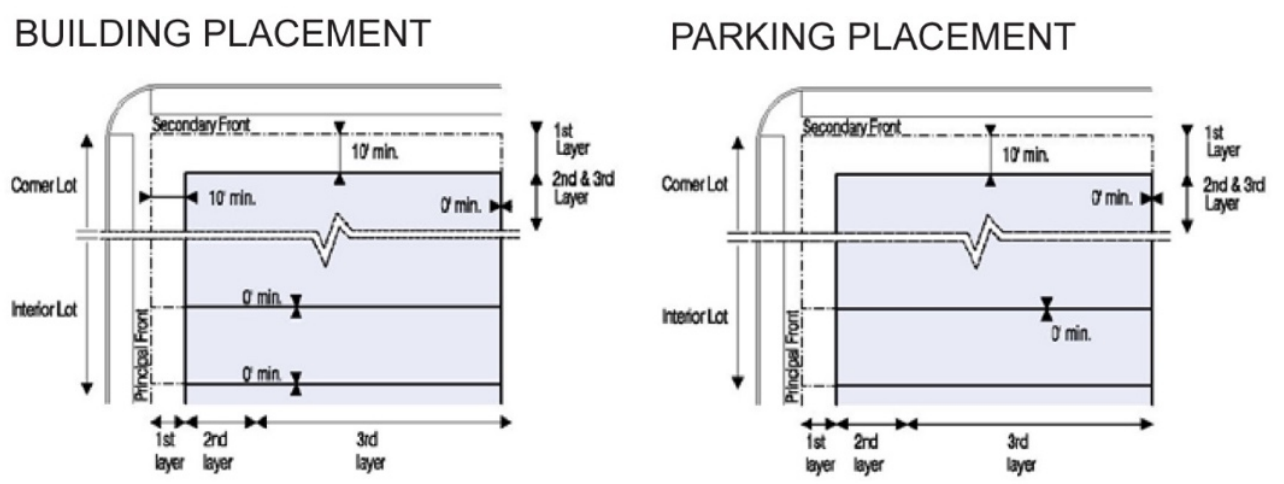

\section{BUILDING HEIGHT}
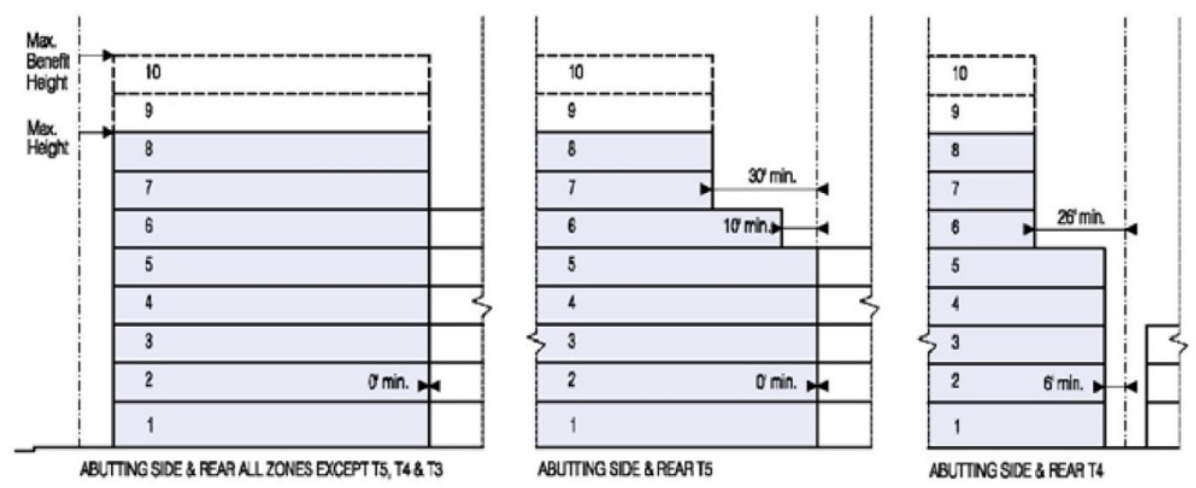

Figure 37. Examples of building standards of Miami 21 Code, City of Miami, 2015

Each district has independent regulations in Miami 21 Code. This research uses the Miami World Centre as an example. The building regulations of this district contain the measurement of height, building disposition, building configuration, and building use and density. Figure 37 presents the examples of building form standards.

Miami 21 Code also includes parking standards, architectural standards, landscape standards, sign standards and civic space standards. While FBCI states that these codes are not required components, they are contained in FormBased Code to further regulate forms and prescribe the built result. 


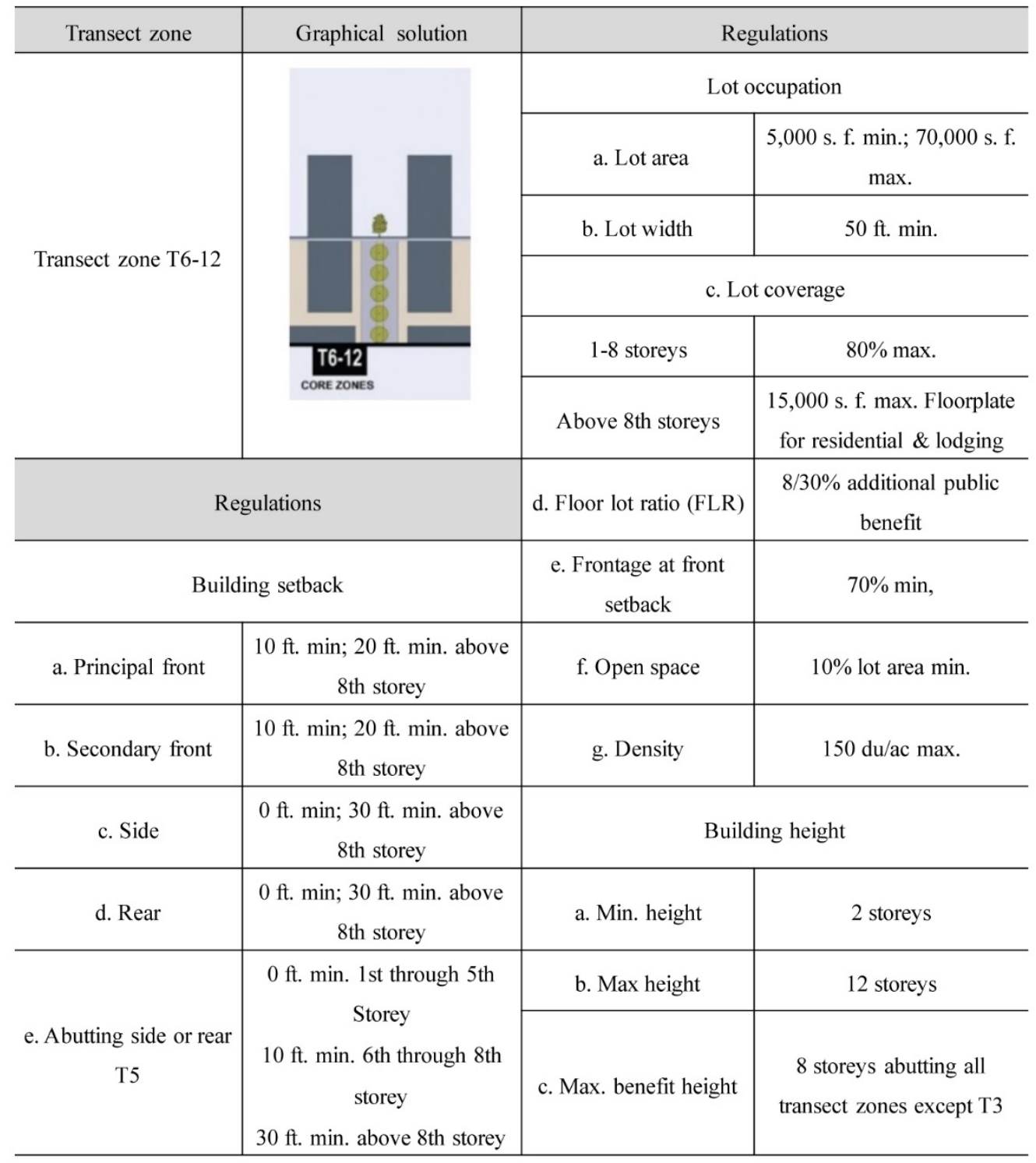

Table 7. An example of the parameters of transect zone T6-12 of Miami 21 Code, City of Miami, 2015

\subsubsection{Main parameters}

The parameters of the Miami 21 Code have three groups, including lot occupation, building setback, and building height (Table 7). Specific ranges of parameters regulate building types, sizes and forms. For instance, in the transect zone T6-12, lot coverage cannot exceed $80 \%$ if the building is lower than eight 
stories. If the building is above eight stories, lot coverage should not be more than 15,000 sq. $\mathrm{ft}$. for residential and lodging, or 30,000 sq. $\mathrm{ft}$. for office and commercial.
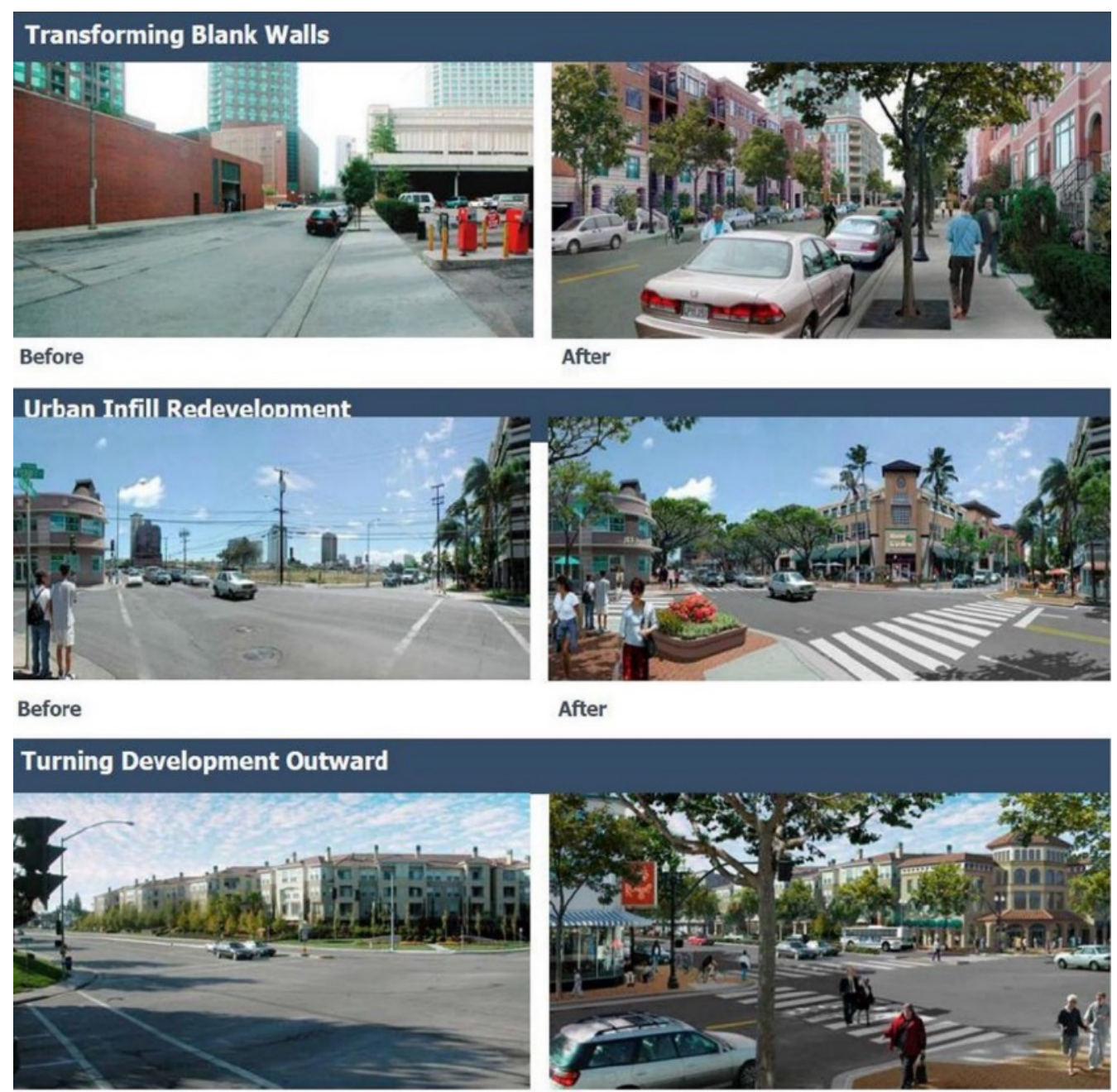

Before

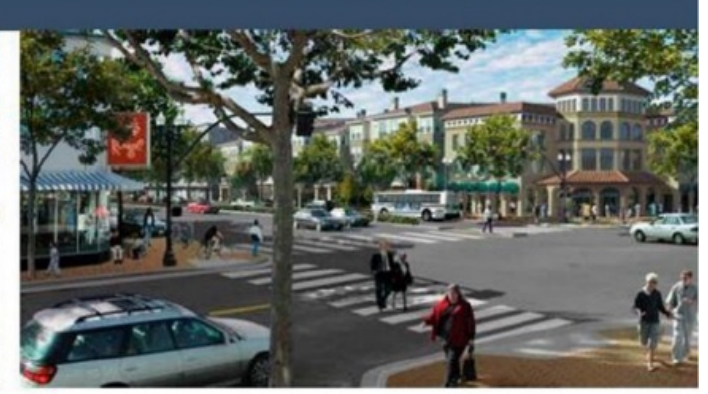

After

Figure 38. Before-after comparison of adopting Miami 21 Code (modelled), City of Miami, 2015

\subsubsection{Adoption results}

Miami 21 Code is the most sophisticated application of the Form-Based Code to date (FBCI, 2015c). The code has all the provisions that would be found in a typical zoning ordinance but goes further, addressing important aspects such as 
sustainability, view corridors, and solar access (FBCI, 2015c). Figure 38 presents a before-after comparison if adopting Miami 21 Code. Miami 21 Code works to create pedestrian-friendly street atmosphere but not land use principles. Before the generation of Miami 21 Code, nearly all Form-Based Codes were adopted by small-scale counties. The Miami Form-Based Code is the first application by a central city encompassing suburban to downtown areas. While good neighbourhood development has taken place in Miami under current law, the problem is that in almost every case it has required regulatory exceptions to do so (Benfield, 2010). Rather than being the norm, smart growth has borne the extra burden of justifying zoning variances case by case (Benfield, 2010). 


\subsection{Downtown Code for Nashville}

Downtown Code for Nashville is one of the latest examples of Form-Based Code regulation, up to 2017. The code adoption area is on a relatively small scale in which the downtown area is the site where Form-Based Code is adopted. The Downtown Code (DTC) covers much of the city centre and regulates the physical form of buildings to ensure each makes a positive contribution to the public realm (FBCI, 2017).

\begin{tabular}{c|c}
\hline Basic Information & Description \\
\hline Project Area & 25 acres \\
\hline Client & Downtown of Nashville \\
\hline Year Adopted & 2017 \\
\hline Location &
\end{tabular}

Figure 39. Basic information of Downtown of Nashville

\subsubsection{Main components}

There is no transect matrix with categories from the most natural to the most urban in DTC. The DTC reflects the characteristics of the built environment as identified by the T6 Downtown transect category (FBCI, 2017). T6 zone is subcategorised as T6 Downtown Second and Broadway (T6-SB), T6 Downtown Core (T6-DC), T6 Downtown Capitol (T6-CP), and T6 Downtown Neighbourhood (T6 DN). Other zone types include Special Policy Areas, Water, Transition (TR), Conservation (CO), Civic (CI), and Open Space (OS). The rural zone or suburban zone are not essential elements in this project. Unlike the 
Miami 21 Code using the whole city as the coding site, this project adopts FormBased Code in one small special district (Figure 40).

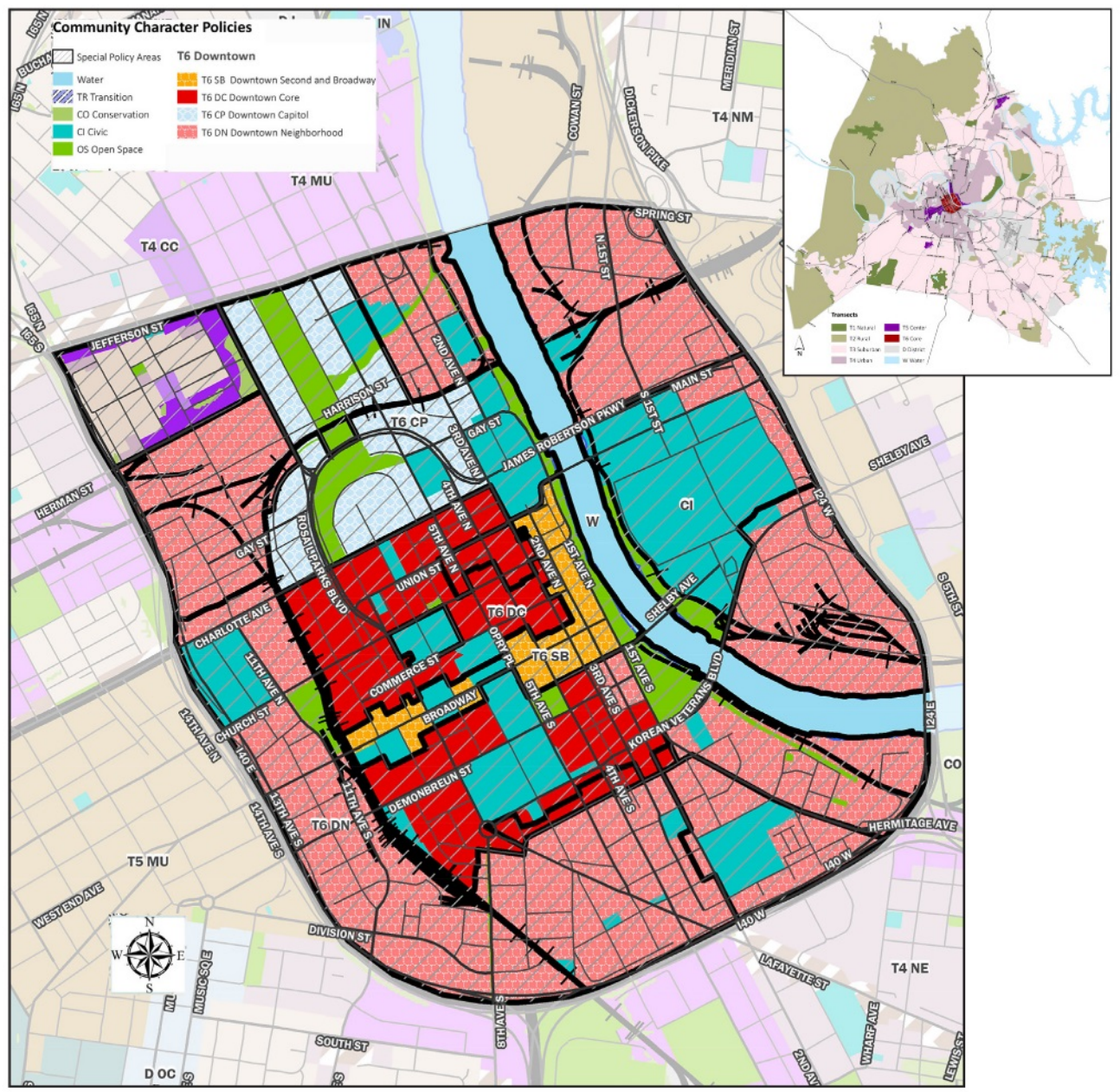

Figure 40. Regulating plan of Downtown Code for Nashville, City of Nashville, 2017

General standards include street character, future streets plan, lots and frontages, parking and access, fences and walls, and open space standards. The open space standards specifically regulate greens, squares, plazas, courts, and playgrounds. DTC of Nashville has detailed regulations for signs (Figure 41). It regulates sign types and area by street types, building signs, ground signs, and skyline signs. 

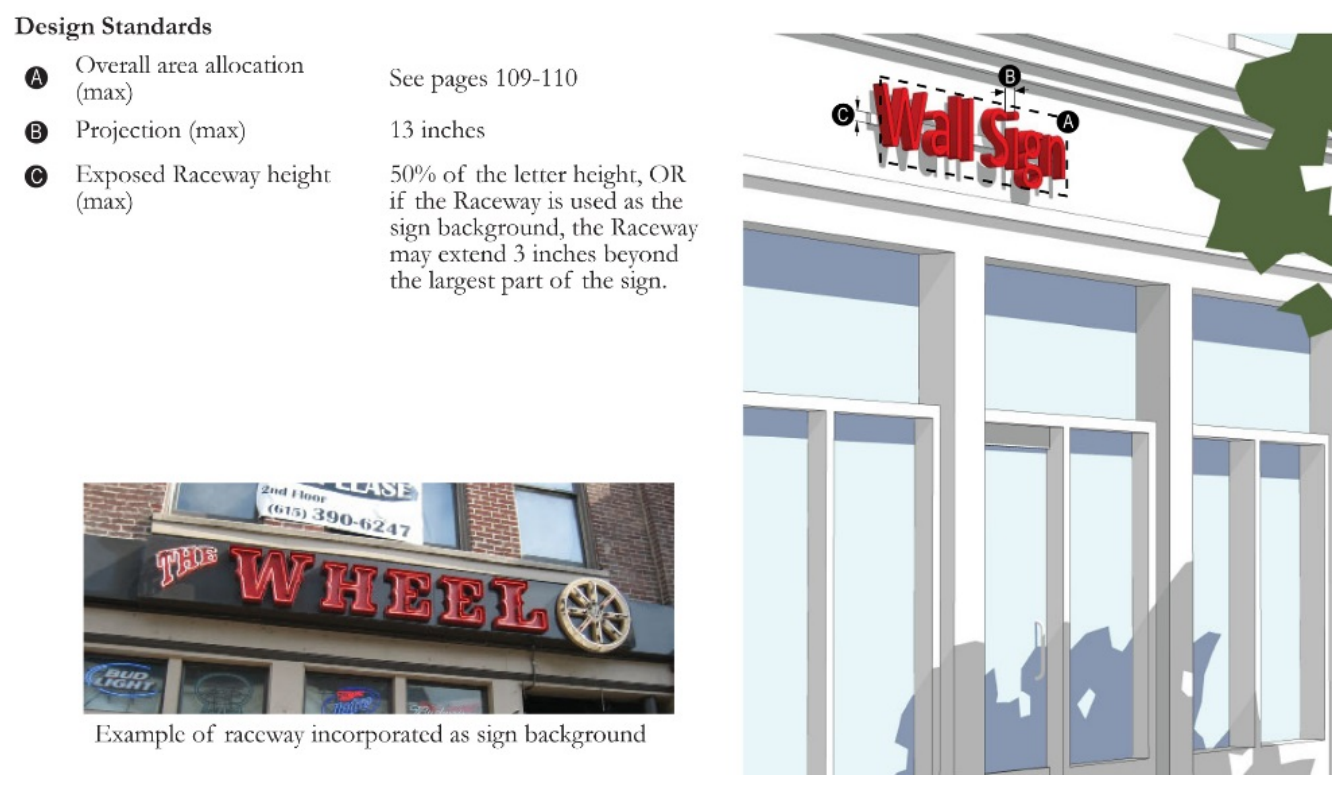

Figure 41. An example of sign standards of Downtown Code for Nashville, City of Nashville, 2017

\subsubsection{Main parameters}

The DTC offers preliminary massing models to represent what the neighbourhood looks like and how the parameters work. These models help the community understand what the existing zoning allowed and what the proposed Form-Based Code could allow (FBCI, 2017).

The existing zoning created an unpredictable urban form (

Figure 42). For example, areas such as core frame and industrial restricted are regulated by index values. Although there are specific limitations, the possible built results cannot be controlled. In contrast, the proposed form-based zoning (

Figure 43) provided more development rights and a more predictable public realm tailored to each neighbourhood (FBCI, 2017). In different areas like Hope Gardens, Gulch South, Lafayette, and SoBro, buildings are regulated by various conditions to effectively prescribe zoning results. Table 8 shows a standard group of parameters in DTC. 


\section{Existing}

Core Frame (CF)

$\mathrm{FAR}=5.0,65$ feet at the street,

$\mathrm{SEP}=1$ foot horizontal to 1.5 feet vertical
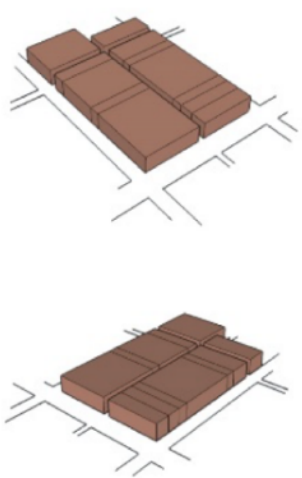
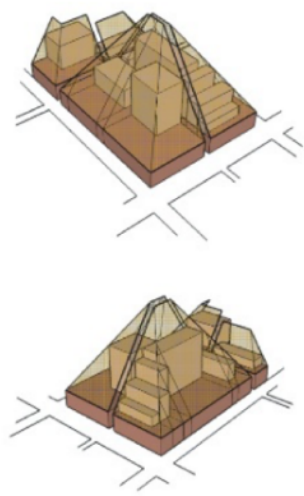

Industrial Restricted (IR)

$\mathrm{FAR}=0.6,45$ feet at the street,

$\mathrm{SEP}=1$ foot horizontal to 1.5 feet vertical
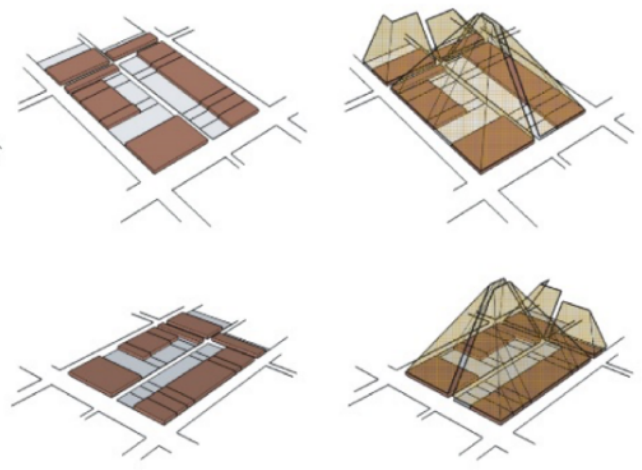

Figure 42. Existing zoning and results of Downtown Code for Nashville, City of Nashville, 2017

FBC
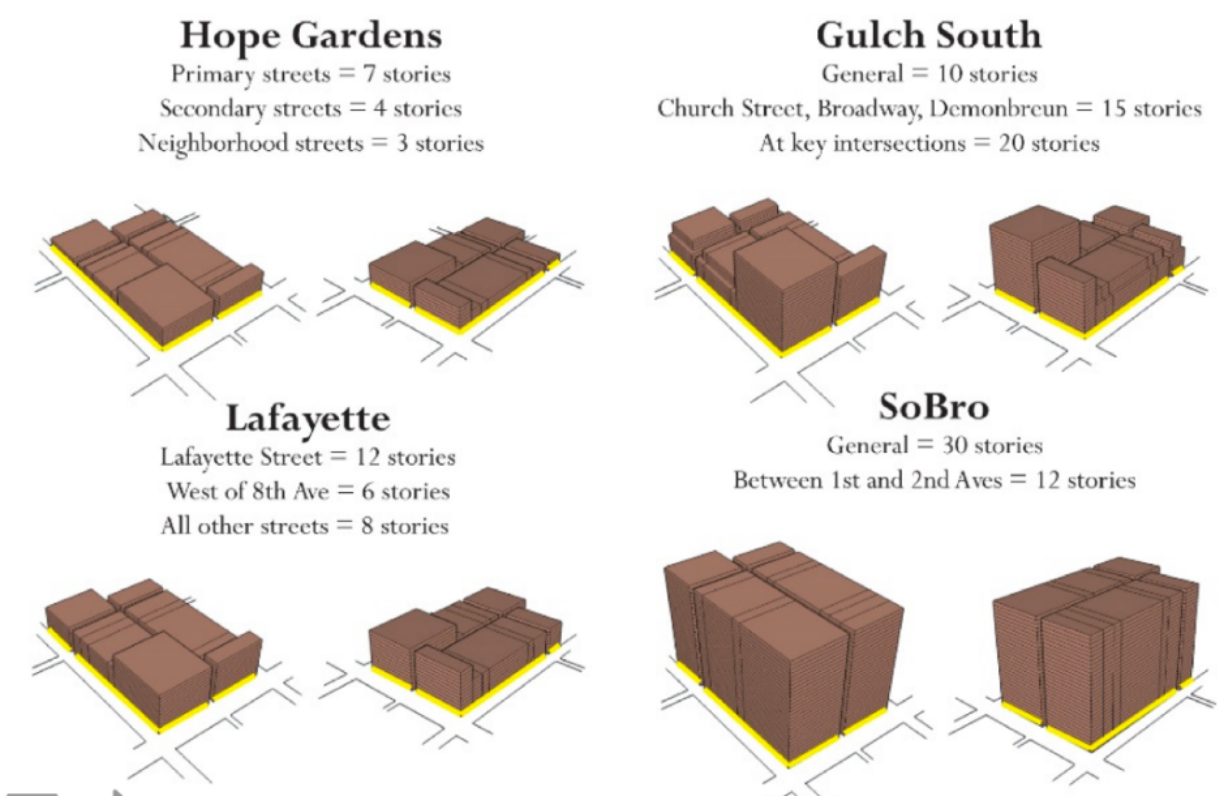

Figure 43. Form-Based Code and results of Downtown Code for Nashville, City of Nashville, 2017 


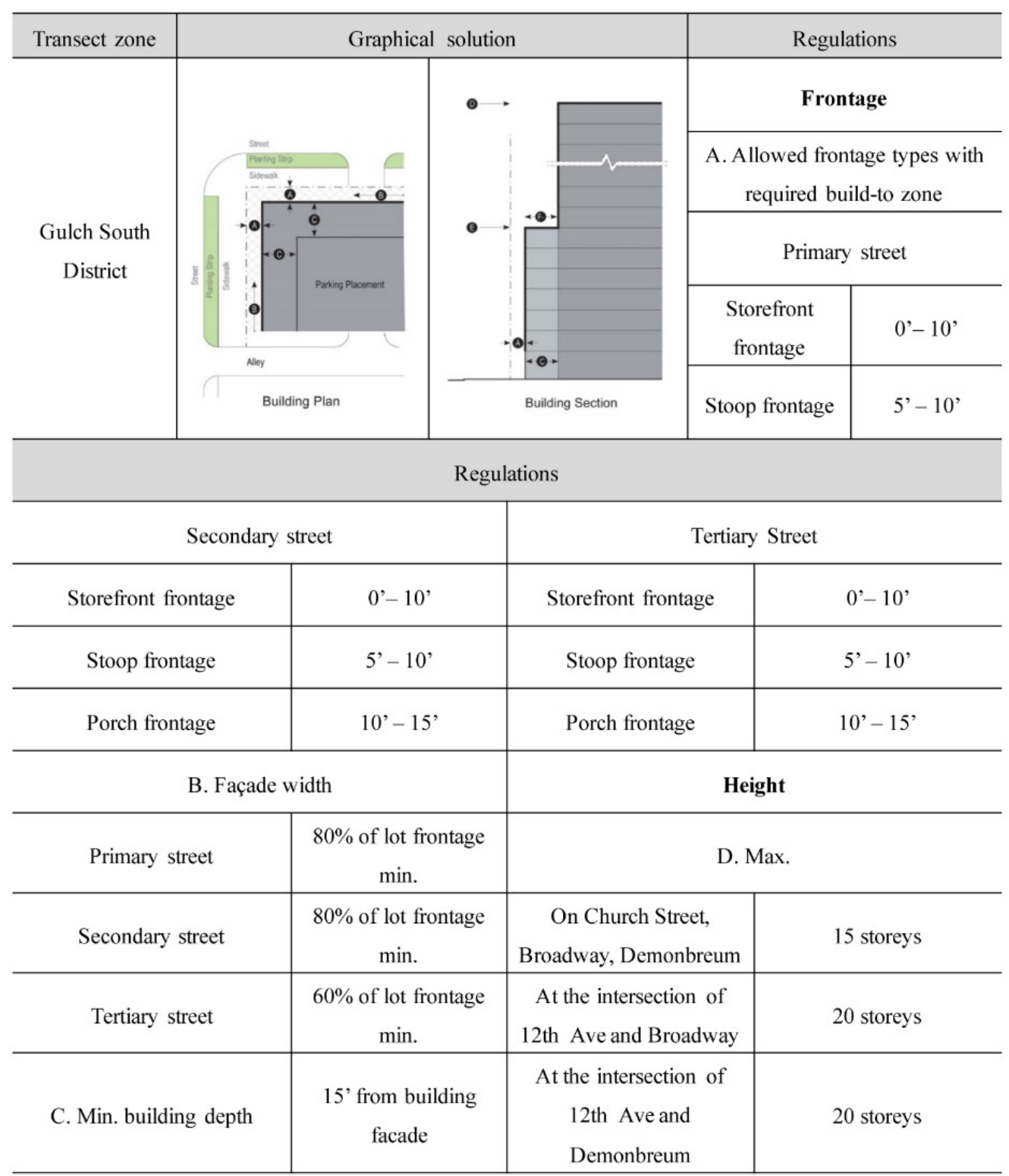

Table 8. Parameters of Downtown Code for Nashville, City of Nashville, 2017

\subsubsection{Adoption results}

The last version of the DTC was adopted in 2010. Since then, 84 projects under the DTC have been approved, of which 27 have broken ground and 32 are completed (FBCI, 2017). One possible built result is depicted in Figure 44. The new version of the DTC, edited with a Form-Based Code concept of the old one, has no real-work adoption results to review. 

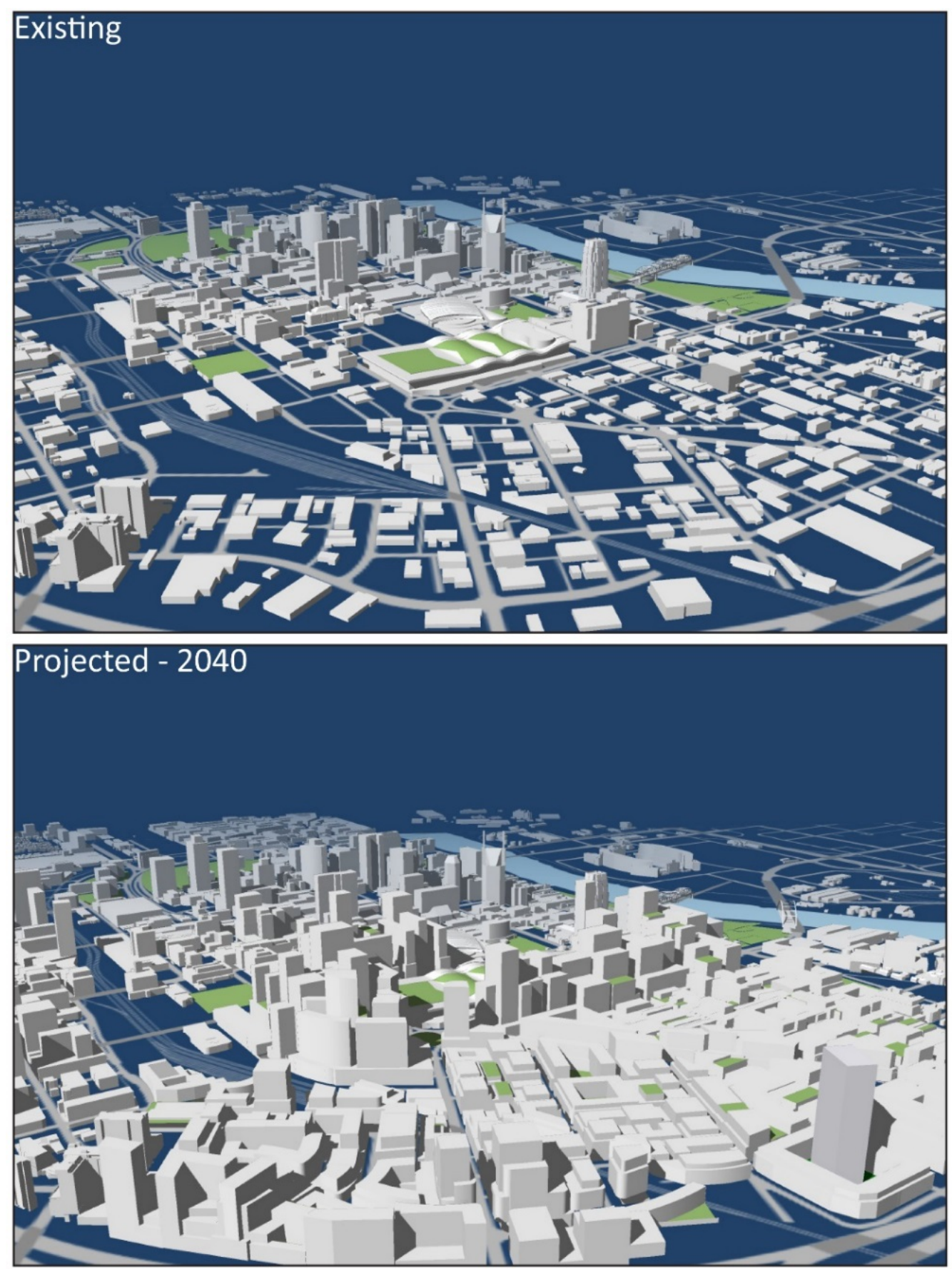

Figure 44. Regulation result prediction of Downtown Code for Nashville, City of Nashville, 2017 


\subsection{East Billings Renewal District Code}

The East Billings Urban Renewal District (EBURD) zoning is a unique hybrid Form-Based Code aimed at increasing flexibility in development while maintaining the character reflected in the EBURD Master Plan (2014). FormBased Code is adopted to allow existing uses to continue, while integrating new mixed-use and residential development appropriately through form-based regulations (City of Billings, 2014). The purpose of the EBURD code is to provide regulations and specific standards for the EBURD Master Plan, which has been applied since 2009 .

\begin{tabular}{c|c}
\hline Basic Information & Description \\
\hline Project Area & 2.72 acres \\
\hline Client & City of Billings \\
\hline Year Adopted & 2014 \\
\hline &
\end{tabular}

Figure 45. Basic information of City of Billings

\subsubsection{Main components}

There is no transect matrix and transect types in the EBURD Code. As Figure 46 shows, the zoning map is defined by five categories. EBURD RSV means the Rail Spur Village District. RSV offers walkable neighbourhoods for residential use. Green spaces and commercial stores are included in RSV. EBURD RSVMS is Rail Spur Village Main Streets. This area is an extension of Montana Avenue with continuous shopping and dining corridors and upper floor residential and office space. 
The concept of vertical and volumetric development merges into EBURD Code. EBURD CW is the Central Works district. This area allows the mixed use of commercial and light industrial. EBURD 13th is the North13th Street Main Street District. It provides a walkable, shopping and dining corridor with upper floor office and residential space adjacent to the Central Works and Industrial Sanctuary districts, while allowing appropriate craftsman industrial and commercial business (City of Billings, 2014). EBURD IS means Industrial Sanctuary District. It enables the mixed use of industrial business. The regulating plan blends the current land-use zoning approach with Form-Based Code. Land-use division and form division are both elements in the Form-Based Code generation.

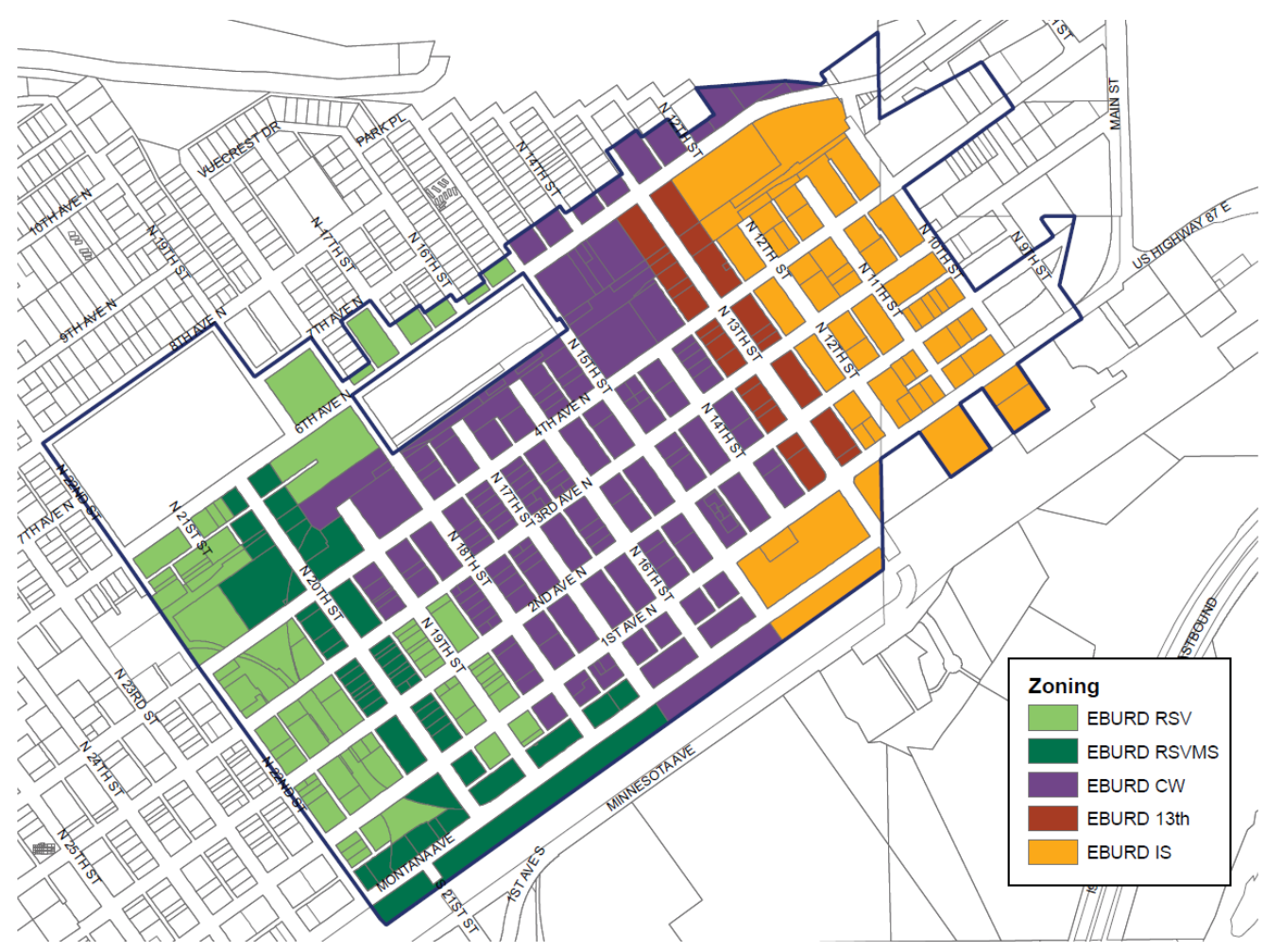

Figure 46. Regulating map of EBURD of EBURD Code, City of Billings, 2014

The EBURD code regulates sustainable development requirements. The construction projects belonging to this site must document sustainability 
measures, and all applicants must achieve no fewer than five total points from any combination of measures. The measures include Certified Green Buildings Measure (3 points), Building Energy Efficiency Measure (2 points), Building Water Efficiency Measure (2 points), Water-Efficient Landscaping Measure (2 points), Renewable Energy Sources Measure (2 points), Green Roof Measure (2 points), Heat Island Reduction Measure (2 points), Previous Pavement Measure (2 points), and Enhanced Bicycle Amenities Measure (1 point).

EBURD also contains frontage code. It is applied to all new construction and exterior renovations of existing structures (City of Billings, 2014). The use of frontage types is shown in

Table 9.

\begin{tabular}{|c|c|c|c|c|c|}
\hline & \multicolumn{5}{|c|}{ EBURD Districts } \\
\hline $\begin{aligned} &=\text { Permitted Boulevard } \\
&= \text { Permitted Only on Boulevard } \\
& \text { Street Type }\end{aligned}$ & 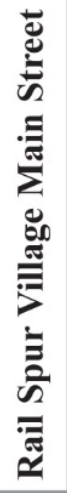 & 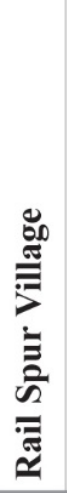 & 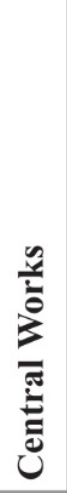 & 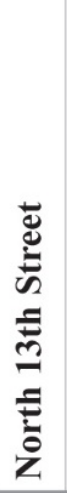 & 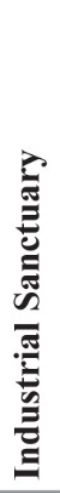 \\
\hline Yard Frontage & & 0 & & & \\
\hline General Stoop & & 0 & ○ & & 0 \\
\hline Storefront & $\bullet$ & 0 & $\bullet$ & 0 & 0 \\
\hline Limited Bay & & 0 & ○ & 0 & 0 \\
\hline Commerce & & & O & & 0 \\
\hline Open Frontage & & & & & 0 \\
\hline Civic Frontage & $\bullet$ & 0 & 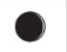 & 0 & 0 \\
\hline Commercial Outdoor Site & & $\mathrm{O}$ & 0 & 0 & 0 \\
\hline
\end{tabular}


Table 9. Permitted frontage types by district of EBURD Code, City of Billings, 2014

Standards of parking overlay districts, landscape, signage, and street types contribute to the EBURD coding. For example, the on-street bicycle facilities (Figure 47) are regulated in the street type standards. The facilities include designated shared lane, dedicated bike lane, and cycle track. Dedicated bike lanes must be on both street sides and be four or five feet width. A designated shared lane must be a minimum of thirteen feet wide. And a cycle track must be physically separated from vehicular traffic (City of Billings, 2014).
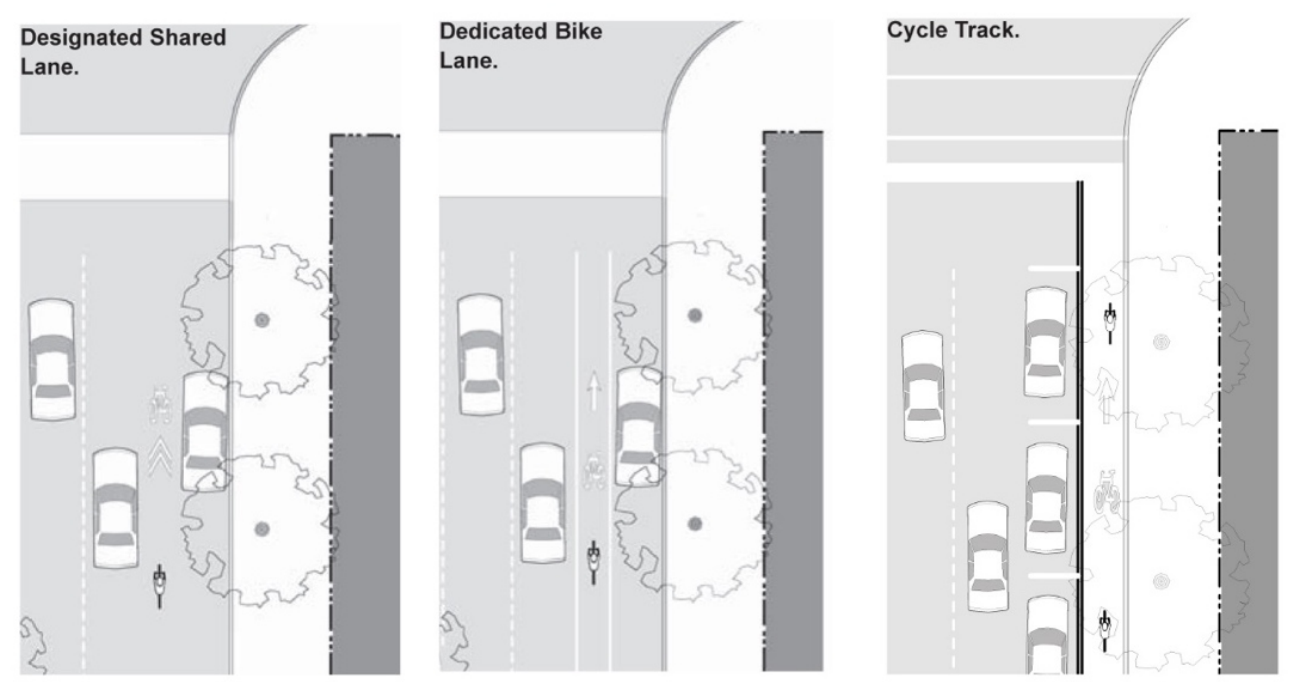

Figure 47. On-street bicycle facilities of EBURD Code, City of Billings, 2014

\subsubsection{Main parameters}

The parameters of EBURD include three categories: building siting, height, and street façade requirements. Building siting and height are for regulating buildings on a site, and street façade is for the street atmosphere and perceived urban space from people's perspective.

Building siting parameters include front lot line coverage, front build-to zone, corner build-to zone, side yard setback, rear yard setback, minimum lot width, maximum lot width, maximum impervious coverage, and additional semi- 
pervious coverage. Height is regulated by minimum overall height, maximum overall height, ground story minimum and maximum height, upper stories minimum and maximum height. Street façade requirements parameters contain ground floor minimum transparency, upper floor minimum transparency, number of entrances, vertical increments, balcony size, and balcony façade coverage.

\subsubsection{Adoption results}

The EBURD was created in 2006 when the Billing City Council approved an Urban Renewal Plan and Tax Increment Finance (TIF) district for the east end industrial area of Billings (Billings Industrial Revitalization District incorporated, 2014). TIF supports urban infill and brownfield investment in blighted areas. Taxable values increase when underutilised properties start to redevelop. Meanwhile, the fund can reinvest in public projects or support landowners with infrastructure improvement. Based on the report of Billings Industrial Revitalisation District, the EBURD Code contributes to improved revenue and over $\$ 500,000$ in TIF funding has been reinvested in the district (Figure 48). The implementation of Form-Based Code supports the redevelopment of the East Billing area's physical built environment and economic sphere.

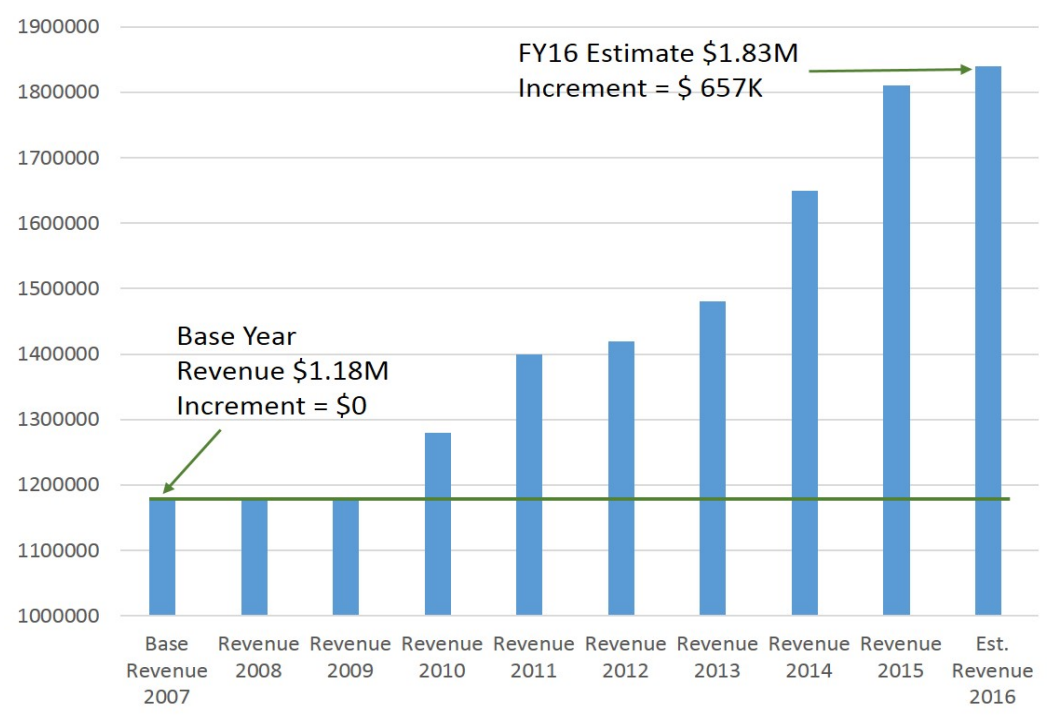


Figure 48. Revenue trends of year 2007-2016 of EBURD Code, Billings Industrial Revitalization District incorporated, 2014

\subsection{Comparisons and findings}

According to the preceding Form-Based Code projects, the main components include a regulating plan with transect matrix and map, building standards, frontage standards, and public space standards. Table 10 presents the main components generated by Smart Code Montgomery, Miami 21 Code, Downtown Code for Nashville, and East Billings Urban Renewal District Code. Components are scored to explore the most and least incorporated ones in the real applications. The Form-Based Code projects which have one black circle in Table 10 get 1 point, and a white circle get 0 point. The rating results are shown in Table 11. Regulating maps, frontage standards, building standards, parking standards, sign standards, and transect matrix get 4 or 3 points. This means they are the most used components of the four Form-Based Codes. These components are thus the priority considerations in generating parametric FormBased Code for this research. 


\begin{tabular}{|c|c|c|c|c|}
\hline \multicolumn{5}{|c|}{ Components } \\
\hline $\begin{array}{l}\text { Included } \\
\text { excluded }\end{array}$ & 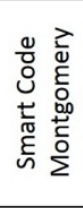 & 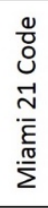 & 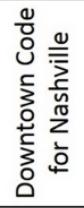 & 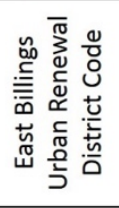 \\
\hline Transect Matrix & 0 & 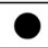 & 0 & $\mathrm{O}$ \\
\hline Regulation Map & 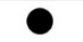 & 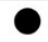 & O & O \\
\hline Building Standards & 0 & 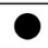 & O & O \\
\hline Thoroughfare \& Street & O & $\mathrm{O}$ & 0 & 0 \\
\hline Frontage & 0 & O & O & O \\
\hline Parking Standards & 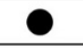 & O & O & O \\
\hline Architectural Standards & $\bigcirc$ & O & $\mathrm{O}$ & $\mathrm{O}$ \\
\hline Landscape Standards & $\mathrm{O}$ & 0 & $\mathrm{O}$ & 0 \\
\hline Sign Standards & O & 0 & 0 & 0 \\
\hline Ambient Lighting Standards & 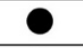 & 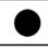 & $\bigcirc$ & 0 \\
\hline Civic Space Standards & 0 & 0 & 0 & $\mathrm{O}$ \\
\hline Allowable Increases in FAR & O & 0 & $\mathrm{O}$ & $\mathrm{O}$ \\
\hline Sub-district Standards & O & 0 & O & $\bigcirc$ \\
\hline $\begin{array}{l}\text { Sustainable Development } \\
\text { Measures }\end{array}$ & 0 & $\bigcirc$ & $\mathrm{O}$ & \\
\hline Development Phases & & $\mathrm{O}$ & $\mathrm{O}$ & $\mathrm{O}$ \\
\hline
\end{tabular}

Table 10. Main components of Form-Based Code projects

\begin{tabular}{|c|c|c|c|c|c|c|c|}
\hline Components & Rate & Components & Rate & Components & Rate & Components & Rate \\
\hline $\begin{array}{l}\text { Regulation } \\
\text { Map }\end{array}$ & 4 & $\begin{array}{l}\text { Transect } \\
\text { Matrix }\end{array}$ & 3 & $\begin{array}{l}\text { Landscape } \\
\text { Standards }\end{array}$ & 2 & $\begin{array}{l}\text { Architectural } \\
\text { Standards }\end{array}$ & 1 \\
\hline Frontage & 4 & $\begin{array}{c}\text { Thoroughfare } \\
\text { \& Street }\end{array}$ & 3 & $\begin{array}{l}\text { Ambient } \\
\text { Lighting } \\
\text { Standards }\end{array}$ & 2 & $\begin{array}{c}\text { Allowable } \\
\text { Increase in } \\
\text { FAR }\end{array}$ & 1 \\
\hline $\begin{array}{l}\text { Building } \\
\text { Standards }\end{array}$ & 4 & $\begin{array}{l}\text { Civic Space } \\
\text { Standards }\end{array}$ & 3 & $\begin{array}{l}\text { Sub-district } \\
\text { Standards }\end{array}$ & 2 & $\begin{array}{l}\text { Sustainable } \\
\text { Development } \\
\text { Measures }\end{array}$ & 1 \\
\hline $\begin{array}{l}\text { Parking } \\
\text { Standards }\end{array}$ & 4 & & & & & $\begin{array}{c}\text { Development } \\
\text { Phases }\end{array}$ & 1 \\
\hline Sign Standards & 4 & & & & & & \\
\hline
\end{tabular}

Table 11. Rate of components in Form-Based Code projects 


\begin{tabular}{|c|c|c|c|c|}
\hline \multicolumn{5}{|c|}{ Parameters } \\
\hline $\begin{array}{l}\text { Included } \\
\text { excluded }\end{array}$ & 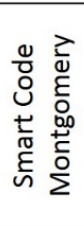 & 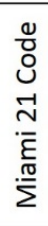 & 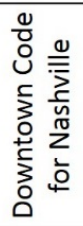 & 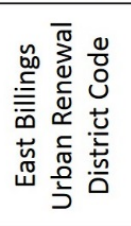 \\
\hline \multicolumn{5}{|l|}{ Building Configuration/Height } \\
\hline Min. Height & & & $\bigcirc$ & \\
\hline Max. Height & D & & O & \\
\hline \multicolumn{5}{|l|}{ Lot Occupation } \\
\hline Area & O & & O & O \\
\hline Coverage & O & O & O & 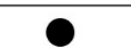 \\
\hline width & 0 & 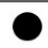 & $\bigcirc$ & \\
\hline Floor Lot Ratio (FLR) & O & 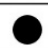 & $\bigcirc$ & O \\
\hline Density & O & O & $\bigcirc$ & O \\
\hline \multicolumn{5}{|c|}{ Setbacks - Principle Building and Outbuilding } \\
\hline \multicolumn{5}{|l|}{ Front Setback } \\
\hline \multicolumn{5}{|l|}{ Side Setback } \\
\hline Rear Setback & & O & $\bigcirc$ & ? \\
\hline Abutting Side Setback & $\mathrm{O}$ & O & O & O \\
\hline \multicolumn{5}{|l|}{ Frontage } \\
\hline Primary/Secondary/Tertiary Street & $\mathrm{O}$ & $\bigcirc$ & O & $\mathrm{O}$ \\
\hline Facade & $\bigcirc$ & $\mathrm{O}$ & 0 & 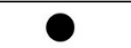 \\
\hline Buildout & 0 & 0 & 0 & \\
\hline
\end{tabular}

Table 12. Main parameters of Form-Based Code projects

The examples use different parameters to regulate street and building forms in medium or small scale. As Table 12 shows, the main parameter categories are building height, lot occupation, setbacks, and frontage. One black circle represents 1 point, and one white circle represents 0 point; the weighting scores of each parameter are shown in Table 13. Building height, front setbacks and side setbacks are scored highest (4) compared with other parameters. These three parameters are thus most often applied in the four Form-Based Code projects. Lot coverage, lot width and rear setbacks also get relatively high scores. These parameters will be considered first for the parametric Form-Based Code generation. 


\begin{tabular}{|c|c|c|c|c|c|c|c|}
\hline Components & Rate & Components & Rate & Components & Rate & Components & Rate \\
\hline Max. Height & 4 & Min. Height & 3 & $\begin{array}{l}\text { Frontage } \\
\text { Facade }\end{array}$ & 2 & Lot Area & 1 \\
\hline Front Setback & 4 & Lot Coverage & 3 & $\begin{array}{c}\text { Frontage Build } \\
\text { out }\end{array}$ & 2 & FLR & 1 \\
\hline \multirow[t]{3}{*}{ Side Setback } & 4 & Lot Width & 3 & & & Density & 1 \\
\hline & & Rear Setback & 3 & & & $\begin{array}{l}\text { Abutting Side } \\
\text { Setback }\end{array}$ & 1 \\
\hline & & & & & & $\begin{array}{c}\text { Frontage in } \\
\text { Street } \\
\text { Hierarchy }\end{array}$ & 1 \\
\hline
\end{tabular}

Table 13. Rate of parameters in Form-Based Code projects

This section starts with reviewing the application trends of Form-Based Code according to Borys, Talen and Lambert's Code Study. An increasing number of cities have accepted Form-Based Code as an alternative approach to regulation and have started to implement it in urban regulation projects. The Code Study and representative Form-Based Code cases demonstrate:

- There is no mature Form-Based Code study or implementations in highdensity cities outside of the USA

- Form-Based Code has relatively positive results in the reviewed projects with various scales and circumstances

- The frequently used Form-Based Code components are the regulating plan, transect matrix and map, building standards, frontage standards and public space standards

- The frequently used Form-Based Code parameters are building height, front setbacks, side setbacks, lot coverage, and lot width 


\subsection{Chapter summary}

Form-Based Code examples are accomplished in this chapter. Document review and examples comparison demonstrate that Form-Based Code has the capability to bring benefits to the urban regulation framework in practice.

The analysis of Form-Based Code examples finds that the components that frequently included in Form-Based Code frameworks are regulating map, frontage standards, building standards, parking standards, and sign standards.

The parameters that frequently regulated in Form-Based Code frameworks are building heights, setbacks, lot coverage, and lot width. To date, there is inadequate research about the application of Form-Based Code in high-density cities outside of the USA.

Form-Based Code places a higher priority on controlling urban form. Predicting urban regulation outcomes is still difficult in the regulation-making process (Imrie and Street, 2009; Kim, 2014). In order to establish a parametric modelling system and implement the system in Form-Based Code, the next chapter explores Form-Based Code in an experimental site by exploring the specific transect matrix and multi-layered regulating plans to aid the prediction of urban regulation outcomes. 


\section{Chapter 4. Form Transecting and Results}

This research aims to develop a parametric modelling system and implement that system through a Form-Based Code suited to the volumetric morphology of a high-density city. The system integrates regulation generation, modification and performance feedback at the conceptual stage of a project. It provides interactive and visualised schema for urban regulation. To be implemented in context, such a system must accommodate the peculiarities of Form-Based Code in a high-density environment. Hence, it is essential to first understand the specific context and establish a methodological framework for developing Form-Based Code appropriate for the volumetric morphology of high-density cities, which is presented in this chapter. Experiment 1, briefly described in Section 1.5, is further explored in this chapter with the following main operations:

1. Understand the characteristics of the volumetric morphology of highdensity cities. The Tsim Sha Tsui area of Hong Kong is the experimental site used to identify the regulatory peculiarities of a high-density environment

2. Field study and physical data collection to capture the building and street forms in the established urban space

3. Statistical analysis of the collected data to redefine the transect matrix of Form-Based Code in context

4. Use topological analysis to reorganise the urban zones and develop regulating plans for multiple grounds 
This chapter provides pre-modelling preparation for implementing the parametric modelling system in a Form-Based Code. It concludes with the development of a series of multi-layered transect matrix and regulating plans. These are embedded into the parametric modelling platform in the next experiment. 


\subsection{Understand the context}

This section focuses on the experimental context. It describes the formation of a high-density environment and the characteristics of the volumetric morphology. The regulation particularities of the context are presented to facilitate the generation of Form-Based Code.

\subsubsection{Site location}

Tsim Sha Tsui, is representative of the urban core zone of Hong Kong and the experimental site of this research. Choosing Tsim Sha Tsui is a response to the political and practical uncertainty about the desirability of Form-Based Code in the high-density cities of Asia. Mixed land use is a tradition broadly accepted by the society of Hong Kong, so aligns with a Form-Based Code approach to regulation. Hong Kong's acceptance of western urban development approaches is relatively high due to its social and cultural background. Current zoning ordinance and acts of Hong Kong draw on lessons from western cities. As a result, Hong Kong has the right conditions to be the experimental context of this research. Choosing Tsim Sha Tsui as the site extends the implementation range of Form-Based Code and provides a reference for the rest of Hong Kong and other high-density cities.

Tsim Sha Tsui was a small fishing village in the 1860 s at the south tip of Kowloon Peninsula. The place has since been enlarged by marine reclamation from Hung Hom Bay to accommodate the increasing population. Today, Tsim Sha Tsui already become one of the urban cores of Hong Kong with volumetric transportation space and dynamic commercial entities.

The experimental site's boundary is consistent with Tsim Sha Tsui Zoning Plan, Town Planning Ordinance, Hong Kong, 2008. The research site consists of Jordan Road Area, Hong Kong Observation Area, Nathan Road East Area, Kowloon Park Area, Nathan Road West Area, Canton Road Area, and Hung 
Hom Area (Town Planning Board of Hong Kong, 2008). Special land uses like the central transportation station, civic square waterfront and construction areas (as at 2016) are not included in the site.

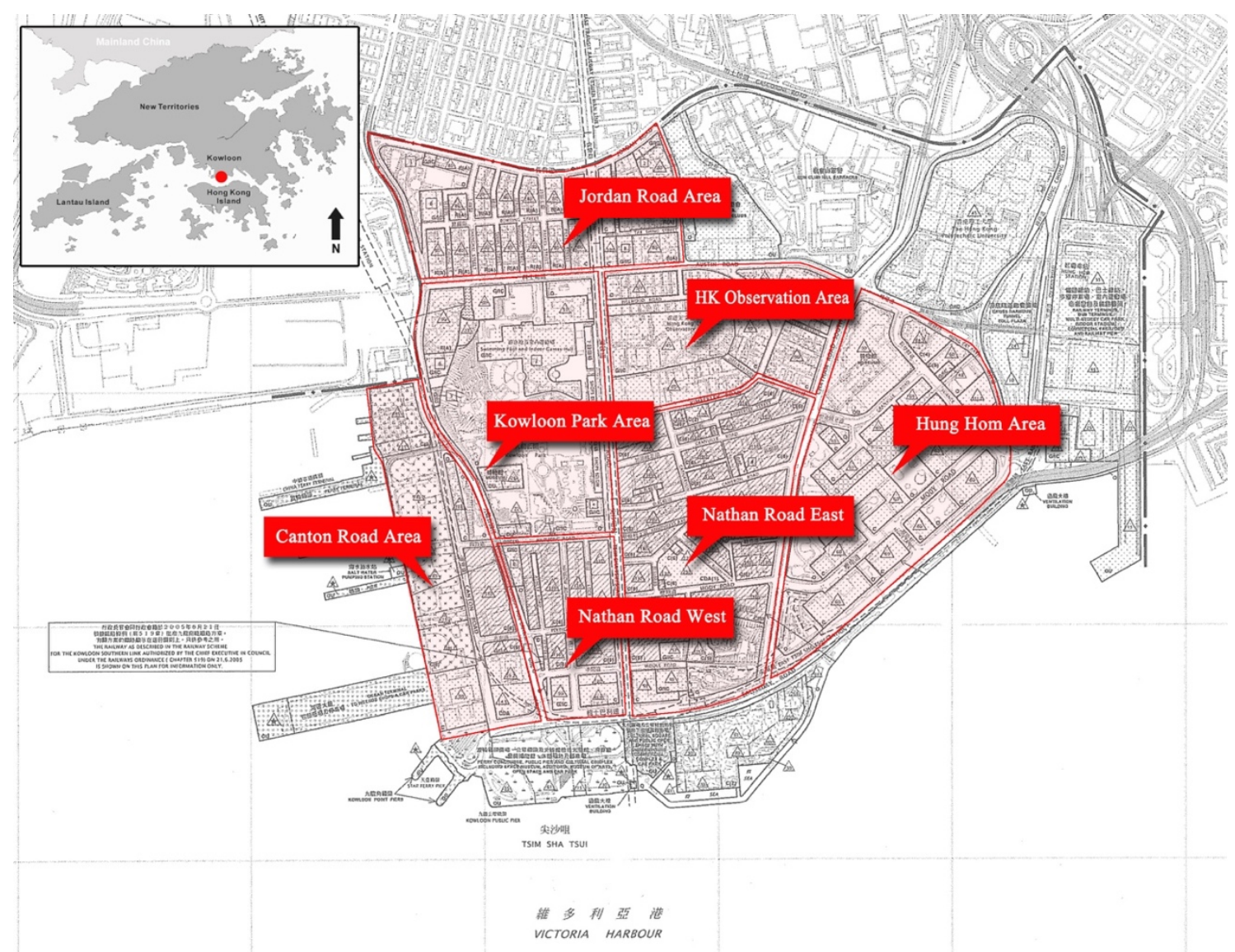

Figure 49. Areas of Tsim Sha Tsui, Hong Kong, re-edited by author based on Town Planning Ordinance, Town Planning Board of Hong Kong, 2008

\subsubsection{Identify high-density}

Tsim Sha Tsui's compact living place with a vast population has been described as high density. Density begins with population, but must move beyond it (Rapoport, 1975). The concentration of humans - in some cases judged as too high, in others not high enough - and the problems connected to this, have resulted in discussions on density (Berghauser and Haupt, 2009). High-density identification relates to population, buildings and perceived density (Cheng, 2009). 


\subsubsection{Population density}

The report of 2016 Demographia World Urban Areas (DWUA) of Wendell Cox Consultancy indicates that the population ratio of $15,000 / \mathrm{km}^{2}$ can be regarded as the lower end of the high density range (Wendell Cox Consultancy, 2016, Table 14). Per DWUA's ranking, there are 92 high-density cities, including 14 super high-density cities, above the population density of $22,000 / \mathrm{km}^{2}$ around the world. Most high-density cities are located in India (34) and China (9), others are in Africa and Latin America.

\begin{tabular}{c|c}
\hline Population density & Description \\
\hline$\leq 1,000 / \mathrm{km}^{2}$ & Low-density \\
\hline $1,000-8,000 / \mathrm{km}^{2}$ & Mid-low-density \\
\hline $8,000-15,000 / \mathrm{km}^{2}$ & Mid-density \\
\hline $15,000-22,000 / \mathrm{km}^{2}$ & High-density \\
\hline$\geq 22,000 / \mathrm{km}^{2}$ & Super-high-density \\
\hline
\end{tabular}

Table 14. Population density description

These high-density cities have three development contexts. The first of these is cities like Hong Kong, where high population occupy limited land. Second is the regional central town with high primacy, like Dhaka and Bogota. Third is the regional major port or industrial city, like Zhongshan and General Santos. This research focuses on the first type of high-density city, those with a large population and limited land.

There are two reasons for high-density development in Hong Kong. One is deficient land resources; the other rapid urbanization in a short time. Figure 50 presents the relationships between built-up land and population density in metropolitan areas. Compared with other cities, Hong Kong has little land but must house a large number of individuals. These realities result in a multi-level morphology which duplicates land to accommodate the population. Shelton states that Hong Kong turned into a volumetric city even faster than Chicago. 
With two waves of population increase since the 1950s, many people clustered in Hong Kong in a short time. The first wave was in response to World War II and the Chinese Civil War. Many displaced immigrants settled at this time. The second wave was during the 1980s. Chinese Economic Reform offered a relatively loose political environment. Hong Kong attracted immigrants from mainland of China to start business and find job opportunities. It became a mega international metropolitan in only 30 years.
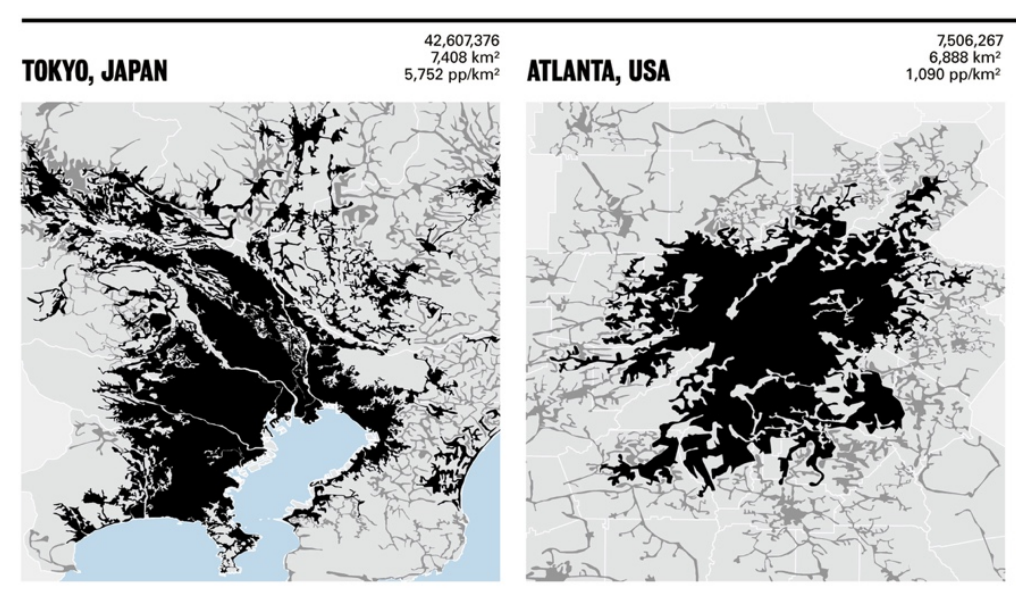

$\begin{array}{lr} & 14,830,051 \\ 2,668 \mathrm{~km}^{2} \\ 5,259 \mathrm{pp} / \mathrm{km}^{2}\end{array}$

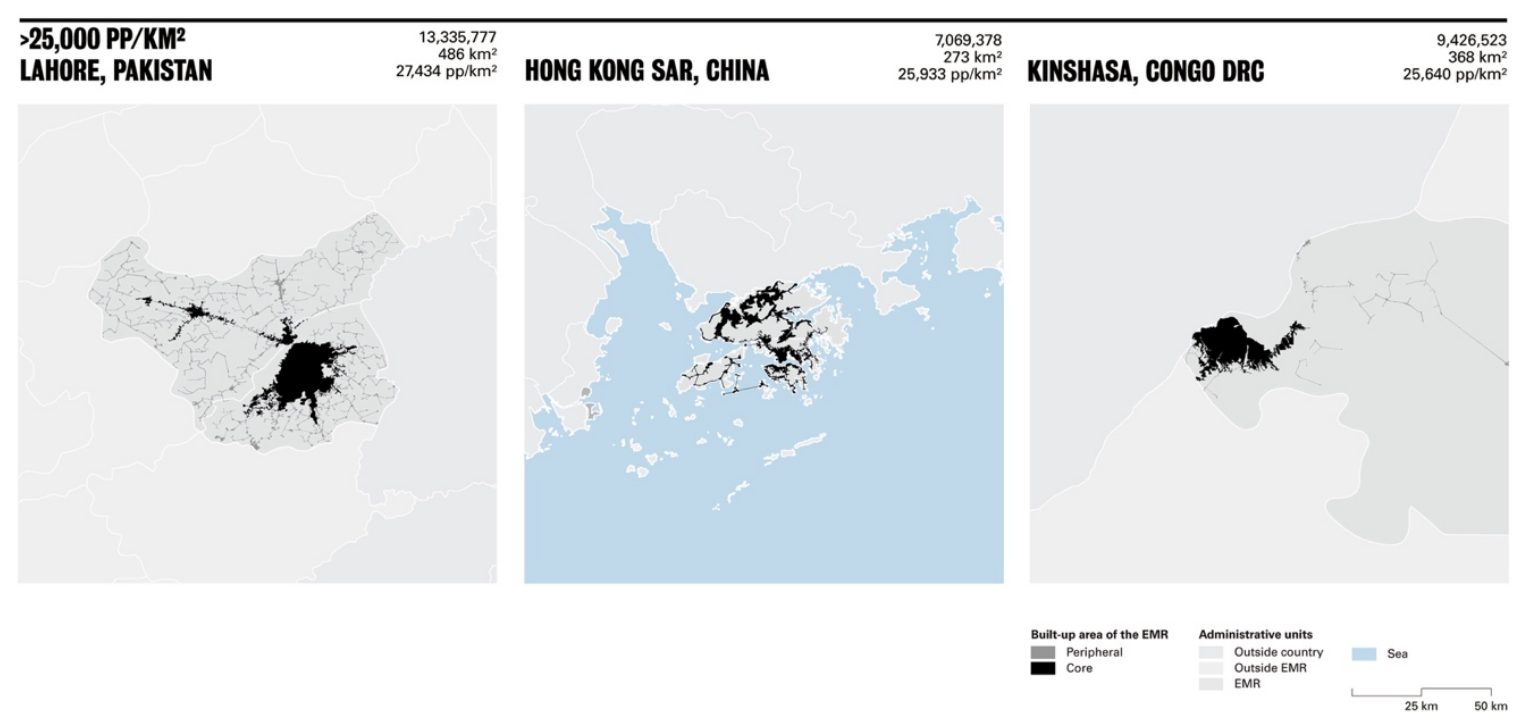

Figure 50. Population comparison among high-density cities, Burdett, et al., 2011 
Figure 51 compares population density between large cities. Hong Kong's population is concentrated in urban core zones, with nearly no suburban-spread. Based on Burdett, et al. (2011), the peak value of the population in Hong Kong is $111,065 / \mathrm{km}^{2}$, twice that of New York City and 6.4 times that of London. The population rate is much higher than the $15,000 / \mathrm{km} 2$ high-density standard set by DWUA (2016).
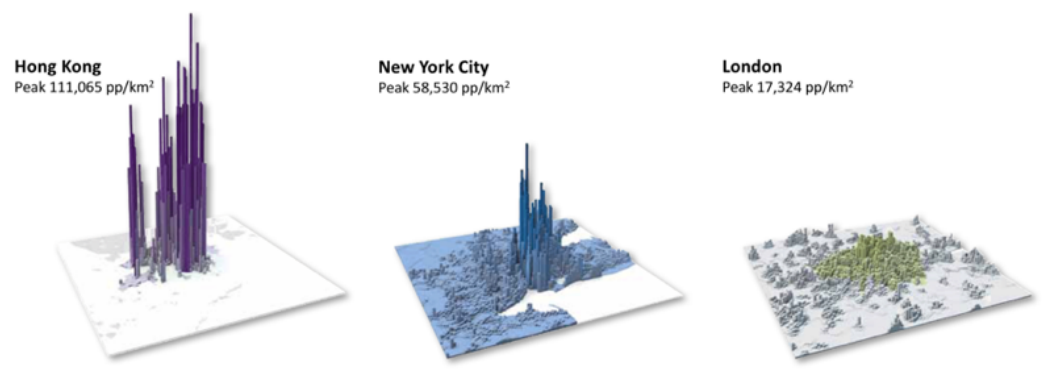

Mexico City
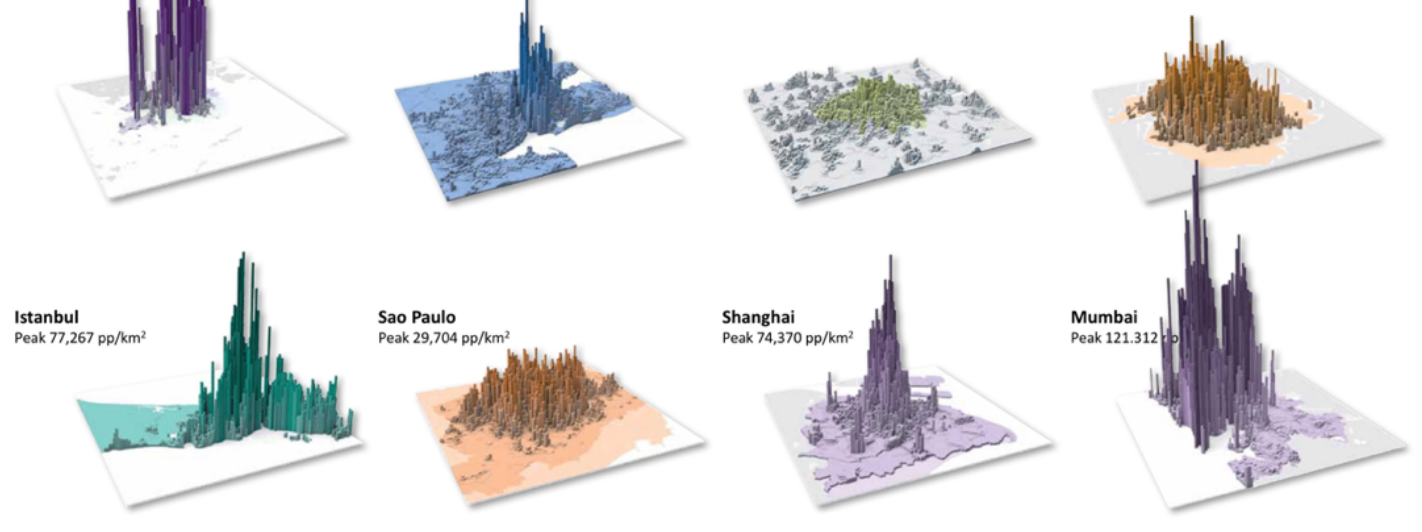

Figure 51. Population distribution in high-density cities, Burdett, et al., 2011

\subsubsection{Building density}

Building coverage ratio (BCR) and floor area ratio (FAR) are two representative indexes for measuring building density. BCR is the ratio of a building's footprint area to the size of the site on which it is built. High-rise buildings with a lower BCR are a conventional approach to creating more open space in highdensity cities. FAR reflects the ratio of a building's total floor area to its site size. Crawford (2000) argues that an FAR of 1.5 is appropriate for a car-free city. According to Crawford, an FAR of more than 1.5 is too high to create a pleasant street atmosphere. However, an FAR of 1.5 is often exceeded in today's large cities. In Brisbane, Australia, high-density areas consist of buildings with 
eight stories plus with an FAR of 1.5-3.0. In high-density Tsim Sha Tsui, Hong Kong, FAR values can get to 10 plus. Using residential land use as an example (Table 15), according to Hong Kong Planning Standards and Guidelines (HKPSG), the maximum domestic FAR is 8-10 in the Hong Kong Island and 7.5 in Kowloon. In Tsuen Wan New Town of Hong Kong, the maximum value for residential areas is 8 (Planning Department of Hong Kong, 2018).

\begin{tabular}{c|c|c|c}
\hline $\begin{array}{c}\text { Density } \\
\text { zone }\end{array}$ & Type of area & Location & $\begin{array}{c}\text { Maximum domestic plot } \\
\text { ratio }\end{array}$ \\
\hline \multirow{2}{*}{ R1 } & Hong Kong Island & $\begin{array}{c}8 / 9 / 10 \text { (depends on Site } \\
\text { Class A, B and C } \\
\text { respectively) }\end{array}$ \\
\cline { 3 - 4 } & $\begin{array}{c}\text { Existing } \\
\text { Development } \\
\text { Area }\end{array}$ & $\begin{array}{c}\text { Kowloon \& New } \\
\text { Kowloon }\end{array}$ & $\begin{array}{c}7.5 \text { (according to statutory } \\
\text { town plans and site class is } \\
\text { not relevant) }\end{array}$ \\
\cline { 3 - 4 } & $\begin{array}{c}\text { Tsuen Wan New } \\
\text { Town (Covers } \\
\text { Tsuen Wan, Kwai } \\
\text { Chung \& Tsing Yi } \\
\text { Island) }\end{array}$ & 8 \\
\hline R2 & $\begin{array}{c}\text { New Development Area and } \\
\text { Comprehensive Development Area }\end{array}$ \\
\hline R3 & \multicolumn{2}{|c|}{6} \\
\hline
\end{tabular}

Table 15. FAR standards for Residential zones in Hong Kong, HKPSG, 2017

\subsubsection{Perceived density}

Perceived density encompasses far more than just physical density (Alexander, 1993; Stokols, 1972). In an urban environment, spatial density refers to the perception of density with respect to the relationships between spatial elements such as height, spacing and juxtaposition (Cheng, 2009). Based on Bonnes' research in 1990, the equilibrium between built-up and open areas, the density of buildings, availability of green space, uniformity of buildings, heterogeneous style of buildings, and suitable height of buildings are all factors that affect 
residents' perception of density. The mechanisms for controlling interaction levels such as spacing, physical elements, territorial boundaries, hierarchy, the size and nature of the group involved, its homogeneity and rules for behaviour all affect the rates of social interaction (Chan, 1999).

According to Rapoport, density itself is a perceived experience and should be seen as more than a simple ratio model. Clear, stable hierarchies which reduce tension and maintain order and stability also reduce the effects of numbers and thus change the effective density (Dubos, 1965; Leyhausen, 1971, and Rapoport, 1975). High-density is not equivalent to crowding. Crowding is the perception that there are too many people (Churchman, 1999). It is possible to live at a very high density in a spacious apartment with no crowding, and conversely, it is possible to live in a detached farmhouse that is crowded in terms of having many people per room (Forsyth, 2003b). Thus, urban regulation in high-density cities needs to create efficient land use or urban space to decrease the feeling of crowding.

\subsubsection{Volumetric morphology}

Volumetric morphology is a typical urban form pattern of Tsim Sha Tsui. Shelton, Karakiewicz and Kvan described the high-rise buildings as Dim Sum containers - a kind of identical stacking baskets for separating single food types. In Hong Kong, tower and podium consist of a town centre and single strand connections to isolated "tower neighbourhoods" above, in which floors are isolated from each other (Shelton, et al., 2011). Complex tower groups also exist. High-rise buildings tend to connect with each other at both underground and upper ground levels to fully use the land resources and sculpt a volumetric morphology.

Volumetric means multiple modes of movement and varied programs stacked up across many levels, which are above and below ground, and where 
connections between levels are extremely effective (Shelton, et al., 2011). Vertical morphology can translate to volumetric. Concentrated vertical developments create three-dimensional multi-directional connections, and permeable and legible volumes (Shelton, et al., 2011). The volumetric morphology has a few specific characteristics, including layered grounds, layered functions, and homogeneous housing forms.

\subsubsection{Layered grounds}

In a volumetric morphology, "ground" has complex meanings including duplicated ground, split ground and borrowed ground. Duplicated ground is a common phenomenon to enable pedestrians to conveniently cross roads or walk between buildings. The main purpose is to relieve traffic pressure on the ground. Split ground is designed because of steep geography. The entrances of buildings locate at different levels considering the different horizontal lines in hilly places. Borrowed ground relies on changing natural limitations to concentrate residents. Because of the rapidly clustered dwellings, some reserved open space belts must be constructed to meet standards of living in increasing density. The Hong Kong government decided to use landfill from upland areas.

Multiple grounds result in volumetric movement by layered transportation. The transportation system has a significate role in Hong Kong. The system of rail, highway, subway, light-rail, tramcar, and bus can meet the daily-life transport demands of most individuals. Public transportation accounts for nearly $90 \%$ of transportation in Hong Kong each year. The first metro line of Hong Kong was opened in 1979. Now the Mass Transit Railway (MTR) covers $218.2 \mathrm{~km}$ and is one of the most profitable systems in the world according to the 2012 Annual Report (MTR Corporation Limited, 2013). Figure 52 shows the highly connected subway stations of Tsim Sha Tsui and Tsim Sha Tsui East. Compared with private vehicles, public transportation is more convenient and economic with respect to demographic dividends. 


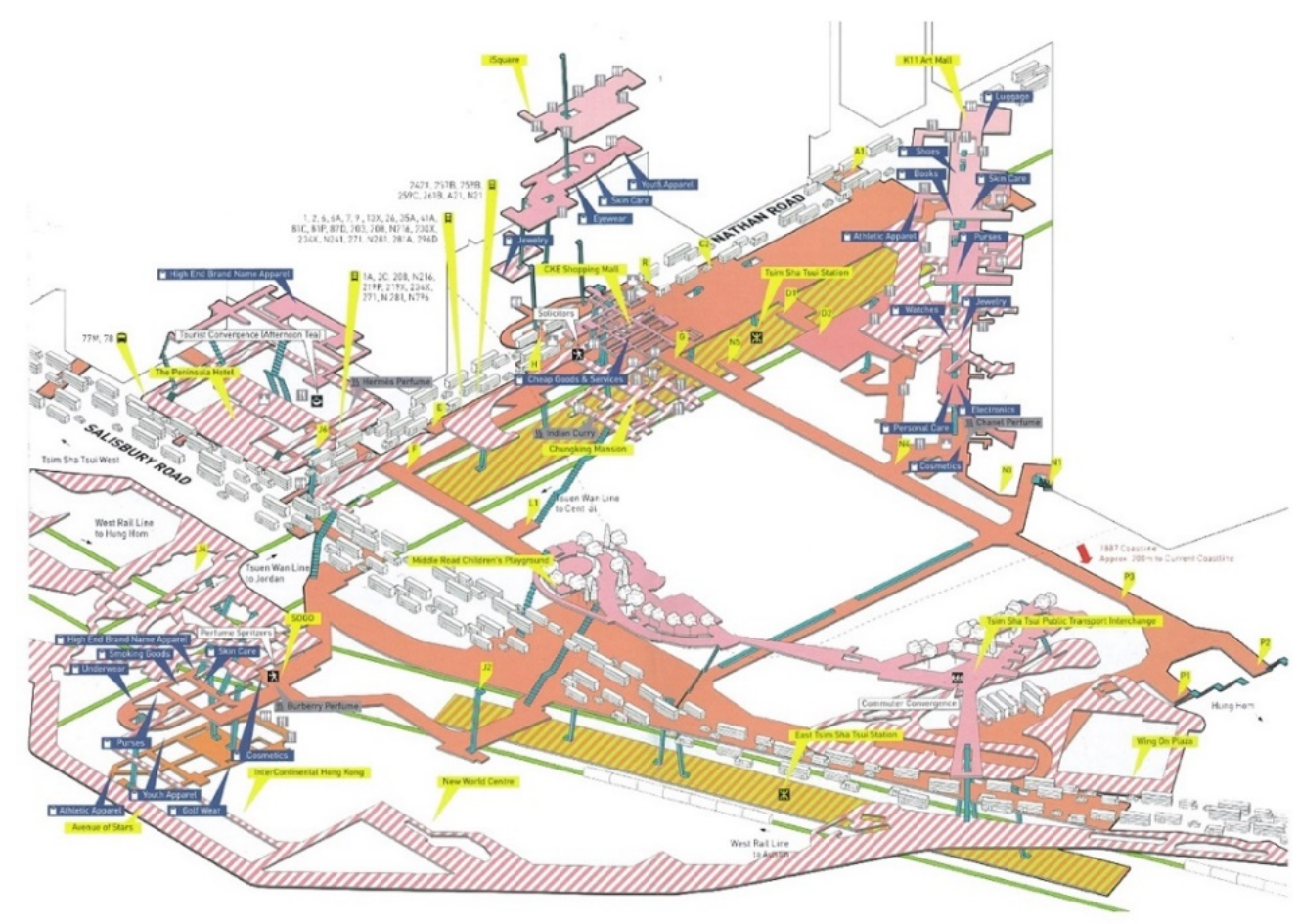

Figure 52. Underground connections of Tsim Sha Tsui Station, Frampton, et al., 2012

\subsubsection{Layered functions}

To complement a ground that can be manipulated and multiplied and accessed in a variety of ways, functions can be freed from their conventional positions on the ground (Shelton, et al., 2011). Volumetric space is a consequence of populations concentrated on limited ground space. Multi-level functions emerge following the layered grounds.

In Hong Kong, when urban density grows to a certain amount, volumetric growth occurs with underground shopping centres, rooftop houses and multilevel corridors. For instance, Hong Kong has "rooftop houses" above high-rise towers (Figure 53). Due to insufficient public housing, rooftop families are staying in the city centre to share the convenient transportation and infrastructure. Gardening, farming and commercial land uses are clustered on rooftops to create "ground" and enlarge activity space. 


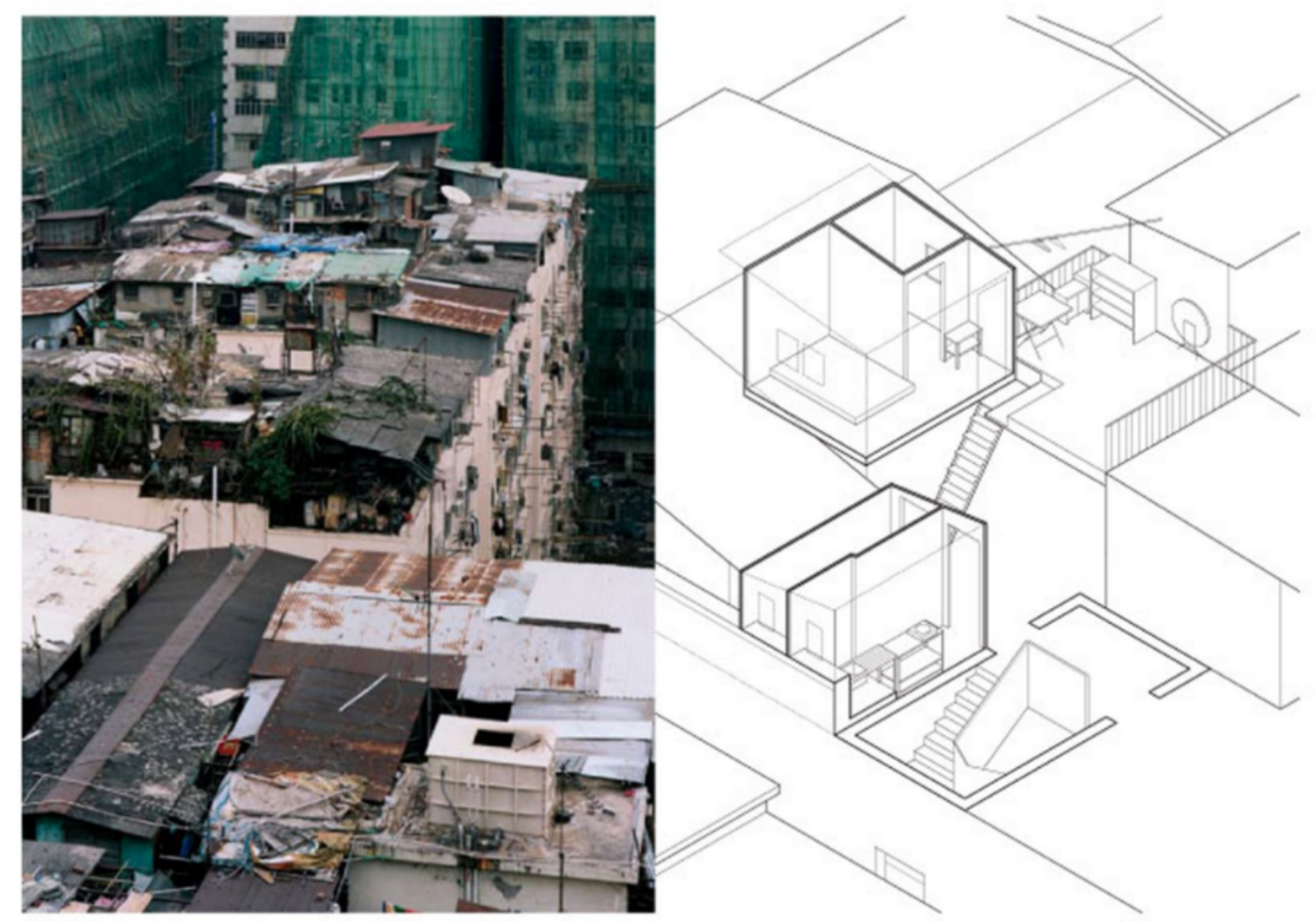

Figure 53. Rooftop space usage, Canham and Wu, 2008

\subsubsection{Homogeneous housing forms}

Hong Kong has intensive road networks to transport people promptly. These road networks segment city blocks into small-size squares. And these blocks, especially in newly developing areas, are similarly constrained by limited space. One reason for the homogenous housing is the concentrated terrain which limits the design of the residential buildings. By adhering to precedent construction codes and meeting economic and safety demands, architects and designers have small spaces in which to accommodate high-rise buildings. Another reason is the mass housing and mass circulation of goods in Hong Kong, which results in surprisingly similar forms (Figure 54, Esther and Li, 2014). There are approximately 3.6 million residents living in similar forms of public housing (Census and Statistics Department, 2015). 


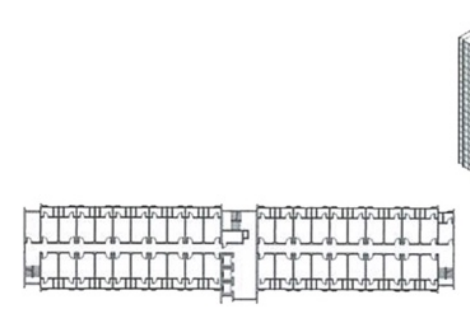

Slab Block

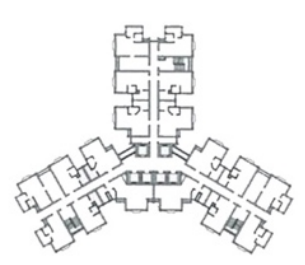

Trident 4
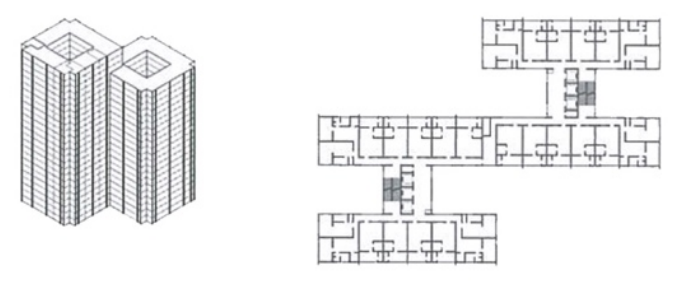

Twin H-Block
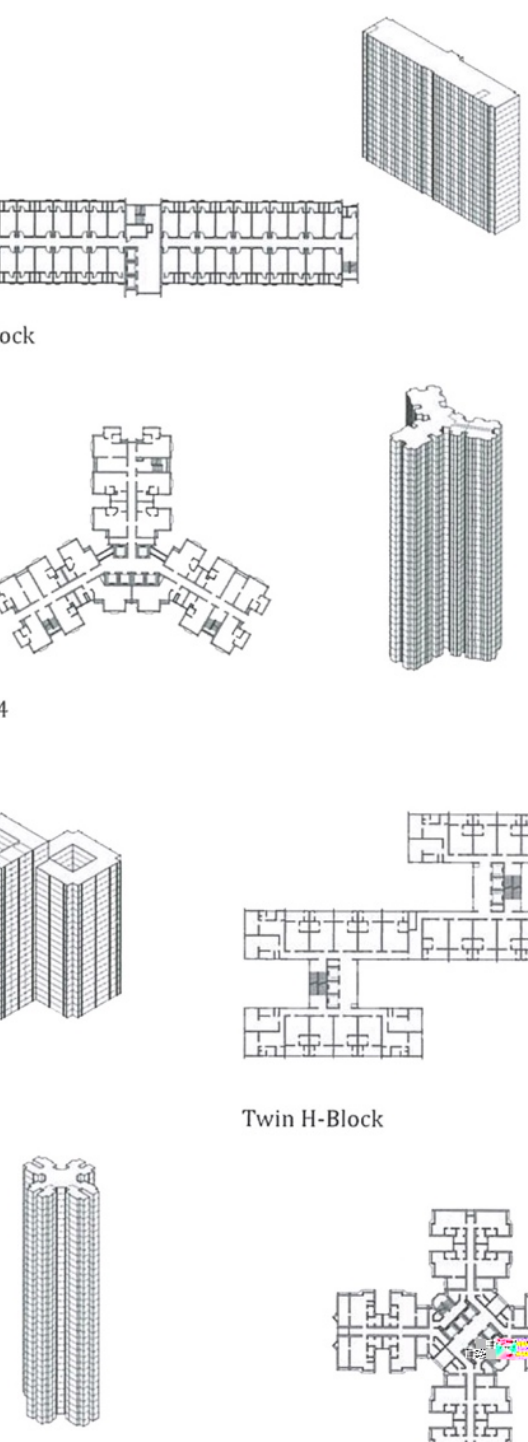

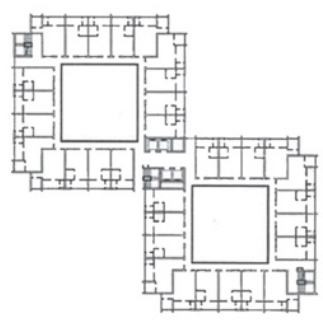

Twin Tower

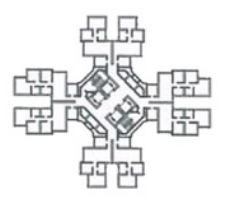

Concord 1
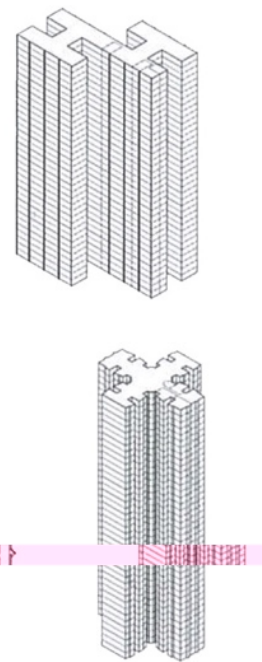

Harmony 1

Figure 54. Housing types in Hong Kong, Esther and Li, 2014

\subsubsection{Regulation peculiarities in high-density situations}

The previous section analysed the features and performance of high-density cities with a volumetric morphology. In this specific urban development situation, urban regulation differs from more loosely formed cities. It is widely accepted that denser living and building conditions in compact cities have more intrinsic potential to become less resource consuming than more sprawling 
cities with sparser living and building patterns (Shelton, et al., 2011). Haarhoff's research demonstrates that higher density leads to resident's experience as enhanced liveability (Haarhoff, et al., 2016). Moving from urban sprawl to a compact city has been proposed as one method for improved urban sustainability (Arbury, 2005). The resulting volumetric phenomenon prompts improved cost and building technology. The value of land increases sharply and the extent of volumetric morphology expanded. A circuit is formed consisting of land, tech, and finance. To remit this situation, government and urban management agencies encourage renewed development in conventional urban centres and old communities. This reduces the economic consumption of the newly developed urban land, increases the population capacity of the old area, and maximises the sharing of urban infrastructure to save resources and protect the environment. The United Nations states that population increase and concentration threatens cities with social conflict, environmental degradation and the collapse of basic services (Basiago, 1998). According to the data of the World Health Organisation, the urban population in 2014 accounted for 54\% of the total global population, up from $34 \%$ in 1960, and continues to grow (World Health Organisation, 2016). When high-density development has become the only choice, the role of urban regulation lies in:

1. Organising land and space effectively

2. Reusing old areas

3. Reducing people's sense of congestion

4. Ensuring the natural environment is not damaged

Hong Kong has a multi-level morphology with volumetric characteristics. Ground-level regulation is insufficient to meet space requirements. Although Hong Kong is high-density, the perception of crowding can be alleviated with appropriate urban regulation and design using upper ground and underground space. Volumetric form and multi-level codes must be a consideration of 
regulation procedures, aiming towards a liveable and sustainable high-density environment. The following section describes the field study of Tsim Sha Tsui to further analyse the volumetric forms of the experimental site. 


\subsection{Field study and physical data collection}

This section presents a field study of Tsim Sha Tsui for understanding the building and street forms of the high-density environment. A workflow of physical data collection is provided for the field study. By investigating the current urban form and categorising the form types, this section concludes with an analysis of form-based zone types and subtypes in the transect matrix of Tsim Sha Tsui.

\subsubsection{Field study set-up}

The field study aims to demonstrate the physical performance of Tsim Sha Tsui and redefine the transect matrix for volumetric morphology according to the data collection results. The information that should be collected includes:

1. Elements that relate to building and street forms, including pavement width, building height limitations of each community, depth-width ratio, and FAR. The information is gained by reviewing the current regulations, measurement survey, calculation and text-based records.

2. Elements that relate to streetscape and space usage, including road hierarchy, infrastructure, pedestrian environment, public space usage, and underground space usage. This information is the result of observation and photographic records.

3. Elements that relate to transportation and movement flow, including street elevators, upper ground corridors, underground connections, and pedestrian routes. The information is gained through observation and photographic records.

\footnotetext{
All information required to be collected is based on the existing built environment. No opinions, activities, or portraits of people are recorded. The field study starts with a beta testing data collection session to test the survey sheets and gain an understanding of how long a collection session needs to be.
} 
The information required for the data collecting sheet (Table 16) contains photorecoding data and measure-recording data. Photo-recording data such as pedestrian environment and public space is image information. Measurerecording data such as FAR and pavement width is quantised information. Data collection results are used to reflect the hierarchies and arrays of zones in the transect matrix of the experimental site. The following paragraphs describe the variables in detail.

\begin{tabular}{|c|c|c|c|c|c|c|c|c|}
\hline No. & Location & & & & & & & Date \\
\hline \multirow{5}{*}{ 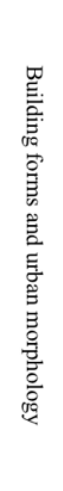 } & Pavement width & $\begin{array}{l}\text { Measured } \\
\text { number }\end{array}$ & \multirow{5}{*}{ 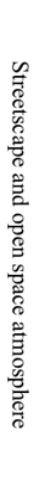 } & Road hierarchy & Rank and score & \multirow{5}{*}{ 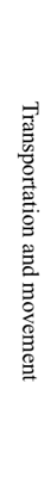 } & Street elevators & Photo record \\
\hline & $\begin{array}{l}\text { Max. building } \\
\text { height }\end{array}$ & $\begin{array}{l}\text { Measured } \\
\text { number }\end{array}$ & & Infrastructure & Rank and score & & $\begin{array}{l}\text { Upper ground } \\
\text { corridors }\end{array}$ & Photo record \\
\hline & Depth-width ratio & $\begin{array}{l}\text { Measured } \\
\text { number }\end{array}$ & & $\begin{array}{l}\text { Pedestrian } \\
\text { environment }\end{array}$ & Photo record & & $\begin{array}{c}\text { Pedestrian } \\
\text { routes }\end{array}$ & Photo record \\
\hline & \multirow{2}{*}{ FAR } & \multirow{2}{*}{$\begin{array}{c}\text { Measured } \\
\text { number and } \\
\text { calculated result }\end{array}$} & & Public space & Photo record & & \multirow{2}{*}{$\begin{array}{l}\text { Underground } \\
\text { connections }\end{array}$} & \multirow{2}{*}{ Photo record } \\
\hline & & & & $\begin{array}{l}\text { Underground } \\
\text { space }\end{array}$ & Photo record & & & \\
\hline \multicolumn{9}{|c|}{ Notes and first impression } \\
\hline
\end{tabular}

- Layers of the urban space (upper ground level, ground level, underground level)

- Accessible and walkable degree

- Building forms

- Public space

- Special usage of urban space

- Estimate "Artificial" or "Natural" degree in transect matrix of FBC

Table 16. Example of a physical data collection sheet

\subsubsection{Floor area ratio (FAR)}

FAR, as discussed in Section 3.7, is a widely used index for reflecting the compact level of a place. In both conventional zoning and Form-Based Code, FAR is a significant parameter for describing density, measuring urban land usage, and assessing the level of urban atmosphere pleasantness. In the field 
study, FAR acts as one of the quantised variables used to analyse the physical characteristics of Tsim Sha Tsui. A community with a higher FAR means it may be closer to the artificial point in the transect matrix and vice-versa.

\subsubsection{Pavement width}

Pavement width is a key variable regulated in Form-Based Code projects. The pavement width can partly reflect the amount of pedestrian flow and the frequency of pedestrian space use. A wide pavement is possibility designed to accommodate a large amount of walking. Because of the capacious walking space, a number of public activities may happen. Thus the place with a wide pavement is probably close to the artificial point, while the place with a narrow pavement is likely closer to the natural point in the transect matrix.

\subsubsection{Road hierarchy}

Road hierarchy is regulated by the urban regulations of Hong Kong. Based on the current urban codes and observation, the road system has six types (Table 17). Road hierarchy helps to propose the potential vehicle and population flow. Like pavement width outcomes, a high-grade road means that largely autotransportation happens in this area. Low-grade passageways are for a small volume of auto-transportation.

\begin{tabular}{ccc}
\hline Grade & Width & Description \\
\hline 1 & $2.5 \mathrm{~m}-4 \mathrm{~m}$ & One-way street, single lane \\
2 & $4.5 \mathrm{~m}-6 \mathrm{~m}$ & One-way street, double lanes \\
3 & $6 \mathrm{~m}-9 \mathrm{~m}$ & One-way street, treble lanes \\
4 & $5 \mathrm{~m}-8 \mathrm{~m}$ & Two-way street, double lanes \\
5 & $10 \mathrm{~m}-12 \mathrm{~m}$ & Two-way street, four lanes \\
6 & $\geq 15 \mathrm{~m}$ & Two-way street, six lanes and above \\
\hline
\end{tabular}

Table 17. Road hierarchy

\subsubsection{Infrastructure}

Infrastructure describes the municipal service facilities in communities. The facilities include fire hydrants, plumbing wells, trash cans, as well as street 
furniture like benches, lamps, and street art. This variable consists of four grades from necessaries to accessories. Ample infrastructure means the community has a high level of artificial characteristics. The infrastructure with only basic facilities means a community is relatively close to the natural point of the transect matrix.

\begin{tabular}{cc}
\hline Grade & Description \\
\hline 1 & Fire hydrant, plumbing well, trash can \\
2 & Fire hydrant, plumbing well, trash can, substation box, border tree \\
3 & Fire hydrant, plumbing well, trash can, substation box, border tree, street \\
lamp, bench
\end{tabular}

Table 18. Infrastructure descriptions

\subsubsection{Depth-to-width ratio of streets}

The streets in Tsim Sha Tsui are always flanked by buildings on both sides, so a canyon-like environment emerges. The variable of depth-to-width of streets describes the urban canyon. It is defined by the width of the specific streets and the average building height along the street. Considering the definition of transect matrix in Chapter 2, the communities with higher the value of depthto-width ratio means they are closer to the artificial point of the transect matrix.

\subsubsection{Maximum height}

The maximum height of buildings is based on the current code of Building Height Restrictions of Tsim Sha Tsui Outline Zone Plan, Hong Kong. This variable partly reflects the skylines and artificial levels of particular areas.

Factors that define urban morphology include far more than those elements enumerated in the field study. This research chooses a series of representative 
form-related elements and limits the data types as above. Some of them are included in the existing urban regulation system; some work existing FormBased Code projects. After setting the field study by deciding the aims and identifying required information, the following section presents a workflow for collecting data.

\subsubsection{Data collection}

Physical data collection in Tsim Sha Tsui is targeted to identify the form-based zone types of the site and designate these zone types in the transect matrix. The research site has very limited land resources, the locals' words are "an inch of land, an inch of gold". Due to this condition, the transect matrix of Tsim Sha Tsui consists of urban core zones using the transect classification in Form-Based Code framework. Hong Kong's urban development does not follow the continuous transformation pattern of the standard transect matrix that generally transits from the loose countryside to highly compact downtown. Nearly all permitted land is densely occupied. If using the standard transect matrix as the land division principle, most of the plots and blocks of Tsim Sha Tsui will belong to the urban core zone. Hence the subdivision of the urban core zone is the key to redefining the transect matrix of Tsim Sha Tsui. To demonstrate the subdivision of the urban core zone, data is collected from sixty plots and blocks of seven areas (

Figure 55). The plots and blocks are numbered sequentially according to the current street network. The seven areas are:
A. Jordan Road Area
B. Hong Kong Observation Area
C. Nathan Road East Area
D. Kowloon Park Area
E. Nathan Road West Area
F. Canton Road Area 


\section{G. Hung Hom Area}

Using the Jordan Road Area as an example, the target streets and neighbourhoods are labelled on the base map (Table 19) before visiting the site. The study takes place over seven days. Five days are for data collection; the final two days are for data gathering and preparation. The values of the variables and photographic records are collected block by block. When the observational information and measured data has been collected, each plot in the research site gets a report page per Table 20. The report pages help to understand the existing urban morphology and establish the subdivision of the urban core zone of Tsim Sha Tsui.

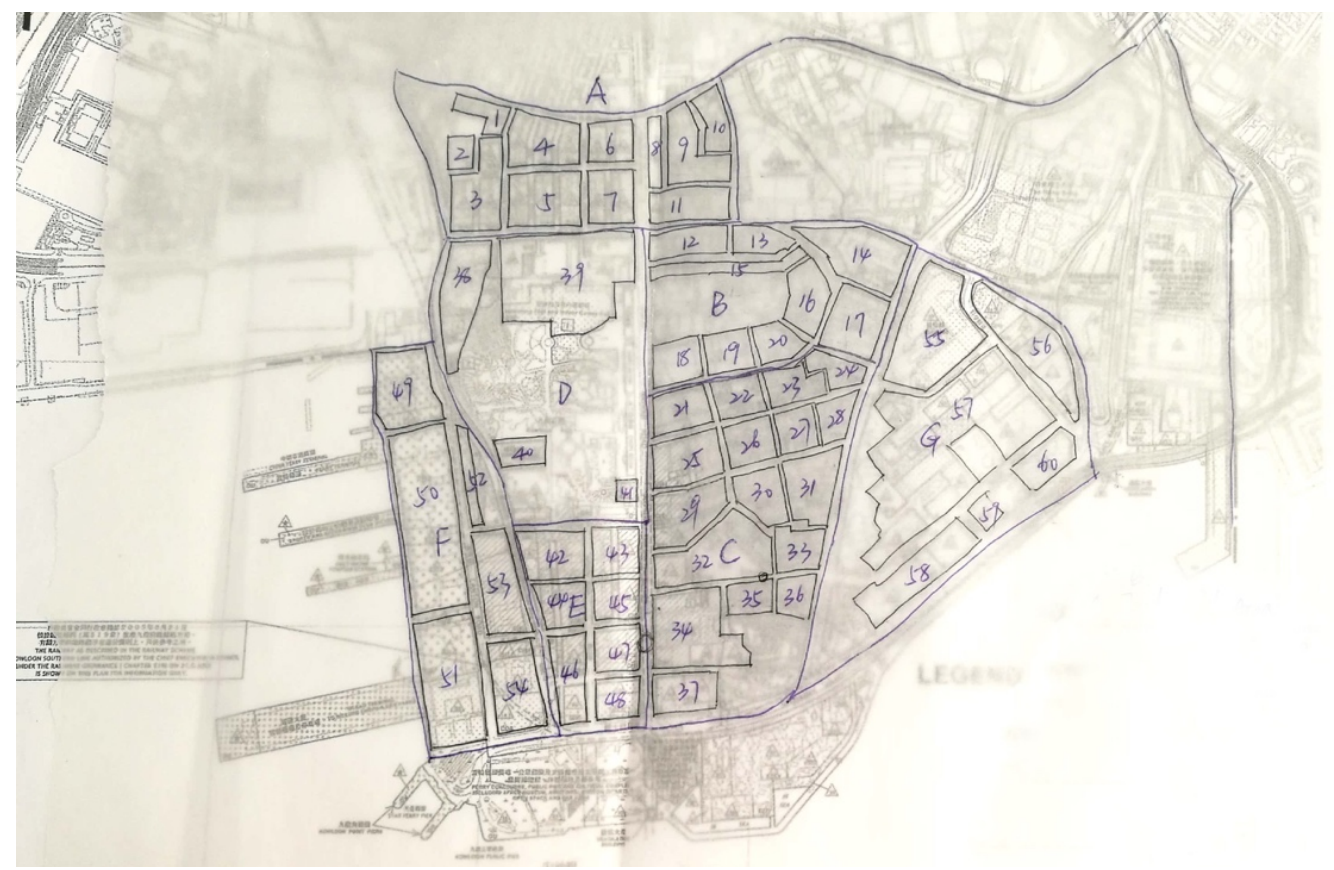

Figure 55. Field study areas in Tsim Sha Tsui 


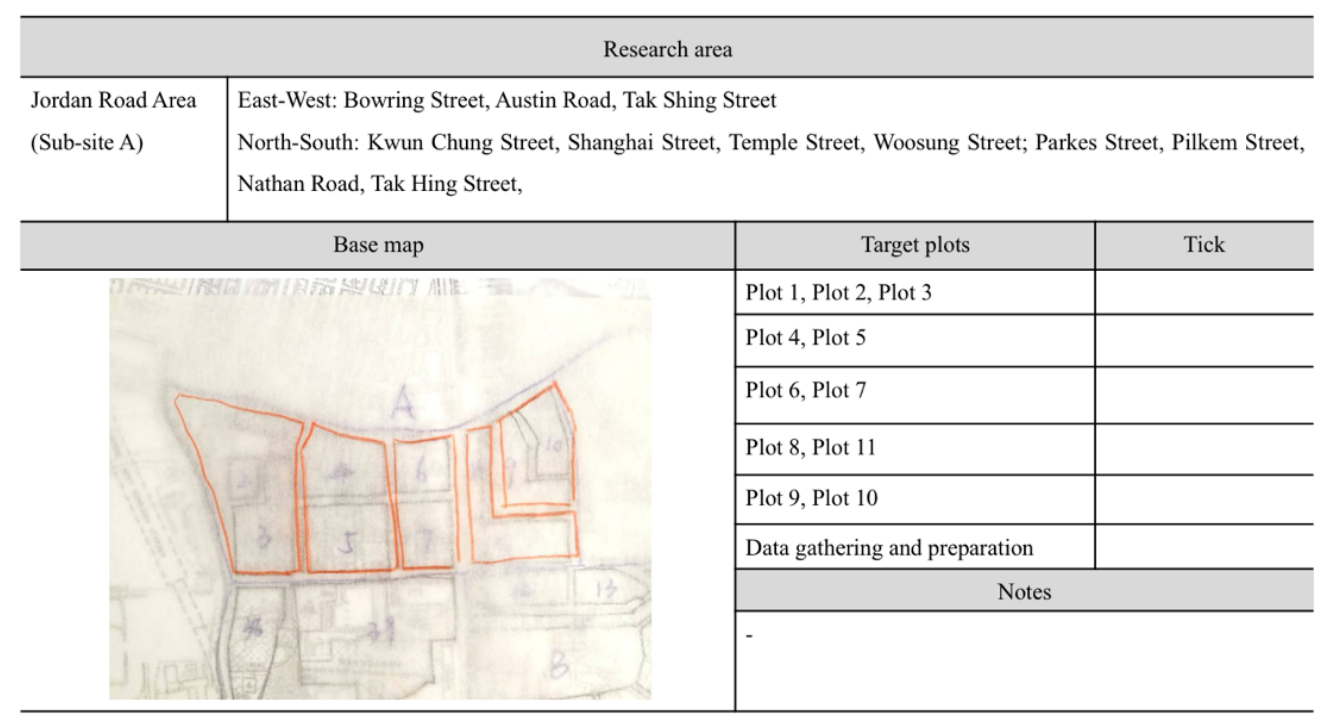

Table 19. Example of a data collection sheet of Jordan Road Area

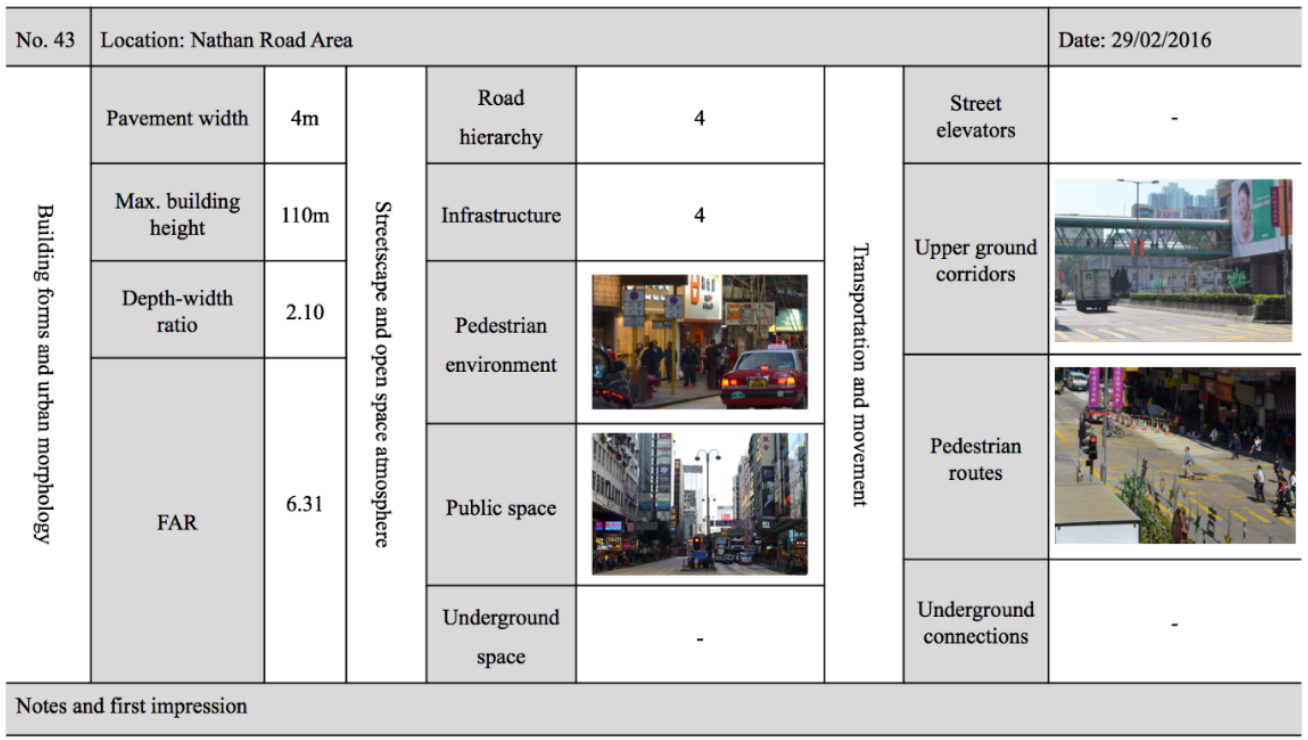

This plot contains upper-ground corridors to relieve pedestrian pressure at ground level. It offers a relatively walkable environment. The buildings are comprised of podium and main building; they accommodate a mix of commercial and residential functions. There is almost no large-scale public space. This plot belongs in the medium artificial to artificial level in the transect matrix of Form-Based Code.

Table 20. Example of a data collection report page

\subsubsection{Data compilation}

Data is compiled according to the report pages generated during data collection.

The research site consists of seven areas; each area has a series of report pages. 
Data compilation sheets are generated by integrating quantised variables, locations, plots, and an image of the report pages. The outcome of the data collection is a series of data compilation sheets representing different areas.

\subsubsection{Jordan Road Area}

Divided into eleven plots, the Jordan Road Area is located at the north point of Tsim Sha Tsui. The narrow streets and alleys provide space for the growth of small shops and restaurants. Jordan Metro station enables population flow into this area. The buildings are largely a mix of residential and commercial. . The data compilation result is shown in Table 21.

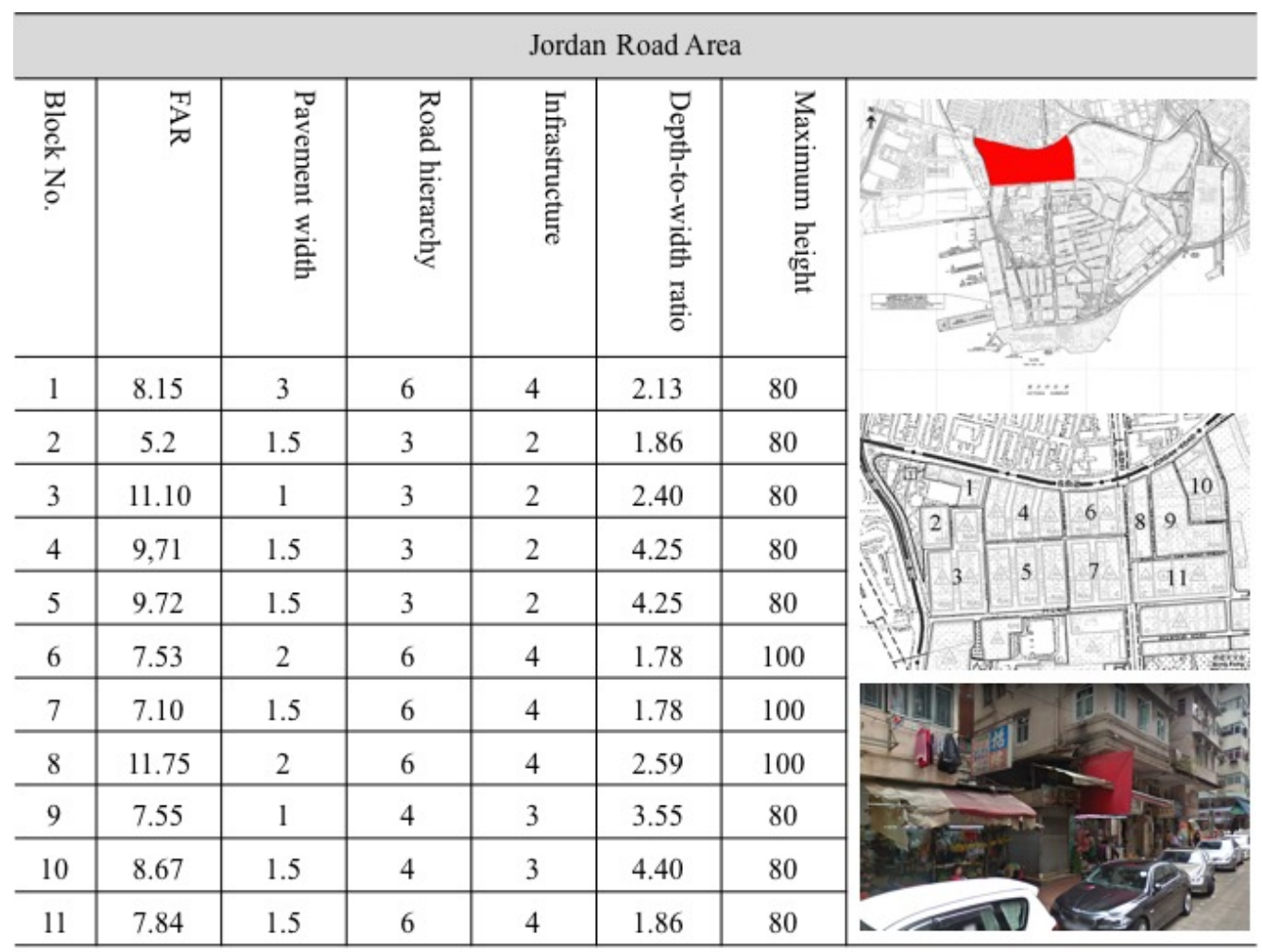

Table 21. Data compilation for Jordan Road Area

\subsubsection{Hong Kong Observation Area}

The urban space pattern of the Hong Kong Observation Area is approximately symmetrical. The core public space consists of the Hong Kong Observation, St 
Andrew's Church and the ambient town greenery. High-rise building groups semi-surround the open core. The data compilation results are presented in Table 22 .

\subsubsection{Nathan Road East Area}

The Nathan Road East area is one of the earliest sites of development in Tsim Sha Tsui because of the construction of the Kowloon-Canton Railway from 1904. Today, more than ten thousand people live and work in the area. Urban sites and many historical buildings are protected by government and society groups. As an historic urban centre of the Kowloon Peninsula, Nathan Road is lined with malls and restaurants. Numerous businesses, such as banks, hotels, shopping malls, and offices, are appearing in the high-rise storeys along Nathan Road. The Tsim Sha Tsui metro station is underground with eleven exits. Table 23 shows the data compilation sheet of Nathan Road East Area.

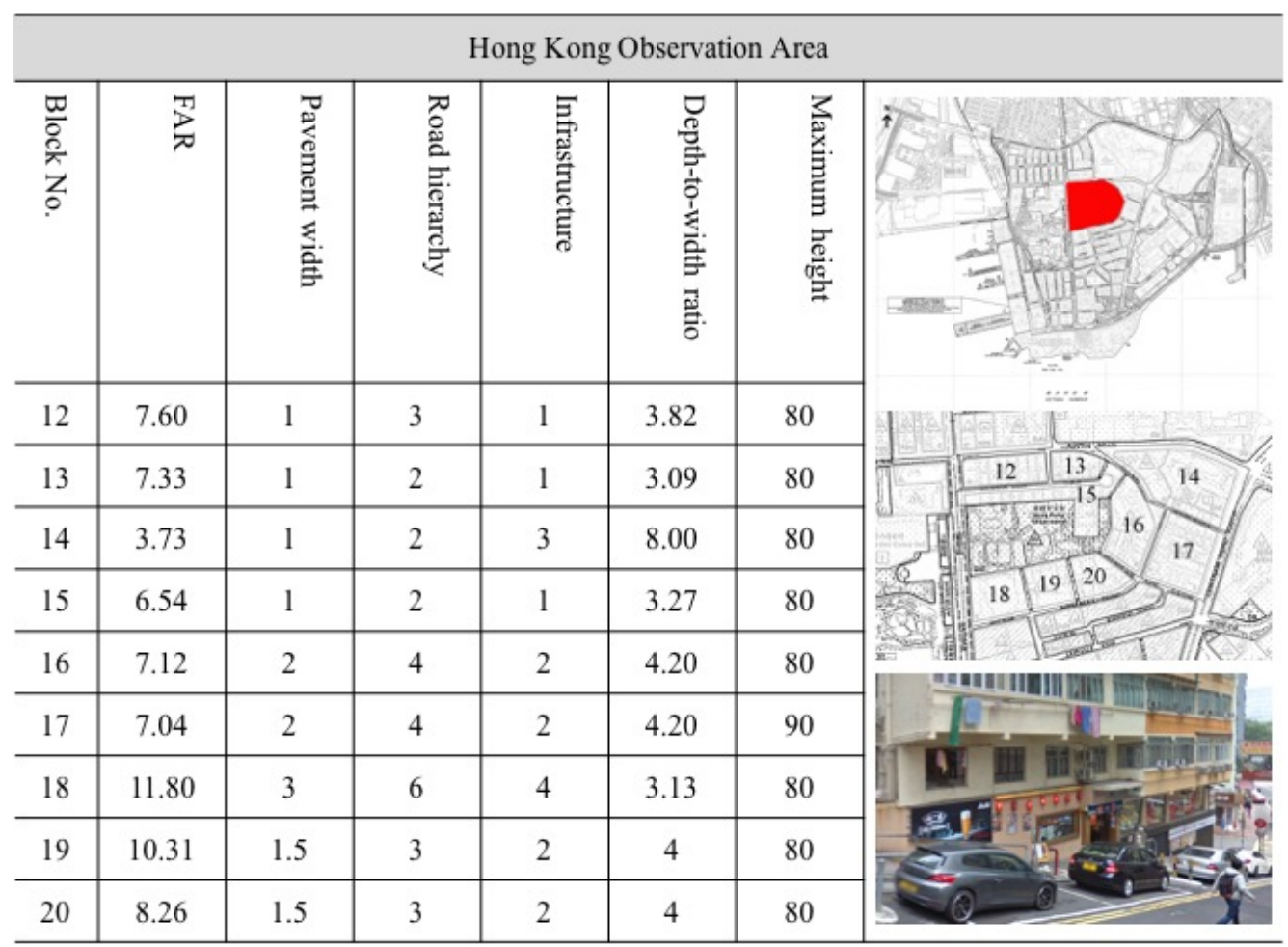

Table 22. Data compilation for Hong Kong Observation Area 


\subsubsection{Kowloon Park Area}

Kowloon Park is the largest open space in Tsim Sha Tsui. The Kowloon Swimming Pool, Sports Centre, Hong Kong Heritage Discovery, and Kowloon Mosque are all here. The park was formerly used by the Whitfield Barracks of the British Army and redeveloped as a park by the City Council who demolished more than 70 buildings in 1970 . This area has only four plots. The greenery makes them close to the natural point in the transect matrix. Table 24 shows the data compilation sheet of Kowloon Park Area.

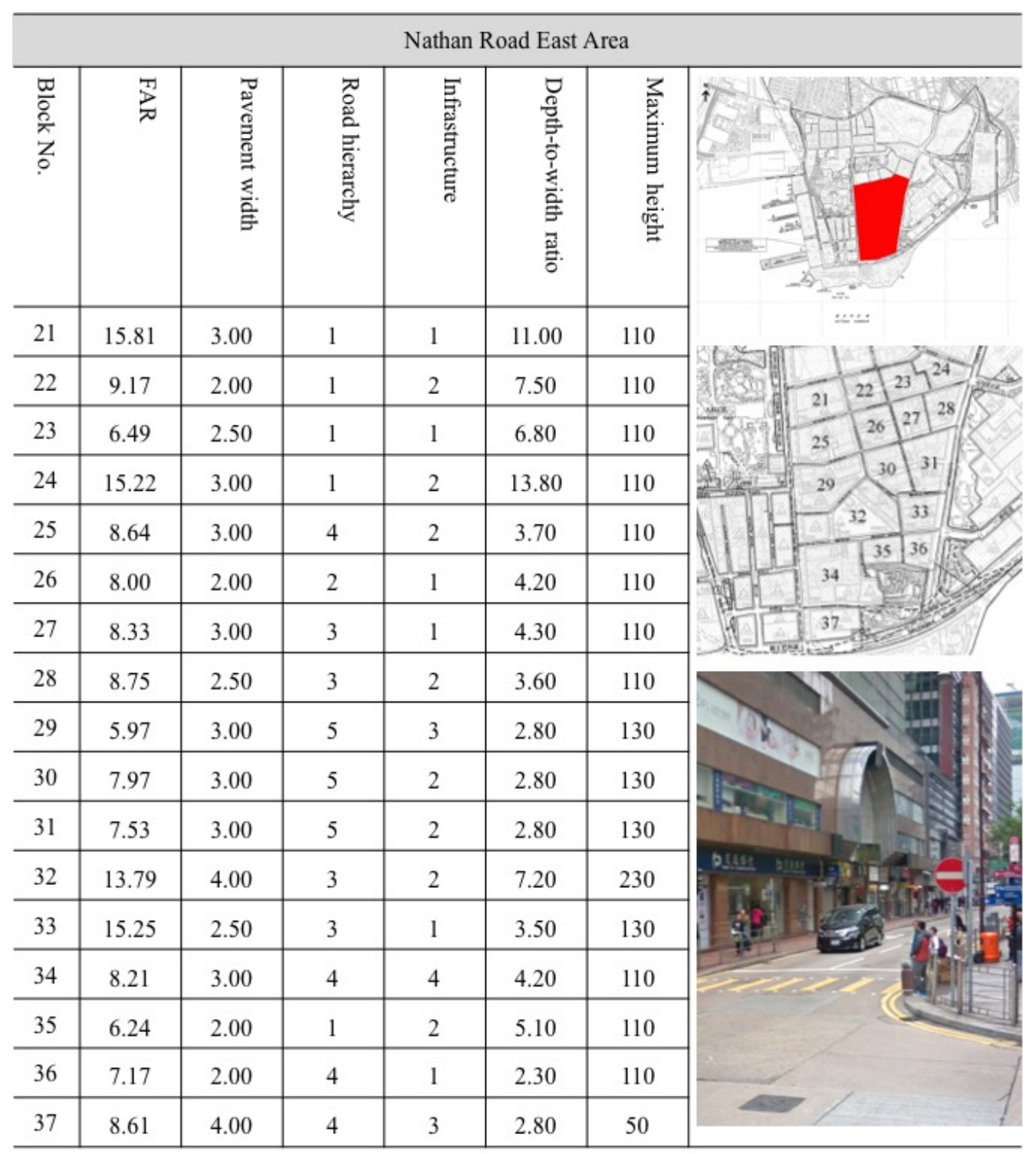

Table 23. Data compilation for Nathan Road East Area 


\subsubsection{Nathan Road West Area}

The urban forms and space characteristics of the Nathen Road West Area are similar to those of the Nathan Road East Area. Dividing the Nathan Road area into west and east part is to facilitate the data collection for the large community. Table 25 shows the data compilation sheet of Nathan Road West Area.

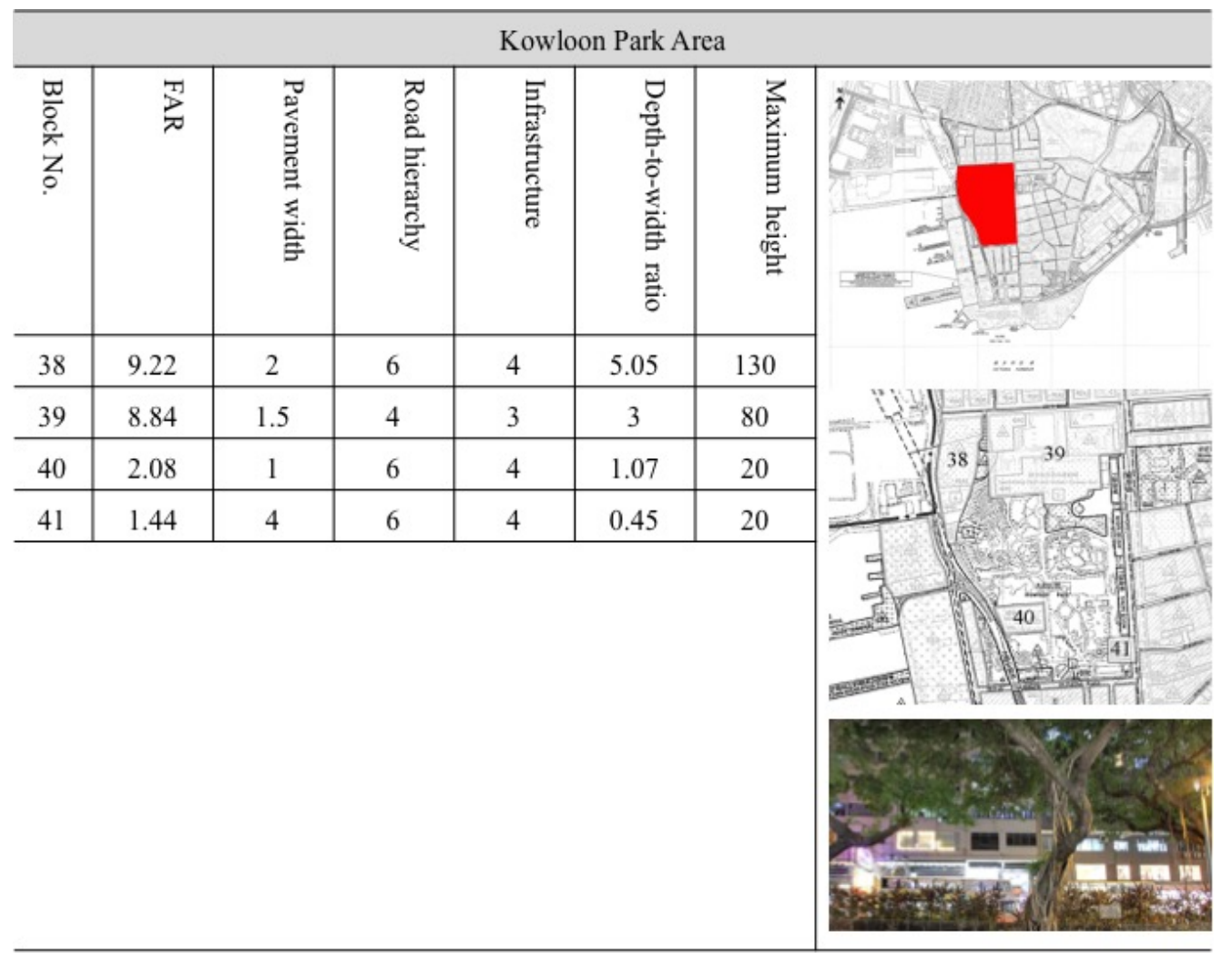

Table 24. Data compilation for Kowloon Park Area

\subsubsection{Canton Road Area}

Canton Road Area is surrounded by the Victoria Harbour Wharf for Kowloon to Macau Lane, Salisbury Road, and Kowloon Park Road. The China Ferry Terminal, Ocean Centre, Pacific Club Kowloon and a few super high buildings are located here. Modern shopping malls and business centres in Canton Road area make the skyline of Victoria Harbour splendid. Table 26 shows the data compilation sheet of Canton Road Area. 


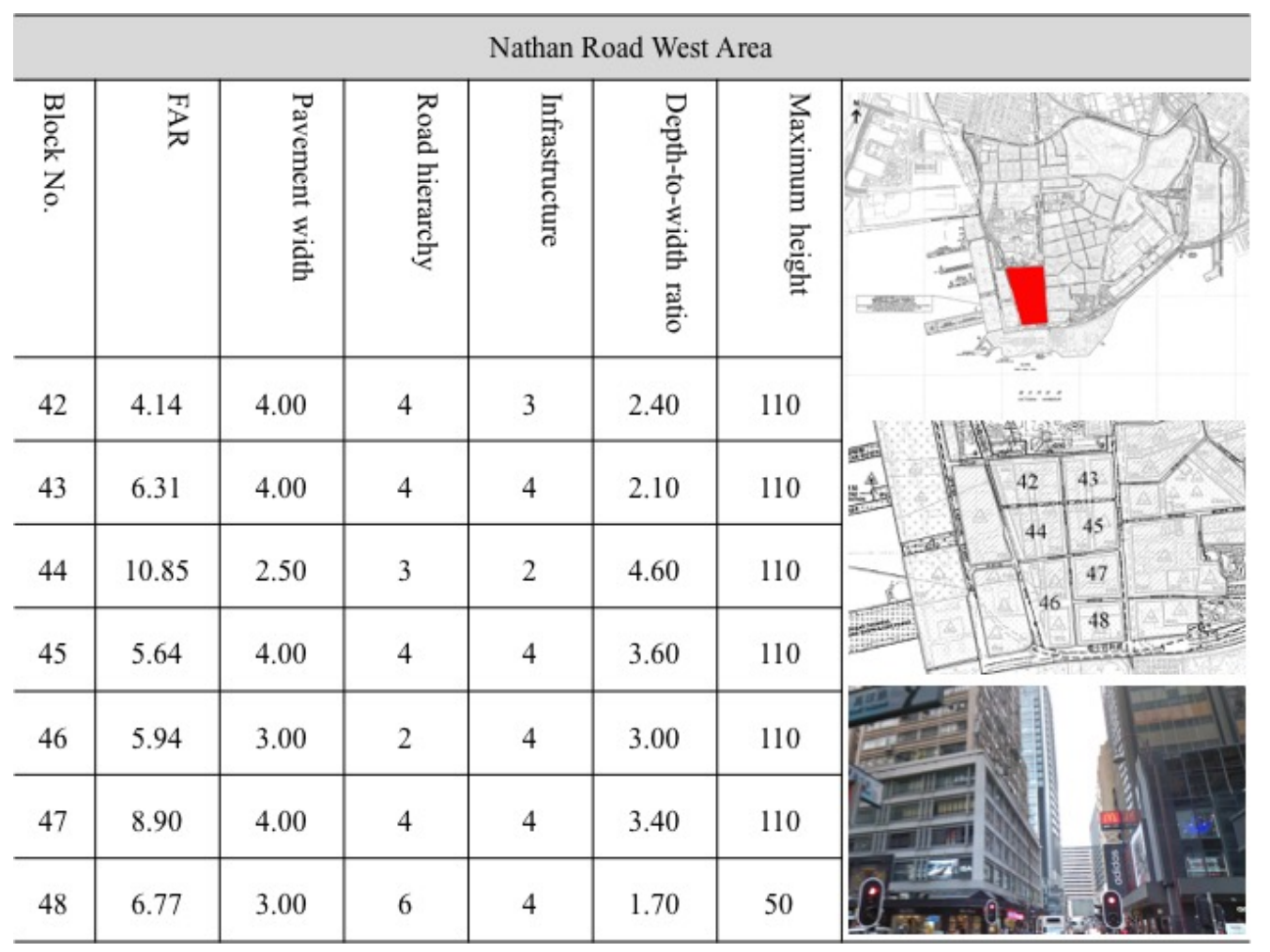

Table 25. Data compilation for Nathan Road West Area

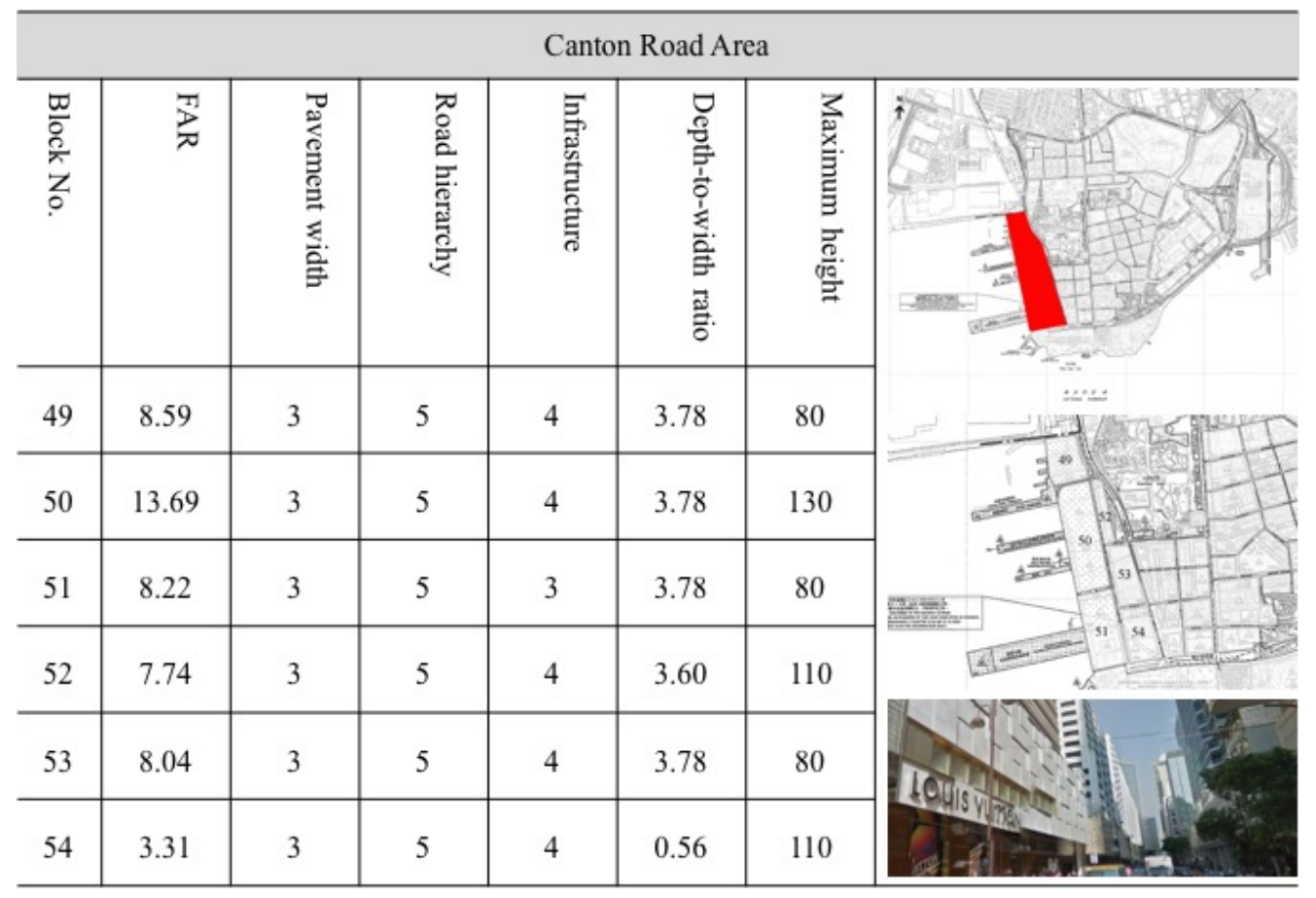

Table 26. Data compilation for Canton Road Area 


\section{2.3.7 Hung Hom Area}

Tsim Sha Tsui is enlarged by marine reclamation in response to the increasing population density. The Hung Hom Area is a newly-developed place created by pouring sand into the harbour. Compared with the old communities, this area has had relatively complete urban planning and regulation before its growth. Table 27 shows the data compilation sheet of Hung Hom Area.

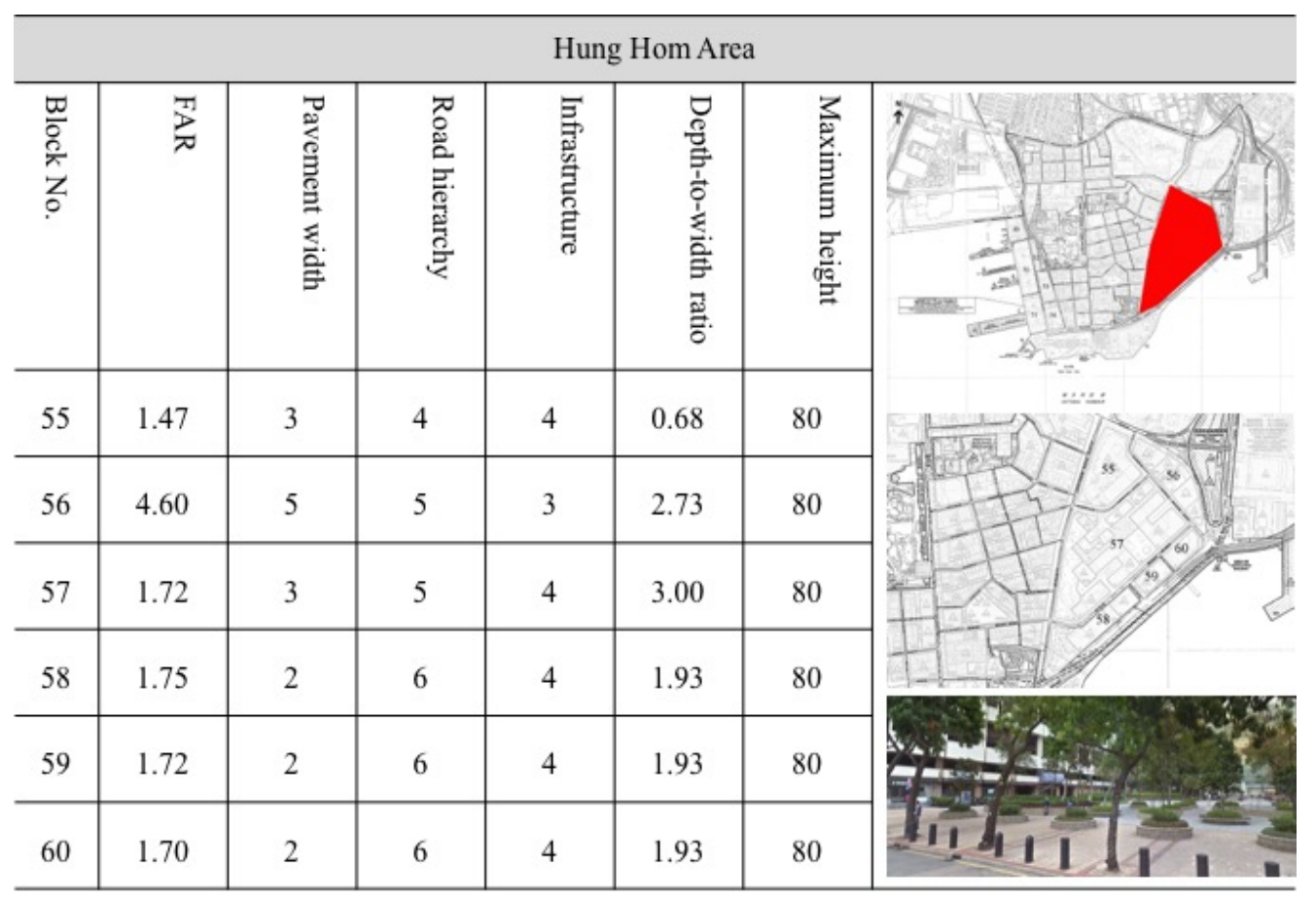

Table 27. Dara compilation for Hung Hom Area

The field study uses variables to describe the building and street forms of different areas. With a goal of redeveloping the transect matrix of Form-Based Code, the research chooses variables, including FAR, pavement width, infrastructure, depth-width ratio, and maximum height, as impact factors of zone type identification. The following section describes a statistical analysis to identify subdivisions of zone types in Form-Based Code's transect matrix. 


\subsection{Statistical analysis}

The data collected in the last segment is statistically analysed in this section. The analysis demonstrates a method of using variables to describe building and street forms in Form-Based Code. Min-Max Normalisation works to achieve dimensionless indicators. This section concludes with form-based zone subdivisions to create the transect matrix of Form-Based Code.

\subsubsection{Multi-factor system}

In the Form-Based Code of Tsim Sha Tsui, a series of variables work as factors to describe urban form. Zones with similar urban forms can be regarded as the same zone type. Identifying zone types is a complex process due to the various forces which may affect the results. A single factor cannot define the zone types in blocks and plots. Thus, the multi-factor system based on variable values is generated before creating the transect matrix. The factors are aligned with the variables including FAR, pavement width, road hierarchy, infrastructure, depthto-width ratio of streets, and maximum building height. The multi-factor system works to synthesise variables towards a reliable zone subdivision.

In the multi-factor system, data has different dimensions and orders of magnitude. Due to these varying attributes, the direct operation of those factors' values in statistical and mathematical approaches cannot correctly reflect the comprehensive influence of different forces. Directly using the original factors may inappropriately strengthen the role of the factors with high values and weaken the factors with low values. The additive operation cannot be processed between two factors, for example FAR and maximum building, due to their different value ranges and natures. FAR values normally range from 1 to 15 . Maximum building height values are generally in a range of 30 to 130 meters.

To ensure the reliable results from statistical analysis, these values must be standardised. Eliminating the factors' natures makes the impact forces 
comparable. It results in non-dimensional indexes so that the data can be conveniently calculated and compared (Figure 56).

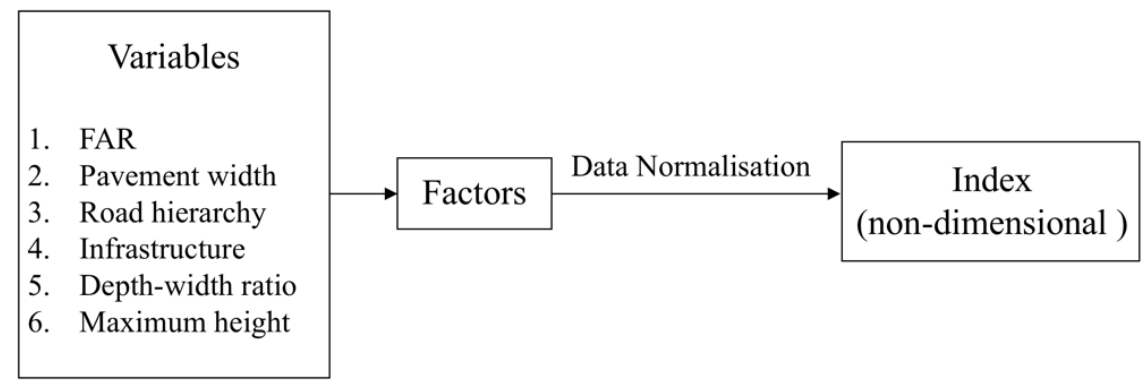

Figure 56. Relationships between variables, factors and data index

\subsubsection{Data normalisation}

The original factors need to be converted to a dimensionless index by implementing data normalisation methods. Each normalised index value is of the comparable magnitude, and can be operated and compared directly. Data normalisation includes two processes: Data-oriented processing and dimensionless processing. The former is for changing data properties. The latter is used for direct comparisons of factors with different natures. Data dimensionless processing is used for the statistical analysis of this research. There are many dimensionless processing methods for normalising data, including Z-Score Normalisation, Decimal Scaling Normalisation and MinMax Normalisation.

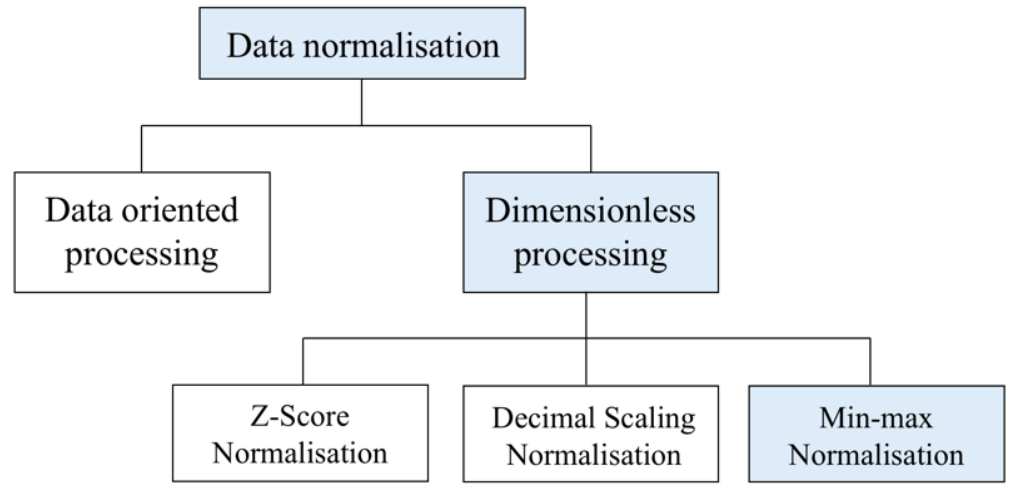

Figure 57. Method options of data normalisation 
Z-Score Normalisation requires the mean value of original data and standard deviation. It is suitable for a situation in which maximum and minimum data cannot be confirmed. Decimal Scaling Normalisation is suitable for cases where data has many decimals. Min-Max Normalisation requires the maximum and minimum value of each index type to be confirmed. This section uses the MinMax Normalisation method to normalise the data collected during field study (Figure 57). The method linearly transforms the original data into a closed interval $[0,1]$. The formula presents:

$$
\text { Normalized }(e i)=\frac{\mathrm{ei}-\mathrm{Emin}}{\operatorname{Emax}-\operatorname{Emin}}
$$

Where

Emin $=$ the min. Value of $\mathrm{E}$

Emax $=$ the max. Value of $\mathrm{E}$

If Emax is equal to Emin then Normalized ei is 0.5

Operating the formula above results in a series of non-dimensional indexes for each factor. The higher the index value is, the closer the plot or block to the artificial point of the Form-Based Code's transect matrix. The normalised indexes are presented in the columns of factors in Table 28. For instance, according to the table, Block 1's FAR index value is 0.47 , which is higher than Block 2 with a value of 0.26 . This indicates Block 1 has more urban space characteristics than Block 2 from the perspective of FAR. Block 1's maximum building height index value is 0.29 , equal to that of Block 2 . That means Block 1 and Block 2 present the same form characteristics from the perspective of maximum building height. It signifies that Block 1 and Block 2 belong to the same belt in the transect matrix of the Form-Based Code. 
Identifying a block's zone type and location in the transect matrix is a consequence of comprehensive analysis based on multiple indexes. Hence when obtaining dimensionless indexes, factors that affect zone type subdivision are summed to get values that represent a zone sequence in the transect matrix. The formula presents:

$$
\Sigma=\sum_{k=1}^{n} X k
$$

Where

$\mathrm{X}_{\mathrm{k}}=\mathrm{X}_{1}$

$\mathrm{n}=$ the number of the variables

For convenient comparison, the value of the zone sequence of each plot is divided by the number of factors to get an average value. Calculating the average zone sequence makes the index into a closed interval $[0,1]$. The formula presents:

$$
x=\frac{\sum_{k=1}^{n} X k}{\mathrm{n}}
$$

Where

$\mathrm{n}=$ the number of the variables

The consequence of data normalization is depicted in Table 28. The average value $(\mathrm{X})$ helps to reflect the form hierarchy in the transect matrix of FormBased Code. It defines the transect values of each block. If a block has high X value, it may contain the communities with artificial characteristics in the aspect of urban form and vice versa. 


\begin{tabular}{|c|c|c|c|c|c|c|c|c|}
\hline $\begin{array}{l}\frac{\varpi}{\circ} \\
\frac{\partial}{\lambda} \\
Z \\
\vdots\end{array}$ & $\sum_{d}^{\pi}$ & 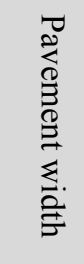 & 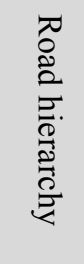 & 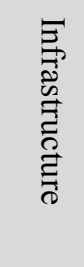 & 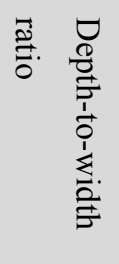 & 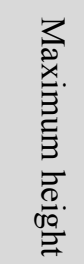 & $M$ & $x$ \\
\hline 1 & 0.47 & 0.50 & 1.00 & 1.00 & 0.13 & 0.29 & 3.39 & 0.57 \\
\hline 2 & 0.26 & 0.13 & 0.40 & 0.33 & 0.11 & 0.29 & 1.52 & 0.25 \\
\hline 3 & 0.67 & 0.00 & 0.40 & 0.33 & 0.15 & 0.29 & 1.84 & 0.31 \\
\hline 4 & 0.58 & 0.13 & 0.40 & 0.33 & 0.28 & 0.29 & 2.01 & 0.34 \\
\hline 5 & 0.58 & 0.13 & 0.40 & 0.33 & 0.28 & 0.29 & 2.01 & 0.34 \\
\hline 6 & 0.42 & 0.25 & 1.00 & 1.00 & 0.10 & 0.38 & 3.15 & 0.53 \\
\hline 7 & 0.39 & 0.13 & 1.00 & 1.00 & 0.10 & 0.38 & 3.00 & 0.50 \\
\hline 8 & 0.72 & 0.25 & 1.00 & 1.00 & 0.16 & 0.38 & 3.51 & 0.59 \\
\hline 9 & 0.43 & 0.00 & 0.60 & 0.67 & 0.23 & 0.29 & 2.22 & 0.37 \\
\hline 10 & 0.50 & 0.13 & 0.60 & 0.67 & 0.30 & 0.29 & 2.49 & 0.42 \\
\hline 11 & 0.45 & 0.13 & 1.00 & 1.00 & 0.11 & 0.29 & 2.98 & 0.50 \\
\hline 12 & 0.43 & 0.00 & 0.40 & 0.00 & 0.25 & 0.29 & 1.37 & 0.23 \\
\hline 13 & 0.41 & 0.00 & 0.20 & 0.00 & 0.20 & 0.29 & 1.10 & 0.18 \\
\hline 14 & 0.16 & 0.00 & 0.20 & 0.67 & 0.57 & 0.29 & 1.89 & 0.32 \\
\hline 15 & 0.35 & 0.00 & 0.20 & 0.00 & 0.21 & 0.29 & 1.05 & 0.18 \\
\hline 16 & 0.40 & 0.25 & 0.60 & 0.33 & 0.28 & 0.29 & 2.15 & 0.36 \\
\hline 17 & 0.39 & 0.25 & 0.60 & 0.33 & 0.28 & 0.33 & 2.18 & 0.36 \\
\hline 18 & 0.72 & 0.50 & 1.00 & 1.00 & 0.20 & 0.29 & 3.71 & 0.62 \\
\hline 19 & 0.62 & 0.13 & 0.40 & 0.33 & 0.27 & 0.29 & 2.04 & 0.34 \\
\hline 20 & 0.47 & 0.13 & 0.40 & 0.33 & 0.27 & 0.29 & 1.89 & 0.32 \\
\hline 21 & 1.00 & 0.50 & 0.00 & 0.00 & 0.79 & 0.43 & 2.72 & 0.45 \\
\hline 22 & 0.54 & 0.25 & 0.00 & 0.33 & 0.53 & 0.43 & 2.08 & 0.35 \\
\hline 23 & 0.35 & 0.38 & 0.00 & 0.00 & 0.48 & 0.43 & 1.64 & 0.27 \\
\hline 24 & 0.96 & 0.50 & 0.00 & 0.33 & 1.00 & 0.43 & 3.22 & 0.54 \\
\hline 25 & 0.50 & 0.50 & 0.60 & 0.33 & 0.24 & 0.43 & 2.60 & 0.43 \\
\hline 26 & 0.46 & 0.25 & 0.20 & 0.00 & 0.28 & 0.43 & 1.62 & 0.27 \\
\hline 27 & 0.48 & 0.50 & 0.40 & 0.00 & 0.29 & 0.43 & 2.10 & 0.35 \\
\hline 28 & 0.51 & 0.38 & 0.40 & 0.33 & 0.24 & 0.43 & 2.29 & 0.38 \\
\hline 29 & 0.32 & 0.50 & 0.80 & 0.67 & 0.18 & 0.52 & 2.99 & 0.50 \\
\hline 30 & 0.45 & 0.50 & 0.80 & 0.33 & 0.18 & 0.52 & 2.78 & 0.46 \\
\hline 31 & 0.42 & 0.50 & 0.80 & 0.33 & 0.18 & 0.52 & 2.75 & 0.46 \\
\hline 32 & 0.86 & 0.75 & 0.40 & 0.33 & 0.51 & 1.00 & 3.85 & 0.64 \\
\hline 33 & 0.96 & 0.38 & 0.40 & 0.00 & 0.23 & 0.52 & 2.49 & 0.42 \\
\hline 34 & 0.47 & 0.50 & 0.60 & 1.00 & 0.28 & 0.43 & 3.28 & 0.55 \\
\hline 35 & 0.33 & 0.25 & 0.00 & 0.33 & 0.35 & 0.43 & 1.69 & 0.28 \\
\hline 36 & 0.40 & 0.25 & 0.60 & 0.00 & 0.14 & 0.43 & 1.82 & 0.30 \\
\hline 37 & 0.50 & 0.75 & 0.60 & 0.67 & 0.18 & 0.14 & 2.84 & 0.47 \\
\hline 38 & 0.54 & 0.25 & 1.00 & 1.00 & 0.34 & 0.52 & 3.65 & 0.61 \\
\hline 39 & 0.51 & 0.13 & 0.60 & 0.67 & 0.19 & 0.29 & 2.39 & 0.40 \\
\hline 40 & 0.04 & 0.00 & 1.00 & 1.00 & 0.05 & 0.00 & 2.09 & 0.35 \\
\hline 41 & 0.00 & 0.75 & 1.00 & 1.00 & 0.00 & 0.00 & 2.75 & 0.46 \\
\hline 42 & 0.19 & 0.75 & 0.60 & 0.67 & 0.15 & 0.43 & 2.79 & 0.47 \\
\hline 43 & 0.34 & 0.75 & 0.60 & 1.00 & 0.12 & 0.43 & 3.24 & 0.54 \\
\hline 44 & 0.65 & 0.38 & 0.40 & 0.33 & 0.31 & 0.43 & 2.50 & 0.42 \\
\hline 45 & 0.29 & 0.75 & 0.60 & 0.67 & 0.24 & 0.43 & 2.98 & 0.50 \\
\hline
\end{tabular}




\begin{tabular}{r|l|l|l|l|l|l|l|r}
\hline 46 & 0.31 & 0.50 & 0.20 & 1.00 & 0.19 & 0.43 & 2.63 & 0.44 \\
\hline 47 & 0.52 & 0.75 & 0.60 & 1.00 & 0.22 & 0.43 & 3.52 & 0.59 \\
\hline 48 & 0.37 & 0.50 & 1.00 & 1.00 & 0.09 & 0.14 & 3.10 & 0.52 \\
\hline 49 & 0.50 & 0.50 & 0.80 & 1.00 & 0.25 & 0.29 & 3.34 & 0.56 \\
\hline 50 & 0.85 & 0.50 & 0.80 & 1.00 & 0.25 & 0.52 & 3.92 & 0.65 \\
\hline 51 & 0.47 & 0.50 & 0.80 & 0.67 & 0.25 & 0.29 & 2.98 & 0.50 \\
\hline 52 & 0.44 & 0.50 & 0.80 & 1.00 & 0.24 & 0.43 & 3.41 & 0.57 \\
\hline 53 & 0.46 & 0.50 & 0.80 & 1.00 & 0.25 & 0.29 & 3.30 & 0.55 \\
\hline 54 & 0.13 & 0.50 & 0.80 & 1.00 & 0.01 & 0.43 & 2.87 & 0.48 \\
\hline 55 & 0.00 & 0.50 & 0.60 & 1.00 & 0.02 & 0.29 & 2.41 & 0.40 \\
\hline 56 & 0.22 & 1.00 & 0.80 & 0.67 & 0.17 & 0.29 & 3.15 & 0.53 \\
\hline 57 & 0.02 & 0.50 & 0.80 & 1.00 & 0.19 & 0.29 & 2.80 & 0.47 \\
\hline 58 & 0.02 & 0.25 & 1.00 & 1.00 & 0.11 & 0.29 & 2.67 & 0.45 \\
\hline 59 & 0.02 & 0.25 & 1.00 & 1.00 & 0.11 & 0.29 & 2.67 & 0.45 \\
\hline 60 & 0.02 & 0.25 & 1.00 & 1.00 & 0.11 & 0.29 & 2.67 & 0.45 \\
\hline
\end{tabular}

Table 28. Data normalisation

\subsubsection{Zone type subdivision}

The average index value $\mathrm{X}$ is regarded as the comprehensive transect index in this research. The comprehensive transect index decides the hierarchy of blocks in the transect matrix of Tsim Sha Tsui. Dividing the closed interval $[0,1]$ equally into 10 grades creates ten intervals [0.00, 0.09], [0.10, 0.19], [0.20, 0.29], [0.30, 0.39], [0.40, 0.49], [0.50, 0.59], [0.60, 0.69], [0.70, 0.79], [0.80, 0.89], $[0.9,1.00]$ within the major of 0.1 . Plugging the comprehensive transect index of each block into the internals indicates that there are six groups in the range of 0.1 to 0.7 (Figure 58).

With the exception of Kowloon Park, Signal Mountain Park and some relatively large-scale green places, all of the urban space of Tsim Sha Tsui belongs to the urban core zone (T6) based on the standard transect matrix of Form-Based Code. Through grouping the blocks with various comprehensive transect indexes, T6 is divided into six subdivisions. The comprehensive transect index's value represents the artificial level of each block. The higher the value is, the closer the block is to the artificial point of the transect matrix. The lower the value is, the closer the block is to the natural point. For example, the $\mathrm{X}$ value of Block 5 is 0.34 , which belongs to the closed interval [0.30, 0.39]. The $\mathrm{X}$ value of Block 
6 is 0.53. It is higher than Block 5. This means that Block 6 is closer to the artificial point and Block 5 is closer to the natural point in the transect matrix. According to Form-Based Code's standard transition (Figure 59). Block 6 reflects more urban characteristics than Block 5.

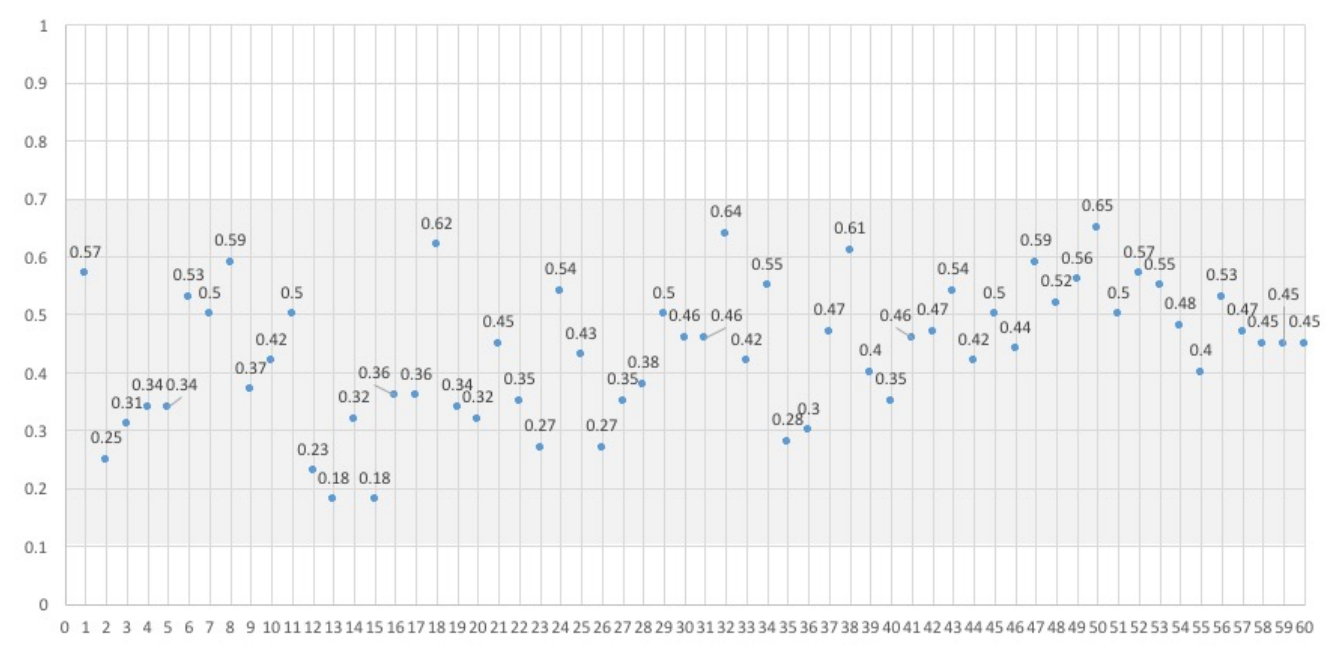

Figure 58. Grouping transect index

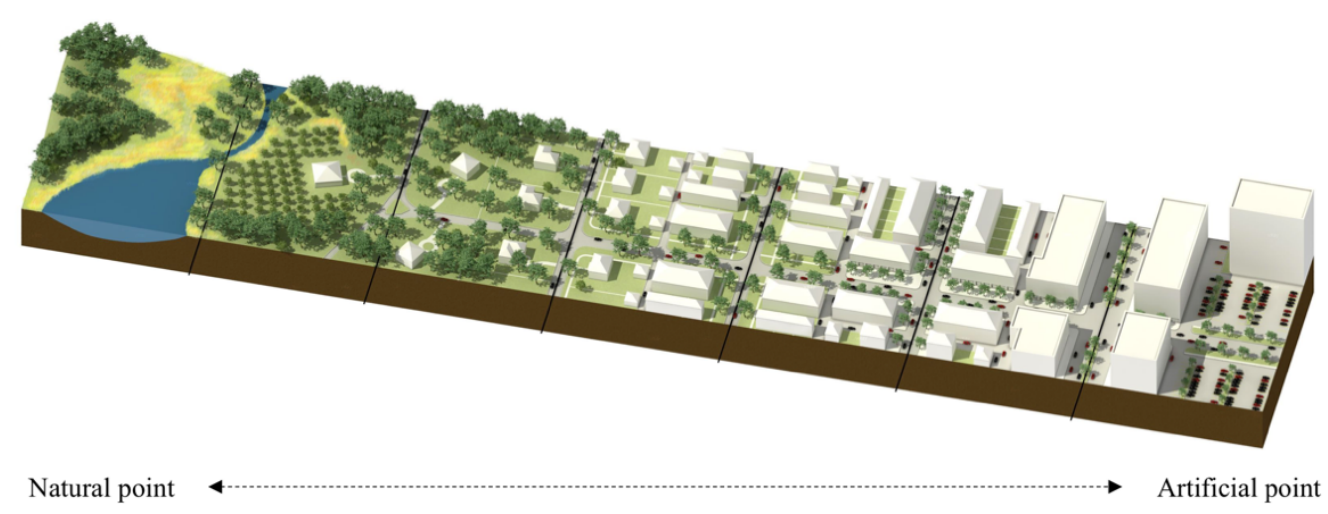

Figure 59. Standard transition from natural to artificial, DPZ, 2015

Based on the classification of the comprehensive transect index in Figure 58, the subdivision of urban core zones in Tsim Sha Tsui includes T6-1, T6-2, T63, T6-4, T6-5, and T6-6 from natural to artificial. Each invested block has a 
specific zone subdivision type. For instance, Block 5 can be defined as the third subdivision zone of T6, and expressed as Urban Core Zone Subtype 3 (T6-3). Table 29 presents all blocks in Tsim Sha Tsui and their corresponding zone types. The proportion of blocks belonging to T6-4 is $30 \%$. This percentage is higher than any other zone type. The blocks belonging to T6-1 and T6-6 are proportionally least, at 3\% and $7 \%$. Most plots and blocks have obvious artificial characteristics.

\begin{tabular}{|c|c|c|c|c|c|c|c|c|c|c|c|c|c|c|c|c|c|c|c|}
\hline \multicolumn{2}{|c|}{$[0.00,0.09]$} & \multicolumn{2}{|c|}{$[0.10,0.19]$} & \multicolumn{2}{|c|}{$[0.20,0.29]$} & \multicolumn{2}{|c|}{$[0.30,0.39]$} & \multicolumn{2}{|c|}{$[0.40,0.49]$} & \multicolumn{2}{|c|}{$[0.50,0.59]$} & \multicolumn{2}{|c|}{$[0.60,0.69]$} & \multicolumn{2}{|c|}{$[0.70,0.79]$} & \multicolumn{2}{|c|}{$[0.80,0.89]$} & \multicolumn{2}{|c|}{$[0.9,1.00]$} \\
\hline $\begin{array}{l}\frac{\omega}{0} \\
\frac{0}{\hat{\lambda}} \\
\underline{\partial}\end{array}$ & 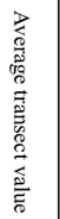 & $\begin{array}{l}\frac{\omega}{0} \\
\frac{0}{\hat{x}} \\
z \\
0\end{array}$ & 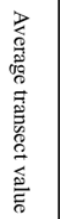 & $\begin{array}{l}\frac{\omega}{\circ} \\
\frac{0}{\hat{\lambda}} \\
z \\
0\end{array}$ & 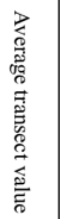 & $\begin{array}{l}\frac{\omega}{0} \\
\frac{0}{\hat{\lambda}} \\
z \\
0\end{array}$ & 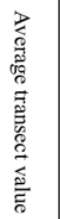 & $\begin{array}{l}\frac{w}{0} \\
\frac{0}{\hat{\lambda}} \\
\frac{\partial}{0}\end{array}$ & 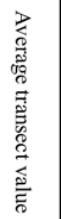 & $\begin{array}{l}\frac{\square}{0} \\
\frac{0}{\hat{x}} \\
\underline{0}\end{array}$ & 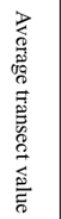 & $\begin{array}{l}\frac{\omega}{0} \\
\frac{0}{\hat{x}} \\
\underline{0}\end{array}$ & 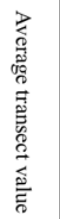 & $\begin{array}{l}\frac{w}{0} \\
\frac{0}{\hat{a}} \\
\underline{0}\end{array}$ & 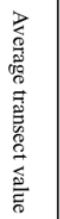 & $\begin{array}{l}\frac{w}{\circ} \\
\frac{0}{\hat{a}} \\
\frac{\partial}{0}\end{array}$ & 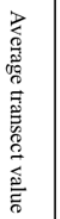 & $\begin{array}{l}\frac{\square}{0} \\
\frac{0}{\lambda} \\
\frac{\partial}{0}\end{array}$ & 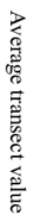 \\
\hline- & - & 13 & 0.18 & 2 & 0.25 & 3 & 0.31 & 10 & 0.42 & 1 & 0.57 & 18 & 0.62 & - & - & - & - & - & - \\
\hline - & - & 15 & 0.18 & 12 & 0.23 & 4 & 0.34 & 21 & 0.45 & 6 & 0.53 & 32 & 0.64 & - & - & - & - & - & - \\
\hline- & - & - & - & 23 & 0.27 & 5 & 0.34 & 25 & 0.43 & 7 & 0.50 & 38 & 0.61 & - & - & - & - & - & - \\
\hline- & - & - & - & 26 & 0.27 & 9 & 0.37 & 30 & 0.46 & 8 & 0.59 & 50 & 0.65 & - & - & - & - & - & - \\
\hline- & - & - & - & 35 & 0.28 & 14 & 0.32 & 31 & 0.46 & 11 & 0.50 & - & - & - & - & - & - & - & - \\
\hline- & - & - & - & - & - & 16 & 0.36 & 33 & 0.42 & 24 & 0.54 & - & - & - & - & - & - & - & - \\
\hline- & - & - & - & - & - & 17 & 0.36 & 37 & 0.47 & 29 & 0.50 & - & - & - & - & - & - & - & - \\
\hline- & - & - & - & - & - & 19 & 0.34 & 39 & 0.40 & 34 & 0.55 & - & - & - & - & - & - & - & - \\
\hline- & - & - & - & - & - & 20 & 0.32 & 41 & 0.46 & 43 & 0.54 & - & - & - & - & - & - & - & - \\
\hline- & - & - & - & - & - & 22 & 0.35 & 42 & 0.47 & 45 & 0.50 & - & - & - & - & - & - & - & - \\
\hline- & - & - & - & - & - & 27 & 0.35 & 44 & 0.42 & 47 & 0.59 & - & - & - & - & - & - & - & - \\
\hline- & - & - & - & - & - & 28 & 0.38 & 46 & 0.44 & 48 & 0.52 & - & - & - & - & - & - & - & - \\
\hline- & - & - & - & - & - & 36 & 0.30 & 54 & 0.48 & 49 & 0.56 & - & - & - & - & - & - & - & - \\
\hline- & - & - & - & - & - & 40 & 0.35 & 55 & 0.40 & 51 & 0.50 & - & - & - & - & - & - & - & - \\
\hline- & - & - & - & - & - & 45 & 0.32 & 57 & 0.47 & 52 & 0.57 & - & - & - & - & - & - & - & - \\
\hline- & - & - & - & - & - & - & - & 58 & 0.45 & 53 & 0.55 & - & - & - & - & - & - & - & - \\
\hline- & - & - & - & - & - & - & - & 59 & 0.45 & 56 & 0.53 & - & - & - & - & - & - & - & - \\
\hline- & - & - & - & - & - & - & - & 60 & 0.45 & - & - & - & - & - & - & - & - & - & - \\
\hline 0 & - & 2 & - & 5 & - & 14 & - & 18 & - & 17 & - & 4 & - & 0 & - & 0 & - & 0 & - \\
\hline
\end{tabular}

Table 29. Blocks of Tsim Sha Tsui and the classification of the average transect value of each block

Transect types in the Form-Based Code framework describes the characteristics of form from natural to artificial as Figure 59 shows. The zone types of Tsim 
Sha Tsui have been identified by understanding the existing urban morphology and using rational mathematical calculation. Applying the outcomes of the zone type subdivision, the following section explores extending the transect matrix with graphics and illustrations according to the urban regulation system provided by Form-Based Code. 


\subsection{Transect matrix extension}

This section extends the transect matrix of Form-Based Code by augmenting zone types and subtypes. It aims to provide an innovative mode of transect matrix generation suited to the volumetric morphology of high-density cities. The mode consists of a series of zone types, including ground level, underground level and upper ground level. The section concludes the development and presentation of a volumetric transect matrix with graphical descriptions.

\subsubsection{Volumetric mode: ground}

The transect matrix provides zone types for zoning and urban regulation. A standard transect matrix contains zone types from natural to urban core. Based on the designation of zone types on a zoning map, specific regulations, such as setbacks, envelope sizes and building heights, can be generated for each zone type. Thus, zone types in the transect matrix directly affect the layouts of a Form-Based Code and its in-context application. Due to the high level of urbanisation, most of the blocks and plots of Tsim Sha Tsui belong to the urban core zone. Sharing the same regulations between differentiated blocks deviates from the targets of Form-Based Code. It is essential to provide subdivisions of the urban core zone in Tsim Sha Tsui's transect matrix.

According to the physical data collection and statistical analysis, the transect matrix involves a natural zone, an urban core zone and six subtypes of urban core zone. Natural zone (T1) describes a place without any exploitation or human intervention in Form-Based Code. There is no natural zone substantial in the research site, nor even in the whole of Hong Kong. Large-scale parks and gardens are regarded as natural zones in this research. The subdivision of the urban core zone is a result of understanding the existing urban space and the factors which may affect urban form. Form-Based Code uses illustrations and graphics to describe its components. The standard transect matrix is developed 
in a graphical format pattern. Analogously, the transect matrix of Tsim Sha Tsui can be described as Figure 60 with the natural zone (T1) and the six subtypes of urban core zone (T6). It consists of three rows. The first row is the elevation of each zone type. Although building height limitation is the clearest observation that can be derived from the figures, the transect matrix is an outcome of the combined consideration of FAR, pavement width, road hierarchy, infrastructure, depth-width ratio, and maximum building height. The second row is the plan of each zone type. It suggests possible street forms with the information of street width, greenery and envelopes. The third row is the zone titles.
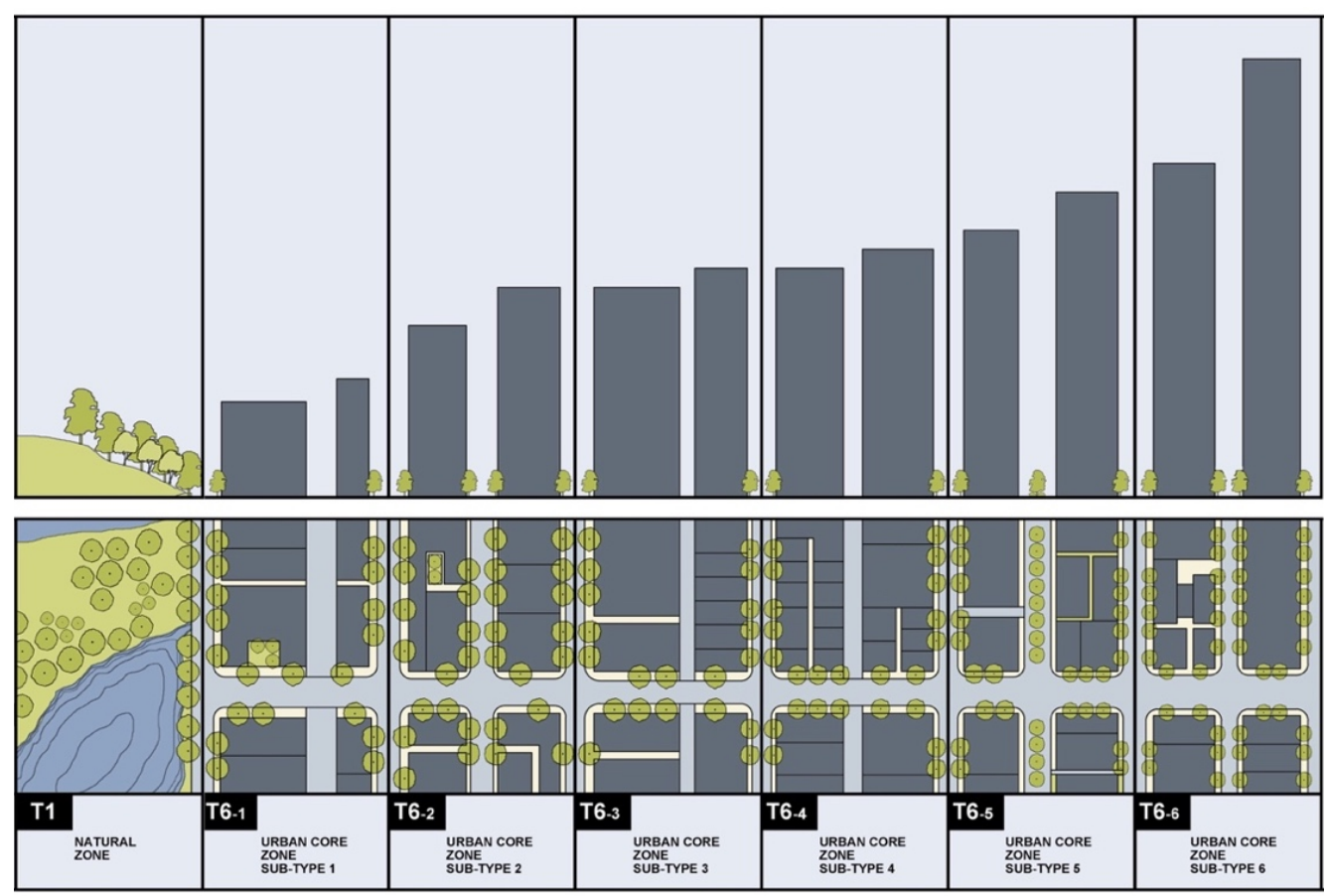

Figure 60. Transect matrix of ground level

Each zone type contains a general description about the urban space's characteristics. As Figure 61, these general descriptions are the principles of generating detailed regulations for buildings and streets. Land use works as a secondary consideration in Form-Based Code, contributing to morphology shaping and urban space usage. Hence land use is also included in the general descriptions at the stage of developing the transect matrix. 


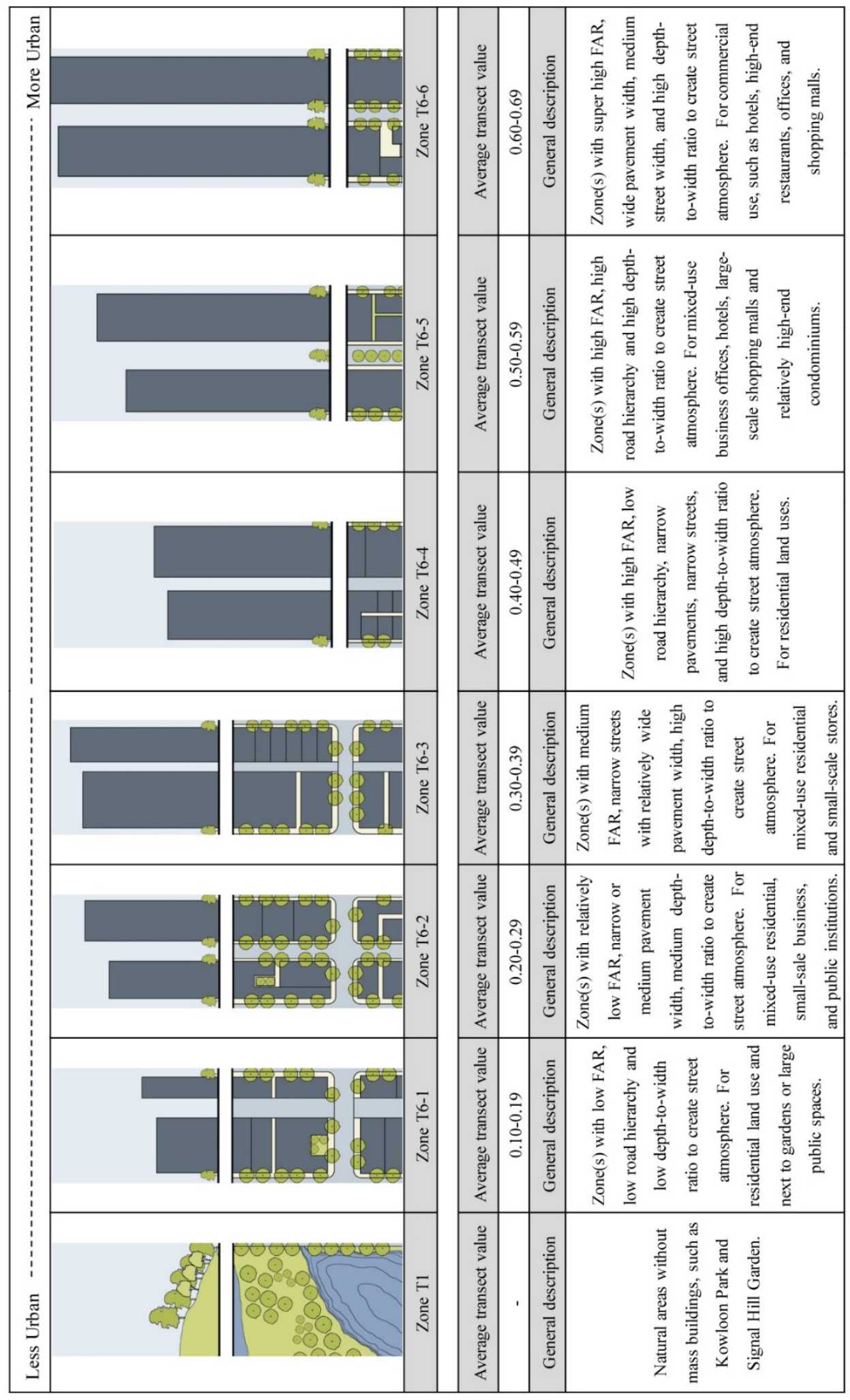

Figure 61. Zone types and descriptions 
Ground, underground and upper ground spaces structure the volumetric morphology in Tsim Sha Tsui. Subdivisions of the urban core zone provide a transect matrix for ground space. This research argues that underground and upper ground space should also be considered in Form-Based Code. The following section explores the multi-ground mode of the transect matrix to extend Form-Based Code into a volumetric urban situation.

\subsubsection{Volumetric mode: underground}

A transect matrix for ground level has been generated based on the standard transect matrix template. It describes zone types and embeds those zone types into urban regulation. This section pursues a transect matrix for underground space. It concludes with a transect matrix which classifies underground zone types and facilitates underground urban regulation.

A standard Form-Based Code works for a built environment with buildings and streets on the ground level. Underground urban regulation cannot be fully formbased. It is not accurate to say that underground space consists of buildings and streets so completely copying the transect matrix on the ground level is inappropriate. Therefore, identifying the degree of artificiality of underground space requires a comprehensive consideration of forms, functions, and transportation. For example, if an underground area contains subway transfer platforms, underground shopping streets, malls, indoor sports venues, and parking places on multiple levels, this area is "urban". It should be located at the artificial point of the underground transect matrix. If an area only contains the underground street-crossing function to relieve above-ground transportation pressure, it is "less urban" and closer to the natural point in the transect matrix.

Tsim Sha Tsui contains three subway stations, including Tsim Sha Tsui Station, Tsim Sha Tsui East Station and Jordan Station. As Kowloon Peninsula's main subway stations, they are equipped with five to twelve entrances, underground 
commercial space and civil air defence facilities. The underground space of Tsim Sha Tsui is built around the three stations and connected to surrounding buildings such as shopping malls and office towers. Factors that affect the classification of underground zones in Tsim Sha Tsui are various, including the number of underground floors, the number of trains, public space usage, infrastructure, and connectivity to surrounding buildings. Figure 62 presents an example of an underground transect matrix in a volumetric mode. The first row describes plans of the ground level using dash lines to label the boundary of underground areas. The second row indicates the sections of underground space. The third row gives the title of each zone type.

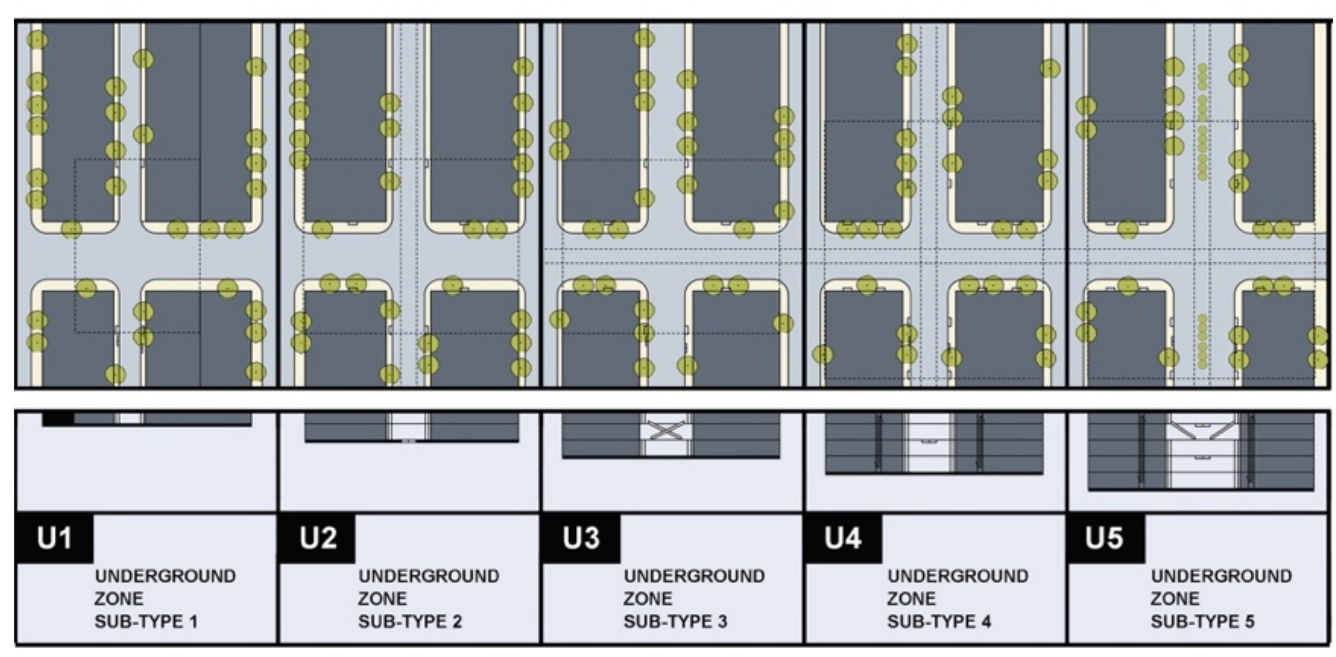

Figure 62. Transect matrix of underground level

According to the factors listed above, the underground transect matrix has five zone types. Underground zone sub-type 1 (U1) works as a street-crossing approach without traffic lights or supplementing public space above ground. Underground zone sub-type 2 (U2) consists of walking corridors and the platforms of a pair of railway lines. Underground zone sub-type 3 (U3) contains more functions such as stores, entertainment space, railway platforms, and vertical elevators to connect with public transportation systems above ground. 
Underground zone sub-type 4 (U4) is filled with multiple railway lines, layered platforms, shopping malls, restaurants, and connects with surrounding buildings. Underground zone sub-type 5 (U5) acts as a comprehensive transition space with multiple functions, such as subway transition, indoor entertainment centre, shopping centre, underground walking streets, and leisure space shared with surrounded buildings. Figure 63 provides an example of an underground transect matrix with graphic sections.

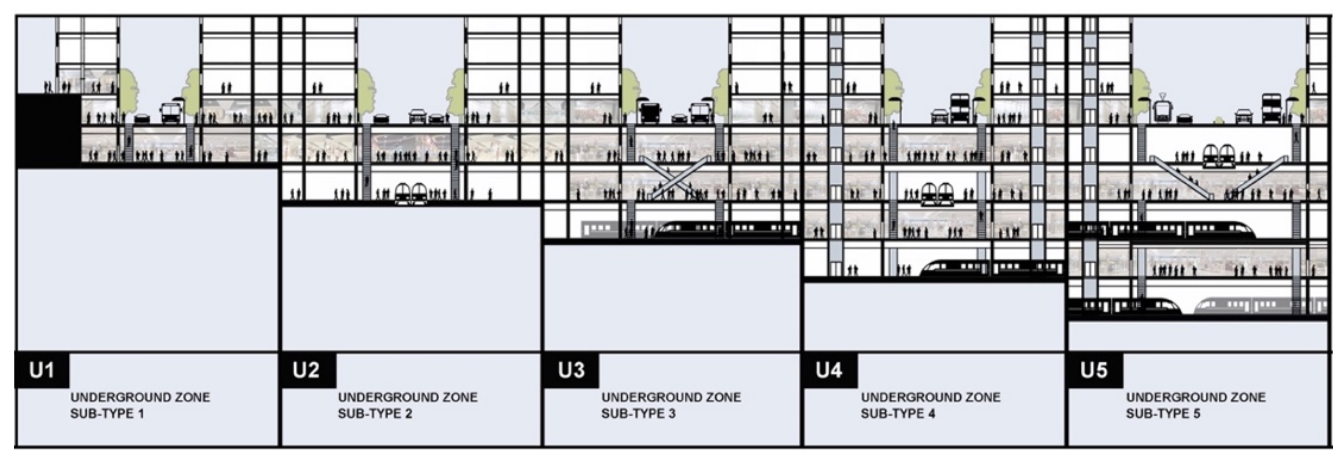

Figure 63. Example of underground usage

\subsubsection{Volumetric mode: upper ground}

Hong Kong has upper ground transportation and functional spaces, including corridors, connections and rooftop grounds. These space patterns build a volumetric system above ground. Corridors duplicating roads and streets are for relieving traffic pressure. Connections between buildings are for transporting people or increasing building areas. Rooftop space is for containing the population in urban zones or enlarging spaces for public or private usage. To consider the above-ground volumetric system part of urban regulation, the zone types of the system must be identified to generate a volumetric mode of transect matrix for upper ground space.

Various factors affect zone type classification, including the number of corridors or connections, space usage and green coverage. Generally, multiple 
connections between buildings reflect more urban characteristics than a single connection. Corridors with a relatively large space available for public activity are more urban than a simple crossing above the streets. A corridor with green rooftop coverage is more urban than an outdoor bridge. One possible transect matrix for upper ground space is presented in Figure 64. The first row here describes the elevations of buildings with corridors and connections; the second describes corresponding plans. The third row names the zone types.

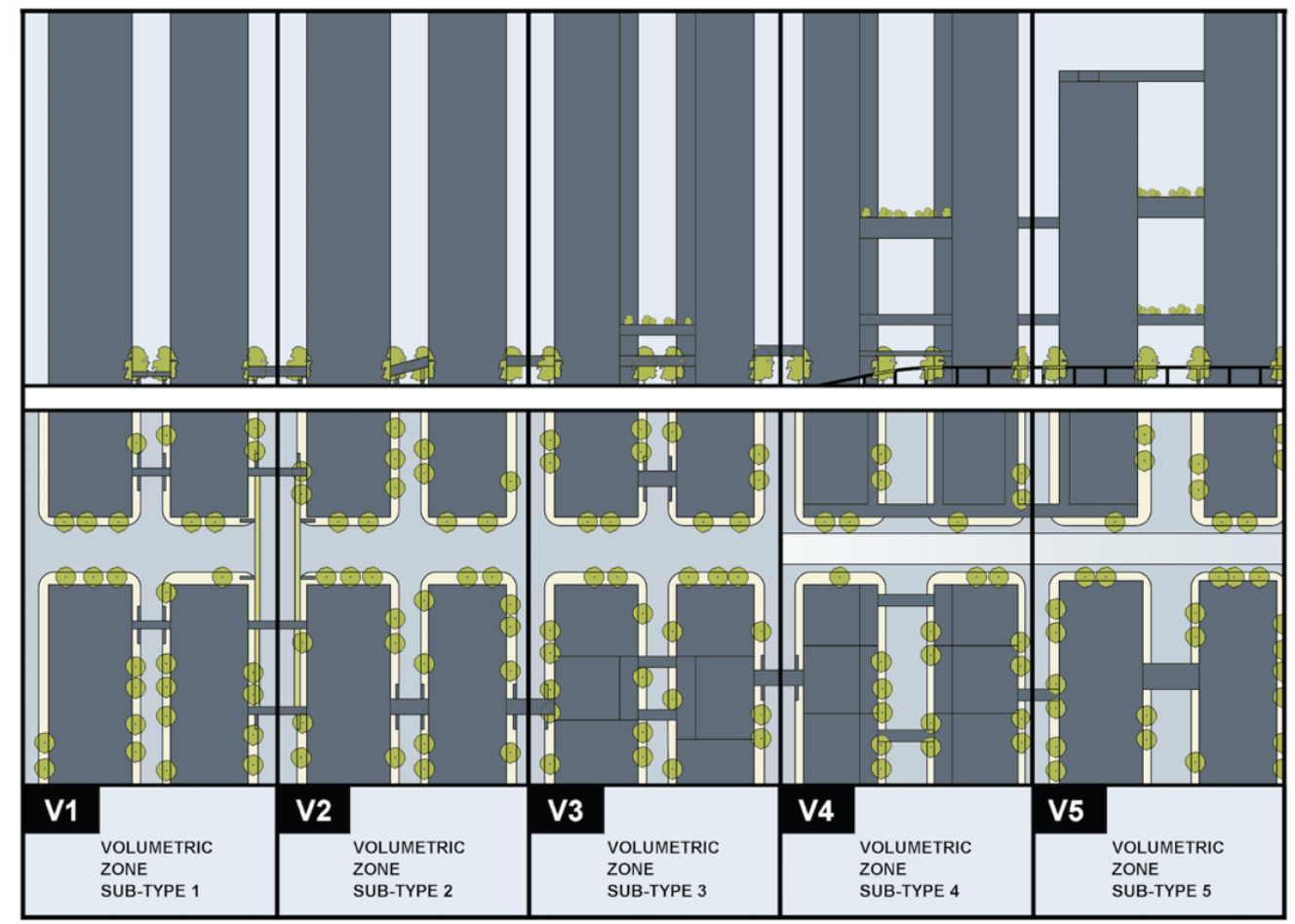

Figure 64. Transect matrix of upper ground level

The transect matrix for the upper ground space has five zone types based on the complexity of the volumetric system in blocks and plots (Figure 65). Volumetric Zone Sub-type 1 (V1) contains a single corridor between buildings to double the pedestrian space on the ground. Volumetric Zone Sub-type 2 (V2) contains connections between different buildings and levels with greenery coverage. Volumetric Zone Sub-type 3 (V3) uses vertical transportation to connect 
multiple sky tubes and extends the usage area of buildings. Volumetric Zone Sub-type 4 (V4) generates sky connections at a higher level for far-looking views and more functional space. Volumetric Zone Sub-type 5 (V5) has connections on the rooftop suitable for bars, hotels or offices. These zone types and graphic examples reflect the regulation's intention of creating or recreating more space for movement and activities in a high-density environment.

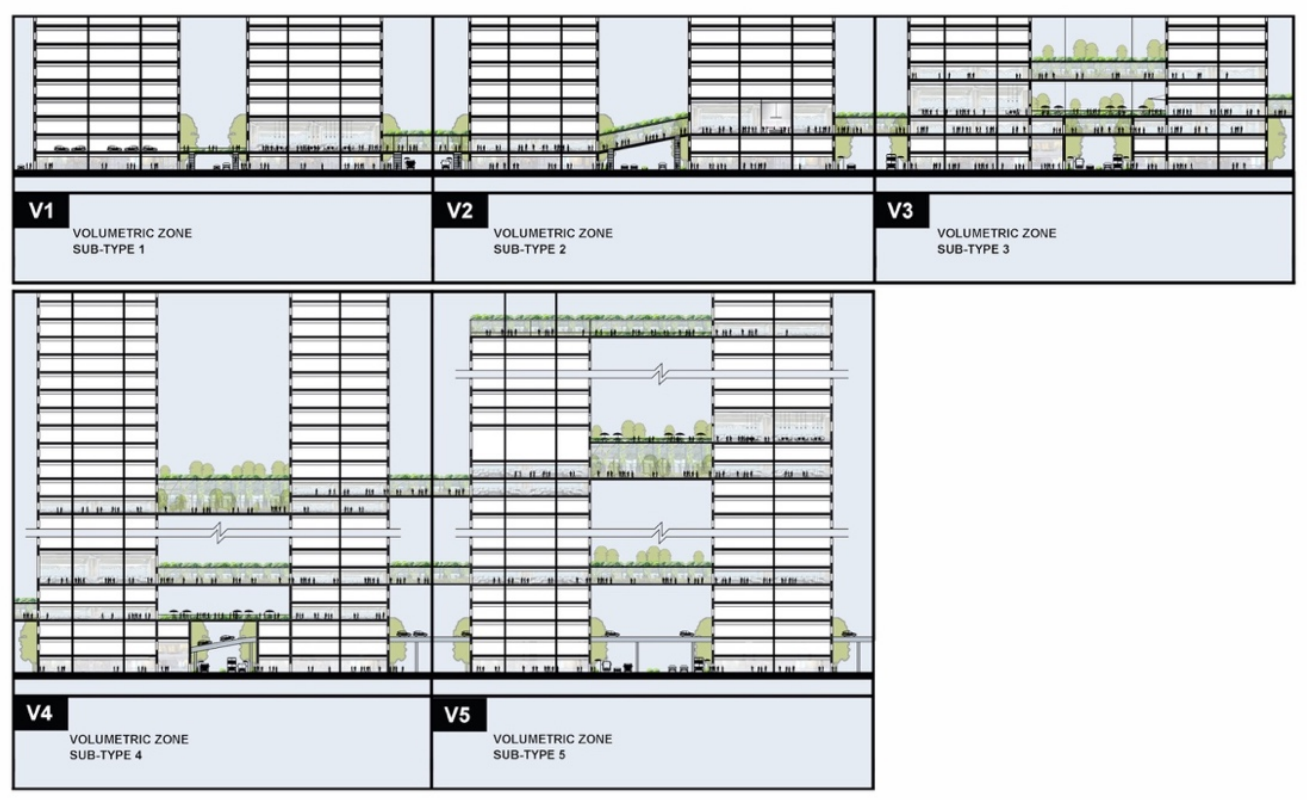

Figure 65. Examples of upper ground usage

The transect matrix of Tsim Sha Tsui includes three sections: ground level, underground level and upper ground level. The ground level transect matrix provides one natural zone and six sub-types of urban core zone. The volumetric levels comprise ten underground and upper ground zone types. Seventeen zone types are identified in Table 30.

\begin{tabular}{c|c|c|c}
\hline No. & Type & \multicolumn{2}{|c}{ Description } \\
\hline 1 & T1 & Natural Zone & \multirow{2}{*}{ Ground Level } \\
\hline 2 & T6-1 & Urban Core Zone Subtype 1 & \\
\hline 3 & T6-2 & Urban Core Zone Subtype 2 & \\
\hline
\end{tabular}




\begin{tabular}{|c|c|c|c|}
\hline 4 & T6-3 & Urban Core Zone Subtype 3 & \\
\hline 5 & T6-4 & Urban Core Zone Subtype 4 & \\
\hline 6 & T6-5 & Urban Core Zone Subtype 5 & \\
\hline 7 & T6-6 & Urban Core Zone Subtype 6 & \\
\hline 8 & U1 & Underground Zone Subtype 1 & \multirow{5}{*}{ Underground Level } \\
\hline 9 & $\mathrm{U} 2$ & Underground Zone Subtype 2 & \\
\hline 10 & U3 & Underground Zone Subtype 3 & \\
\hline 11 & $\mathrm{U} 4$ & Underground Zone Subtype 4 & \\
\hline 12 & U5 & Underground Zone Subtype 5 & \\
\hline 13 & V1 & Volumetric Zone Subtype 1 & \multirow{5}{*}{ Upper Ground Level } \\
\hline 14 & V2 & Volumetric Zone Subtype 2 & \\
\hline 15 & V3 & Volumetric Zone Subtype 3 & \\
\hline 16 & V4 & Volumetric Zone Subtype 4 & \\
\hline 17 & V5 & Volumetric Zone Subtype 5 & \\
\hline
\end{tabular}

Table 30. Zone types of volumetric grounds in Tsim Sha Tsui

\subsubsection{Transect descriptions}

The standard transect matrix has been extended for Tsim Sha Tsui to include volumetric zone types. A more complex urban development situation is accommodated by adding to the original zone types of the standard transect matrix. Figure 66 presents the transect matrix of Tsim Sha Tsui which is generated within a multi-level mode. After confirming the zone types, a FormBased Code requires transect descriptions for documenting detailed regulation. Generally, the transect descriptions contain information about general character, building placement, frontage types, typical building height, and types of civic space (City of Bellevue, 2014). This section uses the representative zone types of ground level, underground level and upper ground level to provide an example of the transect descriptions of Tsim Sha Tsui. 


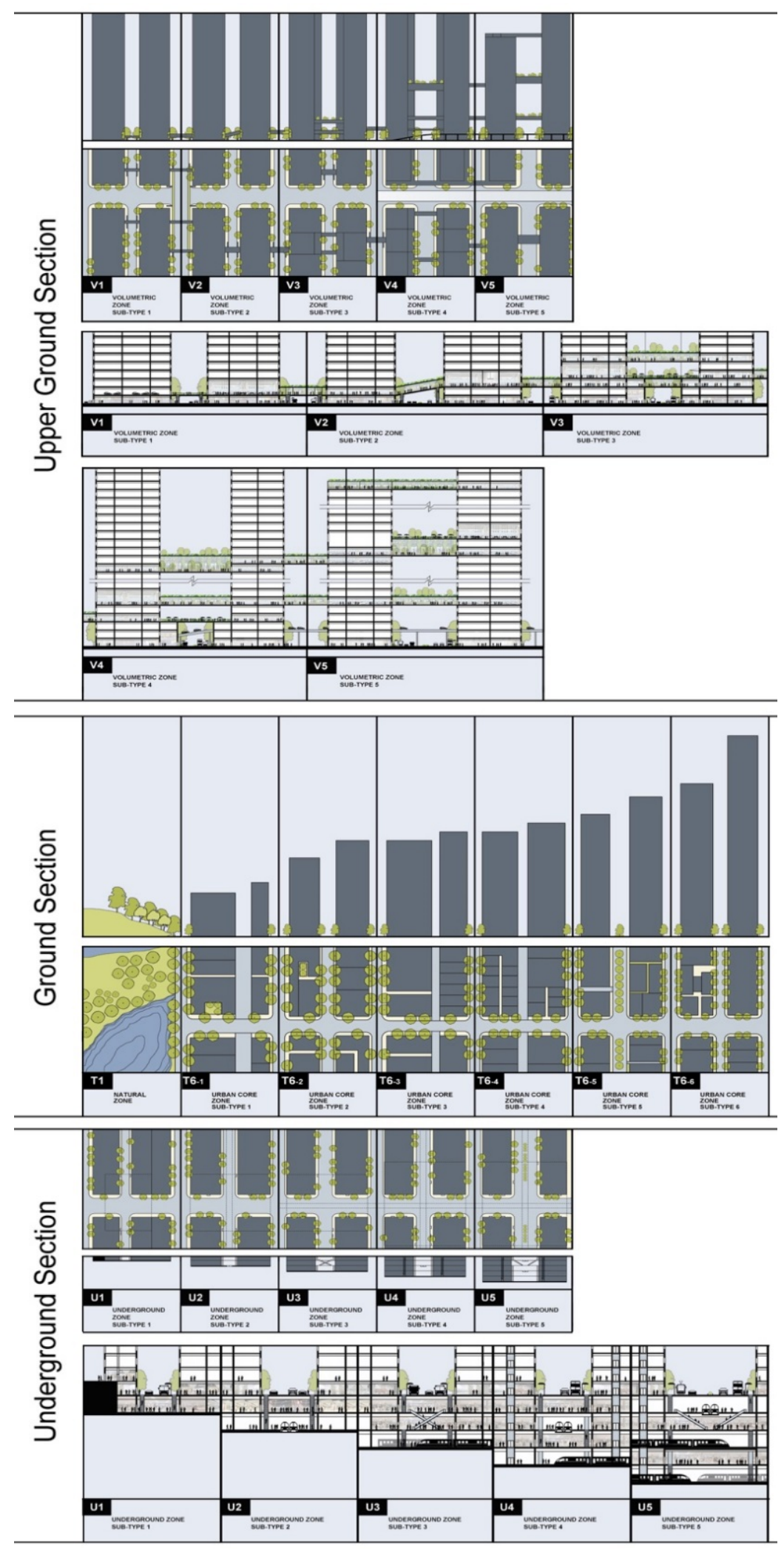

Figure 66. Transect matrix of Form-Based Code for Tsim Sha Tsui 
In the transect matrix of ground level, the transect description example is Urban Core Zone Subtype 4 (T6-4) (Figure 67). The description provides guidelines for the further regulation of buildings and street scale. T6-4 is a typical urban core zone of Tsim Sha Tsui. It consists of high-density, mix-use buildings. Retail, restaurants and multi-family housing are integrated into high-rise towers. This zone type has relatively tight street networks with wide sidewalks, street tree planting, and a spot of street art close to the sidewalks.

\begin{tabular}{c|c|c}
\hline Graphic transect & Items & Descriptions \\
\hline & General character & $\begin{array}{c}\text { Shops mixed with apartments, accommodation, offices } \\
\text { work places and civic buildings; predominantly attached } \\
\text { buildings; trees within the public right-of-way; substantial } \\
\text { pedestrian activity }\end{array}$ \\
\cline { 2 - 3 } & Building placement & Shallow setbacks, buildings oriented to the street defining \\
& Frontage types & Street wall \\
\cline { 2 - 3 } & Typical building height & 35- to 40- story with variations \\
\cline { 2 - 3 } & Type of civic space & Plazas, squares, median landscaping \\
\hline
\end{tabular}

Figure 67. Zone descriptions of T6-4

In the underground level, Underground Zone Subtype 3 (U3) is the transect description example (Figure 68). U3 presents an underground space with mixed functions like subway transfer, parking, and underground streets. Small-sized stores are located at the sides of the pedestrian space and interior greens.

\begin{tabular}{|c|c|c|}
\hline Graphic transect & Items & Descriptions \\
\hline \multirow{5}{*}{ 1. } & General character & $\begin{array}{l}\text { Shops mixed with transportation space, offices, work } \\
\text { places and scattered commercial activity; substantial } \\
\text { pedestrian activity; interior greens }\end{array}$ \\
\hline & Building placement & Not applicable \\
\hline & Frontage types & Not applicable \\
\hline & Typical building height & 3-story with some 4-story \\
\hline & Type of civic space & Plazas, underground squares, parking \\
\hline
\end{tabular}

Figure 68. Zone descriptions of U3 
In the transect matrix of the upper ground level, the transect description example is Volumetric Zone Subtype 3 (V3) (Figure 69). V3 is primarily for upper ground transportation and the extension of interior areas. It is largely mixed use and includes cafes, kiosks and pocket squares, for example. Greenery covers the rooftop.

\begin{tabular}{c|c|c}
\hline Graphic transect & Items & Descriptions \\
\hline & General character & $\begin{array}{c}\text { Shops mixed with transportation space, cafes, substantial } \\
\text { pedestrian activity; interior greenery; Rooftop greens }\end{array}$ \\
\cline { 2 - 3 } & Building placement & Not applicable \\
\hline & Frontage types & Not applicable \\
\hline & Typical building height & 2-story \\
\cline { 2 - 3 } & Type of civic space & Small-scale squares \\
\hline
\end{tabular}

Figure 69. Zone descriptions of V3

The transect matrix has been extended to accommodate the volumetric morphology of the high-density environment. This newly developed transect matrix is more suitable than the standard matrix for compact urban core zones with limited land resources. It regards the layered urban space as a whole. FormBased Code covers urban space patterns whether at ground level, underground level or upper ground level. The following sections describe a series of volumetric regulatory plans based on the extended transect matrix. Thus, the zone types can be embedded into the regulating system of Form-Based Code. 


\subsection{Regulating plans}

The regulating plans map the zone types and subtypes in the ground, underground and upper ground spaces. Developing regulating plans relies on the extended transect matrix and predicting future development. This section concludes with a comparison between the regulatory plans of a Form-Based Code and the established zoning map.

\subsubsection{Ground}

Regulatory plans designate the locations of zone types and subtypes to indicate where building form and public space regulations apply. It integrates regulation intention, physical characteristics and future predictions through mapping and overlapping zones. The regulating plan is a primary component of Form-Based Code.

Tsim Sha Tsui's regulating plan for ground level is a result of overlaying the zone maps of T1, T6-1, T6-2, T6-3, T6-4, T6-5, and T6-6. The blocks defined by different zone types are reorganised in accordance with the transect matrix; from less to more urban. Each block has a specific colour to represent its zone type (Figure 70). For example, the blocks coloured in red belong to the specific zone of T6-6. Layering zone map layers generates the conceptual regulating plan for ground level (Figure 71). The plan is a consequence of the factors that affect its generation, including understanding the urban space context, designating variables during the field study, physical data analyses, and the zone types classification of the transect matrix. In real projects, these factors depend highly on the regulation team, communities and regulating conditions. The regulating plan's layouts are diversified by different people in different projects, with the same workflow. 


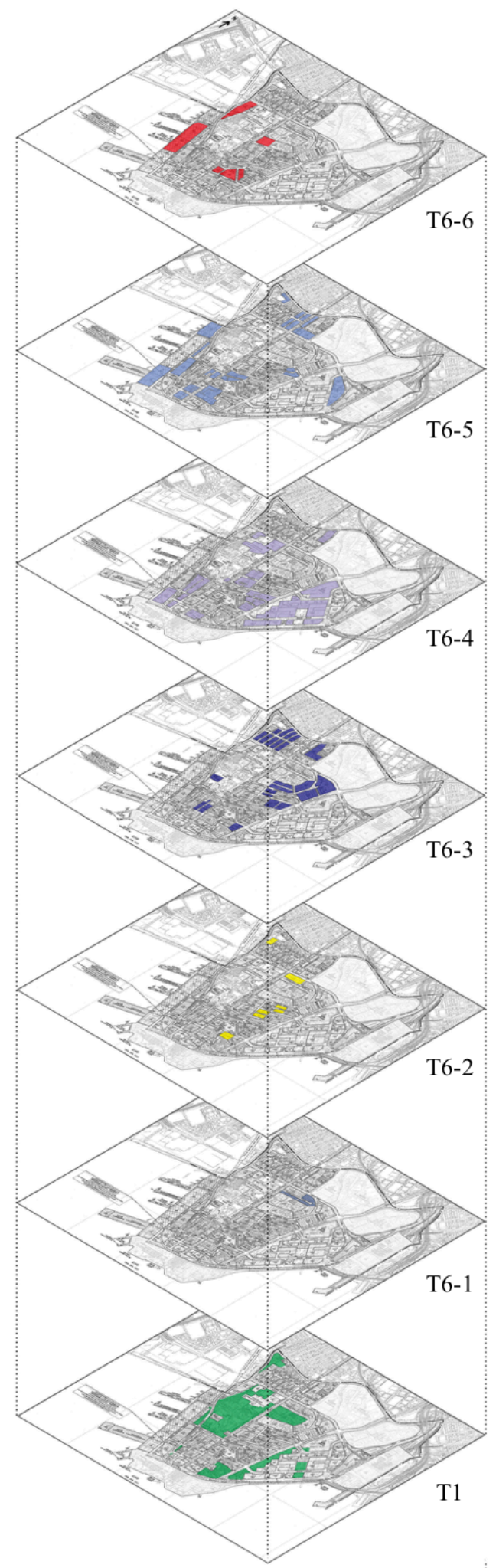

Figure 70. Zoning layers of ground level 


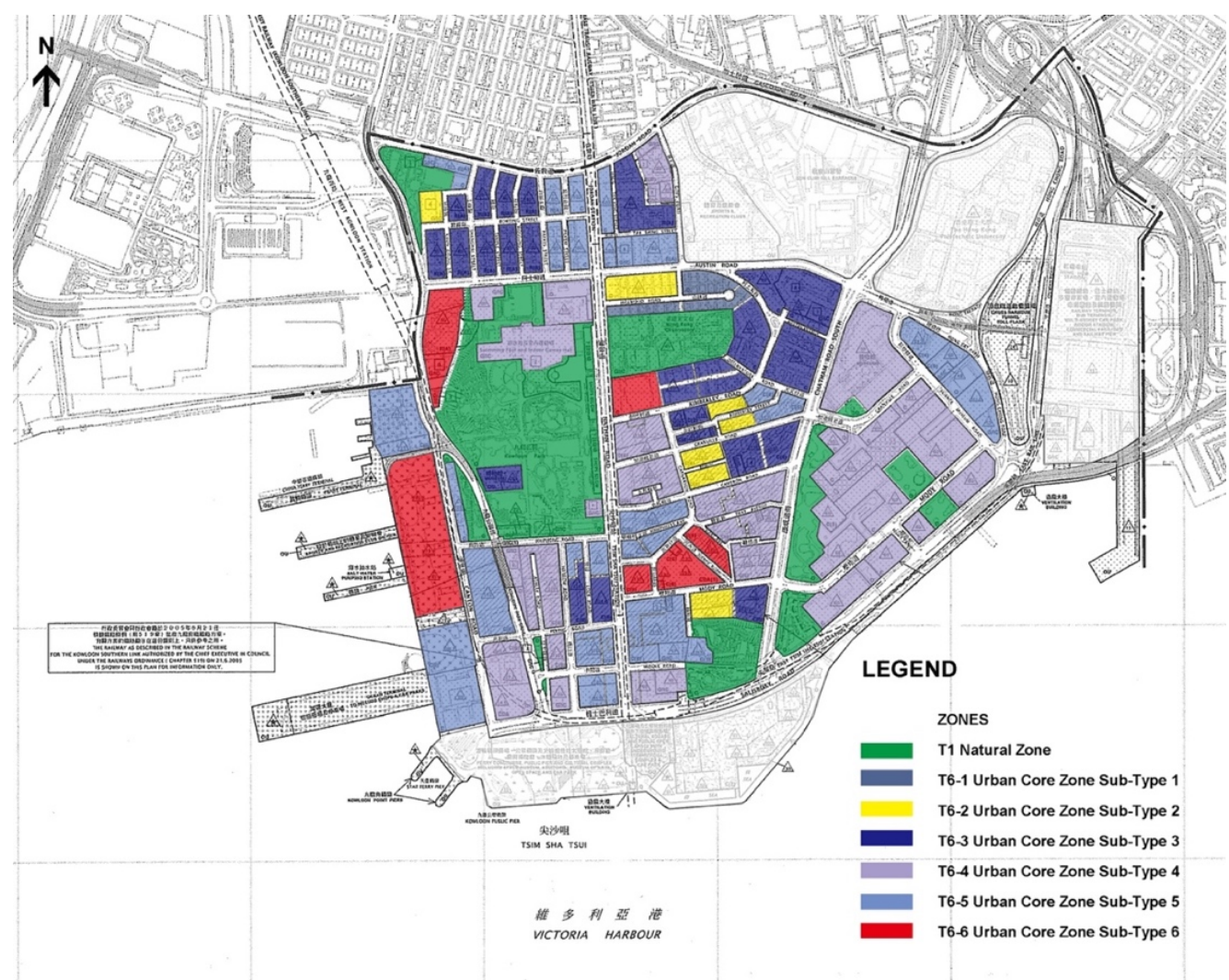

Figure 71. Layout example of ground level regulating plan, re-edited by author based on Town Planning Ordinance, Town Planning Board of Hong Kong, 2008

\subsubsection{Underground}

There is no regulating plan specific for underground space in existing FormBased Code projects. This section explores an underground mode of regulatory plan using an underground transect matrix. The underground mode focuses on three considerations: Existing underground planning and design, the utilisation of established underground space and the prospective regulation. Underground regulation is a complicated process. The section explores that process from the perspective of form and space shaping. Ownership, rights and underground construction are not covered in this research.

Urban planning and design in Hong Kong have included the underground space. The Hong Kong government drew up Underground Space Development in the Selected Strategic Urban Areas in 2016. Tsim Sha Tsui West, Causeway Bay, 
Happy Valley and Admiralty are four priority districts for underground development. According to Underground Space Development, the underground space of Kowloon Park in Tsim Sha Tsui West is of central importance for connecting with Tsim Sha Tsui Station, improving pedestrian connectivity and duplicating public space. Figure 72 presents a design for an all-weather pedestrian system under Kowloon Park. The underground space facilities a mixture of activities, including retail, leisure, cultural, exhibition, and community. Walkable space and vertical transportation are built to enable different functions.

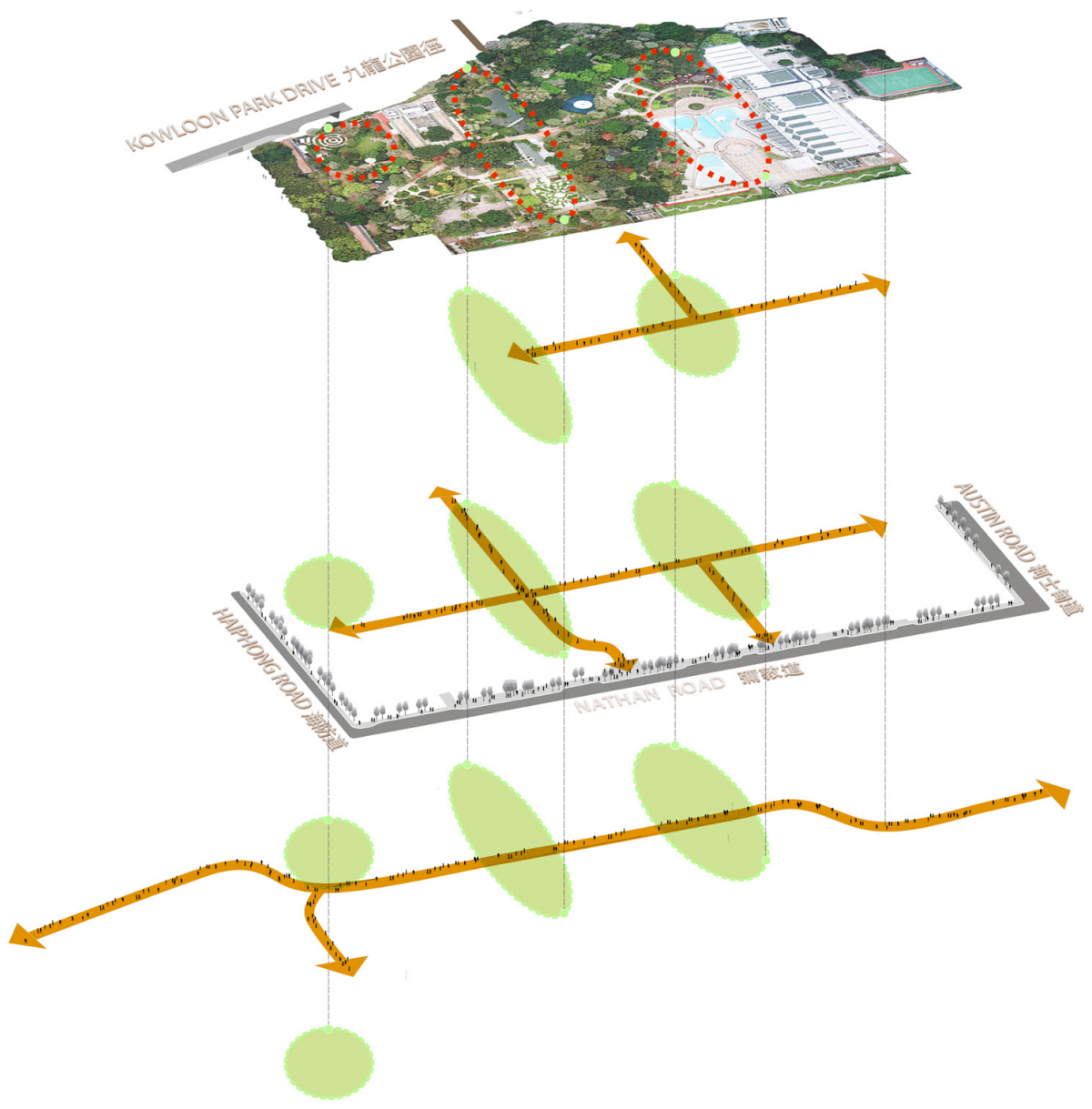

Figure 72. Underground space organisation of Kowloon Park, Underground Space Development in the Selected Strategic Urban Areas, Planning Department of Hong Kong, 2015 
The utilisation of established underground space is mainly concentrated at Tsim Sha Tsui Station, Tsim Sha Tsui East Station and at the tubes between them. The subway stations work as the core of the spatial organisation. Subway transfer is the main use of this underground space, which supports volumetric transportation from underground to upper ground. Figure 73 describes the existing underground space between Tsim Sha Tsui Station and Tsim Sha Tsui East Station. Under the zone classifications of the underground transect matrix, subway stations and surrounded areas are more artificial than other underground areas.

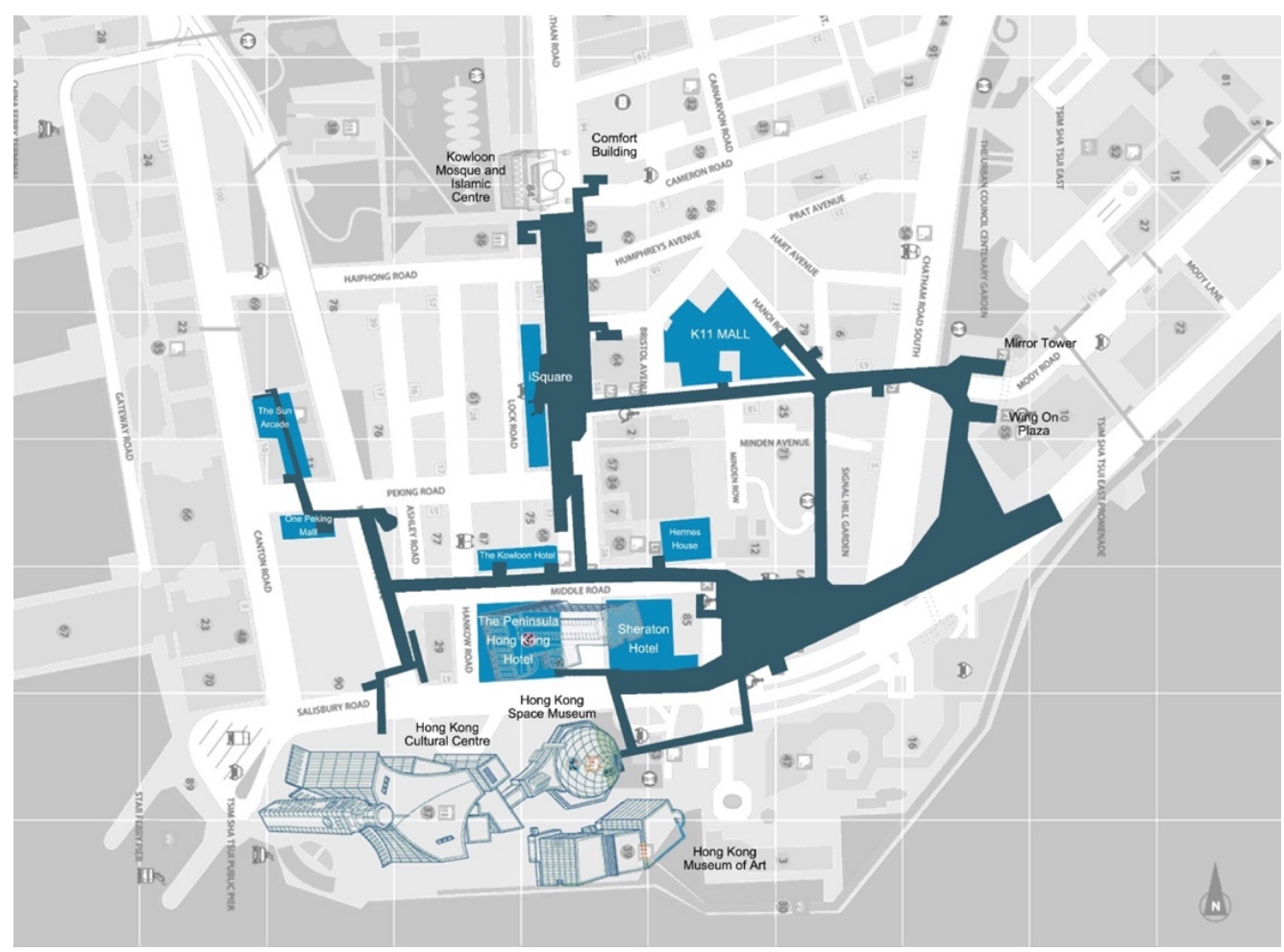

Figure 73. Underground area of Tsim Sha Tsui, re-edited by author based on the Map of Tsim Sha Tsui Mass Transit Railway (MTR) Station, MTR Cooperation Limited, 2017

The prospective regulation of underground space regards subway stations as the zoning core and extends the underground network to surrounding buildings, streets and public spaces; aiming towards a pleasant ground and underground 
space in a high-density environment. Merging existing underground planning and design, the utilisation of established underground space and prospective regulation, the underground regulating plan of Tsim Sha Tsui is generated with five zone types U1, U2, U3, U4, and U5 (Figure 74). Most U1 zones are located under parks or streets without pedestrian crossings. U2 to U5 zones are multilayered underground spaces. They are distributed along Jordan Road, Canton Road and Tsim Sha Tsui East. U5 is the most complex underground zone with multiple trains, a comprehensive transport lobby, commercial facilities, and leisure space. Zones belonging to U5 are clustered around Tsim Sha Tsui Station. By layering all of the transect zone maps, the underground regulating plan is generated as seen in Figure 75.

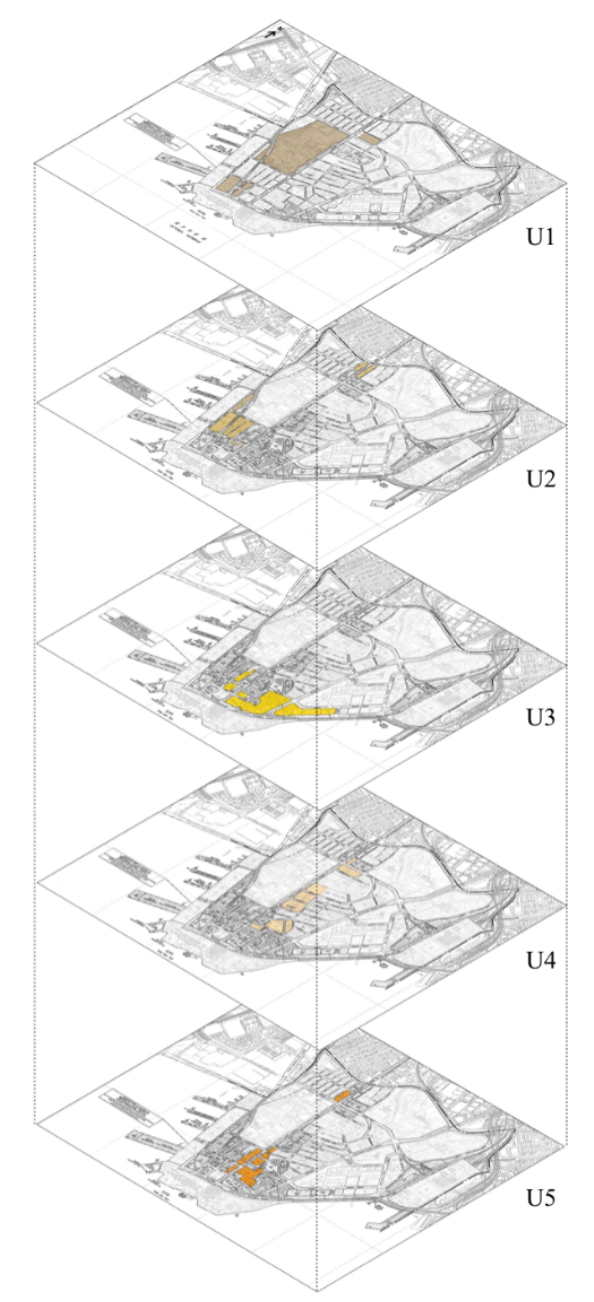

Figure 74. Zoning layers of underground level 


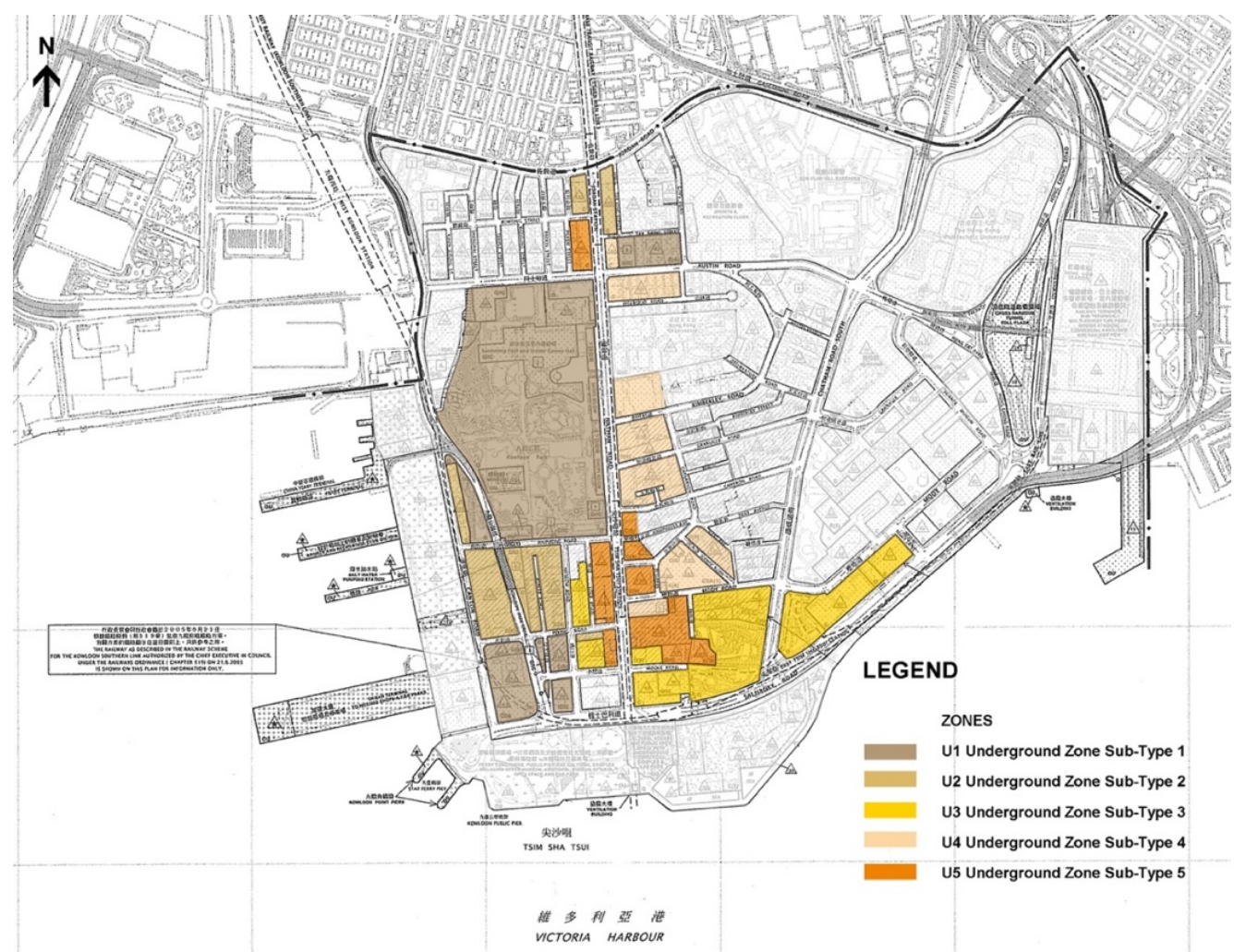

Figure 75. Layout example of underground regulating plan, re-edited by author based on Town Planning Ordinance, Town Planning Board of Hong Kong, 2008

\subsubsection{Upper ground}

There is no consideration of upper ground space in existing traditional FormBased Code projects. This section creatively extends Form-Based Code to include upper ground space, exploring whether upper ground levels can also be regulated by Form-Based Code approaches. It is not accurate to describe upper ground corridors as general zones because they are not built on the land. However, if an area in which a certain amount of people's movement happens is regarded as an urban zone, upper ground areas can also be defined by zone types as ground areas.

The design of upper ground regulatory plans is based on the prospective corridors above ground. There are established corridors between buildings in Tsim Sha Tsui. They act as components of buildings as well as independent 
constructions which can be seen from outside of the buildings. These corridors do affect urban forms, although they are quite tiny compared with giant skyscrapers. From the perspective of people on the ground, the corridors close to the ground level are easier to perceive than the whole façade of the high-rise buildings.

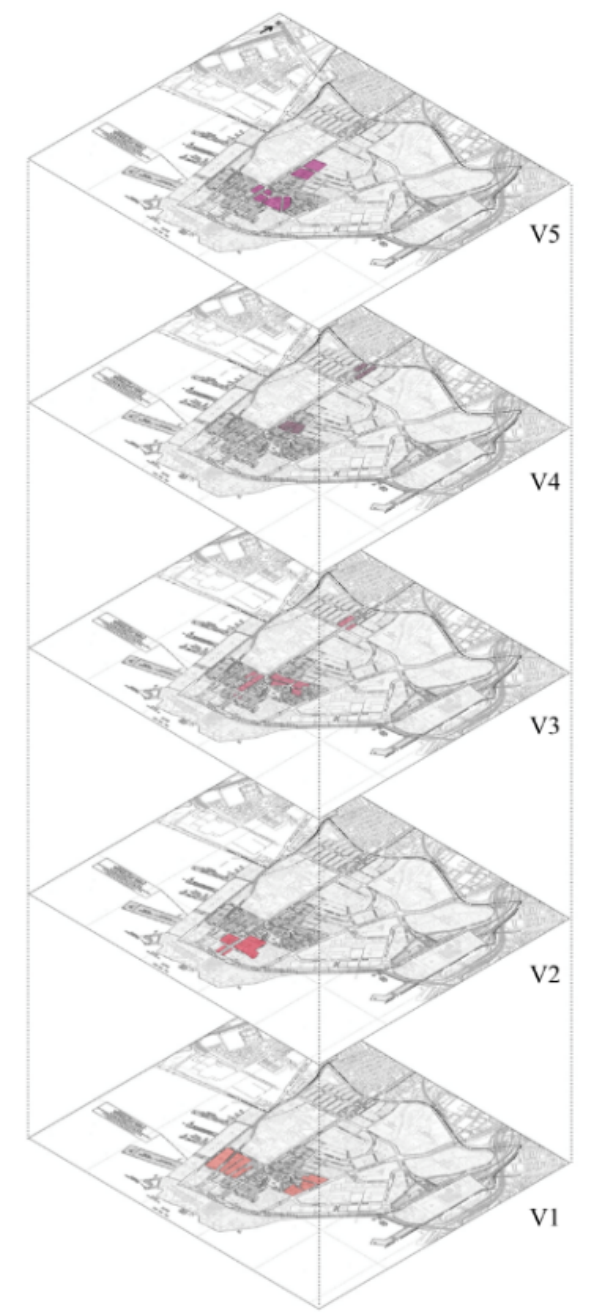

Figure 76. Zoning layers of upper ground level

Based on the zone classifications of the upper ground transect matrix, the upper ground regulating plan of Tsim Sha Tsui is generated with zone types V1, V2, V3, V4, and V5 (Figure 76). Relatively high-density areas, such as Jordan Road Area and Nathan Road Area, function as centres of the upper ground system. Corridors above roads or between buildings provide functional components for 
higher levels, duplicating space and relieving congestion on the ground level. These corridors, including rooftop areas, not only act as transportation tubes but also as places of communication, shopping, gathering, and even housing. Accordingly, Figure 77 presents an example of the upper ground regulating plan of Tsim Sha Tsui.

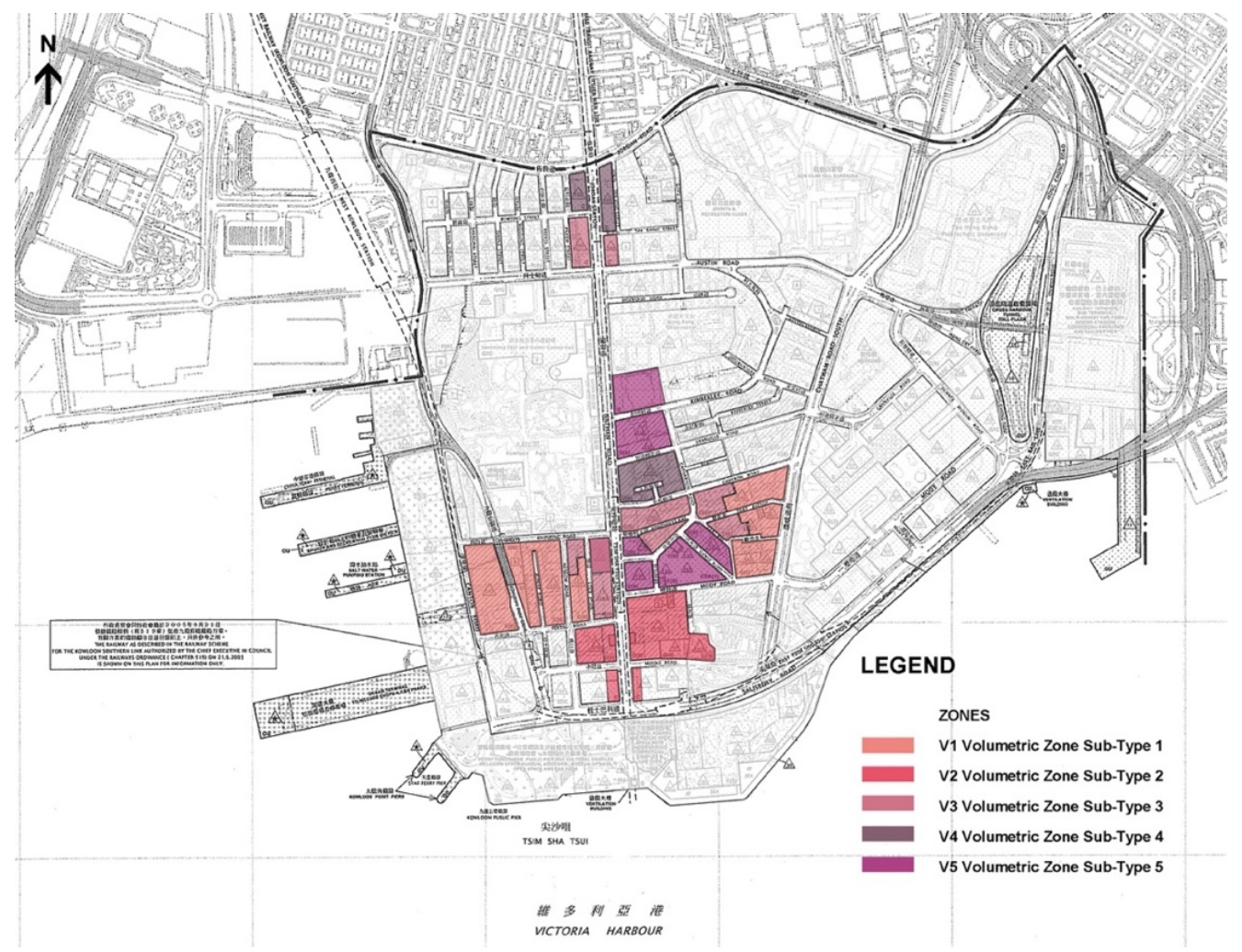

Figure 77. Layout example of upper ground regulating plan, re-edited by author based on Town Planning Ordinance, Town Planning Board of Hong Kong, 2008

A series of regulating plans encompassing ground, underground and upper ground levels have been developed for the conceptual Form-Based Code of Tsim Sha Tsui. The regulating plans can be regarded as maps of detailed urban regulations. As DPZ suggested in the Smart Code Version 9.2, regulations such as specific building configuration, lot occupation, setbacks and building disposition are created for the zones mapped on the regulating plans. 
Form-Based Code encourages detailed urban regulation. Using urban form to guide regulation means Form-Based Code has characteristics of both zoning and urban design. The following section compares the layered regulating plans with the existing zoning map of Tsim Sha Tsui. The differences affect the concepts of, and approaches to, developing a parametric urban regulation system in Chapter 5.

\subsubsection{Comparisons with existing zoning plan}

This section compares the existing zoning plan of Tsim Sha Tsui with the layered regulating plans developed in this research. The existing zoning plan basically follows land use division, while the layered regulating plans adopt the form divisions of the transect matrix. Different approaches to regulation result in different layouts. The section concludes with a comparison between the two regulatory plans and their modes of description in further regulation.

According to the current Town Planning Ordinance of Hong Kong, the fundamental principle of the current regulation system of Hong Kong is land use control. All provisions and codes must align with land use designation. Land use in Tsim Sha Tsui is regulated by Town Planning Ordinance, companies involved with major transportation nodes, land use areas, and amendments. Extracting the land use designation from the original document, a land use map is created with each zone represented by a colour (Figure 78). The map divides the site into seven zone types, namely commercial, comprehensive development area, residential (group A), residential (group B), government and institution, open space, and other specialized uses.

Unlike the existing zoning plan, Form-Based Code's regulating plans provide a volumetric system of ground, underground and upper ground. These are based primarily on urban form and employ land use as a secondary principle. Figure 79 presents a key difference between the regulating plans and the established 
zoning plan. The left side demonstrates Form-Based Code's regulating plans. It consists of underground layer, base map layer, block division layer, natural layer, ground layer and upper ground layer. The right part is the existing zoning plan, comprising base map layer, block division layer and ground layer. The regulating plans are multi-layered to facilitate volumetric development, while the existing zoning plan is single-layered, aligning with conventional zoning approaches.

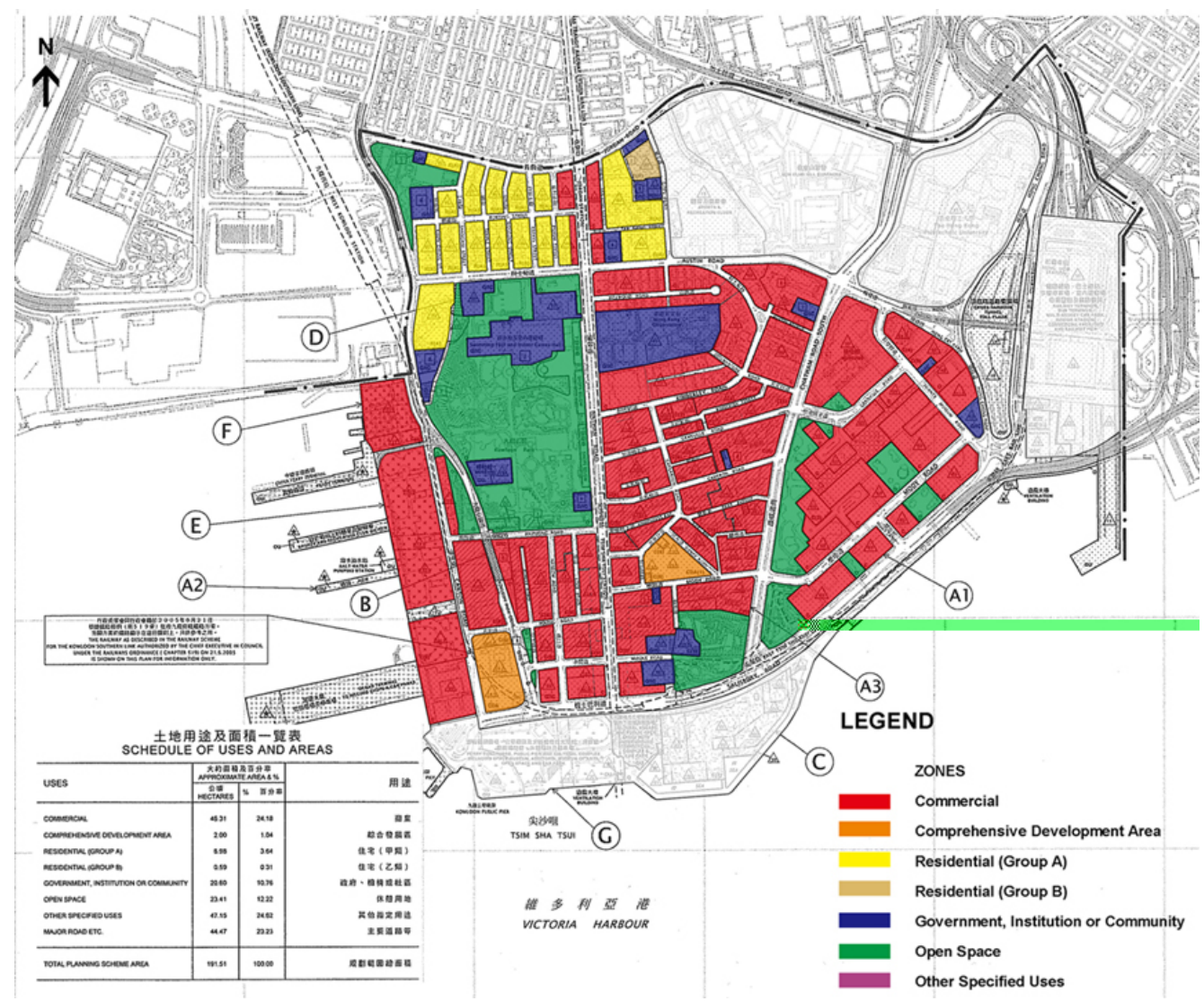

Figure 78. Existing zoning plan according to the Town Planning Ordinance, Town Planning Board of Hong Kong, 2008

The regulating plans have more zone types than the existing zoning plan. Seventeen zone types are created in the development of the regulating plans, while the existing zoning plan contains just seven. The zone types of FormBased Code are generated in reaction to the various factors that affect the shape 
of urban form. The existing zoning plan utilises common land use categories, such as commercial and residential, to define the site.

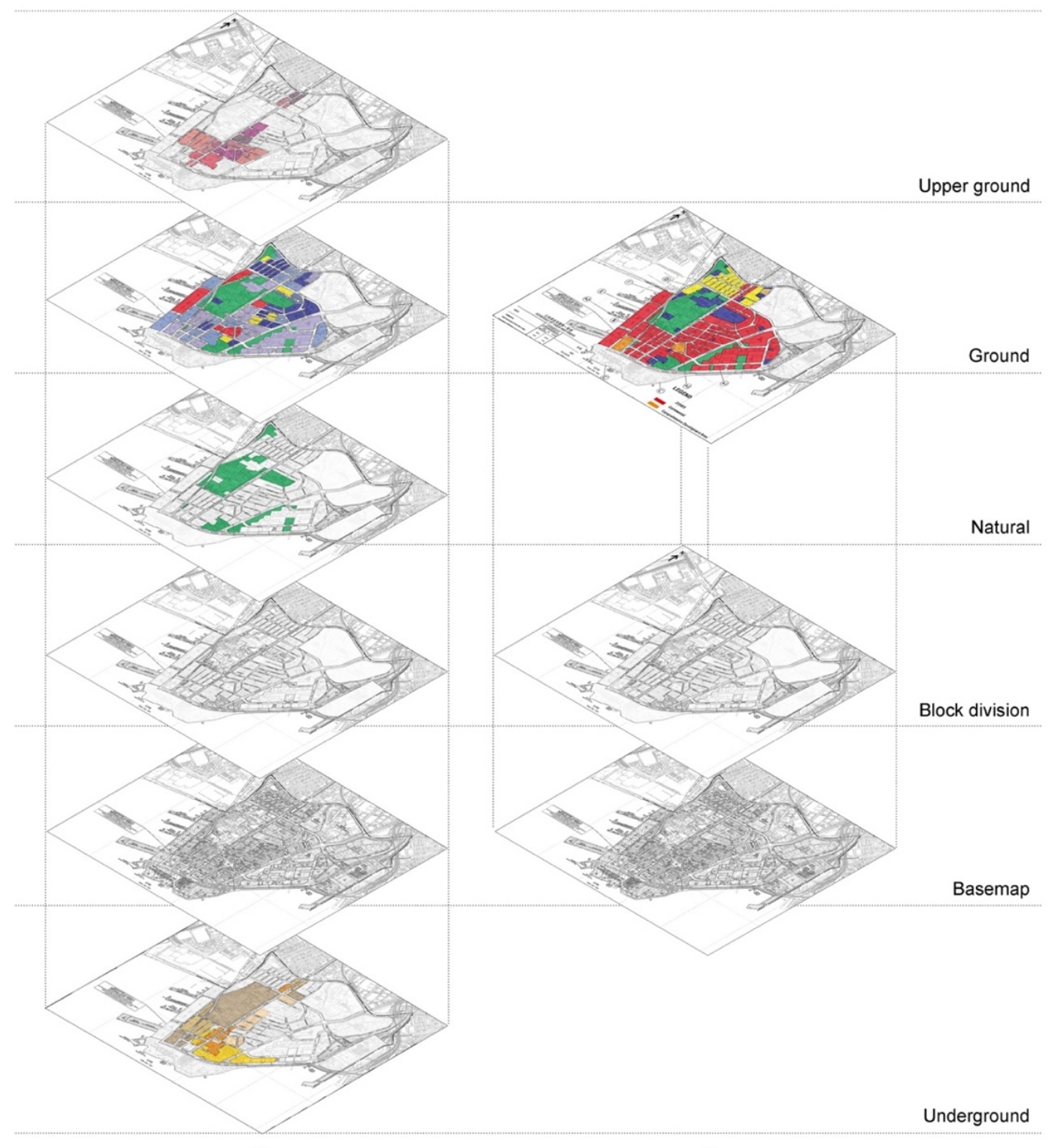

(a)

(b)

Figure 79. Comparisons between the existing zoning plan and regulating plans of Form-Based Code

It is argued that rigidly separating land use cannot fully support urban regulation in a high-density environment. For instance, in the Residential (Group A) area of the existing zoning plan, there are numerous small and medium scale stores 
and shops located on the first floor of residential buildings. It is not accurate to say that the area purely residential. In Tsim Sha Tsui, a large amount of commercial activity is mixed with residential areas and non-profit institutions. From this perspective, a land use-based zoning plan lacks the capability to control and predict future development.

This lack of capability for urban space control somehow leads to a worse street atmosphere and creates an unpleasant living environment. In residential zones, street width, open space, and road hierarchy should, in principle, be smaller or fewer than in commercial zones. However, in the real urban development example of Jordan Road, the residential area contains many small-scale stores. This area must accommodate a higher flow of people than normal residential zones. The narrow streets and residents' public space are shared with a large number of customers. The balance between function and form are overlooked by the existing zoning plan.

Form-Based Code's regulating plans attempt to circumvent these contradictions. Controlling spatial performance is a priority of the regulating process. Regardless of function or land use, specific performance patterns are apparent in the zone. Form-Based Code uses form to guide people's corresponding activities, and then controls function and land use. Land use is an important element of controlling urban development, but it must cooperate with form and development realities. Introducing Form-Based Code to the existing zoning system facilitates seeing urban form as a multi-level morphology and enhances the feasibility of urban regulation. Further analysis of embedding Form-Based Code into Hong Kong's urban regulation mechanism is described in later sections. 


\subsection{Chapter summary}

This chapter describes a methodological framework for generating the transect matrix and regulating plans of Form-Based Codes that are developed for the volumetric morphology of a high-density environment. The framework encompasses an understanding of context, a physical data collection using quantitative values to describe urban forms, and a zone type subdivision based on urban forms. The transect matrix is extended by a volumetric mode that includes zone types of ground, underground and upper ground. Following the transect matrix, a series of regulating plans are developed that involve multilayer configurations in an attempt to create a volumetric Form-Based Code to enhance urban regulation.

The zone subdivision and regulating plans of Form-Based Code are compared with the existing zoning plan. The zoning plan is limited; lacking capability for regulating volumetric morphology and predicting future development. FormBased Code, however, subdivides zones and develops regulatory plans according to the requirements of form shaping and space usage. They have the potential to supplement existing zoning plans. Chapter 5 further explores the cooperation between Form-Based Code and existing zoning. It describes the process of generating the parametric building and street regulations of a FormBased Code according to the transect matrix and regulating plans. A parametric modelling system is implemented in Form-Based Code, aiming towards flexible and predictable urban regulation in the volumetric morphology of high-density cities. 


\section{Chapter 5. Parametric modelling and results}

Based on the transect matrix and regulating plans created in the last chapter, this chapter generates and implements a parametric modelling system for a FormBased Code for Hong Kong. A workflow for establishing the system is described within the original framework of generating a Form-Based Code. Working in the visioning phase, the modelling procedure aims to provide visualised regulations and real-time performance feedback presented on a parametric software interface. The chapter concludes with a series of graphic regulations and models that demonstrate codes in a three-dimensional way. Experiment 2, described in Section 1.5, is further analysed in this chapter. 


\subsection{Parametric design}

This section analyses parametric concepts to enhance urban design with efficient generation and amendment processes. Parametric design allows an integration of visions, models and manipulations on one platform. The analysis involves five elements, namely parameter definition, scripts, massing models, manipulations, and layouts. They are briefly described in this section and based on an understanding of parametric concepts and software.

\subsubsection{Parametric concepts}

Digital tools have been applied in the building industry. A complete building process can use contemporary digital tools from design through to fabrication (Agkathidis and Brown, 2013). As a main component of digital methodology, parametric design is based on algorithmic thinking that enables the expression of parameters and rules that, together, define, encode and clarify the relationship between design intent and design response (Jabi, et al., 2013; Woodbury, 2010). According to Rogers (1987), an algorithm is expressed within a finite amount of space and time and in a well-defined formal language for calculating a function in mathematics and computer science. For instance, Figure 80 presents the flowchart of Euclid's Algorithm for calculating the greatest common divisor of two variables $\mathrm{a}$ and $\mathrm{b}$ in locations $\mathrm{A}$ and $\mathrm{B}$.

"The algorithm proceeds by successive subtractions in two loops: if the test $\mathrm{B} \geq$ A yields "yes" (or true) (more accurately the number $b$ in location B is greater than or equal to the number a in location $\mathrm{A}$ ) then, the algorithm specifies $\mathrm{B} \leftarrow$ $\mathrm{B}-\mathrm{A}$ (meaning the number $\mathrm{b}-\mathrm{a}$ replaces the old $\mathrm{b}$ ). Similarly, if $\mathrm{A}>\mathrm{B}$, then $\mathrm{A} \leftarrow \mathrm{A}-\mathrm{B}$. The process terminates when (the contents of) $\mathrm{B}$ is 0 , yielding the greatest common divisor in A." (Scott, 2009; Tausworthe, 1977). Based on Knuth (1969), the algorithm starts from an initial state and initial input and describes a computation that, when executed, proceeds through a finite number of well-defined successive state, eventually producing "output" and terminating. 


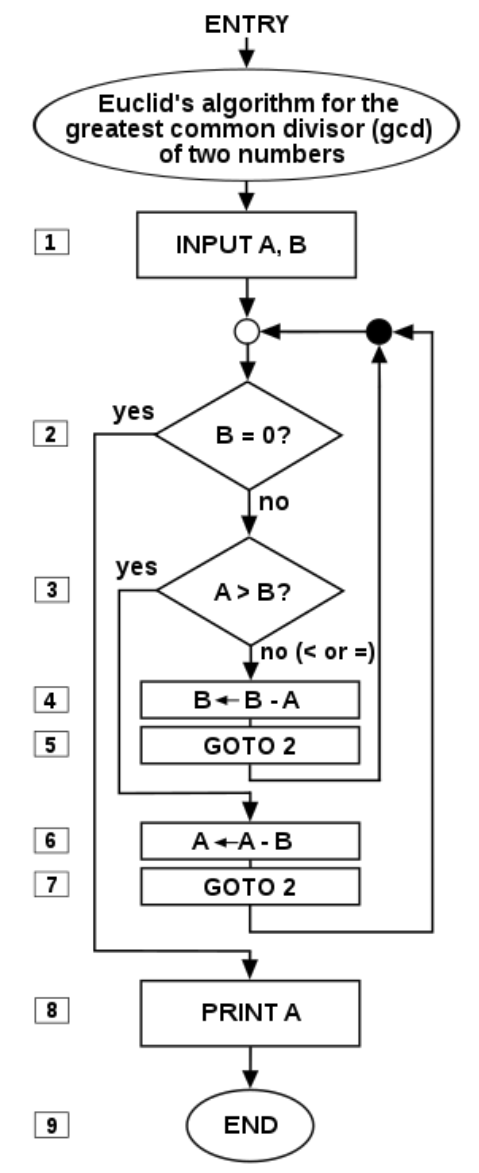

Figure 80. Flowchart of Euclid's Algorithm, Tausworthe, 1977

Originally coming from mathematics, parametric concepts use parameters or variables to manipulate the layouts of a system. As Woodbury, et al. (2006) describe, parametric modelling has two main types. One is propagation-based systems, where one computes from known to unknowns with a data flow model; the other is constraint systems, which solve sets of continuous and discrete constraints (Woodbury, et al., 2006). Parametric design works as a style rooted in digital animation techniques, its latest refinements are based on advanced parametric design systems and scripting methods (Schumacher, 2009).

There are two parametric approaches (Suyoto, et al., 2015). The first approach considers all designs to be parametric because design is based on parameters, 
such as legal aspects, orientation, solar radiation, and wind (Gerber, 2007; Aish and Woodbury, 2005; Hudson, 2010). The second approach considers parametric design as using a certain tool (Grasshopper 3D, Maya MEL, Rhino Scripting, Processing) to improve design by interconnecting and coordinating design components simultaneously (Woodbury, 2010). In the documenting phase of Form-Based Code, it is possible to practice the first parametric approach if the morphological control variables can be regarded as parameters. The visioning and assembling phases make it possible to practice the second approach. Software supports the parametric regulation system to generate threedimensional models. In the following section, parametric software that can be used in urban-scale regulations is presented before exploring the modelling system.

\subsubsection{Software}

A series of software can support parametric modelling in urban-scale design and regulation. There is no specific parametric software for Form-Based Code. The software that has the potential for regulation modelling includes Autodesk Revit, CityCAD, CityEngine, Project Galileo, and Grasshopper 3D.

Autodesk Revit is a tool of Building Information Modelling (BIM) used by architects and other building professionals. Parametric modelling is one of the main features of BIM that has been widely used in AEC industry, and has the potential to support Form-Based Code (Kim et al., 2011). As mentioned in Chapter 2, Form-Based Code implementation in Texas has already applied Autodesk Revit in the coding process. BIM software focuses on architectural details, such as windows and doors, materials, and façade details. It is suitable for building form regulation rather than large-scale massing and urban morphology control.

CityCAD was developed by Holistic City, which has been created specifically 
for the needs of the city design and planning community (Holistic City Company, 2015). It has built-in object libraries to help set façade types. The built-in objects are based on parametric techniques, but users can access limited parameters of the site information and urban typologies (Kim et al., 2011). CityCAD does not offer programming interfaces that allow its extension (Gil et al., 2010).

CityEngine is a three-dimensional modelling tool for an urban environment, which focuses on the visualisation aspects of realistic cityscapes for the movie and video game industries (Procedural Incorporated, 2015). It provides a limited interface for editing the regulation parameters without any analysis features (Kim, et al., 2011).

Project Galileo is a planning tool created by Autodesk, Inc. It can help create three-dimensional urban space by simulating real scenarios. The models also can be merged with GIS files, Revit, AutoCAD, and Project Vasari. But the software is in a testing stage (as of 2015). Only a test version is available (Autodesk Incorporated, 2015).

Grasshopper 3D is a plug-in for Rhinoceros 3D that presents users with a visual programming language interface to create and edit geometry (Reilly, 2014). The advantage of Grasshopper 3D is that it allows designers to build form generators from the simple to the awe-inspiring (Reilly, 2014). Dragging components or nodes onto the canvas and mapping the flow of parameter relations, a userdefined result is achieved with geometries and materials. Changing parameters causes changes to propagate throughout all functions, and the geometry to be redrawn (Davis, 2013). Because of its convenient operation and relatively mature technology, Grasshopper 3D for Rhinoceros 3D may allow parametric modelling for Form-Based Code. The following section presents the general process of large-scale urban design in parametric software. 


\subsubsection{Process}

Parametric modelling in urban-scale projects presents five elements, including parameter definition, scripts, massing models, manipulations, and layouts. Reviewing the five elements facilitates an understanding of the basic phases of parametric design

\subsubsection{Parameter definition}

The parameter definition phase attempts to designate specific parameters that control geometries. For parametric tools to apply in Form-Based Code, a wellwritten Form-Based Code should contain appropriate parameter types which make the code richer than Euclidean zoning, as well as avoid most of the quarrels that erupt over architectural style (Madden and Spikowski, 2006). The identification of parameters is a foundation of parametric design.

\subsubsection{Scripts}

Software scripts are essential for describing design as a series of relationships. Grasshopper 3D provides the parametric platform to edit scripts according to visions, deconstructing design into parameters, components and mathematic rules.

\subsubsection{Massing models}

In urban-scale projects, massing models briefly describe the characteristics of space and forms for modelling solutions. The models demonstrate scenarios based on the parameters and visions provided by the design team and the community.

\subsubsection{Manipulations}

Parameter manipulation provides real-time updated models by manipulating scripts in, for instance, Grasshopper 3D when multiple scenarios are required. Manipulation by adjusting parameter sliders is more convenient than 
conventional methods. In conventional methods, designers need to adjust the two-dimensional drawings, sizes or orientations, to obtain new threedimensional models. Comparing multiple layouts and models need time and human resource. While in parametric methods, parameters control both the twodimensional drawings and three-dimensional models. Adjusting parameter sliders of the scripts, a large number of real-time models are generated following the parameter changes.

\subsubsection{Layouts}

After a few rounds of evaluation and modification, layouts using parametric design processes demonstrate a well-conditioned result of design through visualised models. The parameters and models can be exported from software or directly used in further design (

Figure 81$)$.

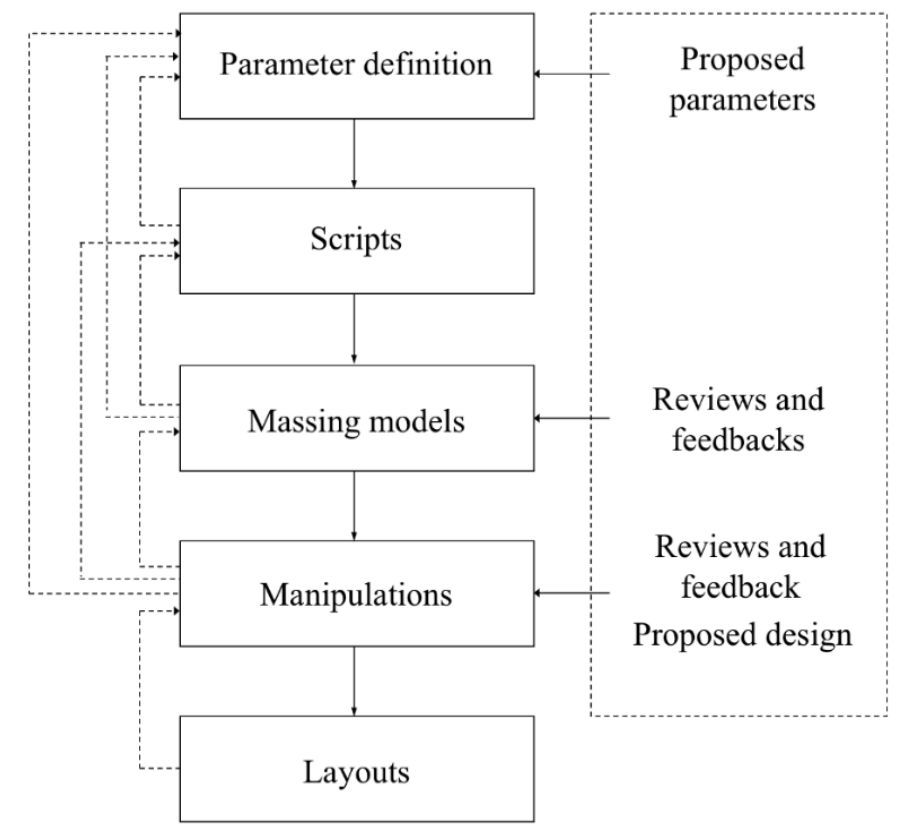

Figure 81. Parametric design process

\subsubsection{Parametric Form-Based Code}


Form-Based Code potentially works with parametric concepts. Euclidean zoning makes the urban form unpredictable (Barnett, 2011). It must be expressed in a two-dimensional manner due to regulating land use. Land use cannot be modelled in a three-dimensional way. Form-Based Code, however, consists of parameters, variables and numerical values. It has the potential to embed the coding process into modelling platforms. Modelling through parametric software offers a chance to describe the built results on an urban scale. People can experience detailed models at the conceptual stage of a project.

Parametric Form-Based Code offers an information-sharing platform for both regulation team and downstream architects and urban designers. Architects and urban designers can check the parameter values and the possible regulation results. They can change the parameters within a certain range according to their design strategies and modifications are fed directly to the regulation team. The regulation team can evaluate the models and feedback through deterministic scripts. Additionally, building spatial databases of urban performance provides service planners and government authorities with timely information to guide the planning process (Batty, et al., 2012; Oliveria et al., 2015). As a tool developed by architects for planners Rangwala (2013), Form-Based Code posits itself at the confluence of architecture, urban design and regulation. It can implement parametric instruments for architecture and urban design projects. Merged with parametric concepts, Form-Based Code becomes a novel zoning approach with new concepts, mechanisms and methodology.

The visualisation of efficient planning and decision making is possible with three-dimensional computational analysis (Ahmed and Sekar, 2013). While there are limited attempts at parametric urban regulation, which this research explores. Before further analysis of the parametric urban regulation system, a framework of parametric system in Form-Based Code is analysed in the following section. 


\subsection{Parametric systems in Form-Based Code frameworks}

The application of a Form-Based Code is generally set within a specific framework for creating and expressing regulations. This section explains the workflow of merging the parametric modelling system with a Form-Based Code framework. The system is an alternative approach to regulation and describes the resulting scenarios with illustrations for the communities who will adopt Form-Based Code. Chapter 4 analysed the pre-modelling part of the system which resulted in an extended transect matrix and a series of multi-layered regulating plans. This chapter explores modelling the system for parametric urban regulation (Figure 82).

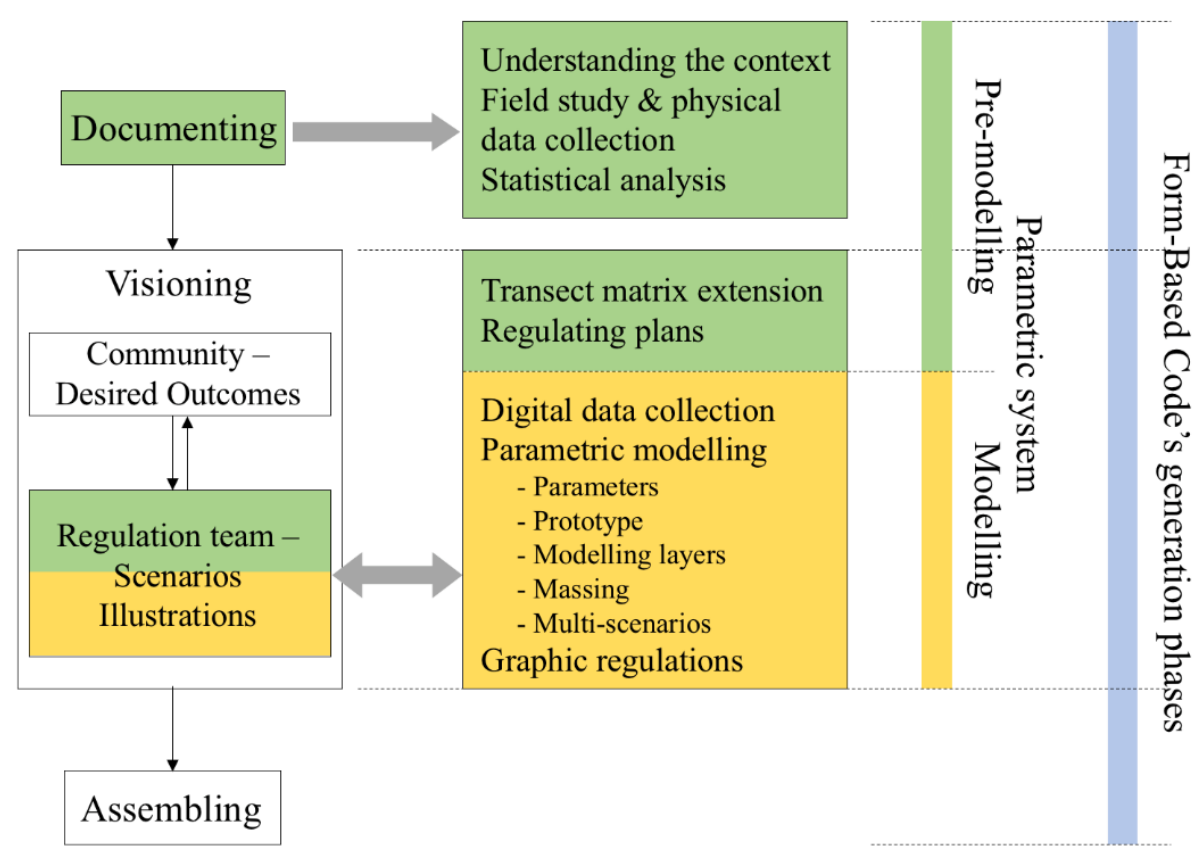

Figure 82. Structure of merging a parametric system in Form-Based Code

The parametric system works in the documenting and visioning phases of FormBased Code. As analysed in Chapter 2, generating a Form-Based Code requires three phases, namely documenting, visioning and assembling. Documenting is conducted by the regulation team, who collect general information about the 
target community. It includes understanding the context, field study, and physical data collection, as well as statistical analysis. The documenting phase establishes a foundation for generating Form-Based Code and parametric modelling. The visioning phase is a cooperation between the target community and the regulation team. This research focuses on the work of the regulation team, rather than the community's contribution. Members of the regulation team provide scenarios and illustrations to describe the intended outcome of regulation to the community. Parametric models contribute to providing a visualised description and three-dimensional models enhance the code generation and expression for communities. The assembling phase clusters the graphic regulations of all zones within a final code file. With a target of describing urban regulation with parametric models, the modelling procedure contains:

1. Digital data collection

2. Parametric modelling

3. Graphic regulations

Digital data collection imports existing building data, such as footprint coordinates and density, for the parametric modelling platform. This enables software-generated parametric models. Parametric modelling works to create multiple models at the ground, underground, and upper ground levels that correspond with the transect matrix and regulatory plans developed in Chapter 4. The parametric system provides graphic regulations, which translate twodimensional expressions of Form-Based Code into a new mode with model renders and parameter manipulations. Using parametric tools on a computational interface presents visualisations of urban regulation in a novel manner. The following sections describe the individual processes of the parametric system. 


\subsection{Digital data collection}

This section describes collecting digital data and importing it into the parametric modelling platform. Tsim Sha Tsui has established urban form configurations. The purpose of digital data collection is to enable the use of the data of Tsim Sha Tsui to build a foundation for the parametric modelling of urban regulations.

\subsubsection{Data type and base}

In addition to the physical data, digital data is also essential for the parametric modelling system. It reflects the locations of existing buildings, the scale of the sites, and the construction density of each area for the modelling software interface, which directly affects the layouts of the parametric urban regulation. The digital data collected in this section contains the coordinates of the buildings of each area in Tsim Sha Tsui.

One widely used tool for collecting geographic and spatial data is GIS software. GIS applications allow users to create interactive queries (user-created searches), analyse spatial information, edit data in maps, and present the results of all these operations (Clarke, 1986; Maliene, et al., 2011). It is argued, however, that GIS cannot work well for detailed regulation and urban design. The difficulty of regulation interpretation and the inaccuracy of the GIS data conversion process have been criticised (Kim and Clayton, 2010). According to Kim and Clayton, the inaccuracy data form GIS database including road network and building footprint is not easily cooperating with the parametric urban regulation.

Given the aim of parametric modelling for Form-Based Code, geographical data must first be exported from GIS software then imported into the parametric software with an additional process of coordinate correction. Additionally, most GIS data must be purchased. Considering accuracy, efficiency and economy, this research chooses OpenStreetMap (OSM) as the digital database, rather than GIS applications. 
OSM was founded by Steven Coast in the UK in 2004. The OSM Foundation, a non-profit organisation of England and Wales, began distributing free geospatial data for use and sharing in 2006. Through an online interface, users can collect data through various approaches such as manual surveys and Global Position System (GPS) devices. Compared with GIS geodatabase data, OSM data contains less geography information and limited information layers. The longitudinal information such as elevation coordinates is not collected by OSM. The topography that directly gained from OSM is flat without longitudinal values. The primary focus of OSM is creating an editable map of transportation infrastructure (streets, paths, railways, or rivers). Besides, OSM data also collects a multitude of points of interest, buildings, natural features and land use information, as well as coastlines and administrative boundaries (Geofabrik, 2017). OSM provides a relatively accurate substantial database rather than geographical database that can be directly embedded and edited in parametric modelling platforms.

\subsubsection{Workflow}

The workflow describes geospatial data collection using OSM and converting this data to a format that parametric modelling software can recognise. The aim here is to generate a group of OSM coordinate points of buildings that can be presented in a modelling platform. The workflow consists of determining coordinates, generating OSM files and importing the files into Grasshopper 3D (Figure 83).

To determine coordinates, the author searches Tsim Sha Tsui, Hong Kong through the online interface of OSM (Figure 84). This research defines Tsim Sha Tsui as a rectangular area with specific coordinates. To generate an OSM file, the application creates a geospatial database with suffix .osm according to coordinates defined by the Form-Based Code team. OSM offers four database 
types to suit different requirements, including Standard, Bicycle, Transportation, and Humanitarian. Each database type has a series of specific map legends. This research chooses the Standard database type of Tsim Sha Tsui to generate the OSM file.

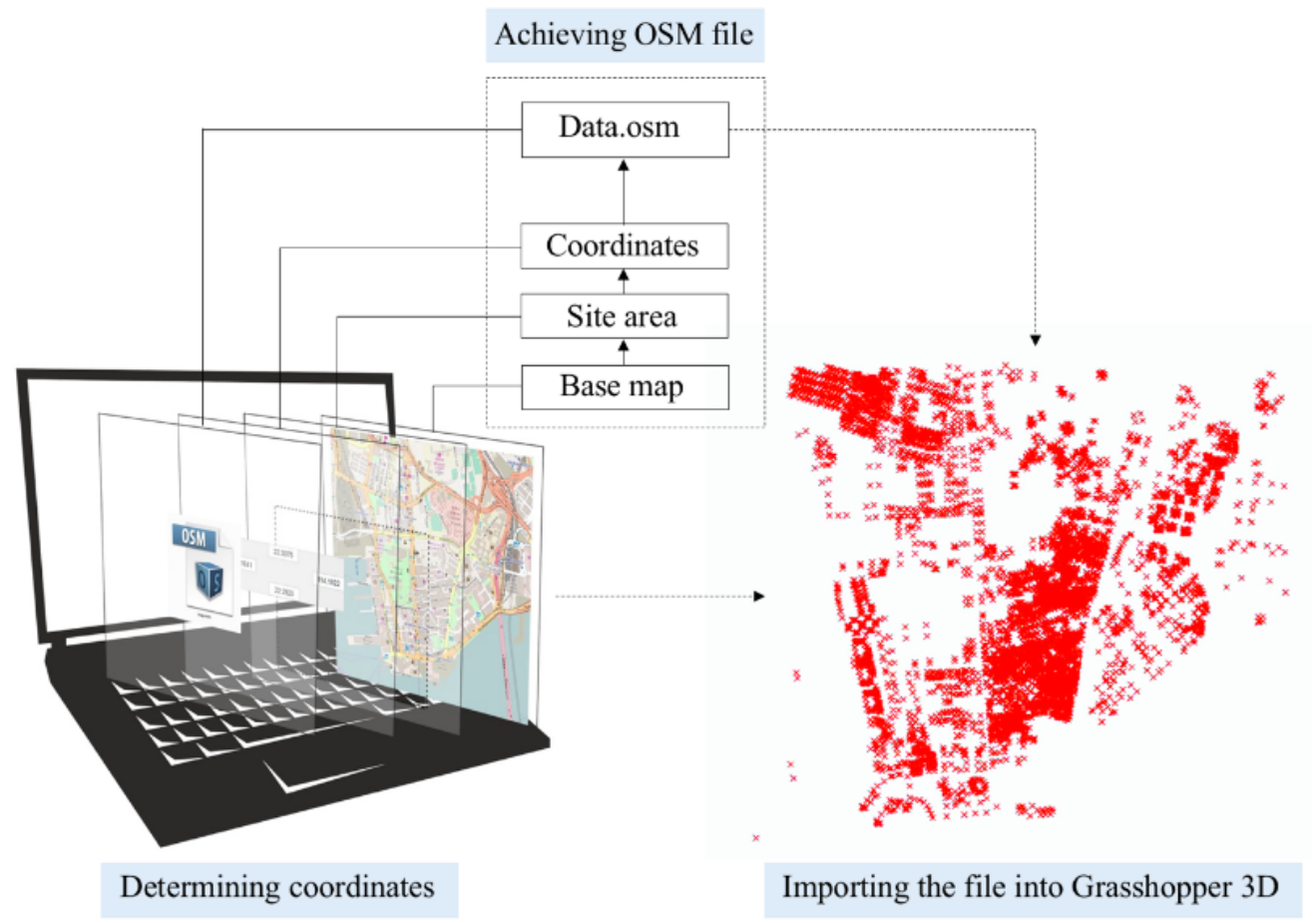

Figure 83. Generating an OSM file

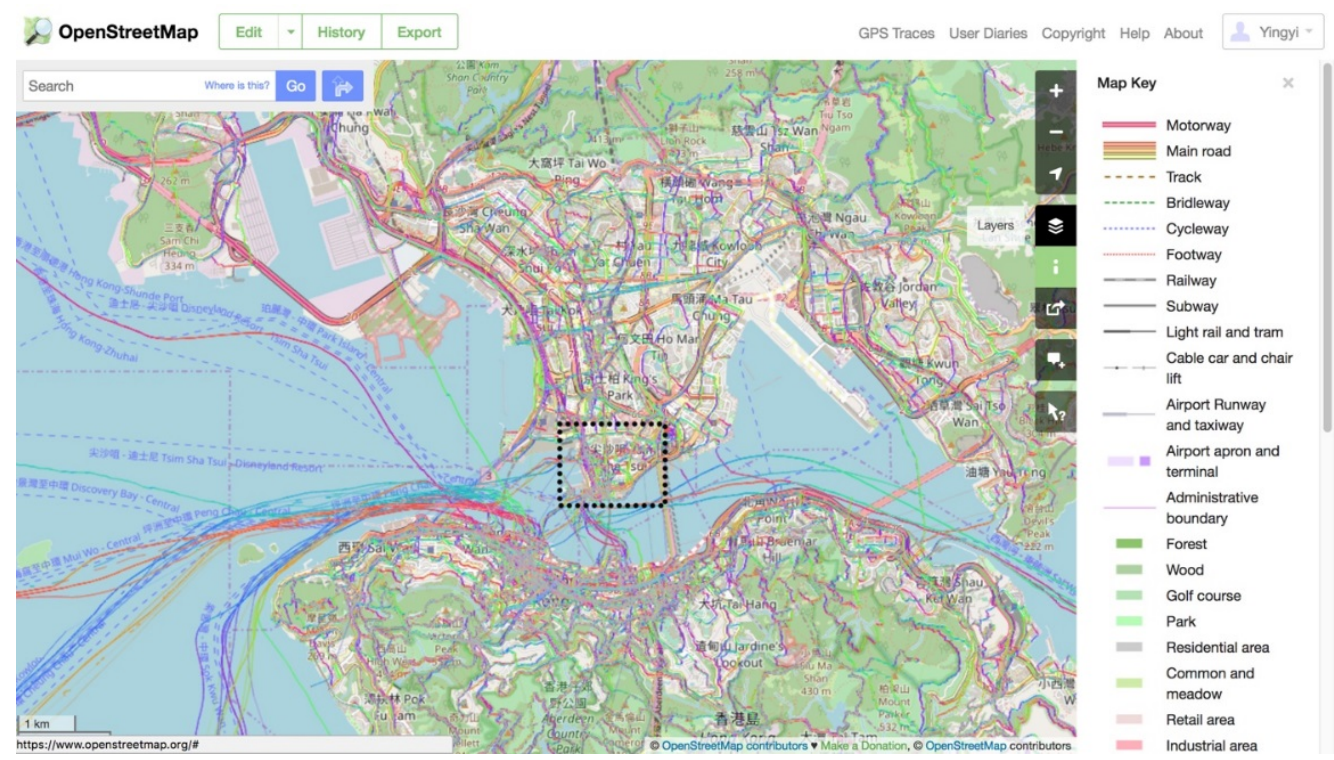

Figure 84. Screenshot of OSM interface, OpenStreetMap Foundation, 2017 
Elk, a plug-in of Grasshopper 3D, completes the process of importing the file into Grasshopper 3D. Elk organises and constructs collections of point and tag data so that people can begin creating curves and other Rhinoceros $3 \mathrm{D}$ or Grasshopper 3D geometry (Logan, 2016). OSM files provide a database that can connect with Elk components by writing a prototype in Grasshopper 3D. The following section describes the details of generating a prototype for clustering the geospatial data.

\subsubsection{Prototype of clustering geospatial data}

The prototype of clustering geospatial data translates OSM files to parametric languages in Grasshopper 3D. It incorporates the Elk components of File Path, Location and OSM Data. The File Path component provides the initial spatial database for the prototype. The Location component works to process data of OSM file and provides OSM Point Data for the OSM Data component. Connecting the File Path to OSM Data, a map of building coordinate points is generated in Grasshopper 3D (Table 31).

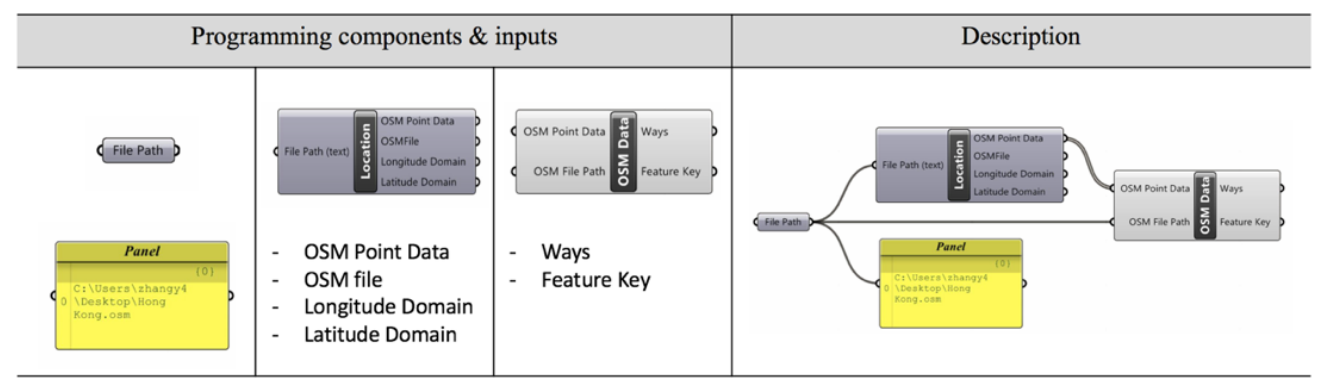

Table 31. Components and script of clustering digital data

Elk also offers multiple building coordinate point types to. The pop-up menu (Figure 85) specifies features before processing the connection between Location and OSM Data. The menu defaults to selecting types of building. The layered database makes it possible to edit customised information in different 
conditions. When modifying the building coordinates of the experimental site, the Form-Based Code team can reconnect the OSM file with a component of File Path to achieve a real-time updated map of coordinate points in Grasshopper 3D.

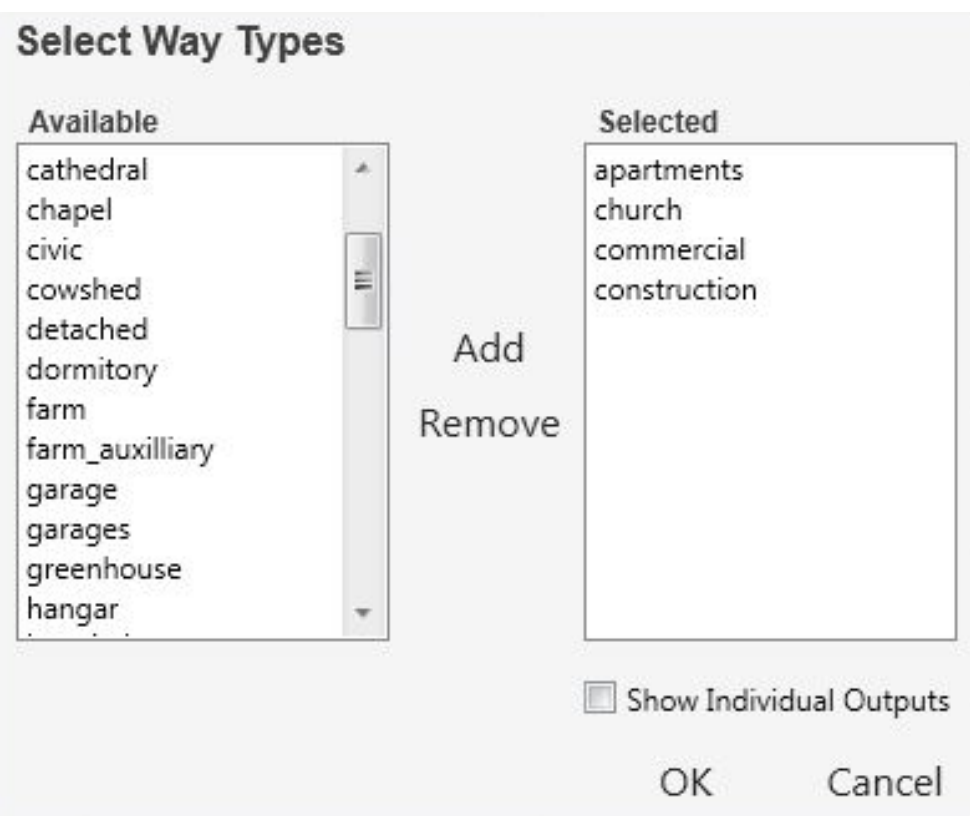

Figure 85. Pop-up screen of Elk

The OSM format file establishes the foundation of parametric modelling by embedding the corner coordinates of the footprint of each building into the modelling platform. Through the tools of Elk and Grasshopper 3D, the building coordinate points are allocated to the site. Building footprints in each area can be represented by a number of coordinate points without height information. In principle, the place with more coordinate points contains more buildings and vice versa. Dividing Tsim Sha Tsui into a matrix of rectangles demonstrates that rectangles with coordinate points have clustered buildings, and the blank rectangles without coordinate points have no buildings (Figure 86). Considering the high degree of exploitation and urbanisation in Tsim Sha Tsui, there is no undeveloped land available for newly developing urban space. Thus this 
research regards blank rectangles as large-scale public spaces or parks on which construction is forbidden. Parametric modelling is processed in the rectangles with building coordinate points. The following section explores the parameters and prototypes of the parametric modelling in these rectangles.

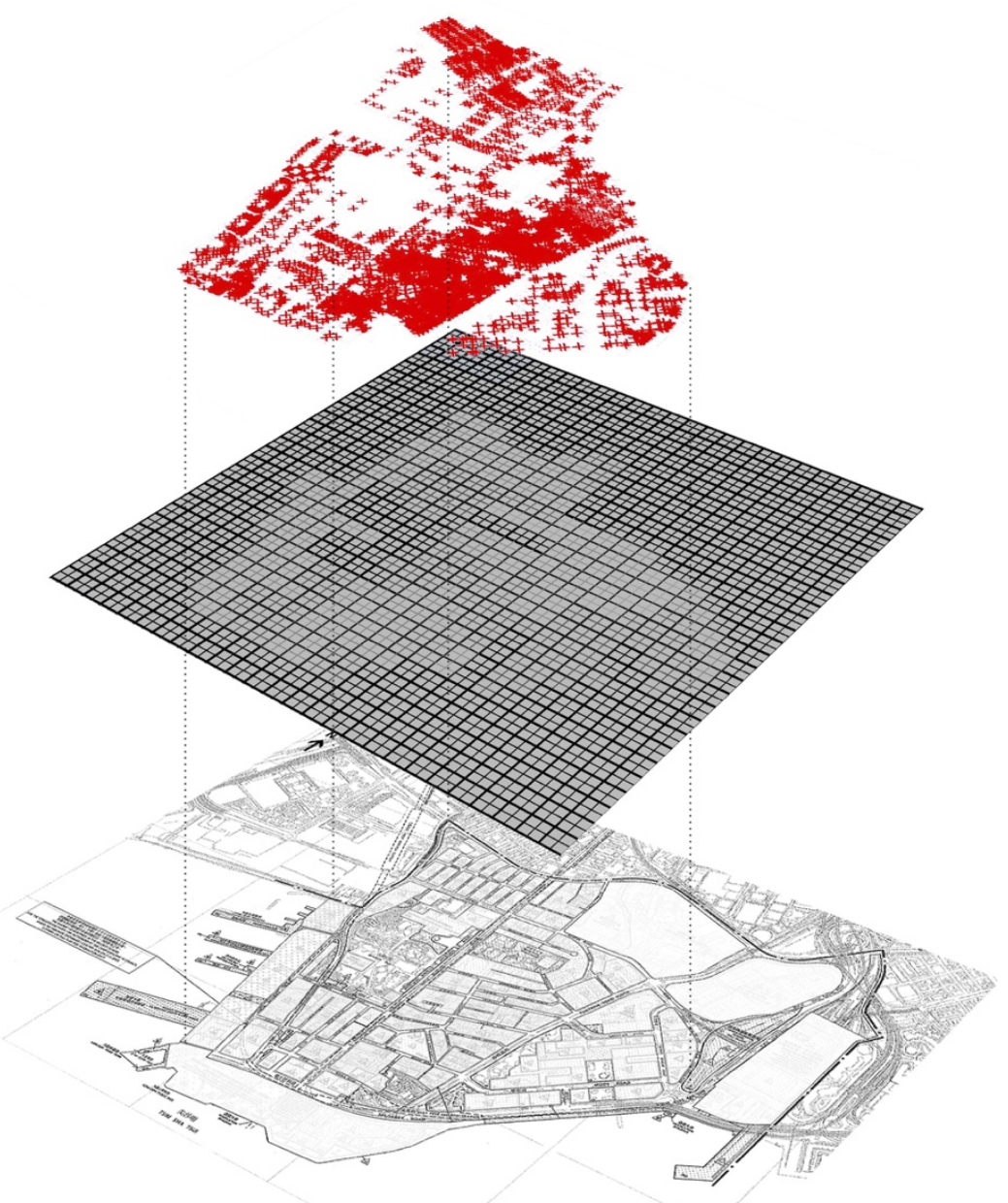

Figure 86. Coordinates of buildings maps on the modelling site 


\subsection{Parametric modelling}

This section explores parametric modelling for Form-Based Code to integrate related parameters, and generate logic and manipulations in one modelling process. The system intends to provide performance feedback at the conceptual stage of urban regulation. This performance feedback helps to describe the provisions visually for visioning between communities and Form-Based Code teams.

\subsubsection{Parameters}

The parameters used to compose the modelling rules are aligned with the variables used to regulate forms in a Form-Based Code. The Form-Based Code examples in Chapter 3 demonstrates the frequently used variables of FormBased Code, such as building height, lot coverage and the number of building storeys. These variables all contribute to regulating urban forms at ground level. Due to the volumetric morphology of Tsim Sha Tsui, parameters need to be extended to ground, underground and upper ground to graphically describe the regulations of multiple layers.

At ground level, regulating building form is a major component in a FormBased Code process (as analysed in Chapter 2). Parametric modelling in this section regards building regulation modelling as the primary task of the conceptual stage. In a large-scale urban project like the Form-Based Code of Tsim Sha Tsui, building heights and scales reflect general urban forms and regulatory purpose. Other detailed elements such as street width or plot size are difficult to clearly describe in a conceptual massing. So in this section, the building forms are largely regulated by height related parameters. The building regulation parameters are:

1. First ceiling height

2. Standard ceiling height 


\section{Storeys}

4. Minimum building height

5. Maximum building height

6. Building coverage

The First ceiling height describes the distance in buildings between the first floor and the first floor's ceiling. Located at the urban core zone, most of the buildings in Tsim Sha Tsui have mixed functions; the first storeys are often shops and the upper storeys residences or offices. The storeys for commercial use are higher, and those for residential or general office use are lower. Therefore, setting the parameter of first ceiling height is to meet the requirements of mixed function buildings. Standard ceiling height describes the ceiling-to-ceiling distance. It is related to the range of total building heights cooperating with the storeys parameter. Minimum and maximum building height are parameters controlled by single storey height and number of storeys. Tsim Sha Tsui contains a high population within a constrained land resource. It is necessary to limit building heights to a suitable range. Regulating the minimum building height ensures efficient land use and avoids resource wastage. Regulating the maximum building height controls the city skyline, ensuring a relatively high quality of living environment while avoiding solar obstruction. The building coverage parameter controls a certain amount of outdoor space. Using the rectilinear matrix developed in the previous section, areas of open space and public activity places are distributed into the rectangle matrix. Assuming each rectangle with coordinate points contains one building unit, the building coverage value can be calculated by scaling the rectangular areas. This parameter helps to estimate the index of total public place areas and the building coverage ratio of the site.

For the underground level, it is not accurate to describe an underground FormBased Code as fully form-based because underground space is not composed of 
buildings and streets. The underground transect matrix is a hybrid of form and function. However, parametric modelling must be conducted according to form with specific value ranges. The form-related parameters for underground level include:

7. Minimum ceiling height

8. Maximum ceiling height

9. Storeys

The regulation, oversight and policies of underground construction in Hong Kong are managed by the Transport Department of the Government of Hong Kong Special Administrative Region, Railway Development Office, and Legislative Council. There are standards of underground space construction in the provisions established for Hong Kong. A Form-Based Code for underground space limits regulation to a conceptual model from the perspective of form control. It intends to generally describe the distribution and various depths of the underground space of Tsim Sha Tsui.

For the upper ground level, the forms of corridors and connections between buildings are related to the size and location of constructions in both vertical and horizontal directions. Like underground regulation, the upper ground regulation of Form-Based Code limits the modelling parameters to the formrelated ones, including:

10. Minimum ceiling height

11. Maximum ceiling height

12. Connection numbers

13. Distance to ground 
The parameters of upper ground regulation support a general description of connecting forms between buildings. Minimum ceiling height and maximum ceiling height describe the scales of connections that can be perceived. The connection numbers parameter defines the total number and location of connections at the same height. Distance to ground describes the locations in the vertical direction. A series of parameters are prepared to generally describe the building forms in a volumetric morphology. The following section provides a prototype embedding these parameters in a computational platform to generate parametric models for a Form-Based Code for Tsim Sha Tsui.

\subsubsection{Prototype of parametric modelling}

To generate parametric models, a prototype is created by integrating parameters into a visualised coding procedure. The prototype consists of modules of ground, underground and upper ground levels. These modules align with the zone subdivision, transect matrix and regulating plans described in Chapter 4. Each module contains one system with in-put, running, and ex-put parts. Manipulating the in-put information directly changes the performance feedback of ex-put. Figure 87 presents a simplified mode of the modelling system.

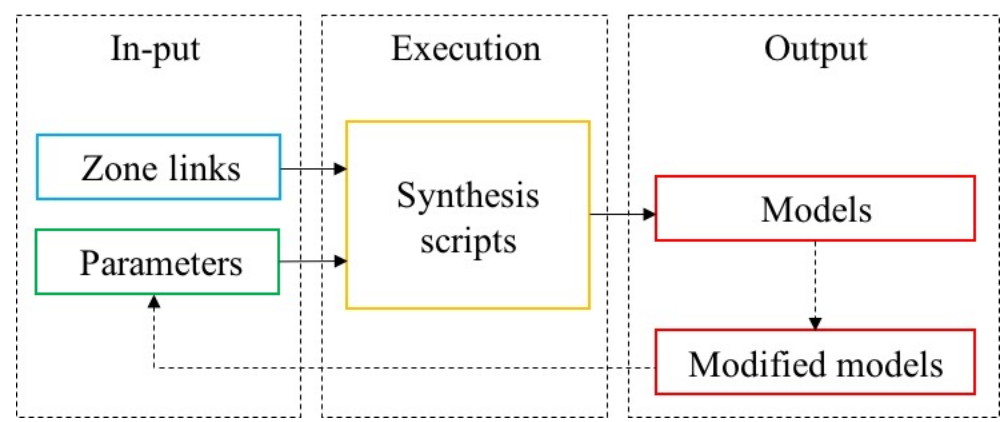

Figure 87. Structure of the prototype of parametric modelling

\subsubsection{In-put}

Modules of multiple layers compose the parametric modelling prototype for a Form-Based Code. Grasshopper 3D provides the script editing interface (Figure 
88). The in-put part of the prototype contains two elements: Zone links to the corresponding regulating plan, and parameters of individual ground areas. These two elements provide the original material for prototype execution and output. Zone links are based on the multi-layered regulating plans developed in Section 4.4. For instance, the ground zones T6-1, T6-2, T6-3, T6-4, T6-5, and T6-6 can be in-put and mapped on the rectangle matrix in Rhinoceros 3D. They form the modelling site of the ground module. Similarly, underground and upper ground zone links can also be in-put and mapped on the rectangle matrix. Mapping zones is based on the ground regulating plan developed in Section 4.5. The parameters of individual levels, such as standard ceiling height and storeys, are then described as number sliders which can be manipulated during the modelling process.

\subsubsection{Execution}

The execution part provides synthesis scripts consisting of commands to conduct the modelling procedure. The commands' composition reflects the running logic of each module. The synthesis scripts of the running part are established by the script units of different zone types. According to the transect matrix of Tsim Sha Tsui, there are seventeen zone types in multi-layered grounds. Each zone type has a script unit for parametric modelling.

For ground level, the script unit is described in Figure 89. Group A is for the maximum building height regulation. By setting the ceiling height and building layers in a certain range, a series of different maximum building height ranges is generated. Similarly, Group B manipulates the minimum building height range. Group C controls building coverage. Assuming plots are in a rectangular shape, the coverage of buildings can be roughly calculated by scaling the plots. Group D works for multiple scenarios testing by changing the random seed value. The combined components with parameter value sliders result in the modelling performances in Group E. 


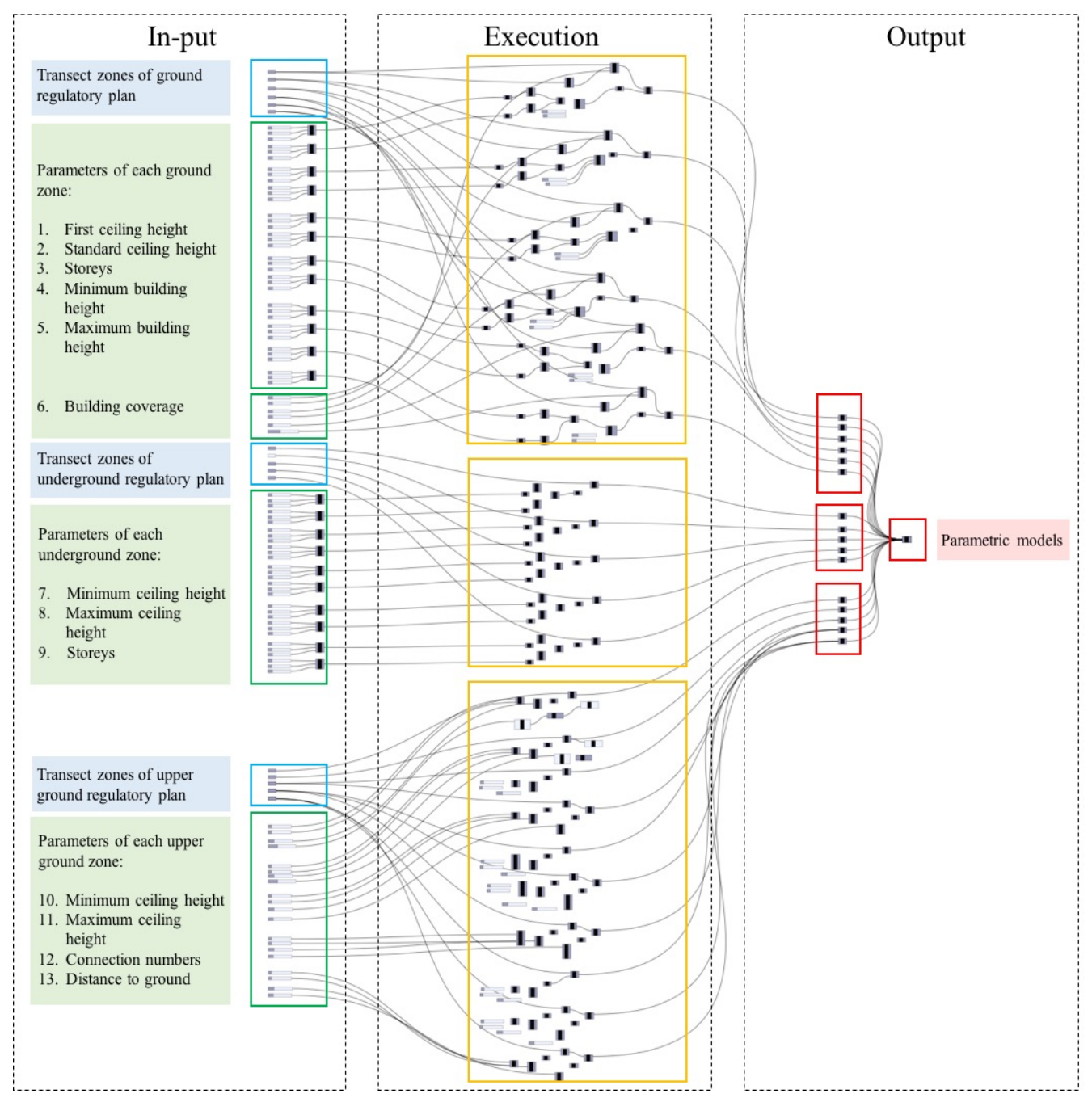

Figure 88 . Script of the parametric modelling system

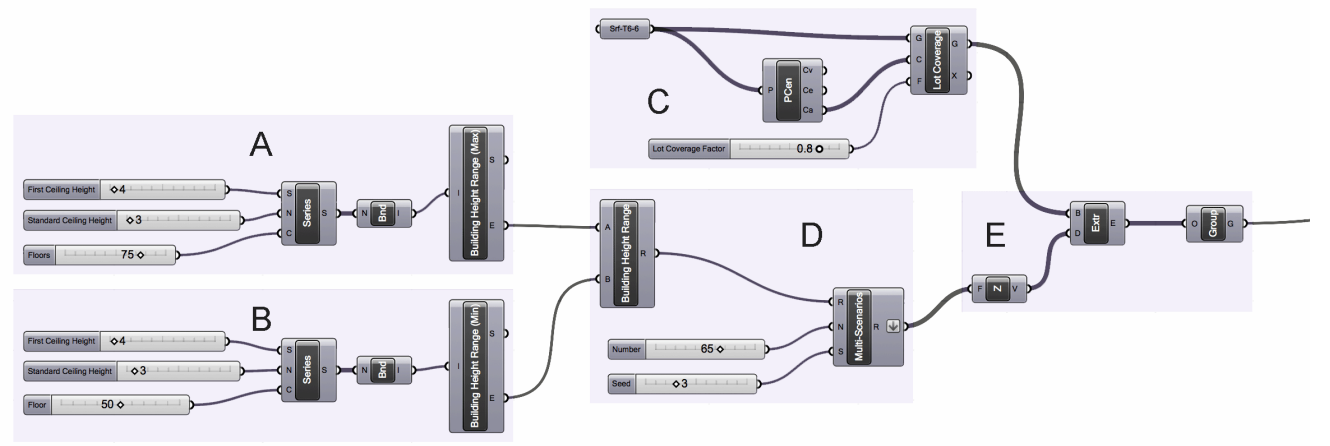

Figure 89. Script unit for modelling of the ground level 
The script unit for the underground level is described in Figure 90. Group A reflects the maximum ceiling height range. Group $\mathrm{B}$ reflects the minimum ceiling height range. Group $\mathrm{C}$ roughly reflects underground depth by calculating ceiling height and storeys under the ground. Construction depths are not included in the modelling. The script units of zone U1, U2, U3, U4, and U5 create the synthesized script relating to the underground level.

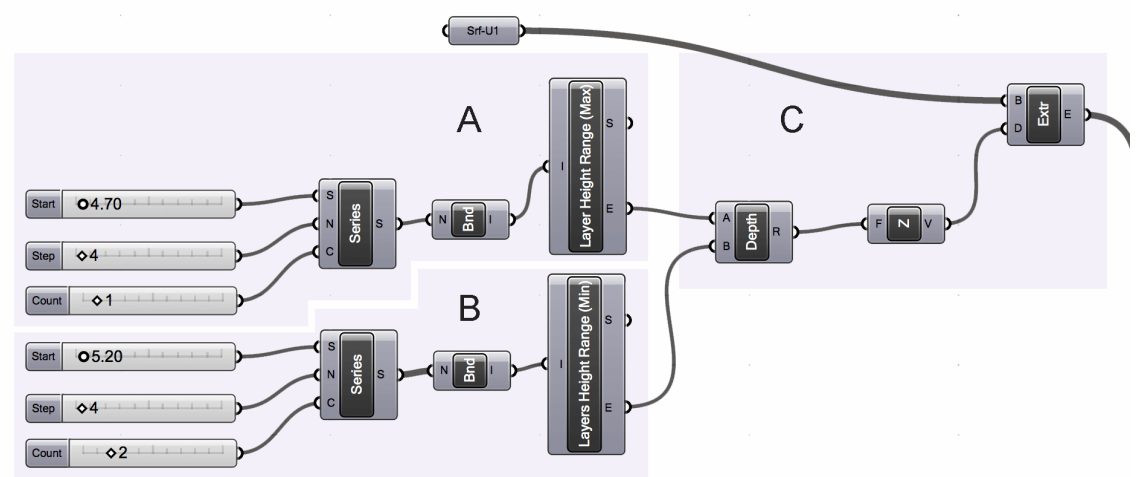

Figure 90. Script unit for modelling of the underground level

For the upper ground level, the script unit is described in Figure 91. Group A regulates the range of ceiling heights. Group B regulates the number of connections between buildings. Group $\mathrm{C}$ controls the vertical connecting layers of the specific building. Combining the script units of zone V1, V2, V3, V4, and V5, an independent model of the upper ground level connections is roughly generated, with various locations in vertical and horizontal directions.

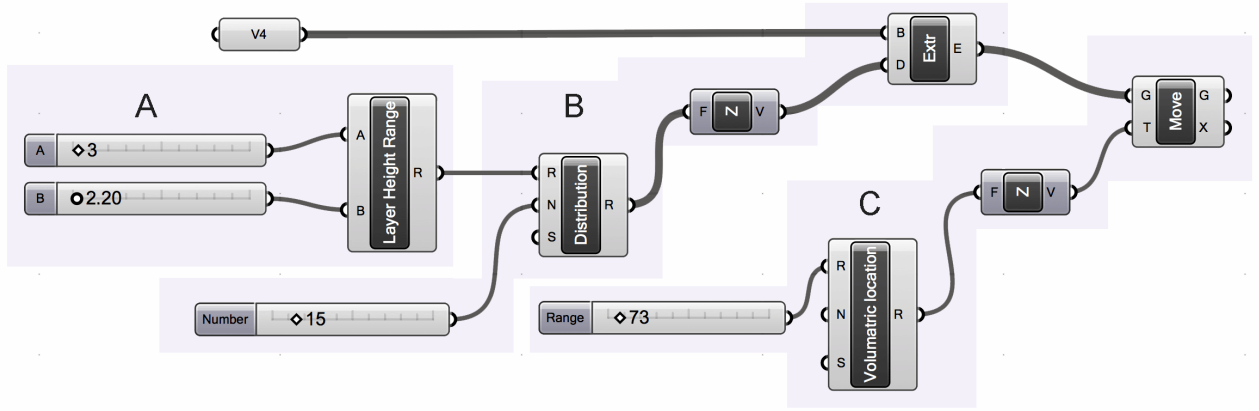

Figure 91. Script unit for modelling the upper ground level 


\subsubsection{Output}

The output part of the system clusters ground, underground and upper ground level modules. It automatically relates to the modelling performances described in Rhinoceros 3D. The prototype of this section is developed according to the morphology of Tsim Sha Tsui. Due to the regenerative feature, this prototype has the capability to be re-applied in other Form-Based Code projects by manipulating zone links and parameters to gain a different modelling result. It provides real-time performance feedback when in-putting any required zone links and parameters. A Form-Based Code team can use the prototype to generate massing models for communities who wish to adopt Form-Based Code as their approach to urban regulation. Before exploring the massing models, the following section establishes a series of modelling layers in Rhinoceros 3D.

\subsubsection{Modelling layers}

According to the former analysis, the volumetric urban morphology of Tsim Sha Tsui leads to a multi-level transect matrix and regulating plans. Underground and upper ground models are also components of the parametric modelling system. To embed the idea of multi-level urban regulation in a parametric platform, it is necessary to create layers as data containers.

The visualised coding process in Grasshopper 3D directly connects with the performance in Rhinoceros 3D. The parametric models follow the manipulation of the parameter value sliders. Due to the multiple zone types and volumetric layers, it is necessary to generate a layer system to contain the extensive information. This section uses a layer management panel of Rhinoceros 3D to divide each spatial level, base map and transect zone type into different layers (Figure 92). Data changes can be processed separately to reduce impacting the information of other layers. By applying the modelling system in Grasshopper 3D to different layers in Rhinoceros 3D, platforms can generate continuous differentiation massing models in real time. The classification layer reflects the 
zone type subdivisions of Form-Based Code and their manner of cooperation with the parametric platform.

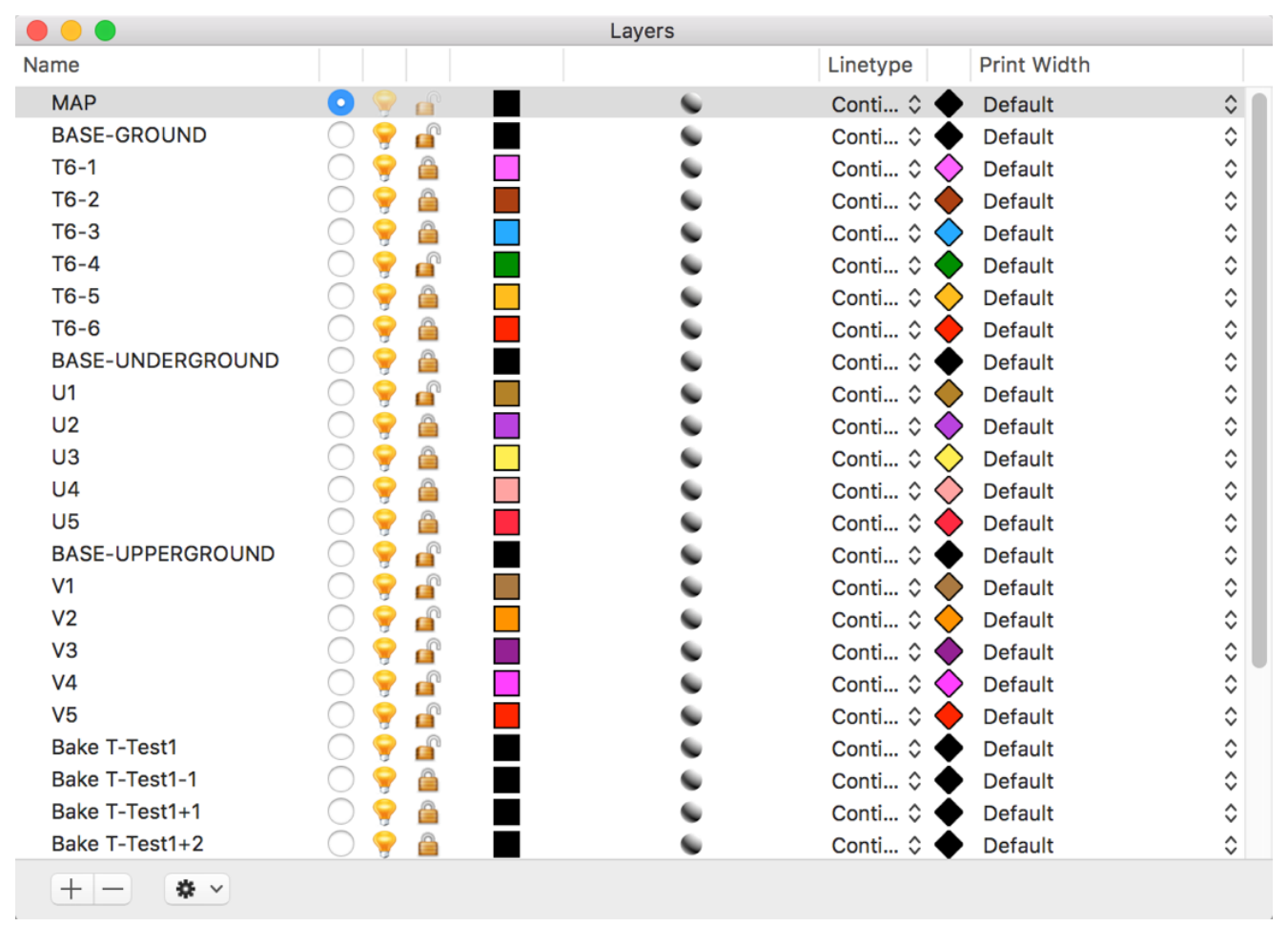

Figure 92. Modelling layers on the modelling platform of Rhinoceros 3D

\subsubsection{Massing}

As analysed in Chapter 2, Form-Based Code describes zones by using form. Form is regulated by specific size or a range of sizes, rather than land use. Massing provides performance feedback under the regulatory concepts of FormBased Code. This section analyses the massing models aligned with the prototype developed in Section 5.4. Reflecting on the interface of Rhinoceros $3 \mathrm{D}$, the massing models conceptually estimate form-related elements such as the general height of building units, skyline, density, and FAR trends in Tsim Sha Tsui.

Building units represent buildings in the rectangle matrix created during digital 
data collection. Although the current buildings are of different sizes and footprints, most have a regular shape with an approximately rectangular footprint. This section uses the building unit in each rectangle to simulate building regulations. The skyline is reflected by the heights of the building units. Density and FAR trends are indicated by the coverage of building units. Using the ground level as an example, the massing model is created following the example prototype and modelling layers of the previous sections (Figure 93).

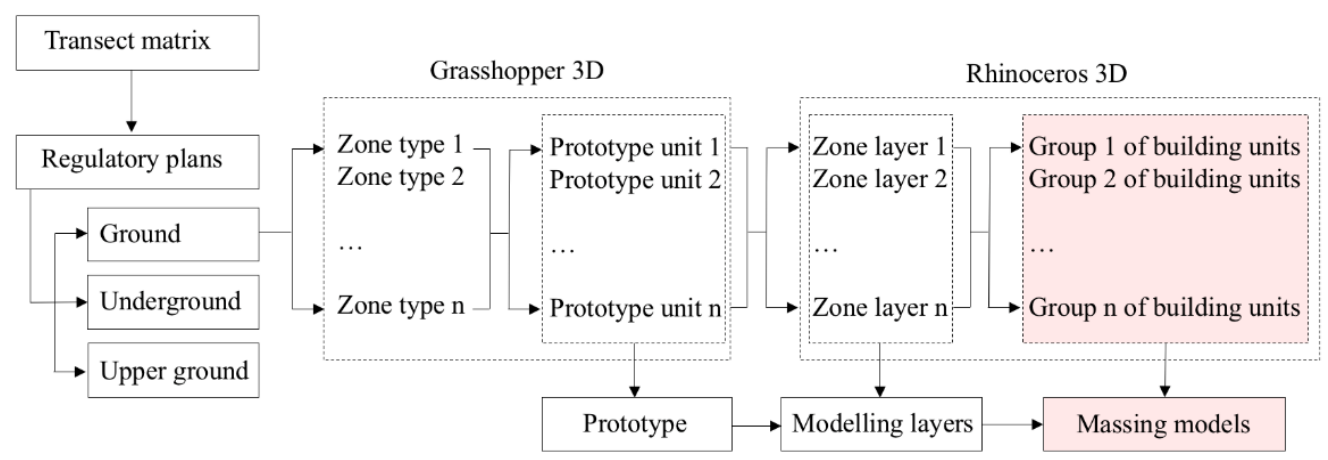

Figure 93. Structure of generating massing models

The models of each zone type at ground level are generated according to the parameter ranges and the coordinates of transect types (Figure 94). The highlighted parts of each model represent the massing of the specific zones of T6-1, T6-2, T6-3, T6-4, T6-5, and T6-6. One transect zone corresponds to one prototype unit in Grasshopper 3D and one zone layer in Rhinoceros 3D. Grouping the building units benefits parameter modification and multiple scenarios testing. It is common for Form-Based Code teams to receive feedback from communities or government regulatory departments during the conceptual modelling stage. When amendments are required, each unit can be modified independently to reduce influencing other building groups and zone types.

Parametric Form-Based Code regards the form-related parameters as the basic modelling materials on computer-aid platforms. Building forms, such as height, width and lot coverage, are regulated by parameters with numerical values. 
Modelling the forms through parametric software provides an opportunity to predict the building results on an urban scale. Communities who intend to adopt a Form-Based Code can experience "code models" through a software interface. In real implementations, a Form-Based Code team can script programmes in Rhinoceros 3D and Grasshopper 3D to achieve specific regulatory targets with real-time performance feedback.
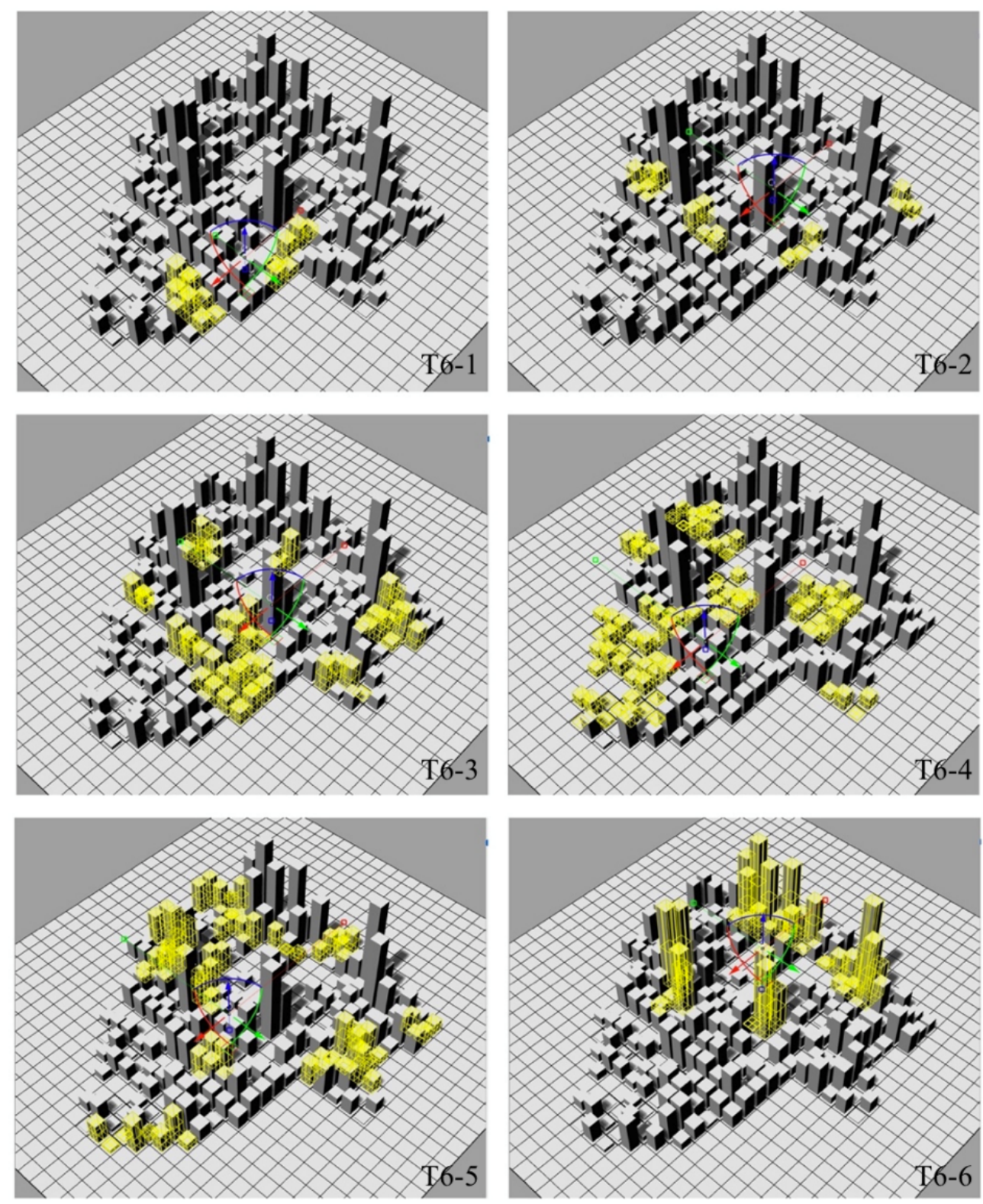

Figure 94. Massing models of different zones 
In contrast to the parametric approach within Form-Based Code, conventional urban regulation based on the division of land use cannot be expressed by models. Land use-based approaches to regulation make the determined urban form unpredictable (Barnett, 2011) as conventional regulation must describe codes in a two-dimensional manner. Without form-based parameters, land use cannot be modelled three-dimensionally. Traditional Form-Based Code relies on specified numerical values such as FAR to regulate urban forms. Using parametric instruments to aid the traditional Form-Based Code, the new FormBased Code enhanced by parametric capability demonstrates an alternative approach to urban regulation by using the parametric modelling system. The parametric modelling system consists of a series of scripts. Changing the parameter values or relationships in the scripts, real-time three-dimensional models are generated for presenting possible scenarios. The numerical values of traditional Form-Based Code do not directly reflect three-dimensional scenarios but parameters and scripts of parametric Form-Based Code do. The following section implements the system in parametric Form-Based Code to test multiple scenarios.

\subsubsection{Multi-scenarios}

Multiple scenarios can be generated by implementing the parametric modelling system in Form-Based Code. Manipulating the parameters of the system allows differentiated layouts on the parametric platforms. Understandings of primary regulation factors differ between Form-Based Code teams. Changing the parameters to other types or values varies results, even within the same programming prototype. Form-Based Code solutions then present a diversified trend. Testing multiple scenarios can be as achieved by manipulating parameters in Grasshopper 3D to achieve models in Rhinoceros 3D. The models offer visualised feedback to Form-Based Code teams and contribute to predicting the results of regulation. They are in line with the modules of the prototype divided into ground, underground and upper ground level. 
For ground level, one possible regulation solution is described in Table 32. Setting the parameters by using the value sliders of the prototype, the regulation model demonstrates a scenario formed by specific parameter values. There are six zone types and eight sliders for modelling. Any manipulation of the sliders results in a new scenario at ground level. In Table 33, the ceiling height, building coverage and seed are changed. The regulation model incorporates the changes and becomes a new version. Figure 95 presents alternative scenarios resulting from different parameter values. Distinct from manual planning and zoning, parametric instruments create solutions by setting parameter values.

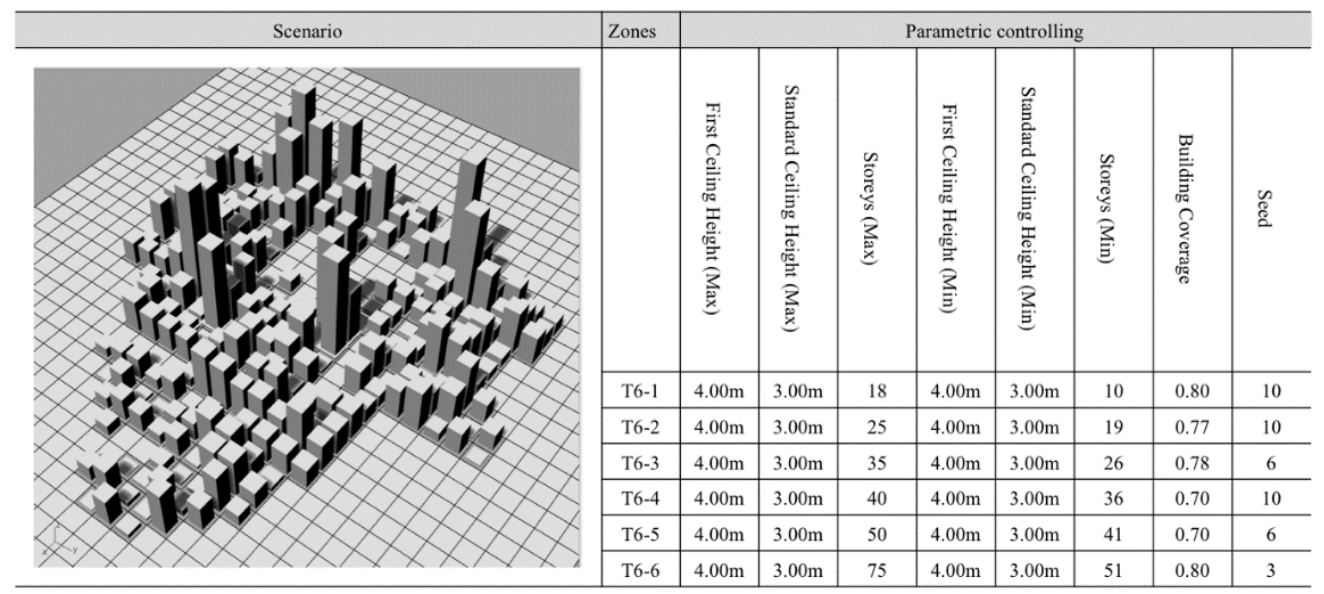

Table 32. Example of regulation solutions

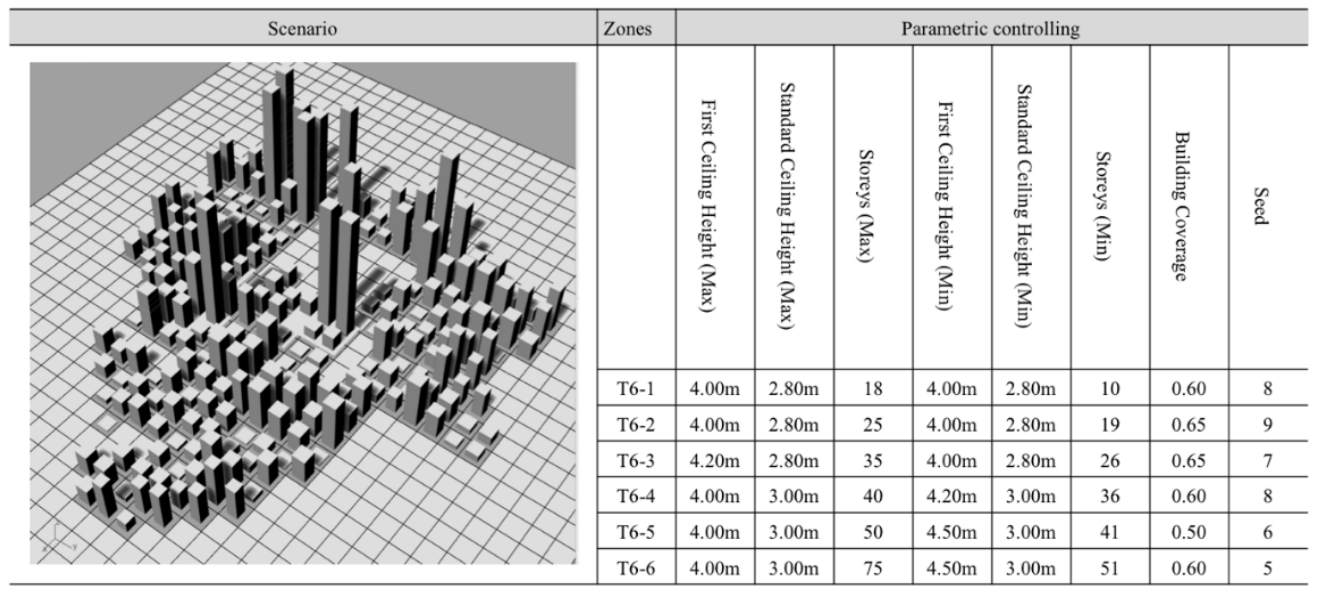

Table 33. Example of regulation solutions 

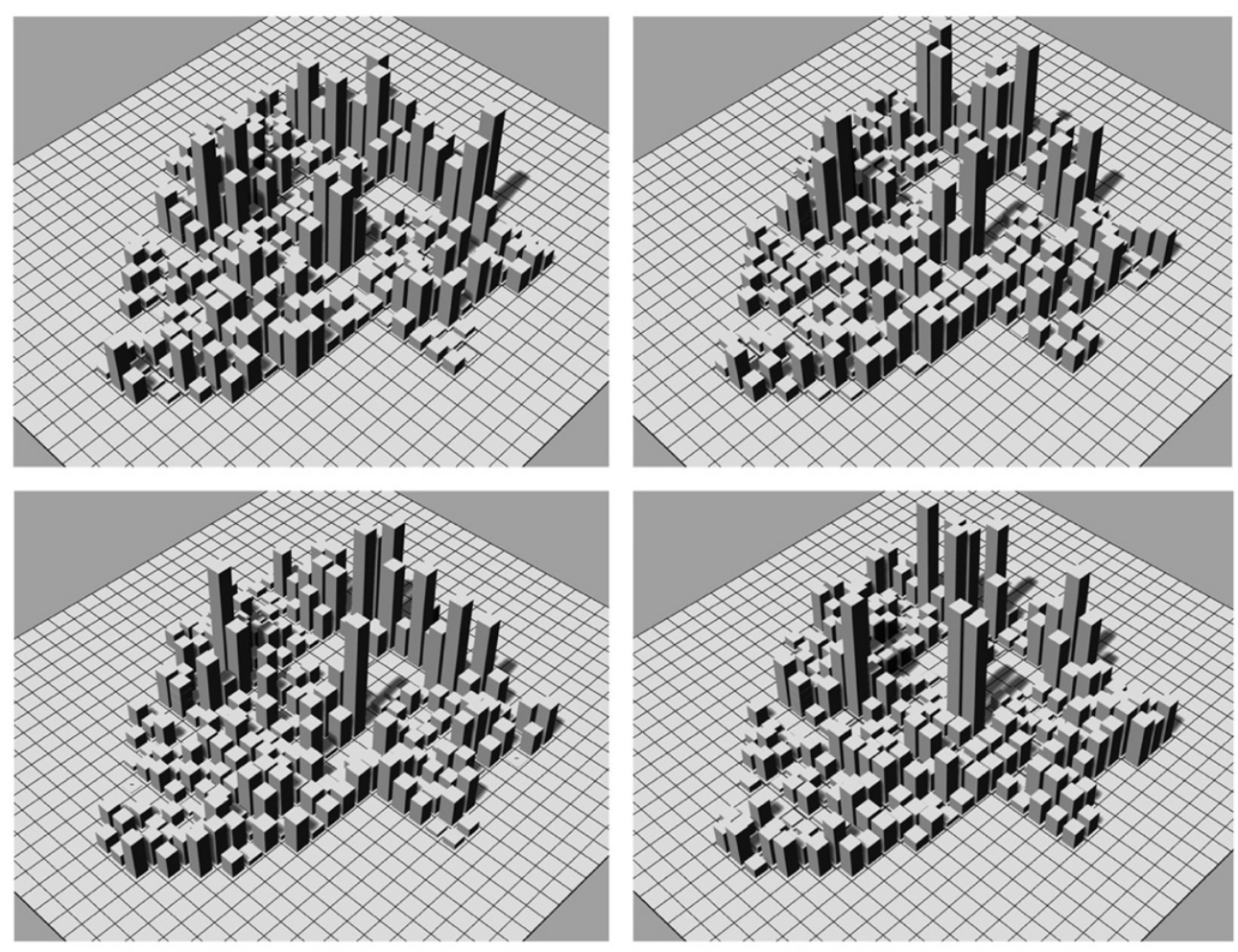

Figure 95. Scenarios of massing for the ground level

There is no practice in current Form-Based Code application for the building form regulation of underground or upper ground. This experiment attempts to extend the modelling process of ground space to underground and upper ground space. According to the field study in Tsim Sha Tsui, it is found that pedestrians feel relative indifference about facades, windows or overall scales of buildings in underground space. They regard the underground space as an extension of ground urban space for daily activities such as shopping or transporting. As analysed in Chapter 2, Form-Based Code needs to contain building form standards. Thus this experiment uses building form standards of underground space as an example to generate underground parametric Form-Based Code models. The script constrains the parameters of storey height and numbers of transitional storeys. These two parameter types work to reflect substantial depth underground. 
Based on the prototype unit of the underground level, various regulation models are generated as in Figure 96. For convenient description, the models are overturned by making the layouts "on the horizon". The storey heights of the layers are in the range of $4.5 \mathrm{~m}$ to $5.2 \mathrm{~m}$. The parameters' values depend largely on the local underground construction code, the land conditions and other elements that might affect underground development. After modelling for underground, the models are turned and placed under the horizontal level. Example ground and underground level scenarios are presented in Figure 97.

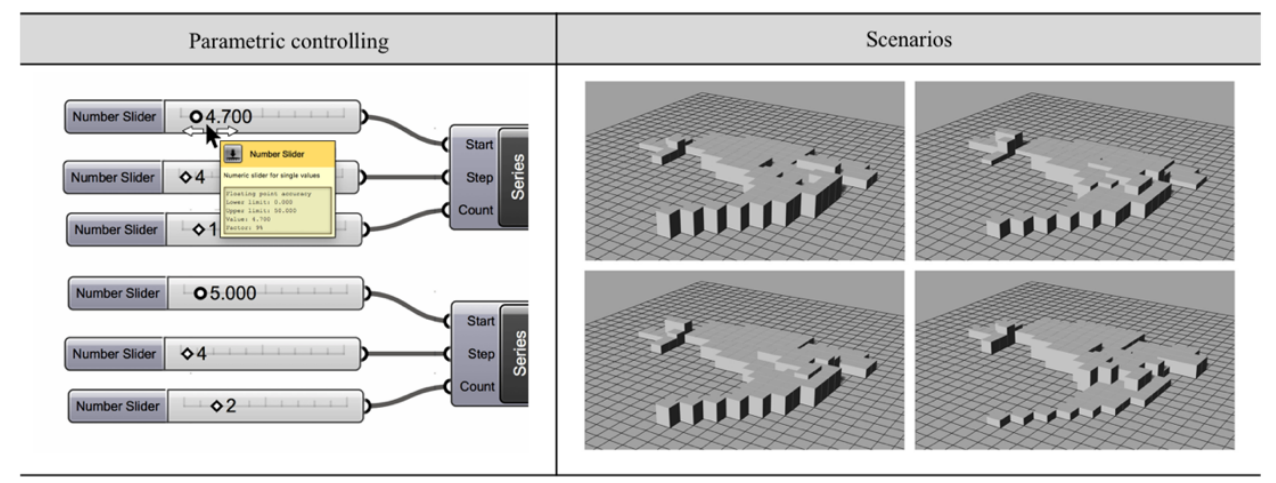

Figure 96. Scenarios of massing for the underground level

For the upper ground level, the connections between high-rise towers and buildings create urban space in multiple levels cooperating with the specific floors of the towers and buildings. Hong Kong's upper ground urban space is used for transporting, gardening or even rooftop living as analysed in Chapter 3. There are no mature Form-Based Code applications that contain standards for upper ground space. This experiment uses building form standards of upper ground space as an example to generate upper ground parametric Form-Based Code models. The script constrains the parameters of the location height of each upper ground connection between buildings, the angle of inclination, the number of connections, and the span of each connection. These parameters work to generate parametric models of the upper ground urban space by constraining horizontal and vertical locations and numbers of upper ground connections. Figure 98 presents a series of scenarios of upper grounds and their relationships 
with building groups. The red parts represent scenarios of upper ground connections at different heights. Connections in horizontal and vertical orientations contribute to land duplication in a high-density environment.
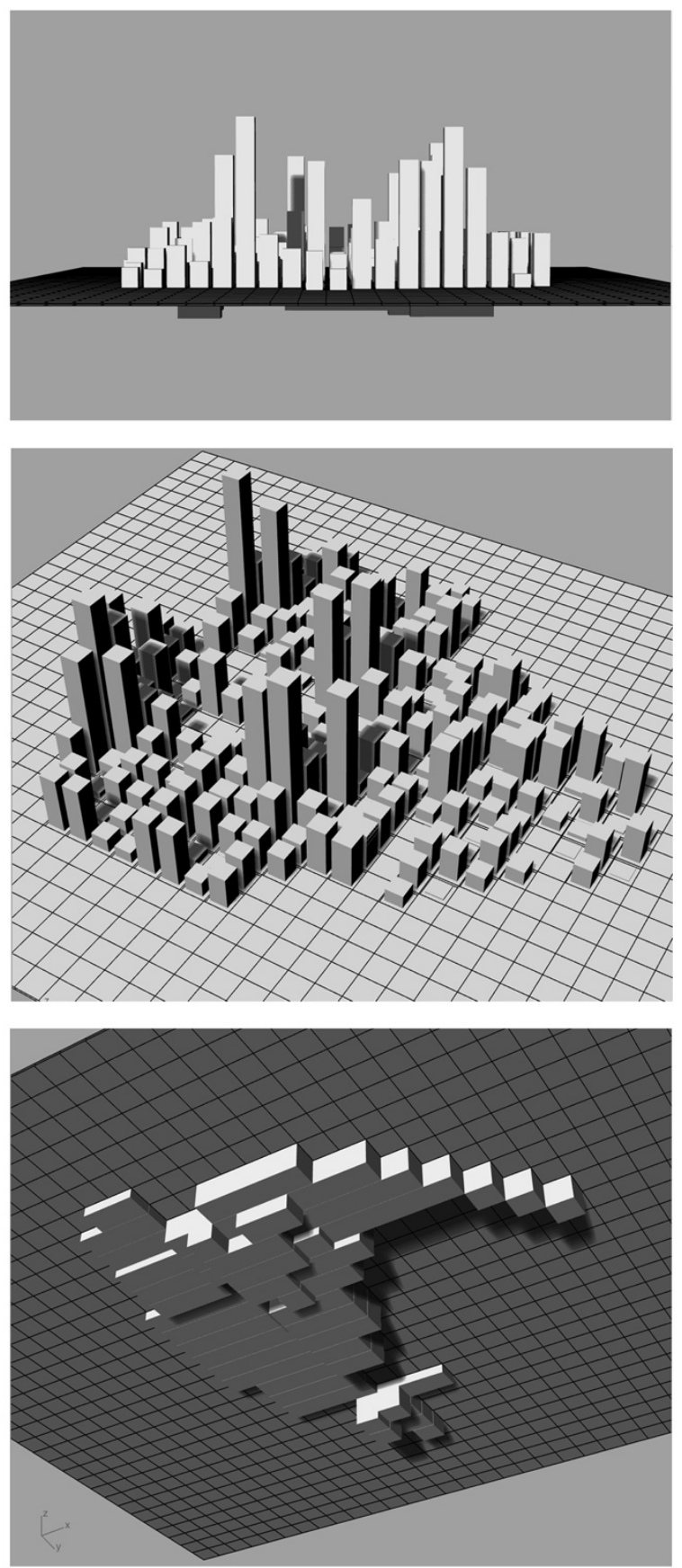

Figure 97. Scenarios of massing for multiple levels 

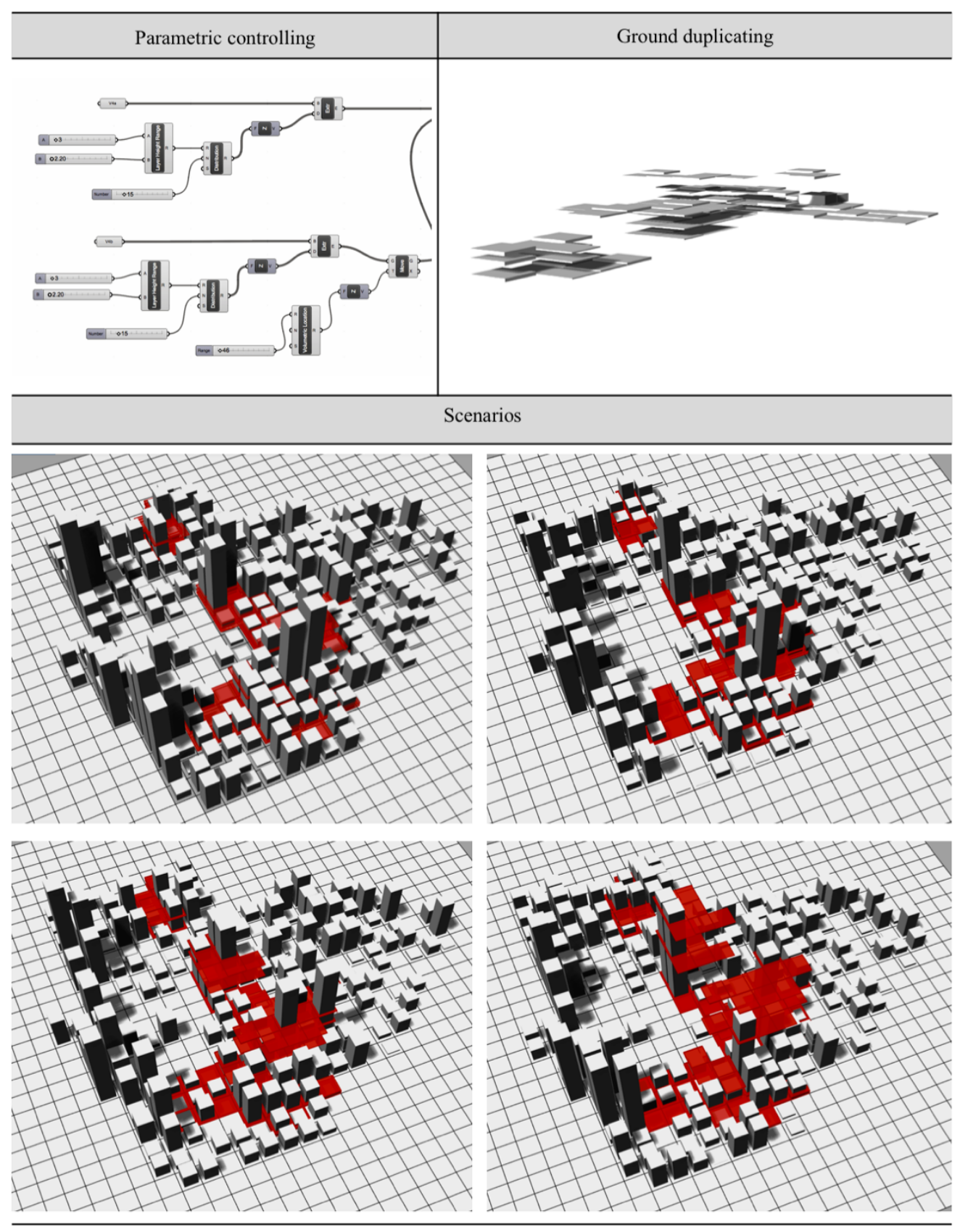

Figure 98. Scenarios of massing for the upper ground level 


\subsection{Graphic regulations}

This section explores the descriptions of parametric Form-Based Code in Tsim Sha Tsui. According to the models and scenarios analysed in former sections, a series of graphic regulations can be documented as Form-Based Code drafts in the visioning phase, or as layouts in the assembling phase. The section concludes with examples of Form-Based Code regulation of Tsim Sha Tsui.

As analysed in Chapter 2, Form-Based Code describes urban regulation by using illustrations and graphs. A conventional way of expressing Form-Based Code is shown in Figure 99. The regulation page covers building function, building configuration, lot occupation, building disposition, setbacks, and parking placement. Building configurations, setbacks of principal buildings and parking placement are described in detailed texts, plans or sections. For example, in the Form-Based Code of the City of Bellevue, the building configuration of T5.5 regulates that "Stories may not exceed 14 feet in height from finished floor to finished ceiling, except for a first-floor commercial function, which shall be a minimum of 11 feet and a maximum of 24 feet". The conventional FormBased Code uses two-dimensional graphics and texts to describe regulations.

Form-Based Code translates tables and numbers into graphics to make regulations more accessible than land use-based urban regulations. It is argued that the regulations of Form-Based Code are not convenient to modify as formrelated factors commonly cooperate together to build a specific form. Changing any factor will result in variations of other factors. To address this issue of expression, parametric models are embedded into the graphic regulations with exported renders, plans and sections. Per Figure 100, the elements included in Figure 99 are described by parameter sliders. When an amendment is needed, new solutions are offered with real-time models and illustrations. Like the ground level, part of the underground and upper ground level regulations can be described graphically (Figure 101). 

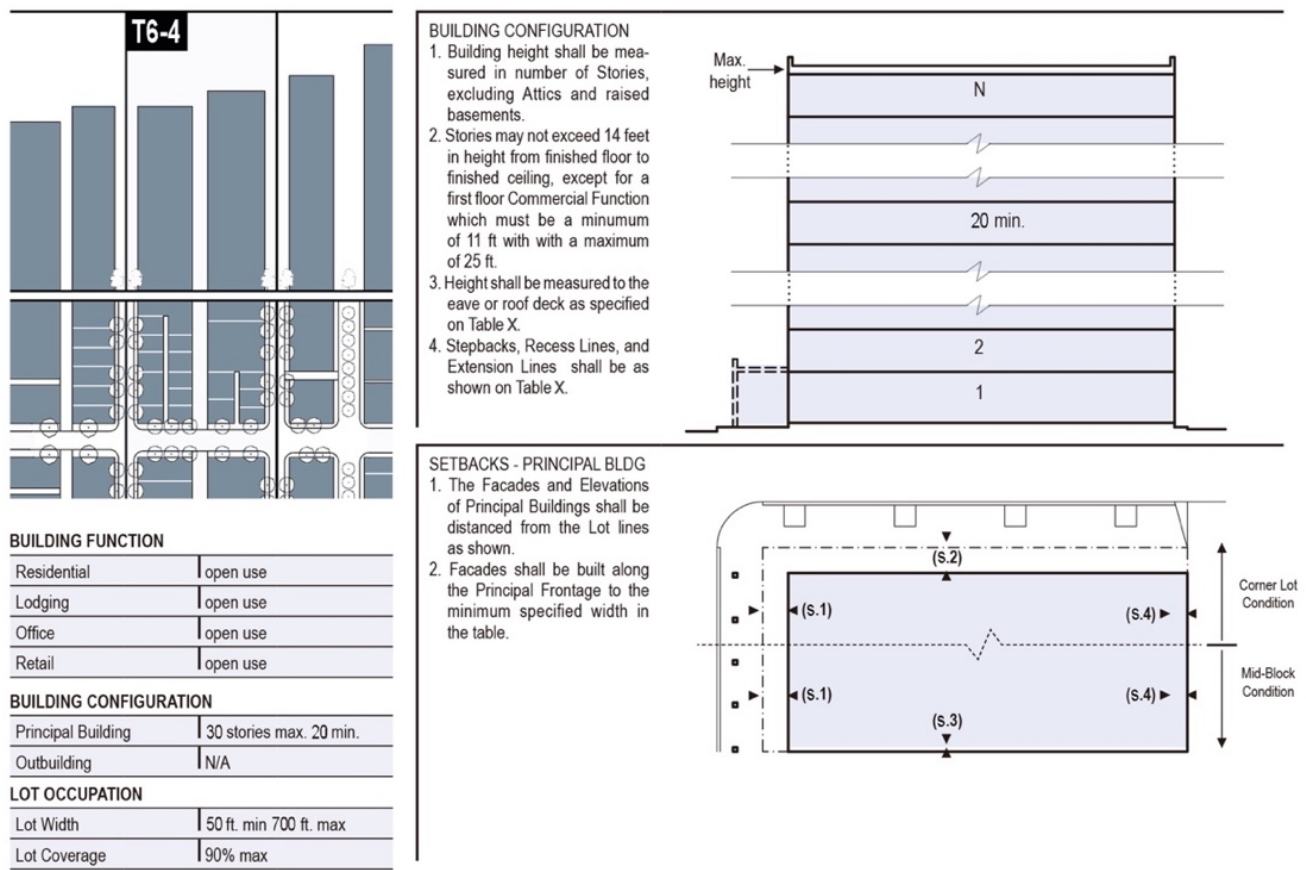

\begin{tabular}{l|l}
\multicolumn{1}{ll}{ Lot Coverage } & \multicolumn{1}{l}{$\mid l$} \\
\multicolumn{1}{l|}{ BUILDING DISPOSITION } & \\
\hline Edgeyard & $\left.\right|_{\text {not permitted }}$ \\
\hline Sideyard & $\left.\right|_{\text {not permitted }}$ \\
\hline Rearyard & $\left.\right|_{\text {permitted }}$ \\
\hline Courtyard & $\left.\right|_{\text {permitted }}$ \\
\hline
\end{tabular}

SETBACKS - PRINCIPAL BUILDING

Front Setback Principal (s.1) 2 ft. min. $12 \mathrm{ft}$. max.

Front Setback Secondary(s.2) 2 ft. min. $12 \mathrm{ft}$ max.

Side Setback(s.3) 10 ft. min. 24 ft. max

Rear Setback(s.4) $\quad$ oft. min.

\begin{tabular}{l|l}
\hline Frontage Buildout & $80 \%$ min. at setback
\end{tabular}

SETBACKS - OUTBUILDING

\begin{tabular}{l|l}
\hline Front Setback & $I_{N} /$ \\
\hline Side Setback & $I_{N A}$
\end{tabular}

\begin{tabular}{l|l}
\hline Side Setback & $I_{N A}$ \\
\hline Rear Setback & $I_{N A}$
\end{tabular}

NA

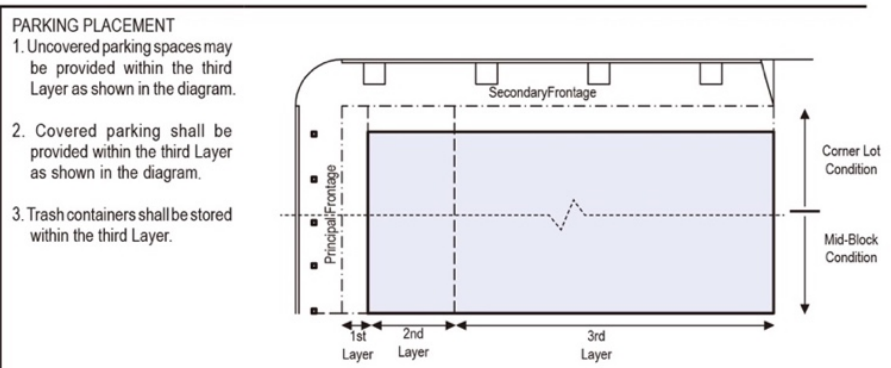

Figure 99. Example page: Conventional Form-Based Code descriptions (T6-4) 


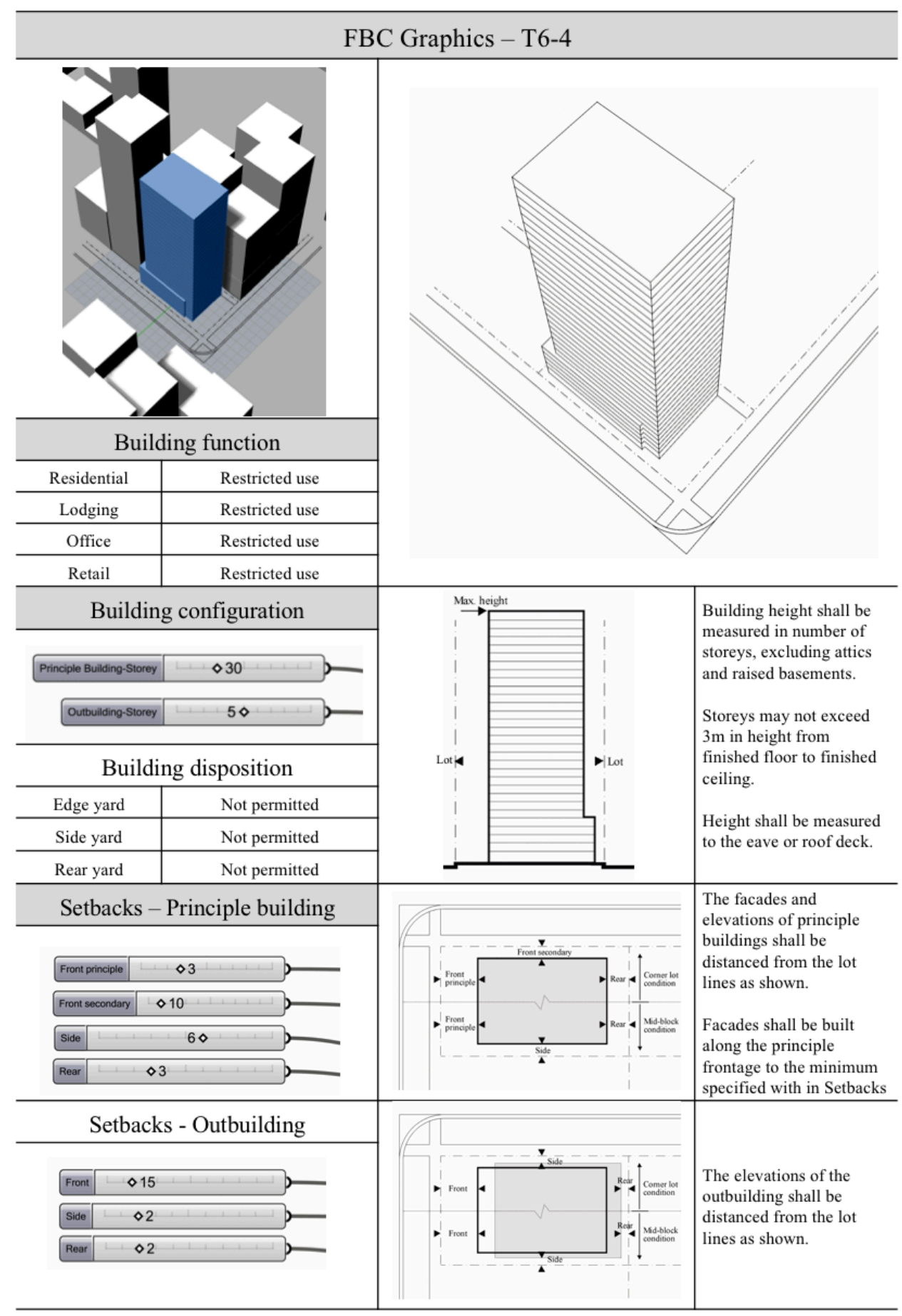

Figure 100. Example page: Parametric Form-Based Code descriptions (T6-4) 


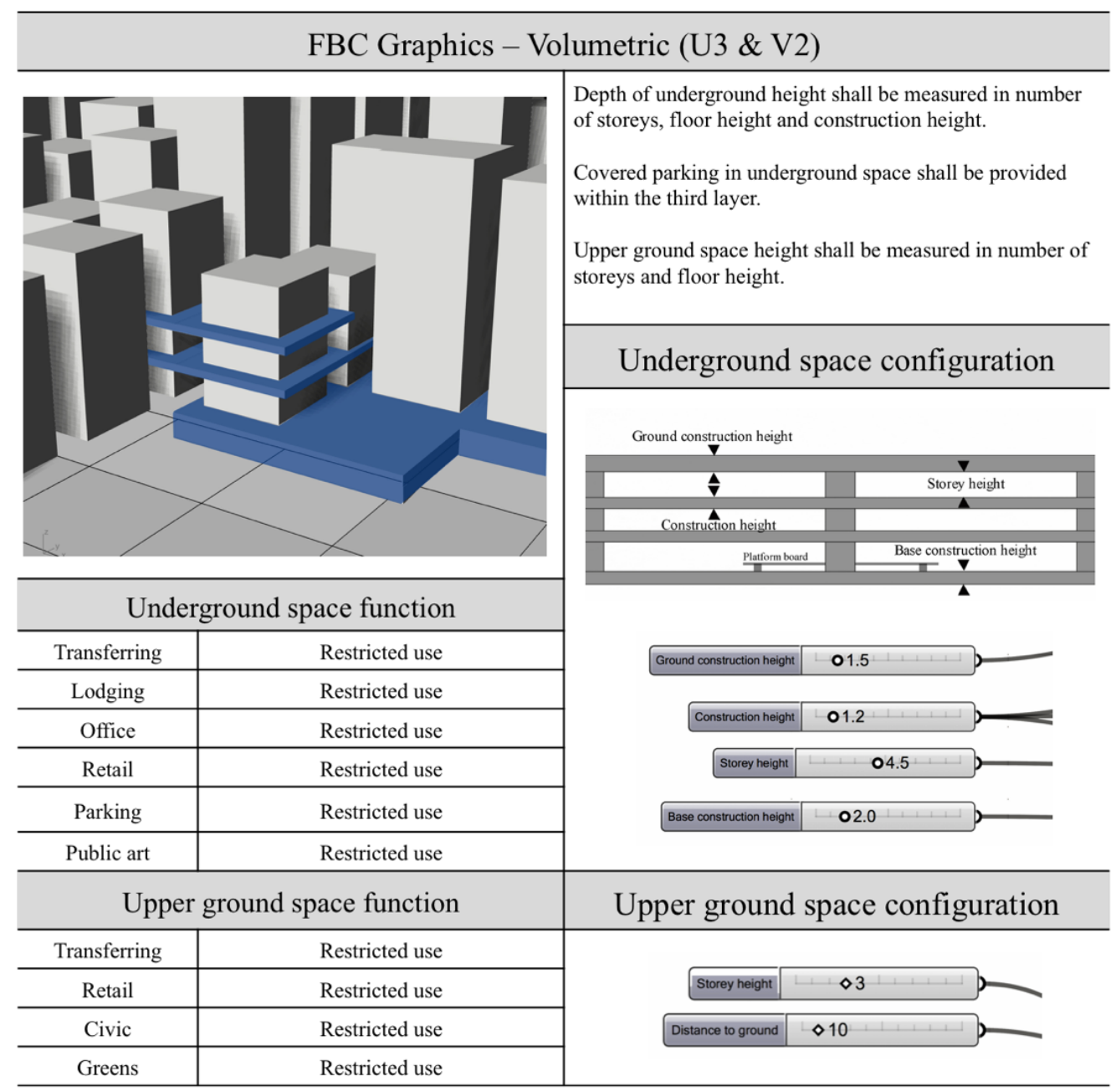

Figure 101. Parametric Form-Based Code descriptions (U3 \& V2) 


\subsection{Chapter summary}

The methodology and workflow for generating a parametric modelling system for a Form-Based Code are explored in this section. The system integrates parameters, models and regulation logic through parametric modelling software. Parameters and models are layered across ground, underground and upper ground levels in alignment with the transect matrix and regulating plans of Chapter 4. The regulation logic is described as a prototype consisting of three parts, namely in-put, running, and ex-put. The in-put part requires a Form-Based Code team to connect the parameters and zone links to scripts. Running operates as a machine for calculating and synthesis control. The ex-put part provides realtime performance feedback to enable a Form-Based Code team to test multiple scenarios. Parametric modelling platforms, such as Grasshopper 3D, Elk and Rhinoceros $3 \mathrm{D}$, are introduced to parameterise the urban regulation for FormBased Code. Converting two-dimensional regulations to three-dimensional models supports the generation of multiple scenarios and enables convenient amendments by changing the parameter values or types.

Chapter 4 and Chapter 5 have explored Form-Based Code in the volumetric morphology of a high-density environment and the establishment of a parametric modelling system for Form-Based Code. Using Tsim Sha Tsui as the experimental site, the results include an extended transect matrix, a series of regulating plans, parametric models, and examples of the graphic representation of regulations. In the next chapter, these results and related Form-Based Code regulations are evaluated by various principles to identify the in-context effects of parametric urban regulation. 


\section{Chapter 6. Evaluation}

The parametric modelling system has been embedded in the regulatory process to support the generation and modification of Form-Based Code. The results of Form-Based Code zoning (Chapter 4) and modelling (Chapter 5) are evaluated in this chapter. A series of criteria are used to establish an evaluation system, including LEED-ND, Smart Scorecard and Hong Kong's existing urban regulation standards. The evaluation system aims to assess the sustainability, code quality and feasibility of Form-Based Code regulation in Tsim Sha Tsui against quantitative and qualitative measures. Experiment 3, introduced in Section 1.5, is further described in this chapter. 


\subsection{Sustainability}

Sustainability is of central importance for implementing Form-Based Code in real urban regulation and zoning. Whilst a Form-Based Code can reflect the morphology and intentions of regulation through parametric software, the codes need to be examined by sustainability-related principles for real practice. The Energy and Environmental Design (LEED) rating system is used to assess the concordance between LEED and Form-Based Code.

\subsubsection{Evaluation system criteria}

The criteria for evaluating sustainability are established according to the LEED Rating System. Choosing LEED is a decision made through the comprehensive consideration of relevant factors. First, Form-Based Code is an American zoning approach and LEED-ND is an American rating system that provides matched criteria on a neighbourhood scale. Second, LEED-ND is broadly used in Asia, and Hong Kong's local system is very much in line with the principles and structure of the LEED Rating System (Thilakaratne and Lew, 2011). Third, the evaluation capability of LEED-ND has been proved in previous Form-Based Code research.

LEED is an American rating system developed through the collaboration of the United States Green Building Council (USGBC), the Congress for the New Urbanism (CNU) and the Natural Resources Defences Council. The USGBC built a program in collaboration with CNU, called "LEED for a Neighbourhood Development (LEED-ND)" - a rating system to help planners and developers create communities that not only protect the environment but also improve the quality of life of the whole community (Mahendriyani, 2016).

Although initiated in the USA, LEED is now establishing its presence globally; providing internationally adopted design, construction and operational guidelines and standards and benchmarks for a wider scope of project sectors 
(Thilakaratne and Lew, 2011). LEED was established rapidly in Asia (Thilakaratne and Lew, 2011), which now contains the most LEED projects outside North America (Mahendriyani, 2016). The system covers a wide range of projects in Asia (Thilakaratne and Schnabel, 2013), and cooperates with the local rating criteria of Asian countries such as China, Japan and Singapore.

LEED-ND has been applied in earlier studies to measure the technical capability of Form-Based Code. Garde, Kim and Tsai (2015) evaluated the extent to which Miami's Form-Based Code (Miami 21 Code) and its traditional zoning code (Ordinance 11000) meet the criteria of the LEED-ND system (Garde, et al., 2015). They use the LEED-ND rating system as the evaluating instrument because it includes key design principles that are considered important in creating a sustainable urban form, including those addressed in the American Planning Association's Policy Guide on Planning for sustainability (Garde, et al., 2015). The LEED-ND rating system is also proposed by Kan (2012) to examine Form-Based Code as it integrates the principles of smart growth and green urbanism for neighbourhood design.

\subsubsection{Limitation}

This section uses the LEED-ND (Version 4 Online) Rating System updated on 5 January 2018 written by USGBC. The zoning and modelling results detailed in Chapters 4 and 5 are not to be considered the final Form-Based Code solution for assessing the credits the code should be awarded. Instead, this section analyses which LEED-ND criteria can be met in the Form-Based Code developed for Tsim Sha Tsui.

\subsubsection{Weight and score}

The zoning and modelling of the Form-Based Code are weighted by the LEEDND System and scored with mathematical approaches. The scoring results indicate the level of concordance between LEED-ND and the Form-Based Code. 


\subsubsection{Choosing the weights}

The LEED-ND rating system consists of five categories, including Smart Location and Linkage (SLL), Neighbourhood Pattern and Design (NPD), Green Infrastructure and Buildings (GIB), Innovation (IN), and Regional Priority (RP). The weighting factors consist of the specific criteria of each of the five categories. To evaluate the Form-Based Code's sustainability, SLL, NPD and GIB criteria are chosen for the weighting system.

SLL seeks "to encourage development within and near existing communities and public transit infrastructure. To encourage improvement and redevelopment of existing cities, suburbs, and towns while limiting the expansion of the development footprint in the region. To reduce vehicle trips and vehicle distance travelled. To reduce the incidence of obesity, heart disease, and hypertension by encouraging daily physical activity associated with walking and bicycling" (USGBC, 2018). SLL provides the credits for the weighting system to measure dense-development and urban morphology regulation for a built environment.

NPD intends "to promote transportation efficiency and reduce vehicle distance travelled. To improve public health by providing safe, appealing, and comfortable street environments that encourage daily physical activity and avoid pedestrian injuries" (USGBC, 2018). NPD provides credits for the weighting system to evaluate performance regulation on a neighbourhood-scale.

GIB criteria is applied "to encourage the design, construction, and retrofit of buildings using green building practices" (USGBC, 2018). Because FormBased Code contains building form standards, it is appropriate to include GIB's criteria in the weighting system.

IN and RP criteria are not appropriate for this weighting structure. IN criteria encourage projects to achieve exceptional or innovative performance (USGBC, 
2018). RP criteria provide an incentive for the achievement of credits that address geographically specific environmental, social equity, and public health priorities (USGBC, 2018). Both IN and RP are largely irrelevant to the example of urban regulation.

There are different criteria types in SLL, NPD and GIB. For instance, SLL includes SLL Prerequisite, Location and Transportation (LT) Credit, and SLL Credit. The weighting system limits the criteria as Credit types because they are quantised by explicit values to score.

\subsubsection{Score}

The Form-Based Code of Tsim Sha Tsui is scored on a 5-point scale (0-4) to measure its concordance with the LEED-ND rating system. This grading approach is aligned with Garde's 2015 research. As Garde stated, that work relied primarily on the weighted concordance score (W) of LEED-ND criteria reflected in the codes to interpret the results and use thresholds to infer the strength of these scores (Garde, et al., 2015). If the value of $\mathrm{W}$ is equal with or higher than 2.5, the LEED-ND principles are strongly incarnated in the FormBased Code. If $\mathrm{W}$ is between 1 and 2.5, it indicates the Form-Based Code contains the LEED-ND principles moderately. If $\mathrm{W}$ is equal with or lower than 1, the Form-Based Code rarely meets the LEED-ND criterion.

Four data categories comprise the measurement system. They are raw frequencies $(F)$, normalised frequencies $(N)$, maximum concordance scores $(M)$, and weighted concordance scores (W) of LEED-ND criteria reflected in codes (Garde, et al., 2015).

F is a combination of credits. For example, in the section on SLL Credit: Preferred Locations, the requirements have three options. They are Location Type (1-5 points), Connectivity (1-5 points) and Designed High-Priority 
Locations ( 3 points). F equals the value of the sum of the points Form-Based Code achieves in each option. The total value may be up to 10 points according to the LEED-ND Rating System regulations. F reflects the normalised raw frequencies. Calculating F standardises raw frequencies into the closed interval $[0,1]$.

According to the values of $\mathrm{F}, \mathrm{N}$ is calculated as:

$$
N=\frac{\text { F-Fmin }}{\text { Fmax-Fmin }}
$$

Where:

$\mathrm{N}$ is the normalised raw frequencies,

$\mathrm{F}$ is the raw frequencies,

Fmin is the minimum $\mathrm{F}$ in the code of specific zone type, and

Fmax is the maximum $\mathrm{F}$ in the code of specific zone type.

M grades the Form-Based Code's level of concordance with LEED-ND criteria. This research uses the measurement proposed by Garde in 2015 (Table 34).

$\mathrm{W}$ is calculated as:

$$
W=\frac{(\mathrm{M} 1 * \mathrm{Wt} 1+\mathrm{M} 2 * \mathrm{Wt} 2+\cdots+\mathrm{Mn} * \mathrm{Wtn})}{\mathrm{Wt} 1+\mathrm{Wt} 2+\cdots+\mathrm{Wtn}}
$$

Where:

$\mathrm{W}$ is the weighted concordance value,

M1 is the concordance value of sub-criterion 1,

Wt1 is the weight for sub-criterion 1 ,

M2 is the concordance value of sub-criterion 2,

$\mathrm{Wt} 2$ is the weight for sub-criterion 2,

$\mathrm{Mn}$ is the concordance value of sub-criterion $\mathrm{n}$, and

$\mathrm{Wtn}$ is the weight for sub-criterion $\mathrm{n}$. 


\begin{tabular}{l|l|l}
\hline $\begin{array}{c}\text { Concordance } \\
\text { score }\end{array}$ & \multicolumn{1}{c|}{$\begin{array}{c}\text { Concordance } \\
\text { level }\end{array}$} & \multicolumn{1}{c}{ Concordance measure } \\
\hline 4 & Excellent & $\begin{array}{l}\text { Criterion is addressed in the regulations to the extent that } \\
\text { maximum LEED-ND points can be achieved }\end{array}$ \\
\hline 3 & Good & $\begin{array}{l}\text { Criterion is addressed in the regulations to the extent that more } \\
\text { than minimum but less than maximum LEED-ND points can } \\
\text { be achieved }\end{array}$ \\
\hline 2 & Fair & $\begin{array}{l}\text { Criterion is addressed in the regulations to the extent that } \\
\text { minimum LEED-ND points can be achieved }\end{array}$ \\
\hline 0 & Weak & $\begin{array}{l}\text { Criterion is addressed in the regulations but no LEED-ND } \\
\text { points can be achieved }\end{array}$ \\
\hline
\end{tabular}

Table 34. Concordance measurement, Garde, et al., 2015

The weight of each sub-criterion is based on the maximum credits the code can achieve in each sub-criterion and the maximum credits of each criterion. It is calculated as:

$$
W t x=\frac{\operatorname{Smaxx} * \mathrm{~T}}{\operatorname{Smax} 1+\mathrm{Smax} 2+\cdots+\operatorname{Smaxn}}
$$

Where:

Wtx is the weight for sub-criterion $\mathrm{x}$,

Smaxx is the maximum score that sub-criterion $\mathrm{x}$ can offer,

Smax1 is the maximum score that sub-criterion 1 can offer,

Smax 2 is the maximum score that sub-criterion 2 can offer,

Smaxn is the maximum score that each sub-criterion can offer, and

$\mathrm{T}$ is the top point that each criterion can offer.

For example, the Preferred Locations criterion in LEED-ND has three subcriteria, including Option 1 Location Type (1-5 points), Option 2 Connectivity 
(1-5 points) and Option 3 Designed High-Priority Locations (3 points), as mentioned above. The highest point of Option 1 is 5, Option 2 is 5 and Option 3 is 3 . The total score is out of 10 . Using the equation (6), the weight of Option 1 is 3.85, the weight of Option 2 is 3.85, and the weight of Option 3 is 2.30 . Assuming the specific code's concordance value of Option 1 is 2 (Fair), the value of Option 2 is 2 (Fair) and the value of Option 3 is 1 (weak), the specific code's $\mathrm{W}$ is 1.8 calculated by equation (5) and $\mathrm{F}$ is 5 by adding the score of each option together. The $\mathrm{W}$ value of 1.8 is between 1 and 2.5 , which indicates that the specific code meets the LEED-ND principles moderately. According to this manner of measurement, Table 35, Table 36 and Table 37 show the SLL, NPD, GIB scores of F, N, M, and W for the Form-Based Code of ground, underground and upper ground.

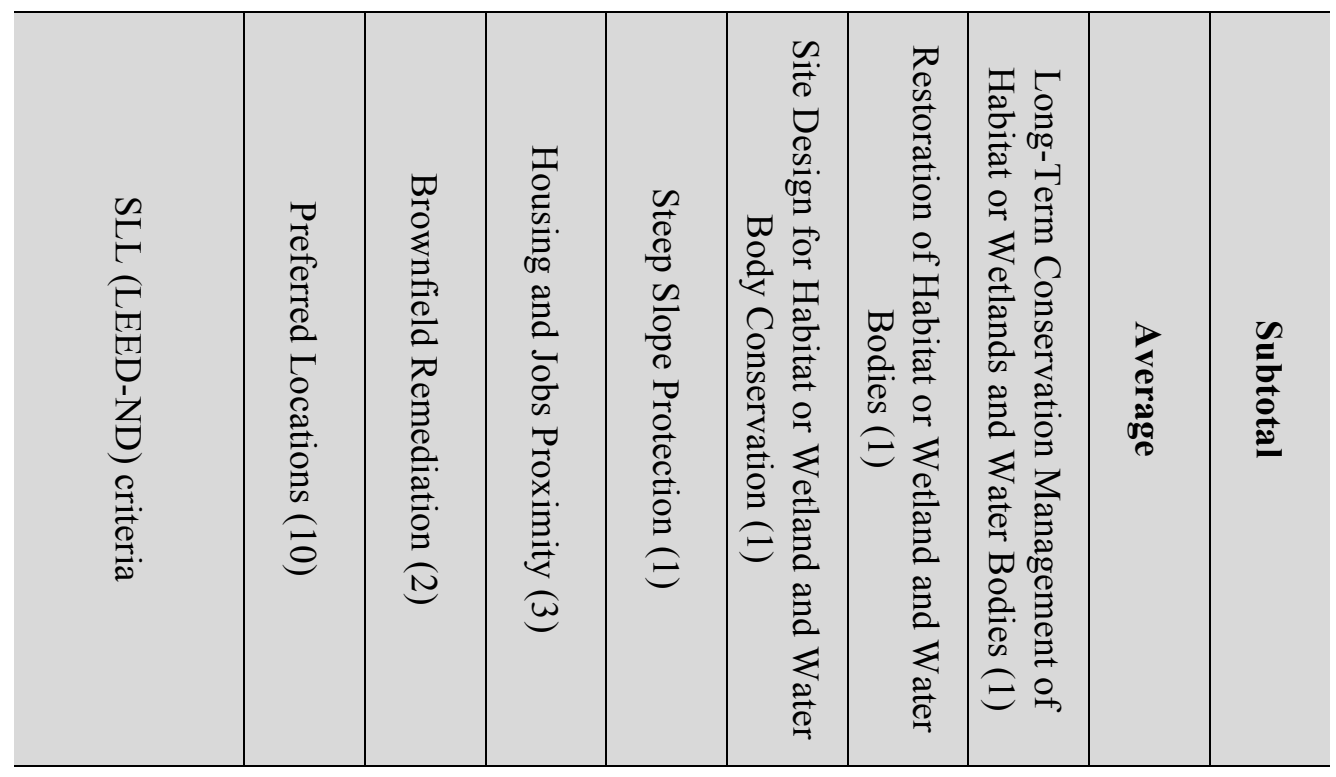

Form-Based Code-Ground Level

\begin{tabular}{|c|c|c|c|c|c|c|c|c|c|c|}
\hline \multirow{4}{*}{$\vec{i}$} & F & 8.0 & 0.0 & 2.0 & 0.0 & 0.0 & 0.0 & 0.0 & 1.4 & 10.0 \\
\hline & $\mathrm{N}$ & 1.0 & 0.0 & 0.3 & 0.0 & 0.0 & 0.0 & 0.0 & 0.2 & 1.3 \\
\hline & $\mathrm{M}$ & 4.0 & 0.0 & 3.0 & 0.0 & 0.0 & 0.0 & 0.0 & \begin{tabular}{ll|}
1.0 \\
\end{tabular} & - \\
\hline & $\mathrm{W}$ & 2.3 & 0.0 & 1.0 & 0.0 & 0.0 & 0.0 & 0.0 & 0.5 & - \\
\hline \multirow{4}{*}{$\vec{i}$} & F & 8.0 & 0.0 & 2.0 & 0.0 & 0.0 & 0.0 & 0.0 & 1.4 & 10.0 \\
\hline & $\mathrm{N}$ & 1.0 & 0.0 & 0.3 & 0.0 & 0.0 & 0.0 & 0.0 & 0.2 & $\begin{array}{ll}1.3 \\
\end{array}$ \\
\hline & $\mathrm{M}$ & 4.0 & 0.0 & 2.0 & 0.0 & 0.0 & 0.0 & 0.0 & 0.9 & - \\
\hline & W & 2.3 & 0.0 & 0.7 & 0.0 & 0.0 & 0.0 & 0.0 & 0.4 & - \\
\hline I & $\mathrm{F}$ & 7.0 & 0.0 & 1.0 & 0.0 & 0.0 & 0.0 & 0.0 & 1.1 & 8.0 \\
\hline
\end{tabular}




\begin{tabular}{|c|c|c|c|c|c|c|c|c|c|c|}
\hline & $\mathrm{N}$ & 1.0 & 0.0 & 0.1 & 0.0 & 0.0 & 0.0 & 0.0 & 0.2 & 1.1 \\
\hline & $\mathrm{M}$ & 4.0 & 0.0 & 2.0 & 0.0 & 0.0 & 0.0 & 0.0 & 0.9 & - \\
\hline & $\mathrm{W}$ & 2.3 & 0.0 & 0.7 & 0.0 & 0.0 & 0.0 & 0.0 & 0.4 & - \\
\hline \multirow{4}{*}{$\vec{a}$} & $F$ & 7.0 & 0.0 & 1.0 & 0.0 & 0.0 & 0.0 & 0.0 & 1.1 & 8.0 \\
\hline & $\mathrm{N}$ & 1.0 & 0.0 & 0.1 & 0.0 & 0.0 & 0.0 & 0.0 & 0.2 & 1.1 \\
\hline & $\mathrm{M}$ & 4.0 & 0.0 & 2.0 & 0.0 & 0.0 & 0.0 & 0.0 & 0.9 & - \\
\hline & $\mathrm{W}$ & 2.3 & 0.0 & 0.7 & 0.0 & 0.0 & 0.0 & 0.0 & 0.4 & - \\
\hline \multirow{4}{*}{$\overrightarrow{\hat{a}}$} & $F$ & 7.0 & 0.0 & 0.0 & 0.0 & 0.0 & 0.0 & 0.0 & 1.0 & 7.0 \\
\hline & $\mathrm{N}$ & 1.0 & 0.0 & 0.0 & 0.0 & 0.0 & 0.0 & 0.0 & 0.2 & 1.0 \\
\hline & $\mathrm{M}$ & 4.0 & 0.0 & 2.0 & 0.0 & 0.0 & 0.0 & 0.0 & 0.9 & - \\
\hline & $\mathrm{W}$ & 2.3 & 0.0 & 0.7 & 0.0 & 0.0 & 0.0 & 0.0 & 0.4 & - \\
\hline \multirow{4}{*}{$\vec{a}$} & $F$ & 7.0 & 0.0 & 0.0 & 0.0 & 0.0 & 0.0 & 0.0 & 1.0 & 7.0 \\
\hline & $\mathrm{N}$ & 1.0 & 0.0 & 0.0 & 0.0 & 0.0 & 0.0 & 0.0 & 0.2 & 1.0 \\
\hline & $\mathrm{M}$ & 4.0 & 0.0 & 2.0 & 0.0 & 0.0 & 0.0 & 0.0 & 0.9 & - \\
\hline & $\mathrm{W}$ & 2.3 & 0.0 & 0.7 & 0.0 & 0.0 & 0.0 & 0.0 & 0.4 & - \\
\hline
\end{tabular}

Form-Based Code-Underground Level

\begin{tabular}{|c|c|c|c|c|c|c|c|c|c|c|}
\hline \multirow{4}{*}{$\subseteq$} & $\mathrm{F}$ & 5.0 & 0.0 & 0.0 & 0.0 & 0.0 & 0.0 & 0.0 & 0.7 & 5.0 \\
\hline & $\mathrm{N}$ & 1.0 & 0.0 & 0.0 & 0.0 & 0.0 & 0.0 & 0.0 & 0.1 & 1.0 \\
\hline & $\mathrm{M}$ & 4.0 & 0.0 & 0.0 & 0.0 & 0.0 & 0.0 & 0.0 & 0.6 & - \\
\hline & $\mathrm{W}$ & 1.5 & 0.0 & 0.0 & 0.0 & 0.0 & 0.0 & 0.0 & 0.2 & - \\
\hline \multirow{4}{*}{$\stackrel{\mathcal{N}}{S}$} & $\mathrm{~F}$ & 5.0 & 0.0 & 0.0 & 0.0 & 0.0 & 0.0 & 0.0 & 0.7 & 5.0 \\
\hline & $\mathrm{N}$ & 1.0 & 0.0 & 0.0 & 0.0 & 0.0 & 0.0 & 0.0 & 0.1 & 1.0 \\
\hline & $\mathrm{M}$ & 4.0 & 0.0 & 0.0 & 0.0 & 0.0 & 0.0 & 0.0 & 0.6 & - \\
\hline & W & 1.5 & 0.0 & 0.0 & 0.0 & 0.0 & 0.0 & 0.0 & 0.2 & - \\
\hline \multirow{4}{*}{$\stackrel{\varsigma}{\subseteq}$} & $\bar{F}$ & 5.0 & 0.0 & 0.0 & 0.0 & 0.0 & 0.0 & 0.0 & 0.7 & 5.0 \\
\hline & $\mathrm{N}$ & 1.0 & 0.0 & 0.0 & 0.0 & 0.0 & 0.0 & 0.0 & 0.1 & 1.0 \\
\hline & $\mathrm{M}$ & 4.0 & 0.0 & 0.0 & 0.0 & 0.0 & 0.0 & 0.0 & 0.6 & - \\
\hline & $\mathrm{W}$ & 1.5 & 0.0 & 0.0 & 0.0 & 0.0 & 0.0 & 0.0 & 0.2 & - \\
\hline \multirow{4}{*}{$\stackrel{\subsetneq}{\mp}$} & $\mathrm{F}$ & 5.0 & 0.0 & 0.0 & 0.0 & 0.0 & 0.0 & 0.0 & 0.7 & 5.0 \\
\hline & $\mathrm{N}$ & 1.0 & 0.0 & 0.0 & 0.0 & 0.0 & 0.0 & 0.0 & 0.1 & $\begin{array}{l}1.0 \\
\end{array}$ \\
\hline & $\mathrm{M}$ & 4.0 & 0.0 & 0.0 & 0.0 & 0.0 & 0.0 & 0.0 & 0.6 & - \\
\hline & $\mathrm{W}$ & 1.5 & 0.0 & 0.0 & 0.0 & 0.0 & 0.0 & 0.0 & 0.2 & - \\
\hline \multirow{4}{*}{$\underset{\cup}{G}$} & $\mathrm{~F}$ & 5.0 & 0.0 & 0.0 & 0.0 & 0.0 & 0.0 & 0.0 & 0.7 & $\begin{array}{l}5.0 \\
\end{array}$ \\
\hline & $\mathrm{N}$ & 1.0 & 0.0 & 0.0 & 0.0 & 0.0 & 0.0 & 0.0 & 0.1 & 1.0 \\
\hline & $\mathrm{M}$ & 4.0 & 0.0 & 0.0 & 0.0 & 0.0 & 0.0 & 0.0 & 0.6 & - \\
\hline & $\mathrm{W}$ & 1.5 & 0.0 & 0.0 & 0.0 & 0.0 & 0.0 & 0.0 & 0.2 & - \\
\hline
\end{tabular}

Form-Based Code-Upper Ground Level

\begin{tabular}{|c|c|c|c|c|c|c|c|c|c|c|}
\hline \multirow{4}{*}{$\leq$} & $F$ & 8.0 & 0.0 & 0.0 & 0.0 & 0.0 & 0.0 & 0.0 & 1.4 & 10.0 \\
\hline & $\mathrm{N}$ & 1.0 & 0.0 & 0.0 & 0.0 & 0.0 & 0.0 & 0.0 & 0.2 & $\begin{array}{ll}1.3 \\
\end{array}$ \\
\hline & $\mathrm{M}$ & 4.0 & 0.0 & 0.0 & 0.0 & 0.0 & 0.0 & 0.0 & 1.0 & - \\
\hline & $\mathrm{W}$ & 2.3 & 0.0 & 0.0 & 0.0 & 0.0 & 0.0 & 0.0 & 0.5 & - \\
\hline \multirow{4}{*}{ 心 } & $F$ & 8.0 & 0.0 & 0.0 & 0.0 & 0.0 & 0.0 & 0.0 & 1.4 & 10.0 \\
\hline & $\mathrm{N}$ & 1.0 & 0.0 & 0.0 & 0.0 & 0.0 & 0.0 & 0.0 & 0.2 & $\begin{array}{ll}1.3 \\
\end{array}$ \\
\hline & $\mathrm{M}$ & 4.0 & 0.0 & 0.0 & 0.0 & 0.0 & 0.0 & 0.0 & 0.9 & - \\
\hline & $\mathrm{W}$ & 2.3 & 0.0 & 0.0 & 0.0 & 0.0 & 0.0 & 0.0 & 0.4 & - \\
\hline \multirow{3}{*}{ } & $F$ & 7.0 & 0.0 & 0.0 & 0.0 & 0.0 & 0.0 & 0.0 & 1.1 & 8.0 \\
\hline & $\mathrm{N}$ & 1.0 & 0.0 & 0.0 & 0.0 & 0.0 & 0.0 & 0.0 & 0.2 & 1.1 \\
\hline & $\mathrm{M}$ & 4.0 & 0.0 & 0.0 & 0.0 & 0.0 & 0.0 & 0.0 & 0.9 & - \\
\hline
\end{tabular}




\begin{tabular}{|c|c|c|c|c|c|c|c|c|c|c|}
\hline & $\mathrm{W}$ & 2.3 & 0.0 & 0.0 & 0.0 & 0.0 & 0.0 & $\overline{0.0}$ & 0.4 & - \\
\hline \multirow{4}{*}{$\lesssim$} & $F$ & 7.0 & 0.0 & 0.0 & 0.0 & 0.0 & 0.0 & 0.0 & 1.1 & 8.0 \\
\hline & $\mathrm{N}$ & 1.0 & 0.0 & 0.0 & 0.0 & 0.0 & 0.0 & 0.0 & 0.2 & 1.1 \\
\hline & $\mathrm{M}$ & 4.0 & 0.0 & 0.0 & 0.0 & 0.0 & 0.0 & 0.0 & \begin{tabular}{ll|}
0.9 \\
\end{tabular} & - \\
\hline & $\mathrm{W}$ & 2.3 & 0.0 & 0.0 & 0.0 & 0.0 & 0.0 & 0.0 & 0.4 & - \\
\hline \multirow{4}{*}{ 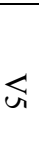 } & $\mathrm{F}$ & 7.0 & 0.0 & 0.0 & 0.0 & 0.0 & 0.0 & 0.0 & 1.0 & 7.0 \\
\hline & $\mathrm{N}$ & 1.0 & 0.0 & 0.0 & 0.0 & 0.0 & 0.0 & 0.0 & 0.2 & 1.0 \\
\hline & $\mathrm{M}$ & 4.0 & 0.0 & 0.0 & 0.0 & 0.0 & 0.0 & 0.0 & $\begin{array}{ll}0.9 \\
\end{array}$ & - \\
\hline & $\mathrm{W}$ & 2.3 & 0.0 & 0.0 & 0.0 & 0.0 & 0.0 & 0.0 & 0.4 & - \\
\hline
\end{tabular}

$\mathrm{F}$ is raw frequency. $\mathrm{N}$ is normalised frequency. $\mathrm{M}$ is the concordance value. $\mathrm{W}$ is the weighted concordance value. Dark shading represents $\mathrm{W}>=2.5$, medium shading represents $1<\mathrm{W}<2.5$, light shading represents $\mathrm{W}<=1$.

Table 35. Scoring results of SLL-LEED-ND

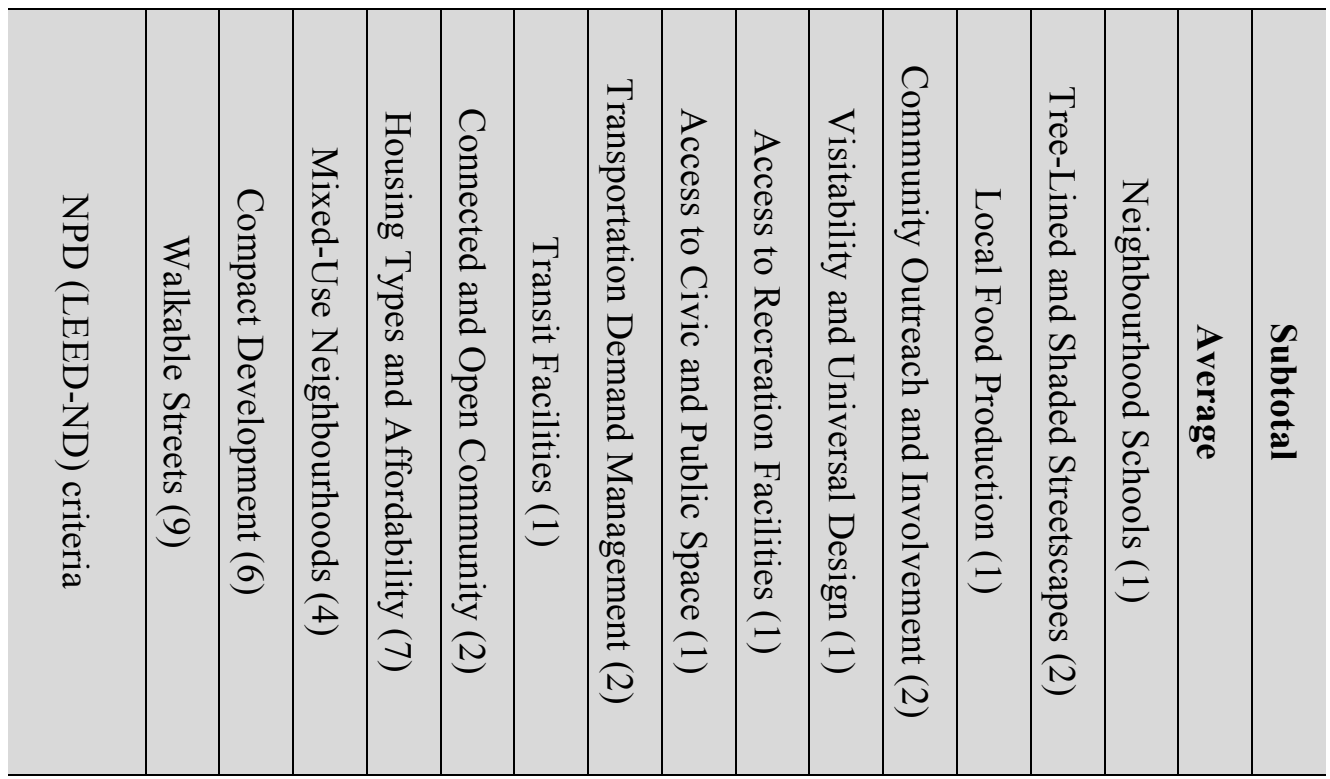

Form-Based Code-Ground level

\begin{tabular}{|c|c|c|c|c|c|c|c|c|c|c|c|c|c|c|c|c|c|}
\hline \multirow{4}{*}{$\vec{i}$} & $\mathrm{~F}$ & 3.0 & 6.0 & 2.0 & 2.0 & 1.0 & 1.0 & 2.0 & 1.0 & 1.0 & 0.0 & 0.0 & 0.0 & 2.0 & 1.0 & 1.6 & $\begin{array}{l}22 . \\
0\end{array}$ \\
\hline & $\mathrm{N}$ & 0.5 & 1.0 & 0.3 & 0.3 & 0.2 & 0.2 & 0.3 & 0.2 & 0.2 & 0.0 & 0.0 & 0.0 & 0.3 & 0.2 & 0.3 & 3.7 \\
\hline & $\mathrm{M}$ & 4.0 & 4.0 & 4.0 & 2.0 & 4.0 & 3.0 & 4.0 & 4.0 & 4.0 & 0.0 & 0.0 & 0.0 & 2.0 & 1.0 & 2.6 & - \\
\hline & $\mathrm{W}$ & 1.3 & 4.0 & 4.0 & 0.9 & 2.0 & 3.0 & 4.0 & 4.0 & 4.0 & 0.0 & 0.0 & 0.0 & 1.0 & 1.0 & 2.1 & - \\
\hline \multirow{4}{*}{$\overrightarrow{\hat{N}}$} & $\mathrm{~F}$ & 4.0 & 6.0 & 3.0 & 2.0 & 1.0 & 1.0 & 2.0 & 1.0 & 1.0 & 0.0 & 0.0 & 0.0 & 2.0 & 1.0 & 1.7 & $\begin{array}{l}24 . \\
0\end{array}$ \\
\hline & $\mathrm{N}$ & 0.7 & 1.0 & 0.5 & 0.3 & 0.2 & 0.2 & 0.3 & 0.2 & 0.2 & 0.0 & 0.0 & 0.0 & 0.3 & 0.2 & 0.3 & 4.1 \\
\hline & $\mathrm{M}$ & 4.0 & 4.0 & 4.0 & 2.0 & 4.0 & 3.0 & 4.0 & 4.0 & 4.0 & 0.0 & 0.0 & 0.0 & 2.0 & 1.0 & 2.6 & - \\
\hline & $\mathrm{W}$ & 1.8 & 4.0 & 4.0 & 0.9 & 2.0 & 3.0 & 4.0 & 4.0 & 4.0 & 0.0 & 0.0 & 0.0 & 1.0 & 1.0 & 2.1 & - \\
\hline$\vec{a}$ & $\mathrm{~F}$ & 5.0 & 6.0 & 3.0 & 2.0 & 2.0 & 1.0 & 2.0 & 1.0 & 1.0 & 0.0 & 0.0 & 0.0 & 2.0 & 1.0 & 1.9 & $\begin{array}{l}26 . \\
0\end{array}$ \\
\hline
\end{tabular}




\begin{tabular}{|c|c|c|c|c|c|c|c|c|c|c|c|c|c|c|c|c|c|}
\hline & $\mathrm{N}$ & 0.8 & 1.0 & 0.5 & 0.3 & 0.3 & 0.2 & 0.3 & 0.2 & 0.2 & 0.0 & 0.0 & 0.0 & 0.3 & 0.2 & 0.3 & 4.3 \\
\hline & $\mathrm{M}$ & 4.0 & 4.0 & 4.0 & 2.0 & 4.0 & 3.0 & 4.0 & 4.0 & 4.0 & 0.0 & 0.0 & 0.0 & 2.0 & 1.0 & 2.6 & - \\
\hline & W & 2.2 & 4.0 & 4.0 & 0.9 & 4.0 & 3.0 & 4.0 & 4.0 & 4.0 & 0.0 & 0.0 & 0.0 & 1.0 & 1.0 & 2.3 & - \\
\hline \multirow{4}{*}{$\vec{a}$} & $\mathrm{~F}$ & 6.0 & 6.0 & 4.0 & 2.0 & 2.0 & 1.0 & 2.0 & 1.0 & 1.0 & 0.0 & 0.0 & 0.0 & 1.0 & 1.0 & 1.9 & $\begin{array}{l}27 . \\
0\end{array}$ \\
\hline & $\mathrm{N}$ & 1.0 & 1.0 & 0.7 & 0.3 & 0.3 & 0.2 & 0.3 & 0.2 & 0.2 & 0.0 & 0.0 & 0.0 & 0.2 & 0.2 & 0.3 & 4.6 \\
\hline & $\mathrm{M}$ & 4.0 & 4.0 & 4.0 & 2.0 & 4.0 & 3.0 & 4.0 & 4.0 & 4.0 & 0.0 & 0.0 & 0.0 & 2.0 & 1.0 & 2.6 & - \\
\hline & W & 3.1 & 4.0 & 4.0 & 0.9 & 4.0 & 3.0 & 4.0 & 4.0 & 4.0 & 0.0 & 0.0 & 0.0 & 1.0 & 1.0 & 2.4 & - \\
\hline \multirow{4}{*}{$\begin{array}{l}\vec{a} \\
\dot{u}\end{array}$} & $\mathrm{~F}$ & 7.0 & 6.0 & 3.0 & 2.0 & 2.0 & 1.0 & 2.0 & 1.0 & 1.0 & 0.0 & 0.0 & 0.0 & 1.0 & 1.0 & 1.9 & $\begin{array}{l}27 . \\
0\end{array}$ \\
\hline & $\mathrm{N}$ & 1.0 & 0.9 & 0.4 & 0.3 & 0.3 & 0.1 & 0.3 & 0.1 & 0.1 & 0.0 & 0.0 & 0.0 & 0.1 & 0.1 & 0.3 & 3.7 \\
\hline & $\mathrm{M}$ & 4.0 & 4.0 & 4.0 & 2.0 & 4.0 & 3.0 & 4.0 & 4.0 & 4.0 & 0.0 & 0.0 & 0.0 & 2.0 & 1.0 & 2.6 & - \\
\hline & W & 3.1 & 4.0 & 4.0 & 0.9 & 4.0 & 3.0 & 4.0 & 4.0 & 4.0 & 0.0 & 0.0 & 0.0 & 1.0 & 1.0 & 2.4 & - \\
\hline \multirow{4}{*}{$\begin{array}{l}\vec{a} \\
\hat{a}\end{array}$} & $\mathrm{~F}$ & 7.0 & 6.0 & 3.0 & 2.0 & 1.0 & 1.0 & 2.0 & 1.0 & 1.0 & 0.0 & 0.0 & 0.0 & 1.0 & 1.0 & 1.9 & $\begin{array}{l}26 . \\
0\end{array}$ \\
\hline & $\mathrm{N}$ & 1.0 & 0.9 & 0.4 & 0.3 & 0.1 & 0.1 & 0.3 & 0.1 & 0.1 & 0.0 & 0.0 & 0.0 & 0.1 & 0.1 & 0.3 & $\mathbf{3 . 5}$ \\
\hline & $\mathrm{M}$ & 4.0 & 4.0 & 4.0 & 2.0 & 4.0 & 3.0 & 4.0 & 4.0 & 4.0 & 0.0 & 0.0 & 0.0 & 2.0 & 1.0 & 2.6 & - \\
\hline & W & 3.1 & 4.0 & 4.0 & 0.9 & 4.0 & 3.0 & 4.0 & 4.0 & 4.0 & 0.0 & 0.0 & 0.0 & 1.0 & 1.0 & 2.4 & - \\
\hline
\end{tabular}

Form-Based Code-Underground level

\begin{tabular}{|c|c|c|c|c|c|c|c|c|c|c|c|c|c|c|c|c|c|}
\hline \multirow{4}{*}{$\subseteq$} & $\mathrm{F}$ & 0.0 & 0.0 & 0.0 & 0.0 & 0.0 & 1.0 & 2.0 & 1.0 & 0.0 & 0.0 & 0.0 & 0.0 & 0.0 & 0.0 & 0.3 & 4.0 \\
\hline & $\mathrm{N}$ & 0.0 & 0.0 & 0.0 & 0.0 & 0.0 & 1.0 & 1.0 & 1.0 & 0.0 & 0.0 & 0.0 & 0.0 & 0.0 & 0.0 & 0.2 & 3.0 \\
\hline & $\mathrm{M}$ & 0.0 & 0.0 & 0.0 & 0.0 & 0.0 & 4.0 & 4.0 & 4.0 & 0.0 & 0.0 & 0.0 & 0.0 & 0.0 & 0.0 & 0.9 & - \\
\hline & $\mathrm{W}$ & 0.0 & 0.0 & 0.0 & 0.0 & 0.0 & 4.0 & 4.0 & 4.0 & 0.0 & 0.0 & 0.0 & 0.0 & 0.0 & 0.0 & 0.9 & - \\
\hline \multirow{4}{*}{$\stackrel{S}{N}$} & $\mathrm{~F}$ & 0.0 & 0.0 & 0.0 & 0.0 & 0.0 & 1.0 & 2.0 & 1.0 & 0.0 & 0.0 & 0.0 & 0.0 & 0.0 & 0.0 & 0.3 & 4.0 \\
\hline & $\mathrm{N}$ & 0.0 & 0.0 & 0.0 & 0.0 & 0.0 & 1.0 & 1.0 & 1.0 & 0.0 & 0.0 & 0.0 & 0.0 & 0.0 & 0.0 & 0.2 & 3.0 \\
\hline & $\mathrm{M}$ & 0.0 & 0.0 & 0.0 & 0.0 & 0.0 & 4.0 & 4.0 & 4.0 & 0.0 & 0.0 & 0.0 & 0.0 & 0.0 & 0.0 & 0.9 & - \\
\hline & $\mathrm{W}$ & 0.0 & 0.0 & 0.0 & 0.0 & 0.0 & 4.0 & 4.0 & 4.0 & 0.0 & 0.0 & 0.0 & 0.0 & 0.0 & 0.0 & 0.9 & - \\
\hline \multirow{4}{*}{$\underset{\omega}{\mathcal{S}}$} & $\mathrm{F}$ & 0.0 & 0.0 & 0.0 & 0.0 & 0.0 & 1.0 & 2.0 & 1.0 & 0.0 & 0.0 & 0.0 & 0.0 & 0.0 & 0.0 & 0.3 & 4.0 \\
\hline & $\mathrm{N}$ & 0.0 & 0.0 & 0.0 & 0.0 & 0.0 & 1.0 & 1.0 & 1.0 & 0.0 & 0.0 & 0.0 & 0.0 & 0.0 & 0.0 & 0.2 & 3.0 \\
\hline & $\mathrm{M}$ & 0.0 & 0.0 & 0.0 & 0.0 & 0.0 & 4.0 & 4.0 & 4.0 & 0.0 & 0.0 & 0.0 & 0.0 & 0.0 & 0.0 & $\begin{array}{ll}0.9 \\
\end{array}$ & - \\
\hline & W & 0.0 & 0.0 & 0.0 & 0.0 & 0.0 & 4.0 & 4.0 & 4.0 & 0.0 & 0.0 & 0.0 & 0.0 & 0.0 & 0.0 & 0.9 & - \\
\hline \multirow{4}{*}{$\stackrel{\subsetneq}{\triangleright}$} & $\mathrm{F}$ & 0.0 & 0.0 & 0.0 & 0.0 & 0.0 & 1.0 & 2.0 & 1.0 & 0.0 & 0.0 & 0.0 & 0.0 & 0.0 & 0.0 & 0.3 & 4.0 \\
\hline & $\mathrm{N}$ & 0.0 & 0.0 & 0.0 & 0.0 & 0.0 & 1.0 & 1.0 & 1.0 & 0.0 & 0.0 & 0.0 & 0.0 & 0.0 & 0.0 & 0.2 & 3.0 \\
\hline & $\mathrm{M}$ & 0.0 & 0.0 & 0.0 & 0.0 & 0.0 & 4.0 & 4.0 & 4.0 & 0.0 & 0.0 & 0.0 & 0.0 & 0.0 & 0.0 & $\begin{array}{l}0.9 \\
\end{array}$ & - \\
\hline & W & 0.0 & 0.0 & 0.0 & 0.0 & 0.0 & 4.0 & 4.0 & 4.0 & 0.0 & 0.0 & 0.0 & 0.0 & 0.0 & 0.0 & 0.9 & - \\
\hline \multirow{4}{*}{$\stackrel{c}{\sim}$} & $\mathrm{F}$ & 0.0 & 0.0 & 0.0 & 0.0 & 0.0 & 1.0 & 2.0 & 1.0 & 0.0 & 0.0 & 0.0 & 0.0 & 0.0 & 0.0 & 0.3 & 4.0 \\
\hline & $\mathrm{N}$ & 0.0 & 0.0 & 0.0 & 0.0 & 0.0 & 1.0 & 1.0 & 1.0 & 0.0 & 0.0 & 0.0 & 0.0 & 0.0 & 0.0 & 0.2 & 3.0 \\
\hline & $\mathrm{M}$ & 0.0 & 0.0 & 0.0 & 0.0 & 0.0 & 4.0 & 4.0 & 4.0 & 0.0 & 0.0 & 0.0 & 0.0 & 0.0 & 0.0 & \begin{tabular}{|l|l|}
0.9 \\
\end{tabular} & - \\
\hline & W & 0.0 & 0.0 & 0.0 & 0.0 & 0.0 & 4.0 & 4.0 & 4.0 & 0.0 & 0.0 & 0.0 & 0.0 & 0.0 & 0.0 & 0.9 & - \\
\hline
\end{tabular}

\section{Form-Based Code-Upper Ground level}

\begin{tabular}{|c|c|c|c|c|c|c|c|c|c|c|c|c|c|c|c|c|c|}
\hline \multirow{4}{*}{$\leq$} & F & 0.0 & 0.0 & 0.0 & 0.0 & 0.0 & 1.0 & 2.0 & 1.0 & 0.0 & 0.0 & 0.0 & 0.0 & 0.0 & 0.0 & 0.3 & 4.0 \\
\hline & $\mathrm{N}$ & 0.0 & 0.0 & 0.0 & 0.0 & 0.0 & 1.0 & 1.0 & 1.0 & 0.0 & 0.0 & 0.0 & 0.0 & 0.0 & 0.0 & 0.2 & 3.0 \\
\hline & $\mathrm{M}$ & 0.0 & 0.0 & 0.0 & 0.0 & 0.0 & 4.0 & 4.0 & 4.0 & 0.0 & 0.0 & 0.0 & 0.0 & 0.0 & 0.0 & 0.9 & - \\
\hline & $\mathrm{W}$ & 0.0 & 0.0 & 0.0 & 0.0 & 0.0 & 4.0 & 4.0 & 4.0 & 0.0 & 0.0 & 0.0 & 0.0 & 0.0 & 0.0 & 0.9 & - \\
\hline \multirow{4}{*}{ 心 } & $\mathrm{F}$ & 0.0 & 0.0 & 0.0 & 0.0 & 0.0 & 1.0 & 2.0 & 1.0 & 0.0 & 0.0 & 0.0 & 0.0 & 0.0 & 0.0 & 0.3 & 4.0 \\
\hline & $\mathrm{N}$ & 0.0 & 0.0 & 0.0 & 0.0 & 0.0 & 1.0 & 1.0 & 1.0 & 0.0 & 0.0 & 0.0 & 0.0 & 0.0 & 0.0 & 0.2 & 3.0 \\
\hline & $\bar{M}$ & 0.0 & 0.0 & 0.0 & 0.0 & 0.0 & 4.0 & 4.0 & 4.0 & 0.0 & 0.0 & 0.0 & 0.0 & 0.0 & 0.0 & 0.9 & - \\
\hline & $\mathrm{W}$ & 0.0 & 0.0 & 0.0 & 0.0 & 0.0 & 4.0 & 4.0 & 4.0 & 0.0 & 0.0 & 0.0 & 0.0 & 0.0 & 0.0 & $\begin{array}{l}0.9 \\
\end{array}$ & - \\
\hline
\end{tabular}




\begin{tabular}{|c|c|c|c|c|c|c|c|c|c|c|c|c|c|c|c|c|c|}
\hline \multirow{4}{*}{$\underset{\omega}{\omega}$} & $\bar{F}$ & 0.0 & 0.0 & 0.0 & 0.0 & 0.0 & 1.0 & 2.0 & 1.0 & 0.0 & 0.0 & 0.0 & 0.0 & 0.0 & 0.0 & 0.3 & 4.0 \\
\hline & $\mathrm{N}$ & 0.0 & 0.0 & 0.0 & 0.0 & 0.0 & 1.0 & 1.0 & 1.0 & 0.0 & 0.0 & 0.0 & 0.0 & 0.0 & 0.0 & 0.2 & 3.0 \\
\hline & $\mathrm{M}$ & 0.0 & 0.0 & 0.0 & 0.0 & 0.0 & 4.0 & 4.0 & 4.0 & 0.0 & 0.0 & 0.0 & 0.0 & 0.0 & 0.0 & 0.9 & - \\
\hline & $\mathrm{W}$ & 0.0 & 0.0 & 0.0 & 0.0 & 0.0 & 4.0 & 4.0 & 4.0 & 0.0 & 0.0 & 0.0 & 0.0 & 0.0 & 0.0 & 0.9 & - \\
\hline \multirow{4}{*}{$\leftrightarrows$} & $\mathrm{F}$ & 0.0 & 0.0 & 0.0 & 0.0 & 0.0 & 1.0 & 2.0 & 1.0 & 0.0 & 0.0 & 0.0 & 0.0 & 0.0 & 0.0 & 0.3 & 4.0 \\
\hline & $\mathrm{N}$ & 0.0 & 0.0 & 0.0 & 0.0 & 0.0 & 1.0 & 1.0 & 1.0 & 0.0 & 0.0 & 0.0 & 0.0 & 0.0 & 0.0 & 0.2 & 3.0 \\
\hline & $\mathrm{M}$ & 0.0 & 0.0 & 0.0 & 0.0 & 0.0 & 4.0 & 4.0 & 4.0 & 0.0 & 0.0 & 0.0 & 0.0 & 0.0 & 0.0 & \begin{tabular}{ll|}
0.9 \\
\end{tabular} & - \\
\hline & $\mathrm{W}$ & 0.0 & 0.0 & 0.0 & 0.0 & 0.0 & 4.0 & 4.0 & 4.0 & 0.0 & 0.0 & 0.0 & 0.0 & 0.0 & 0.0 & $\begin{array}{ll}0.9 \\
\end{array}$ & - \\
\hline \multirow{4}{*}{$\underset{u}{u}$} & $\mathrm{~F}$ & 0.0 & 0.0 & 0.0 & 0.0 & 0.0 & 1.0 & 2.0 & 1.0 & 0.0 & 0.0 & 0.0 & 0.0 & 0.0 & 0.0 & 0.3 & 4.0 \\
\hline & $\mathrm{N}$ & 0.0 & 0.0 & 0.0 & 0.0 & 0.0 & 1.0 & 1.0 & 1.0 & 0.0 & 0.0 & 0.0 & 0.0 & 0.0 & 0.0 & 0.2 & 3.0 \\
\hline & $\bar{M}$ & 0.0 & 0.0 & 0.0 & 0.0 & 0.0 & 4.0 & 4.0 & 4.0 & 0.0 & 0.0 & 0.0 & 0.0 & 0.0 & 0.0 & $\begin{array}{l}0.9 \\
\end{array}$ & - \\
\hline & $\mathrm{W}$ & 0.0 & 0.0 & 0.0 & 0.0 & 0.0 & 4.0 & 4.0 & 4.0 & 0.0 & 0.0 & 0.0 & 0.0 & 0.0 & 0.0 & $\begin{array}{ll}0.9 \\
\end{array}$ & - \\
\hline
\end{tabular}

$\mathrm{F}$ is raw frequency. $\mathrm{N}$ is normalised frequency. $\mathrm{M}$ is the concordance value. $\mathrm{W}$ is the weighted concordance value. Dark shading represents $\mathrm{W}>=2.5$, medium shading represents $1<\mathrm{W}<2.5$, light shading represents $\mathrm{W}<=1$.

Table 36. Scoring results of NPD-LEED-ND

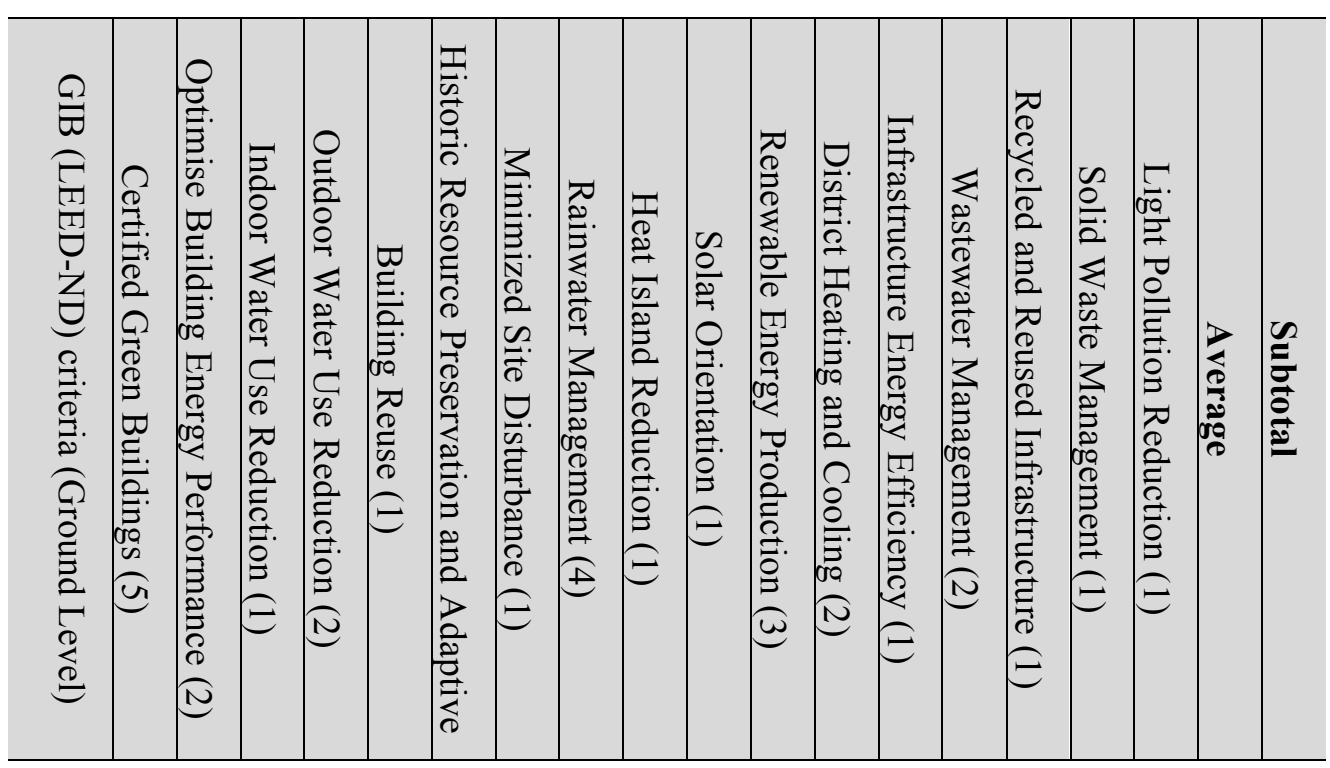

Form-Based Code-Ground Level

\begin{tabular}{|c|c|c|c|c|c|c|c|c|c|c|c|c|c|c|c|c|c|c|c|c|}
\hline \multirow{4}{*}{$\vec{a}$} & $\mathrm{~F}$ & 0.0 & 0.0 & 0.0 & 0.0 & 1.0 & 2.0 & 1.0 & 0.0 & 0.0 & $\overline{0.0}$ & 0.0 & 0.0 & 0.0 & 0.0 & 0.0 & 0.0 & 0.0 & 0.2 & 4.0 \\
\hline & $\mathrm{N}$ & 0.0 & $\overline{0.0}$ & 0.0 & 0.0 & 0.5 & 1.0 & 0.5 & 0.0 & 0.0 & 0.0 & 0.0 & 0.0 & 0.0 & 0.0 & 0.0 & 0.0 & 0.0 & 0.1 & 2.0 \\
\hline & $\mathrm{M}$ & 0.0 & 0.0 & 0.0 & 0.0 & 2.0 & 3.0 & 3.0 & 0.0 & 0.0 & 0.0 & 0.0 & 0.0 & 0.0 & 0.0 & 0.0 & 0.0 & 0.0 & 0.5 & - \\
\hline & $\mathrm{W}$ & 0.0 & 0.0 & 0.0 & 0.0 & 2.0 & 3.0 & 3.0 & 0.0 & 0.0 & 0.0 & 0.0 & 0.0 & 0.0 & 0.0 & 0.0 & 0.0 & 0.0 & 0.5 & \\
\hline & F & 0.0 & $\overline{0.0}$ & 0.0 & 0.0 & 1.0 & 2.0 & 1.0 & 0.0 & 0.0 & 0.0 & 0.0 & 0.0 & 0.0 & 0.0 & $\overline{0.0}$ & 0.0 & 0.0 & 0.2 & 4.0 \\
\hline & $\mathrm{N}$ & 0.0 & 0.0 & 0.0 & 0.0 & 0.5 & 1.0 & 0.5 & 0.0 & 0.0 & 0.0 & 0.0 & 0.0 & 0.0 & 0.0 & 0.0 & 0.0 & 0.0 & 0.1 & 2.0 \\
\hline & $\mathrm{M}$ & 0.0 & 0.0 & 0.0 & 0.0 & 2.0 & 3.0 & 3.0 & 0.0 & 0.0 & 0.0 & 0.0 & 0.0 & 0.0 & 0.0 & $\overline{0.0}$ & 0.0 & 0.0 & 0.5 & - \\
\hline & $\mathrm{W}$ & 0.0 & 0.0 & 0.0 & 0.0 & 2.0 & 3.0 & 3.0 & $\overline{0.0}$ & 0.0 & 0.0 & 0.0 & 0.0 & 0.0 & 0.0 & 0.0 & 0.0 & 0.0 & 0.5 & \\
\hline \multirow{4}{*}{$\vec{a}$} & $F$ & 0.0 & 0.0 & 0.0 & 0.0 & 1.0 & 2.0 & 1.0 & 0.0 & 0.0 & 0.0 & 0.0 & 0.0 & 0.0 & 0.0 & 0.0 & 0.0 & 0.0 & 0.2 & 4.0 \\
\hline & $\mathrm{N}$ & 0.0 & 0.0 & 0.0 & 0.0 & 0.5 & 1.0 & 0.5 & 0.0 & 0.0 & 0.0 & 0.0 & 0.0 & 0.0 & 0.0 & 0.0 & 0.0 & 0.0 & 0.1 & 2.0 \\
\hline & $\mathrm{M}$ & 0.0 & 0.0 & 0.0 & 0.0 & 2.0 & 3.0 & 3.0 & $\overline{0.0}$ & 0.0 & $\overline{0.0}$ & 0.0 & 0.0 & 0.0 & 0.0 & $\overline{0.0}$ & 0.0 & 0.0 & 0.5 & - \\
\hline & W & 0.0 & 0.0 & 0.0 & 0.0 & 2.0 & 3.0 & 3.0 & 0.0 & 0.0 & 0.0 & 0.0 & 0.0 & 0.0 & 0.0 & 0.0 & 0.0 & 0.0 & 0.5 & - \\
\hline
\end{tabular}




\begin{tabular}{|c|c|c|c|c|c|c|c|c|c|c|c|c|c|c|c|c|c|c|c|c|}
\hline \multirow{4}{*}{$\vec{a}$} & $\mathrm{~F}$ & 0.0 & 0.0 & 0.0 & 0.0 & 1.0 & 2.0 & 1.0 & 0.0 & $\overline{0.0}$ & 0.0 & 0.0 & 0.0 & 0.0 & 0.0 & 0.0 & 0.0 & 0.0 & 0.2 & 4.0 \\
\hline & $\mathrm{N}$ & 0.0 & 0.0 & 0.0 & 0.0 & 0.5 & 1.0 & 0.5 & 0.0 & 0.0 & 0.0 & 0.0 & 0.0 & 0.0 & 0.0 & 0.0 & 0.0 & 0.0 & 0.1 & 2.0 \\
\hline & $\mathrm{M}$ & 0.0 & 0.0 & 0.0 & 0.0 & 2.0 & 3.0 & 3.0 & 0.0 & 0.0 & 0.0 & 0.0 & 0.0 & 0.0 & 0.0 & 0.0 & 0.0 & 0.0 & 0.5 & - \\
\hline & $\mathrm{W}$ & 0.0 & 0.0 & 0.0 & 0.0 & 2.0 & 3.0 & 3.0 & 0.0 & $\overline{0.0}$ & 0.0 & 0.0 & 0.0 & 0.0 & 0.0 & 0.0 & 0.0 & 0.0 & 0.5 & - \\
\hline \multirow{4}{*}{$\begin{array}{l}\vec{a} \\
\dot{u}\end{array}$} & $\mathrm{~F}$ & 0.0 & 0.0 & $\overline{0.0}$ & 0.0 & 1.0 & 2.0 & 1.0 & 0.0 & 0.0 & 0.0 & 0.0 & 0.0 & 0.0 & 0.0 & 0.0 & $\overline{0.0}$ & 0.0 & 0.2 & 4.0 \\
\hline & $\mathrm{N}$ & 0.0 & 0.0 & 0.0 & 0.0 & 0.5 & 1.0 & 0.5 & 0.0 & 0.0 & 0.0 & 0.0 & 0.0 & 0.0 & 0.0 & 0.0 & 0.0 & 0.0 & 0.1 & 2.0 \\
\hline & $\mathrm{M}$ & 0.0 & 0.0 & 0.0 & 0.0 & 2.0 & 3.0 & 3.0 & 0.0 & $\overline{0.0}$ & 0.0 & 0.0 & 0.0 & 0.0 & 0.0 & 0.0 & 0.0 & 0.0 & 0.5 & - \\
\hline & $\mathrm{W}$ & 0.0 & 0.0 & 0.0 & 0.0 & 2.0 & 3.0 & 3.0 & 0.0 & 0.0 & 0.0 & 0.0 & 0.0 & 0.0 & 0.0 & 0.0 & 0.0 & 0.0 & 0.5 & - \\
\hline \multirow{4}{*}{$\vec{a}$} & $\mathrm{~F}$ & 0.0 & 0.0 & 0.0 & 0.0 & 1.0 & 2.0 & 1.0 & 0.0 & 0.0 & 0.0 & 0.0 & 0.0 & 0.0 & 0.0 & 0.0 & 0.0 & 0.0 & 0.2 & 4.0 \\
\hline & $\mathrm{N}$ & 0.0 & 0.0 & 0.0 & 0.0 & 0.5 & 1.0 & 0.5 & 0.0 & 0.0 & 0.0 & 0.0 & 0.0 & 0.0 & 0.0 & 0.0 & 0.0 & 0.0 & 0.1 & 2.0 \\
\hline & $\mathrm{M}$ & 0.0 & 0.0 & 0.0 & 0.0 & 2.0 & 3.0 & 3.0 & 0.0 & 0.0 & 0.0 & 0.0 & 0.0 & 0.0 & 0.0 & 0.0 & 0.0 & 0.0 & 0.5 & \\
\hline & W & 0.0 & 0.0 & 0.0 & 0.0 & 2.0 & 3.0 & 3.0 & 0.0 & 0.0 & 0.0 & 0.0 & 0.0 & 0.0 & 0.0 & 0.0 & 0.0 & 0.0 & 0.5 & - \\
\hline
\end{tabular}

Form-Based Code-Underground Level

\begin{tabular}{|c|c|c|c|c|c|c|c|c|c|c|c|c|c|c|c|c|c|c|c|c|}
\hline \multirow{4}{*}{$\subseteq$} & F & 0.0 & 0.0 & 0.0 & 0.0 & 1.0 & 2.0 & 1.0 & 0.0 & 0.0 & 0.0 & 0.0 & 0.0 & 0.0 & 0.0 & 0.0 & 0.0 & 0.0 & 0.2 & 4.0 \\
\hline & $\mathrm{N}$ & 0.0 & 0.0 & 0.0 & 0.0 & 0.5 & 1.0 & 0.5 & 0.0 & 0.0 & 0.0 & 0.0 & 0.0 & 0.0 & 0.0 & 0.0 & 0.0 & 0.0 & 0.1 & 2.0 \\
\hline & $\mathrm{M}$ & 0.0 & 0.0 & 0.0 & 0.0 & 2.0 & 3.0 & 3.0 & 0.0 & 0.0 & 0.0 & 0.0 & 0.0 & 0.0 & 0.0 & 0.0 & 0.0 & 0.0 & 0.5 & - \\
\hline & W & 0.0 & 0.0 & 0.0 & 0.0 & 2.0 & 3.0 & 3.0 & 0.0 & 0.0 & 0.0 & 0.0 & 0.0 & 0.0 & 0.0 & 0.0 & 0.0 & 0.0 & 0.5 & - \\
\hline \multirow{4}{*}{$\stackrel{\sim}{N}$} & $\mathrm{~F}$ & 0.0 & 0.0 & 0.0 & 0.0 & 1.0 & 2.0 & 1.0 & 0.0 & 0.0 & 0.0 & 0.0 & 0.0 & 0.0 & 0.0 & 0.0 & 0.0 & 0.0 & 0.2 & 4.0 \\
\hline & $\mathrm{N}$ & 0.0 & 0.0 & 0.0 & 0.0 & 0.5 & 1.0 & 0.5 & 0.0 & 0.0 & 0.0 & 0.0 & 0.0 & 0.0 & 0.0 & 0.0 & 0.0 & 0.0 & 0.1 & 2.0 \\
\hline & $\mathrm{M}$ & 0.0 & 0.0 & 0.0 & 0.0 & 2.0 & 3.0 & 3.0 & 0.0 & 0.0 & 0.0 & 0.0 & 0.0 & 0.0 & 0.0 & 0.0 & 0.0 & 0.0 & 0.5 & - \\
\hline & $\mathrm{W}$ & 0.0 & 0.0 & 0.0 & 0.0 & 2.0 & 3.0 & 3.0 & 0.0 & 0.0 & 0.0 & 0.0 & 0.0 & 0.0 & 0.0 & 0.0 & 0.0 & 0.0 & 0.5 & - \\
\hline \multirow{4}{*}{$\underset{\omega}{\subset}$} & $\mathrm{F}$ & 0.0 & 0.0 & 0.0 & 0.0 & 1.0 & 2.0 & 1.0 & 0.0 & 0.0 & 0.0 & 0.0 & 0.0 & 0.0 & 0.0 & 0.0 & 0.0 & 0.0 & 0.2 & 4.0 \\
\hline & $\mathrm{N}$ & 0.0 & 0.0 & 0.0 & 0.0 & 0.5 & 1.0 & 0.5 & 0.0 & 0.0 & 0.0 & 0.0 & 0.0 & 0.0 & 0.0 & 0.0 & 0.0 & 0.0 & 0.1 & 2.0 \\
\hline & $\mathrm{M}$ & 0.0 & 0.0 & 0.0 & 0.0 & 2.0 & 3.0 & 3.0 & 0.0 & 0.0 & 0.0 & 0.0 & 0.0 & 0.0 & 0.0 & 0.0 & 0.0 & 0.0 & 0.5 & - \\
\hline & $\mathrm{W}$ & 0.0 & 0.0 & 0.0 & 0.0 & 2.0 & 3.0 & 3.0 & 0.0 & 0.0 & 0.0 & 0.0 & 0.0 & 0.0 & 0.0 & 0.0 & 0.0 & 0.0 & 0.5 & - \\
\hline \multirow{4}{*}{$\stackrel{\subset}{\triangleright}$} & $\mathrm{F}$ & 0.0 & 0.0 & 0.0 & 0.0 & 1.0 & 2.0 & 1.0 & 0.0 & 0.0 & 0.0 & 0.0 & 0.0 & 0.0 & 0.0 & 0.0 & 0.0 & 0.0 & 0.2 & 4.0 \\
\hline & $\mathrm{N}$ & 0.0 & 0.0 & 0.0 & 0.0 & 0.5 & 1.0 & 0.5 & 0.0 & 0.0 & 0.0 & 0.0 & 0.0 & 0.0 & 0.0 & 0.0 & 0.0 & 0.0 & 0.1 & 2.0 \\
\hline & $\mathrm{M}$ & 0.0 & 0.0 & 0.0 & 0.0 & 2.0 & 3.0 & 3.0 & 0.0 & 0.0 & 0.0 & 0.0 & 0.0 & 0.0 & 0.0 & 0.0 & 0.0 & 0.0 & 0.5 & - \\
\hline & $\mathrm{W}$ & 0.0 & 0.0 & 0.0 & 0.0 & 2.0 & 3.0 & 3.0 & 0.0 & 0.0 & 0.0 & 0.0 & 0.0 & 0.0 & 0.0 & 0.0 & 0.0 & 0.0 & 0.5 & - \\
\hline \multirow{4}{*}{$\mathcal{G}$} & $\mathrm{F}$ & 0.0 & 0.0 & 0.0 & 0.0 & 1.0 & 2.0 & 1.0 & 0.0 & 0.0 & 0.0 & 0.0 & 0.0 & 0.0 & 0.0 & 0.0 & 0.0 & 0.0 & 0.2 & 4.0 \\
\hline & $\mathrm{N}$ & 0.0 & $\begin{array}{l}0.0 \\
\end{array}$ & 0.0 & 0.0 & 0.5 & 1.0 & 0.5 & 0.0 & 0.0 & 0.0 & 0.0 & 0.0 & 0.0 & 0.0 & 0.0 & 0.0 & 0.0 & 0.1 & 2.0 \\
\hline & $\mathrm{M}$ & 0.0 & 0.0 & 0.0 & 0.0 & 2.0 & 3.0 & 3.0 & 0.0 & 0.0 & 0.0 & 0.0 & 0.0 & 0.0 & 0.0 & 0.0 & 0.0 & 0.0 & 0.5 & - \\
\hline & $\mathrm{W}$ & 0.0 & 0.0 & 0.0 & 0.0 & 2.0 & 3.0 & 3.0 & 0.0 & 0.0 & 0.0 & 0.0 & 0.0 & 0.0 & 0.0 & 0.0 & 0.0 & 0.0 & 0.5 & - \\
\hline
\end{tabular}

Form-Based Code-Upper Ground Level

\begin{tabular}{|c|c|c|c|c|c|c|c|c|c|c|c|c|c|c|c|c|c|c|c|c|}
\hline \multirow{4}{*}{$\leq$} & $\mathrm{F}$ & 0.0 & 0.0 & 0.0 & 0.0 & 1.0 & 2.0 & 1.0 & 0.0 & 0.0 & 0.0 & 0.0 & 0.0 & 0.0 & 0.0 & 0.0 & 0.0 & 0.0 & 0.2 & 4.0 \\
\hline & $\mathrm{N}$ & 0.0 & 0.0 & 0.0 & 0.0 & 0.5 & 1.0 & 0.5 & 0.0 & 0.0 & 0.0 & 0.0 & 0.0 & 0.0 & 0.0 & 0.0 & 0.0 & 0.0 & 0.1 & 2.0 \\
\hline & $\mathrm{M}$ & 0.0 & 0.0 & 0.0 & 0.0 & 2.0 & 3.0 & 3.0 & 0.0 & 0.0 & 0.0 & 0.0 & 0.0 & 0.0 & 0.0 & 0.0 & 0.0 & 0.0 & 0.5 & - \\
\hline & $\mathrm{W}$ & 0.0 & 0.0 & 0.0 & 0.0 & 2.0 & 3.0 & 3.0 & 0.0 & 0.0 & 0.0 & 0.0 & 0.0 & 0.0 & 0.0 & 0.0 & 0.0 & 0.0 & 0.5 & - \\
\hline \multirow{4}{*}{ ৯ } & $F$ & 0.0 & 0.0 & 0.0 & 0.0 & 1.0 & 2.0 & 1.0 & 0.0 & 0.0 & 0.0 & 0.0 & 0.0 & 0.0 & 0.0 & 0.0 & 0.0 & 0.0 & 0.2 & 4.0 \\
\hline & $\mathrm{N}$ & 0.0 & 0.0 & 0.0 & 0.0 & 0.5 & 1.0 & 0.5 & 0.0 & 0.0 & 0.0 & 0.0 & 0.0 & 0.0 & 0.0 & 0.0 & 0.0 & 0.0 & 0.1 & 2.0 \\
\hline & $\mathrm{M}$ & 0.0 & 0.0 & 0.0 & 0.0 & 2.0 & 3.0 & 3.0 & 0.0 & 0.0 & 0.0 & 0.0 & 0.0 & 0.0 & 0.0 & 0.0 & 0.0 & 0.0 & 0.5 & \\
\hline & W & 0.0 & 0.0 & 0.0 & 0.0 & 2.0 & 3.0 & 3.0 & 0.0 & 0.0 & 0.0 & 0.0 & 0.0 & 0.0 & 0.0 & 0.0 & 0.0 & 0.0 & 0.5 & - \\
\hline \multirow{4}{*}{$\underset{\omega}{\omega}$} & $\mathrm{F}$ & 0.0 & 0.0 & 0.0 & 0.0 & 1.0 & 2.0 & 1.0 & 0.0 & 0.0 & 0.0 & 0.0 & 0.0 & 0.0 & 0.0 & 0.0 & 0.0 & 0.0 & 0.2 & 4.0 \\
\hline & $\mathrm{N}$ & 0.0 & 0.0 & 0.0 & 0.0 & 0.5 & 1.0 & 0.5 & 0.0 & 0.0 & 0.0 & 0.0 & 0.0 & 0.0 & 0.0 & 0.0 & 0.0 & 0.0 & 0.1 & 2.0 \\
\hline & $\mathrm{M}$ & 0.0 & 0.0 & 0.0 & 0.0 & 2.0 & 3.0 & 3.0 & 0.0 & 0.0 & 0.0 & 0.0 & 0.0 & 0.0 & 0.0 & 0.0 & 0.0 & 0.0 & 0.5 & - \\
\hline & $\mathrm{W}$ & 0.0 & 0.0 & 0.0 & 0.0 & 2.0 & 3.0 & 3.0 & 0.0 & 0.0 & 0.0 & 0.0 & 0.0 & 0.0 & 0.0 & 0.0 & 0.0 & 0.0 & 0.5 & - \\
\hline \multirow{4}{*}{$\underset{\Delta}{\Delta}$} & $\mathrm{F}$ & 0.0 & 0.0 & 0.0 & 0.0 & 1.0 & 2.0 & 1.0 & 0.0 & 0.0 & 0.0 & 0.0 & 0.0 & 0.0 & 0.0 & 0.0 & 0.0 & 0.0 & 0.2 & 4.0 \\
\hline & $\mathrm{N}$ & 0.0 & 0.0 & 0.0 & 0.0 & 0.5 & 1.0 & 0.5 & 0.0 & 0.0 & 0.0 & 0.0 & 0.0 & 0.0 & 0.0 & 0.0 & 0.0 & 0.0 & \begin{tabular}{l|l}
0.1 \\
\end{tabular} & 2.0 \\
\hline & $\mathrm{M}$ & 0.0 & 0.0 & 0.0 & $\overline{0.0}$ & 2.0 & 3.0 & 3.0 & 0.0 & 0.0 & 0.0 & 0.0 & 0.0 & 0.0 & $\overline{0.0}$ & 0.0 & 0.0 & 0.0 & 0.5 & - \\
\hline & $\mathrm{W}$ & 0.0 & 0.0 & 0.0 & 0.0 & 2.0 & 3.0 & 3.0 & 0.0 & 0.0 & 0.0 & 0.0 & 0.0 & 0.0 & 0.0 & 0.0 & 0.0 & 0.0 & 0.5 & - \\
\hline \multirow{4}{*}{$\vec{u}$} & $F$ & 0.0 & 0.0 & 0.0 & 0.0 & 1.0 & 2.0 & 1.0 & 0.0 & 0.0 & 0.0 & 0.0 & 0.0 & 0.0 & 0.0 & 0.0 & 0.0 & 0.0 & 0.2 & 4.0 \\
\hline & $\mathrm{N}$ & 0.0 & 0.0 & 0.0 & 0.0 & 0.5 & 1.0 & 0.5 & 0.0 & 0.0 & 0.0 & 0.0 & 0.0 & 0.0 & $\overline{0.0}$ & 0.0 & 0.0 & 0.0 & 0.1 & 2.0 \\
\hline & $\mathrm{M}$ & 0.0 & 0.0 & 0.0 & 0.0 & 2.0 & 3.0 & 3.0 & 0.0 & 0.0 & 0.0 & 0.0 & 0.0 & 0.0 & 0.0 & 0.0 & 0.0 & 0.0 & 0.5 & - \\
\hline & $\mathrm{W}$ & 0.0 & 0.0 & 0.0 & 0.0 & 2.0 & 3.0 & 3.0 & 0.0 & 0.0 & 0.0 & 0.0 & 0.0 & 0.0 & 0.0 & 0.0 & 0.0 & 0.0 & 0.5 & - \\
\hline
\end{tabular}

Table 37. Scoring results of GIB-LEED-ND

\subsubsection{Concordance scoring results}

The scoring results provide a reference for a Form-Based Code team to measure 
the concordance between LEED-ND and Form-Based Code. This is depicted in Table 38. The light shading area indicates that concordance values are less than or equal with 1 , which means nearly no principle of LEED-ND is reflected in the Form-Based Code. The medium shading area with one "X" mark indicates that concordance values are between 1 and 2.5, which means that part of the principles of LEED-ND are reflected in the code; the code moderately aligns with LEED-ND criteria. The dark shading area with two " $X$ " marks means the concordance values are equal to, or higher than 2 and the principles of LEEDND are strongly reflected in the Form-Based Code.

\subsubsection{Findings}

Based on the scoring results, the findings are assessed from the perspectives of SLL, NPD and GIB. The following paragraphs describe further details about the findings to explore the sustainability of Form-Based Code through evaluating the level of concordance between LEED-ND and the Form-Based Code.

\subsubsection{SLL}

Generally, the scoring code indicates that the Form-Based Code is not aligned with the principles of SLL. There are seven weights in the SLL category criteria. Only the principles of Preferred Locations are moderately reflected. The purpose of this weight is to encourage new development in existing cities, suburbs, and towns. It is apparent in the Form-Based Code of Tsim Sha Tsui because of the locations of old communities and the area's compact urban space. Weights such as Brownfield Remediation and Water Body Conservation, are not related to the Form-Based Code. Others, like Housing and Jobs Proximity and Steep Slope Protection, are partly included in the Form-Based Code but do not meet the middle-rank standard. 


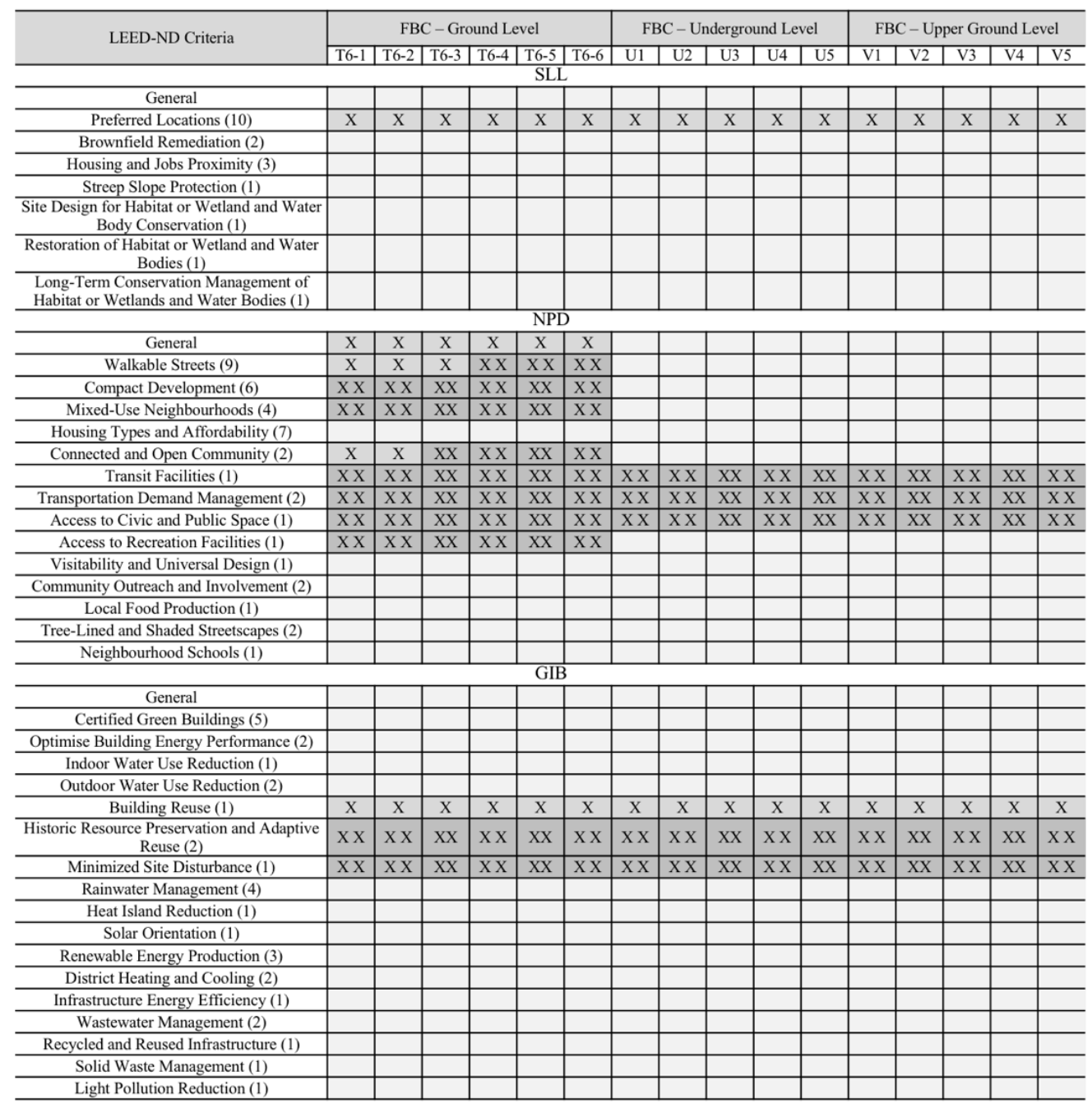

Table 38. Concordance scoring results

\subsubsection{NPD}

NPD has 14 criteria for measuring transportation connection, public health and comfortable street environment. The weights of Transit Facilities, Transportation Demand Management, and Access to Civic and Public Space are strongly reflected in the Form-Based Code at ground level, underground level and upper ground level, as the Form-Based Code regulates the transit waiting areas to be safe, convenient and comfortable. Multi-mode travel is encouraged and ranges from the public subway to walking. Public space can be organised as connecting work and home at different levels to fulfil the 
requirement of "non-residential use entrances within a $1 \frac{1}{4}$ mile (400 meters) walk of at least one civic and passive use space (USGBC, 2018)".

The weights of Compact Development and Mixed-Use Neighbourhoods are strongly reflected in the Form-Based Code of ground level. These weights are about conserving land by encouraging the development of existing infrastructure and car-free, mixed-use communities. The weights of Connected and Open Community are strongly consistent with the regulations of T6-3 to T66 and moderately reflected in T6-1 and T6-2. T6-1 to T6-3 partly achieve the weight of Walkable Streets, while T6-4 to T6-6 strongly reflect these weights. Other weights like Local Food Production, Neighbourhood Schools or Visitability and Universal Design are not related to the Form-Based Code, or are partly reflected but cannot meet the moderate standard.

In summary, nearly half of the NPD principles are moderately reflected in the Form-Based Code of ground level, and weakly reflected in the Form-Based Codes of underground and upper ground levels. The value of $\mathrm{M}$ in each ground level transect zone indicates that criterion is addressed in the regulations to more than a minimum extent, but still not to the degree of achieving the maximum possible LEED-ND points. Although the concordance values are still lower than 2.5 at ground level, they consistently meet the moderate standard of the NPD weights.

\subsubsection{GIB}

There are 17 weights in the category of GIB. Only two weights, Historic Resource Preservation and Adaptive Reuse and Minimized Site Disturbance, can be strongly reflected in the Form-Based Code and one weight, Building Reuse, is moderately reflected in the Form-Based Code. Other principles, such as Certified Green Building, Minimum Building Energy Performance, and Indoor Water Use Reduction are outside the scope of Form-Based Code 
regulation of Hong Kong.

A small number of the SLL and GIB criteria of LEED-ND are concordant with the Form-Based Code of the experimental site. NPD criteria are more moderately or strongly reflected in the ground level code. On average, the FormBased Code of Tsim Sha Tsui has a weak concordance with LEED-ND criteria (Table 39).

\begin{tabular}{c|c|c|c|c}
\hline Excellent & Good & Fair & Weak & None \\
\hline & & & $\sqrt{ }$ & \\
\hline
\end{tabular}

Table 39. Evaluation result of LEED-ND 


\subsection{Code quality}

As a New Urbanism tool, Form-Based Code aims to support smart growth on an urban scale. Evaluating the quality of the code assesses whether the FormBased Code of Tsim Sha Tsui can fulfil the requirements of smart-growth. Code quality evaluation focuses on examining the codes as a Form-Based Code rather than as conventional regulation.

\subsubsection{Criteria system}

There are two common criteria systems for evaluating the code quality of FormBased Code. One is the Smart Scorecard developed by CNU, and the other is the principles of enforceability, usability and functionality developed by FBCI. CNU and FBCI are both significant organisations examining Form-Based Code. After comparing the two systems, this section selects Smart Scorecard to evaluate the code quality.

Smart Scorecard works is the representative smart-growth evaluation approach of CNU. Published in 2002, Smart Scorecard was created by Fleissig and Jacobsen in collaboration with CNU and the United States Environmental Protection Agency (EPA). It was developed as a tool for evaluating the longterm viability and impact of a community generated by a new development project (Kim, 2010), as well as helping decision makers, municipal planners and staff, neighbourhood organizations, and developers determine whether a specific project is fulfilling a community's smart growth goals (EPA, 2018). Smart Scorecard propagates the principles of, and provides detailed guidelines for, new urbanist design by assisting with project-level decisions and evaluating for smart growth (Boer, et al., 2007). It is used to evaluate smart growth projects like Form-Based Code by a number of scholars, including Kim (2010), Scott et al. (2013) and Boer, et al. (2007).

Smart Scorecard contains dozens of questions with a specific scale for each 
rated component. For example, the principle that "the project's location reinforces and logically extends existing and planned development" is expressed as Figure 102. Rating standards are defined with numbers and explanatory notes. Smart Scorecard offers scoring approaches for evaluating results.

\begin{tabular}{|c|c|}
\hline Poor & $\begin{array}{l}\text { Project is on a greenfield site, is not zoned and/or planned for development and is not located adjacent to any } \\
\text { areas already developed or zoned for development. }\end{array}$ \\
\hline Good & 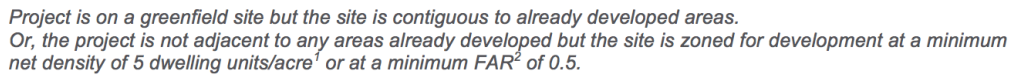 \\
\hline Very Good & $\begin{array}{l}\text { Project is on a site zoned for development at net densities of } 5 \text { DU/acre or at a minimum FAR of } 0.5 \text { and is } \\
\text { contiguous to areas already developed or zoned for development. }\end{array}$ \\
\hline Excellent & $\begin{array}{l}\text { Project is on a site zoned for development and is, either infill (surrounded by development at net densities of } 5 \\
\text { DU/acre or at a minimum FAR of } 0.5 \text { ); or, the project redevelops and increases the density of a previously } \\
\text { developed site; or, the project redevelops a brownfield site or a site/location designated to receive federal, state or } \\
\text { local assistance to support redevelopment. }\end{array}$ \\
\hline \multicolumn{2}{|c|}{$\begin{array}{l}\text { Note: Brownfields are typically former industrial sites that may have (or may be perceived to have) contamination issues. "Brownfield" is a } \\
\text { environmental designation that is often adapted in state or federal regulations to define concomitant requirements for the reuse of the site } \\
\text { (such as: stipulations for cleaning and remediation, the provision of state or federal funding for decontamination or the availability of } \\
\text { incentives to encourage reuse). }\end{array}$} \\
\hline
\end{tabular}

Figure 102. Example of rating standards in the Smart Scorecard

FBCI uses enforceability, usability and functionality to assess if the target Form-Based Code has the capability to create a quality built environment. Enforceability lies in the emphasis or reinforcement of specific community intentions as well as clearly described form contents (Kan, 2012). A wellwritten Form-Based Code must align with the established policies and regulations controlling the same property. Usability evaluates if the users, including communities, neighbourhoods and stakeholders, can access and understand the codes easily. The components ought to be readily discernible with easy-to-find information, a clear description of the technical terms, and readable physical form codes. Functionality relates to public activities and the movement of individuals. A quality Form-Based Code should shape public realms to attract pedestrian use and social interaction by providing a suitable physical plan, considering parking requirements, and offering a clear community vision. Table 40 (FBCI, 2015b) outlines the criteria system. 


\begin{tabular}{l|c}
\hline Categories & Principles \\
\hline \multirow{2}{*}{ Enforceability } & Reflect communities' intentions \\
\cline { 2 - 2 } & Clear description \\
\cline { 2 - 2 } & Effective coordination with existing codes \\
\cline { 2 - 2 } & Easy-to-find information \\
\cline { 2 - 2 } & Understandable codes \\
\cline { 2 - 2 } & Clear interpretation of the technical terms \\
\cline { 2 - 2 } & Convenient to public distribution \\
\hline \multirow{4}{*}{ Functionality } & Clearly description \\
\cline { 2 - 2 } & Attract pedestrian use \\
\cline { 2 - 2 } & Produce identifiable neighbourhoods \\
\cline { 2 - 2 } & Parking compatible with pedestrian-scaled urbanism \\
\cline { 2 - 2 } & Sufficient detailed plan \\
\hline
\end{tabular}

Table 40. Criteria system developed by the FBCI. FBCI, 2015b

Overlaps exist between the two systems' criteria. For example, Smart Scorecard specifies pedestrian friendly criteria and FBCI's criteria require attracting pedestrian use. However, they have many different emphases as well. Smart Scorecard contains specific standards for sustainability, connectivity, diversity, and design optimization and compactness (Kim, 2010). It evaluates the code quality with exact rates. FBCI's criteria emphasize code writing, information expressing and implementation results. It provides general principles without specific ratings. Smart Scorecard's quantitative criteria system is chosen for examining Form-Based Code in this section.

\subsubsection{Limitation}

Smart Growth Project Scorecard (SGPS) written by Smart Growth America's Leadership Institute (2007), is used as the criteria resource. There are various versions of Smart Scorecard for different project types and locations, such as the Vermont Smart Growth Scorecard (2000), Colorado Smart Growth Scorecard (2003), and Commonwealth Capital Scorecard (2006). Hong Kong 
has no Smart Scorecard or similar score system for evaluating smart growth so far and the existing Smart Scorecards of specific projects are unsuitable for the Form-Based Code of Tsim Sha Tsui. This research thus chooses a general version of Smart Scorecard to evaluate the code quality.

\subsubsection{Weight and score}

The scores in Smart Scorecard consist of five levels, including Not Applicable (N.A.), Poor, Good, Very Good, and Excellent. The scores range from 0 to 4. For example, Table 41 shows the criterion "The project provides housing that is consistent with the growth and demand projections (demographic) for the area" which has five levels of description.

\begin{tabular}{|c|c|c|c|}
\hline Indicator & Levels & Description & Score \\
\hline \multirow{5}{*}{$\begin{array}{l}\text { The project provide } \\
\text { housing that is } \\
\text { consistent with the } \\
\text { growth and } \\
\text { demand projections } \\
\text { (demographic) for } \\
\text { the area }\end{array}$} & N.A. & Not applicable. Project does not provide housing. & 0 \\
\hline & Poor & $\begin{array}{l}\text { The project provides housing at lower densities than } \\
\text { programmed in the long-term land use plan. }\end{array}$ & 1 \\
\hline & Good & $\begin{array}{l}\text { The project provides housing at lower densities but offsets } \\
\text { this through a transfer of development rights to areas } \\
\text { designated for higher density development. }\end{array}$ & 2 \\
\hline & Very Good & $\begin{array}{c}\text { The project provides housing at densities that are consistent } \\
\text { with the growth and demand projections for the area. }\end{array}$ & 3 \\
\hline & Excellent & $\begin{array}{l}\text { The project provides housing at higher densities through the } \\
\text { purchase/transfer of development rights. }\end{array}$ & 4 \\
\hline
\end{tabular}

Table 41. Example of Smart Scorecard criterion

Smart Scorecard offers eight weights for examining a Form-Base Code. They are:

1. Location and Service Provision

2. Density and Compactness

3. Density of Use

4. Diversity of Housing

5. Accessibility, Mobility and Connectivity 


\section{Pedestrian Safety, Streetscapes and Parking}

7. Environmental Protection

8. Community Needs and Local Development

The eight elements examine the basic smart growth concepts: that growth should be directed towards existing communities, and away from designated agricultural, open space, cultural and environmentally sensitive areas; and that development should occur at densities that reduce patterns of sprawling land consumption and encourage walking or biking (SGPS, 2007). The code quality evaluation according to the scoring descriptions of the Smart Scorecard system is described in the following sections.

\begin{tabular}{|c|c|c|c|}
\hline \multicolumn{4}{|l|}{ Category 1: Location and Service Provision } \\
\hline Indicators & & Scores & \\
\hline $\begin{array}{l}\text { The location reinforce and logically extend existing and planned } \\
\text { development (1) }\end{array}$ & & & 4.0 \\
\hline $\begin{array}{l}\text { The community or the local comprehensive plan identifies as a priority area } \\
\qquad \text { for development (2) }\end{array}$ & & & 4.0 \\
\hline Locate align with the community's long-range land use plan (3) & & & 4.0 \\
\hline $\begin{array}{l}\text { Provide housing that is consistent with the growth and demand projections } \\
\qquad \text { (demographic) for the area (4) }\end{array}$ & 0.0 & & \\
\hline Require an expansion or extension of the water service in the area (5) & 0.0 & & \\
\hline Require an expansion or extension of the sewer service in the area (6) & 0.0 & & \\
\hline Require an expansion of school capacity (7) & 0.0 & & \\
\hline Require an expansion of school transportation services (8) & 0.0 & & \\
\hline Adversely impact the fiscal health of local or other government entities (9) & 0.0 & & \\
\hline Average: & & 1.3 & \\
\hline Subtotal: & & 12.0 & \\
\hline
\end{tabular}

Table 42. Location and Service Provision Scores

\subsubsection{Location and Service Provision}

This weight category encourages reusing existing infrastructure and services to maximise public investment and conserve resources. In the Form-Based Code 
of Tsim Sha Tsui, the old urban centre is located near existing public resources. The weights of smart location are thus strongly reflected in the code; while weights for water, sewer, fiscal health and housing growth are not included at the conceptual stage. The average score is 1.3 which is slightly better than the Poor level (Table 42).

\subsubsection{Density and Compactness}

Smart Scorecard supports high density and compact building patterns rather than loose patterns. The Form-Based Code of the experimental site is developed in line with existing conditions. According to the scoring standards, the weights of Density and Compactness are highly reflected in the Form-Based Code on average (Table 43).

\begin{tabular}{|c|c|c|c|}
\hline \multicolumn{4}{|l|}{ Category 2: Density and Compactness } \\
\hline Indicators & \multicolumn{3}{|c|}{ Scores } \\
\hline Developed at planned densities (10) & & & 4.0 \\
\hline Minimizes areas devoted to parking (11) & 1.0 & & \\
\hline $\begin{array}{l}\text { Meet or reduces the on-site parking requirements with the inclusion of on- } \\
\text { street parking and/or with complimentary parking strategies such as shared } \\
\text { or joint parking (12) }\end{array}$ & & 3.0 & \\
\hline Achieve the smallest possible development footprint (13) & & & 4.0 \\
\hline Average: & \multicolumn{3}{|c|}{3.0} \\
\hline Subtotal: & \multicolumn{3}{|c|}{12.0} \\
\hline
\end{tabular}

Table 43. Density and Compactness Scores

\subsubsection{Diversity of Use}

Diversity of Use is used to evaluate if a Form-Based Code contains mixed land use. Land use examples in Smart Scorecard include single-family detached housing, small lot single-family detached housing, single-family row houses, condominiums, rental units, grocery or convenience shopping, restaurant or entertainment, significant office, recreational or community facility, park or playing fields, school or day-care, and religious or other institutional. In Smart 
Scorecard, an excellent mix of land use, for example, includes at least eight types from the land-use list for large projects, or at least two uses - one of the which is not prevalent in the surrounding neighbourhood (within 1/4 of a mile from the project) - for infill projects, or at least four not prevalent in the surrounding neighbourhood for small projects (SGPS, 2017). Walkable neighbourhoods and mixed land use are basic principles of Form-Based Code. The weights of Density of Use are fully reflected in the Form-Based Code of Tsim Sha Tsui (Table 44).

\begin{tabular}{c|c|c|c|c|c}
\hline \multicolumn{1}{c}{ Category 3: Density of Use } \\
\hline Indicators & & & & & 4.0 \\
\hline Provide a mix of land uses (14) & & & & & 4.0 \\
\hline $\begin{array}{c}\text { Physically mixes uses or types within the site or within the adjacent (1/4 } \\
\text { mile) neighbourhood (15) }\end{array}$ & & & & 4.0 \\
\hline Average: & \multicolumn{3}{|c}{4.0} \\
\hline Subtotal: & 8.0 \\
\hline
\end{tabular}

Table 44. Density of Use Scores

\begin{tabular}{|c|c|c|c|}
\hline \multicolumn{4}{|l|}{ Category 4: Diversity of housing } \\
\hline Indicators & & Scores & \\
\hline $\begin{array}{l}\text { Provide different housing types and/or increase the diversity of housing } \\
\text { options in the immediate ( } 1 / 4 \text { mile) neighbourhood (16) }\end{array}$ & 0.0 & & \\
\hline $\begin{array}{l}\text { Provide a variety of housing prices accessible to different income levels } \\
\text { and/or increase the diversity of housing prices in the immediate (1/2 mile) } \\
\text { neighbourhood and/or provide workforce housing (17) }\end{array}$ & 0.0 & & \\
\hline $\begin{array}{l}\text { Physically mix housing types and/or price levels within the project or } \\
\text { within the adjacent (1/4 mile) neighbourhood (18) }\end{array}$ & 0.0 & & \\
\hline $\begin{array}{l}\text { At least } 10 \% \text { of the residential units are provided by the project affordable } \\
\text { (less than } 120 \% \text { of AMI x } 30 \% \text { ), or at a price level or type that meets an } \\
\text { explicitly stated housing goal of the local government (19) }\end{array}$ & 0.0 & & \\
\hline Average: & \multicolumn{3}{|c|}{0.0} \\
\hline Subtotal: & \multicolumn{3}{|c|}{0.0} \\
\hline
\end{tabular}

Table 45. Diversity of Housing Scores 


\subsubsection{Diversity of Housing}

Smart Scorecard requires mixed housing types built in a specific area, such as single family detached, small lot, single family detached, single family attached, and apartments. Housing types are not reflected in the Form-Based Code of the experimental site (Table 45).

\subsubsection{Accessibility, Mobility and Connectivity}

Smart growth advocates various transportation options and reducing cardependency. Frequently visited places include housing, convenience shopping, restaurant, entertainment, office, school, and religious institution. Multitransportation at underground level, ground level and upper ground level are apparent in the Form-Based Code. The code fulfils the standards at a higher than "Very Good" level according to the average score (Table 46).

\begin{tabular}{|c|c|c|}
\hline \multicolumn{3}{|l|}{ Category 5: Accessibility, mobility and connectivity } \\
\hline Indicators & Scores & \\
\hline Frequently visited uses are within $1 / 2$ mile of the proposed project (20) & & 4.0 \\
\hline $\begin{array}{c}\text { Majority of the residents or employees safely and reasonably reach existing } \\
\text { or planned public transit service without a car (21) }\end{array}$ & & 4.0 \\
\hline $\begin{array}{l}\text { Interconnect the surrounding street system and provide an interconnected } \\
\text { internal street network (22) }\end{array}$ & 2.0 & \\
\hline The street plan avoids cul-de-sacs and promote connectivity (23) & & 4.0 \\
\hline Provide easy pedestrian access to parks and public open spaces (24) & & 4.0 \\
\hline Average: & 3.6 & \\
\hline Subtotal: & 18.0 & \\
\hline
\end{tabular}

Table 46. Accessibility, Mobility and Connectivity Scores

\subsubsection{Pedestrian Safety, Streetscapes and Parking}

This weight category evaluates walkable neighbourhoods and the comfort of streetscapes in the respects of safe design speeds, street width, parking, and trees. Most of the criteria is met in the Form-Based Code. The code achieves a higher score than "Good", with an average score of 2.3 (Table 47). 


\begin{tabular}{|c|c|c|c|c|}
\hline \multicolumn{5}{|l|}{ Category 6: Pedestrian safety, streetscapes and parking } \\
\hline Indicators & \multicolumn{4}{|c|}{ Scores } \\
\hline $\begin{array}{l}\text { Promote safe environments for pedestrians by using appropriate road design } \\
\text { speeds and appropriate street widths (25) }\end{array}$ & & 2.0 & & \\
\hline Local streets in single-family residential areas designed for safety (26) & 0.0 & & & \\
\hline Pedestrian friendly (27) & & 2.0 & & \\
\hline Encourage walking through the provision of trees and tree cover (28) & & 2.0 & & \\
\hline Provide pedestrian-friendly streetscapes (29) & & & 3.0 & \\
\hline Establish a consistent street edge (30) & & & 3.0 & \\
\hline The proposed buildings present visually interesting street frontage (31) & & & & 4.0 \\
\hline Provides on-street parking (32) & & 2.0 & & \\
\hline $\begin{array}{l}\text { The off-street parking within the project designed and located to maintain } \\
\text { safe, pedestrian-friendly environments (33) }\end{array}$ & & & 3.0 & \\
\hline Average: & & 2.3 & & \\
\hline Subtotal: & & 21.0 & & \\
\hline
\end{tabular}

Table 47. Pedestrian Safety, Streetscapes and Parking Scores

\begin{tabular}{|c|c|c|c|c|}
\hline \multicolumn{5}{|l|}{ Category 7: Environmental protection } \\
\hline Indicators & \multicolumn{4}{|c|}{ Scores } \\
\hline $\begin{array}{l}\text { Use design techniques (clustering / vertical development) to avoid sensitive } \\
\text { environmental features, minimize development area and/or maximize areas } \\
\text { of contiguous open space on site (34) }\end{array}$ & & & & 4.0 \\
\hline $\begin{array}{l}\text { Relieve development pressure on natural resources on or off site through the } \\
\text { use of transfer of development rights, long-term protection strategies or } \\
\text { other means (35) }\end{array}$ & & & & 4.0 \\
\hline $\begin{array}{l}\text { Respect the site's original topography, highlight natural features in the } \\
\text { existing landscape and maintain or rehabilitate existing structures for } \\
\text { continuing use (36) }\end{array}$ & & & & 4.0 \\
\hline Design and location likely contribute to improving regional air quality (37) & 0.0 & & & \\
\hline Use green building design techniques (38) & & 1.0 & & \\
\hline Treat wetlands, streams, shorelines and related buffer areas well (39) & & 1.0 & & \\
\hline $\begin{array}{l}\text { Treat slopes steeper than } 15 \% \text {, or floodplains, or habitat for threatened or } \\
\text { endangered species well }(40)\end{array}$ & & & 3.0 & \\
\hline $\begin{array}{l}\text { Open space plan align with or complement the community's plan to preserve } \\
\text { open spaces and environmentally sensitive areas (41) }\end{array}$ & & & & 4.0 \\
\hline Average: & & & & \\
\hline Subtotal: & & & & \\
\hline
\end{tabular}

Table 48. Environmental Protection Scores 


\subsubsection{Environmental Protection}

The weight of Environmental Protection is focuses primarily on a project's impact on the environment and resources. The Form-Based Code of the experimental site contributes to vertical development by including volumetric space in urban regulation. It follows the existing regulations about sustainability and long-term environmental protection. The code achieves a higher score than "Good" according to the average score value (Table 48).

\subsubsection{Community Needs and Local Development}

This weight category evaluates if a project will support the local economy and make the community more competitive (SGPS, 2017). The four criteria focus on social development, however, offering employment opportunities or jobhousing balances are not included in the Form-Based Code at the conceptual stage. None of these criteria are reflected in the Code (Table 49).

\begin{tabular}{c|c|c|c|c|c}
\hline \multicolumn{3}{c}{ Category 8: Community needs and local development } \\
\hline Indicators & \multicolumn{3}{c}{ Scores } \\
\hline Meet identified community and area needs and plans (42) & 0.0 & & & & \\
\hline Positively impact employment opportunities within the community (43) & 0.0 & & & & \\
\hline Promotes jobs/housing balance in the region (44) & 0.0 & & & & \\
\hline Outside of tax receipts, the project contribute new public resources to the & \multirow{2}{*}{ community from the onset (45) } & & & & \\
\hline Average: & 0.0 & & & \\
\hline Subtotal: & \multicolumn{3}{|c|}{0.0} \\
\hline
\end{tabular}

Table 49. Community Needs and Local Development Scores

\subsubsection{Findings}

The scores the Form-Based Code achieves in each weight category vary. As in Figure 103, the category of Diversity of Use achieves the highest rate (4). It indicates that the Form-Based Code performs at an "Excellent" level in this section, based on its contributions to creating multiple destinations within 
walking distance. The categories of Density and Compactness and Accessibility, Mobility and Connectivity are scored as "Very Good". The Form-Based Code reflects the compact development and efficient connectivity well. The categories of Pedestrian Safety, Streetscapes and Parking and Environmental Protection stay at the "Good" level. Although the Form-Based Code contributes to creating pedestrian-friendly urban space, the high-density situation means the code cannot fully meet the requirements of Smart Scorecard. The criteria are partly reflected in the code of TST. The category of Location and Service Provision stays at the "Poor" stage. Part of the criteria, such as being located in the existing urban area, are fully reflected in the code, while others, such as the extension of the water service, are not met by the Form-Based Code.

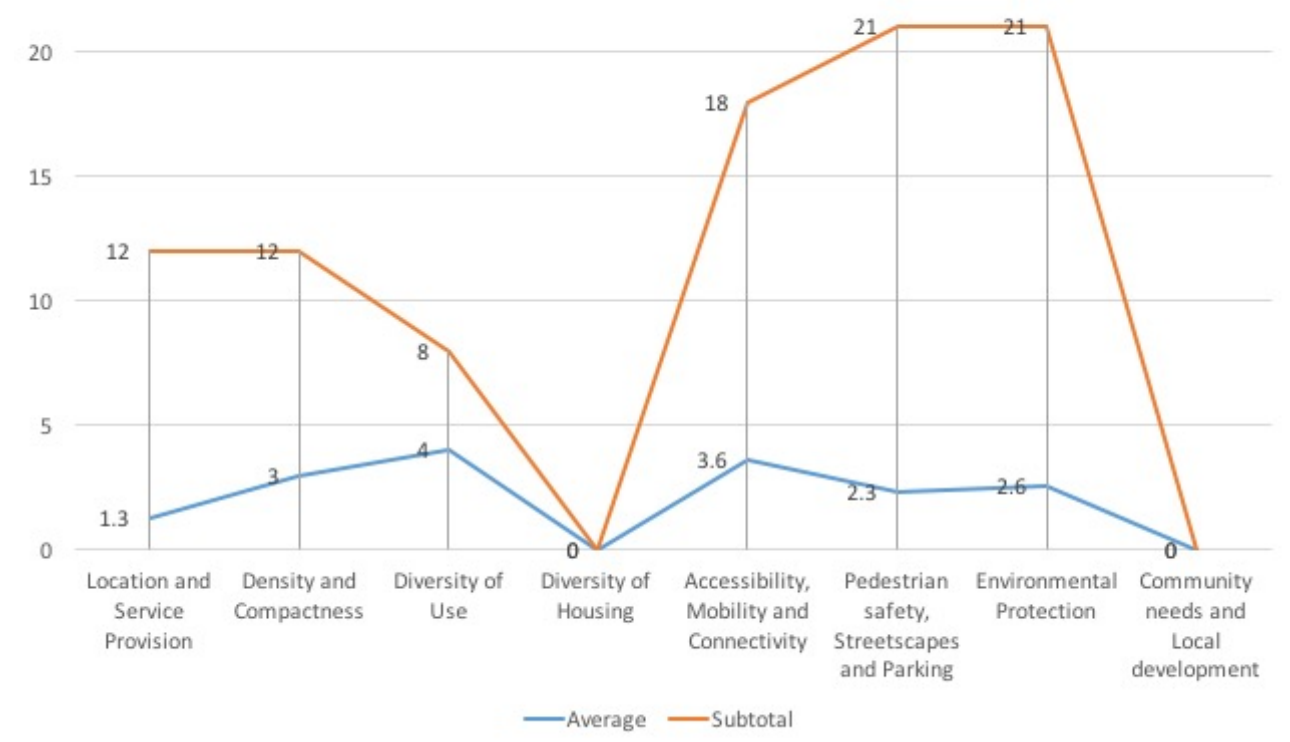

Figure 103. Score chart of the Smart Scorecard

There are 45 criteria in Smart Scorecard. The Form-Based Code of Tsim Sha Tsui can potentially achieve 16 "Excellence" levels, which accounts for $36 \%$ of the whole criteria system. This does not necessarily mean that the Form-Based Code of Tsim Sha Tsui is of very high quality, for there are considerable 
principles (35\%) not achieved by the Form-Based Code. The scoring pillarization is heavy, and the levels of "Very Good", "Good", and "Poor" account for $11 \%, 11 \%$, and $7 \%$ respectively. Figure 104 indicates the rates of each weight in different weight categories. The average trend line is around the row of Good (scoring as 2). The average score of Form-Based Code is calculated as 2.1. It means in the standards of Smart Scorecard, the Form-Based Code stays mostly at the "Good" level, better than "Poor" but weaker than "Very Good" (Table 50).

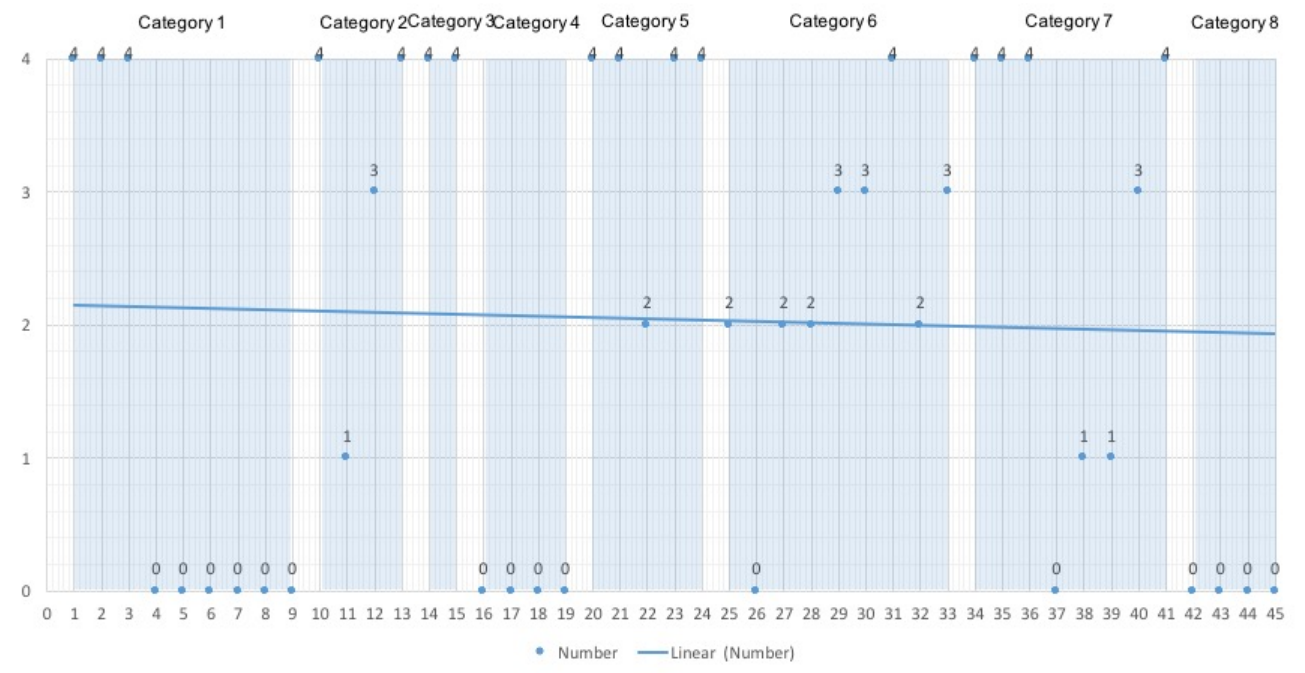

Figure 104. Rates of each weight in different categories

\begin{tabular}{c|c|c|c|c}
\hline Excellent & Very Good & Good & Poor & None \\
\hline & & $\sqrt{ }$ & & \\
\hline
\end{tabular}

Table 50. Evaluation result of the Smart Scorecard 


\subsection{Feasibility}

This section evaluates the feasibility of the Form-Based Code enhanced by parametric capability in context. The evaluation indicates whether Form-Based Code can be a positive influence on the experimental site. The current urban regulation mechanism is analysed to incorporate Form-Based Code into the established framework. This section concludes with an approach to embedding Form-Based Code into Hong Kong's urban regulation mechanism.

\subsubsection{Current urban regulation mechanism}

Before evaluating the feasibility of a Form-Based Code, this section provides an understanding of current urban regulation mechanisms in context, including the established urban regulation documents, management departments and zoning plan of Tsim Sha Tsui.

\subsubsection{Urban regulation documents}

Hong Kong's urban regulation aims at shaping a quality living and working environment, facilitating economic development and promoting the health, safety, convenience and general welfare of the community by guiding and controlling development and the use of land (The Facts Town Planning, Planning Department, 2016). Due to limited land resources and a super highdensity population, current urban regulation documents in Hong Kong regard land use as the primary consideration. Regulations are dominated by land use, permissible property uses and the control of development intensity through numerical parameters such as gross floor area, height limits, setbacks and parking ratios, and rarely consider urban form (Kan, 2012).

The established urban regulation documents specify territorial and district types. The Town Planning Ordinance, belonging to territorial type, is the highest tier of planning in the hierarchy. Within the framework of Town Planning Ordinance, Territorial Development Strategy provides broad planning 
principles for future development and serves as a foundation for district plans. The district type contains numerous planning files, provisions and notes. At the statutory level, the Outline Zoning Plan indicates land uses, zoning maps, road nets, and the regulations of specific areas. The Development Permission Area Plan assists the Outline Zoning Plan to work effectively for rural areas. Following the provisions of statutory plans, departmental plans like the Outline Development Plan, show more detailed regulations including site boundaries, footbridges and public facilities. Generally, Hong Kong planning operates across four grades, namely ordinance; regulations, rules and by-laws; statutory order and notice; and code of practice, notes and guidelines (Kan, 2012, Figure 105). When evaluating a new zoning or urban regulation project, HKPSG provide specific criteria in terms of residential densities, community facilities, open space, environment, and conservation.

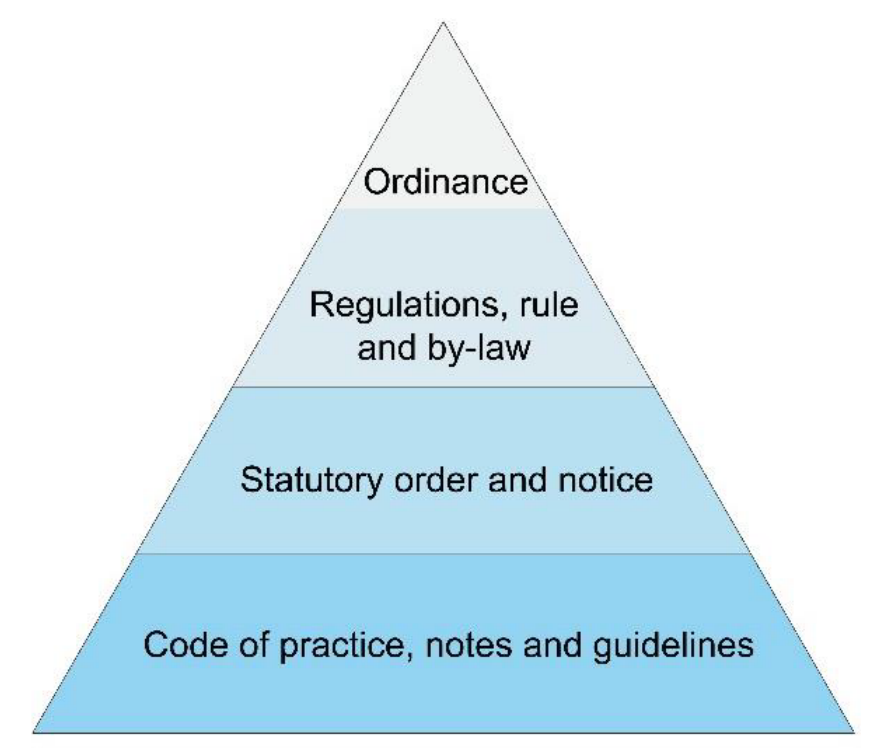

Figure 105. Hierarchy of urban planning in Hong Kong, Kan, 2012

The current urban regulation system of Hong Kong provides limited documents or guidance specifically for urban form. Form-related regulations are merged into different documents for the government, planners, architects, and developers. According to Lai (2010), Hong Kong's urban planning emphasises 
ten main points, including density control, scale and massing of new development, view corridors and sight lines, waterfront, urban green space, place-making, pedestrian environment, heritage preservation, environment performance, and traffic (Lai, 2010, Table 51). The form control of a FormBased Code can supplement urban planning concerns if it can be merged into the established system.

\begin{tabular}{|c|c|c|}
\hline $\begin{array}{c}\text { Urban design } \\
\text { concerns }\end{array}$ & Situation description & Targets \\
\hline Density & $\begin{array}{l}\text { Extremely dense; Predominantly } \\
\text { high-rise environment; Heavy use } \\
\text { of (in-) formal public spaces. }\end{array}$ & $\begin{array}{l}\text { Balance the conflict between } \\
\text { high densities and } \\
\text { expectations for a better } \\
\text { quality of life }\end{array}$ \\
\hline $\begin{array}{l}\text { Scale and } \\
\text { massing of new } \\
\text { development }\end{array}$ & $\begin{array}{l}\text { "Street canyon effect", buildings } \\
\text { are more than twice as tall as the } \\
\text { width of roads; "Wall effect", urban } \\
\text { heat island effect. }\end{array}$ & $\begin{array}{l}\text { Control towers distribution, } \\
\text { circulate air and vehicle } \\
\text { pollutants at street level. }\end{array}$ \\
\hline $\begin{array}{l}\text { View corridors } \\
\text { and sight lines }\end{array}$ & $\begin{array}{l}\text { High-rise buildings obstructed the } \\
\text { hills, water bodies and man-made } \\
\text { landmarks. }\end{array}$ & $\begin{array}{l}\text { Call for the incorporation of } \\
\text { view corridors into urban } \\
\text { layouts and give protection to } \\
\text { views from specific locations } \\
\text { on the waterfront. }\end{array}$ \\
\hline The waterfront & $\begin{array}{l}\text { Victoria Harbour is now } \\
\text { appreciated for its aesthetic beauty, } \\
\text { its iconic views and tourism value. }\end{array}$ & $\begin{array}{l}\text { There is a growing demand } \\
\text { for greater sensitivity in } \\
\text { developing waterfront areas. }\end{array}$ \\
\hline $\begin{array}{l}\text { Urban green } \\
\text { space }\end{array}$ & $\begin{array}{l}\text { The green space hectare (ha) } \\
\text { number per } 1,000 \text { people is less } \\
\text { than Manhattan, London and } \\
\text { Singapore. }\end{array}$ & Protect and add green space \\
\hline
\end{tabular}




\begin{tabular}{|c|c|c|}
\hline Place-making & $\begin{array}{l}\text { Western cities define places relying } \\
\text { on architecture and monuments; } \\
\text { Eastern cities define places by land } \\
\text { uses and activities that take place in } \\
\text { them. }\end{array}$ & $\begin{array}{l}\text { Keep streets characters and } \\
\text { street markets; Promote } \\
\text { social, cultural, and } \\
\text { economic value of streets. }\end{array}$ \\
\hline $\begin{array}{l}\text { Pedestrian } \\
\text { environment }\end{array}$ & $\begin{array}{l}\text { Narrow streets, high traffic } \\
\text { congestion, and extremes of hot and } \\
\text { wet weather. }\end{array}$ & $\begin{array}{l}\text { Incentives for developers to } \\
\text { set aside space for wider } \\
\text { pavements; the construction } \\
\text { of pedestrian footbridges and } \\
\text { underpasses to accommodate } \\
\text { capacity and separate } \\
\text { pedestrians from cars. }\end{array}$ \\
\hline $\begin{array}{l}\text { Heritage } \\
\text { preservation }\end{array}$ & $\begin{array}{l}\text { Relatively few historical buildings } \\
\text { left }\end{array}$ & $\begin{array}{l}\text { Solve the conflicts of rapid } \\
\text { economy development and } \\
\text { heritage reservation. }\end{array}$ \\
\hline $\begin{array}{l}\text { Environment } \\
\text { performance }\end{array}$ & $\begin{array}{l}\text { Climate change; Air pollution } \\
\text { increased; Electricity consumption }\end{array}$ & $\begin{array}{l}\text { Design cities with better air } \\
\text { quality, less pollution, and } \\
\text { more energy efficiency. }\end{array}$ \\
\hline Traffic & $\begin{array}{l}\text { Limited space; increased density in } \\
\text { the urban core }\end{array}$ & $\begin{array}{l}\text { Pedestrian and cars; } \\
\text { pedestrian-friendly and } \\
\text { accommodate vehicular } \\
\text { traffic. }\end{array}$ \\
\hline
\end{tabular}

Table 51. Emphases of the current urban planning in Hong Kong, Lai, 2010

\subsubsection{Management departments}

The Planning and Lands Branch of the Development Bureau is the direct government office for issues of planning and building in Hong Kong. Under the management of the Development Bureau, the Planning, Buildings and Lands Departments build Hong Kong's official development control mechanisms (Figure 106). The Planning Department is responsible for planning control by 
formulating urban regulation documents and principles. The Buildings Department controls building activities by formulating building ordinance, regulations and practice notes. The Lands Department conducts lease control in terms of lease conditions, modifications and land exchanges.

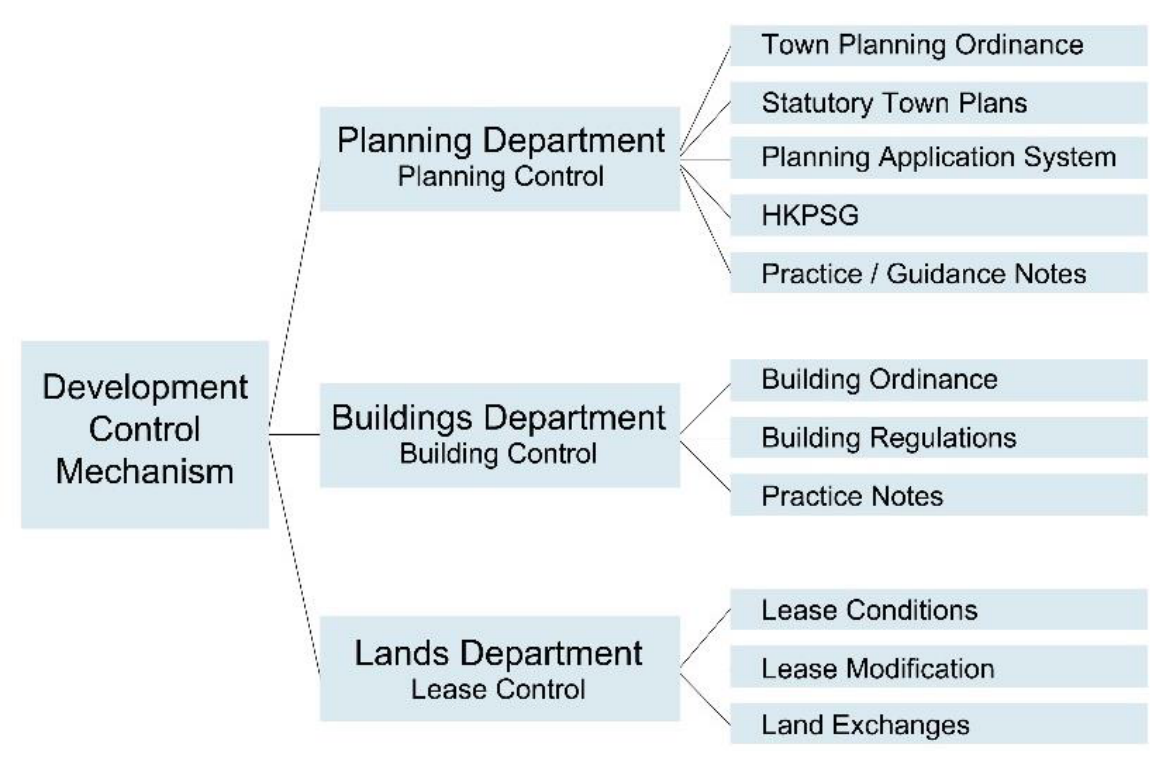

Figure 106. Hong Kong’s official development control mechanism, Kan, 2012

\subsubsection{Zoning plan of Tsim Sha Tsui}

Land use planning is the foundation of zoning and urban regulation in Hong Kong. Tsim Sha Tsui's zoning plan follows the core concept of conventional land use-based zoning. The established plan divides Tsim Sha Tsui into seven zone types, such as commercial, comprehensive development area, and residential. The existing zoning plan indicates that commercial zones and open space occupy the most land usage. The residential zone is clustered at the north of Tsim Sha Tsui and other zone types are distributed across the site. As Tsim Sha Tsui is a place with highly mixed land use, supplements to the conventional zoning approach are required to further regulate this area and balance form and function. 
Form-Based Code is an alternative to the existing zoning plan. It uses specific urban forms to lead corresponding activities so that the zoning effectively guides the practice. A Form-Based Code regulating plan is a volumetric system combining mixed land use, use of space, and building forms. The plans reflect multiple zone types in a transect matrix comprising different layers of ground, underground and upper ground. The existing zoning plan contains only the ground level, zoned by land use which simplifies the urban space. Using the Form-Based Code method, more zone types and subtypes can be generated to accommodate variable settings and planning demands. The existing zoning has only seven land uses, and the land use categories cannot be customised for different requirements and planning depth. Introducing Form-Based Code to the existing zoning plan contributes to extending the practical capability of urban regulation in context.

\subsubsection{Cooperation with established urban regulation}

Form-Based Code is a new coding approach to urban regulation. Its feasibility often depends upon the degree of change that is desired by the community and a realistic assessment of political feasibility (CMAP, 2012). Commonly, FormBased Code has three ways of integrating with existing codes. They are mandatory code, hybrid zoning code, and optional code.

Mandatory code replaces the existing code comprehensively, such as in the case of the Miami 21 Code (2015), Central Petaluma Specific Plan in California (2003), and Winter-Springs Town Centre District Code in Florida (2012). Recoding an entire city is an action conducted by the local government. Mandatory Form-Based Code works as a new regulation without any relationships with previous codes. No intersection with other codes makes mandatory code easier to implement, yet the code may be more politically vulnerable due to lack of policy support. 
Hybrid code combines Form-Based Code with existing regulatory approaches. A hybrid code contains the established zoning with one or more Form-Based Code chapters as special districts. It is cross-referenced to other sections of the pre-existing code for selected development standards, such as parking dimensions or landscaping standards (CMAP, 2012). The advantage of the hybrid code is that it is relatively practical and flexible. The hybrid code can be assessed in one small case-study area. Because of its applicability, most existing Form-Based Codes are hybrid codes.

Optional code, or parallel code, provides a means of resolution in cases where it is difficult to comply with the conventional zoning provisions, such as the Downtown Mixed-Use Master Plan of Benicia, (City of Benicia, 2007). Optional code supplements existing urban regulation, rather than replacing it. Developers and stakeholders may use the optional code to seek government approval. Once they choose this code, the entire project must abide by it. Optional code acts as a supporting document for setting regulatory standards. However, divergence occurs when some choose optional codes, yet others nearby do not. Confusion can result from the different interests of government, developers, stakeholders and municipalities. Furthermore, local management departments maintaining multiple sets of regulations wastes resources and time.

Considering the features of different manners of code cooperation, Form-Based Code is suitable to be adopted as a hybrid code by embedding the codes into the existing urban regulation of Hong Kong and acting as a special code only for Tsim Sha Tsui. There are principles that regulate the hybrid:

1. Form-Based Code works as a special code at the fourth level of Code of Practice, Guidelines and Notes in the planning hierarchy system of Hong Kong

2. Form-Based Code uses an independent urban regulation methodology 
system (transect zoning and parametric modelling) in Tsim Sha Tsui area

3. Form-Based Code fulfils the principles of the established zoning standards and guidelines of Hong Kong

4. Form-Based Code uses the territorial planning and statutory plans as its foundation and aligns with the aims of the Town Planning Ordinance

5. Form-Based Code is examined by the existing evaluation system and controlled by the Planning Department of Hong Kong

The Form-Based Code of Tsim Sha Tsui needs to fulfil the above principles in the framework of the established mechanism and be examined by local evaluation standards. The following section describes the criteria selected to examine the Form-Based Code in context.

\subsubsection{Criteria system}

The criteria system of evaluating Form-Based Code's feasibility is built with multiple urban regulation documents and standards. Form-Based Code adheres to the established examination system thus the HKPSG is the primary document guiding zoning and urban regulation by providing provisions for projects. In addition, form-related criteria from the Green Master Plan (Civil Engineering and Development Department of Hong Kong, 2012), the Urban Renewal Strategy (Development Bureau of Hong Kong, 2011), and the Sustainable Building Design Guidelines (Building Department of Hong Kong, 2016) are also selected to evaluate the Form-Based Code as a supplement to the HKPSG.

\subsubsection{Limitation}

Not all the criteria in the evaluation documents examine Form-Based Code. Only form-related criteria are selected to build the evaluation system. Because of the version amendments of different years, it is necessary to limit the versions before weighting. HKPSG used in this research is the version published on 
March 2017 by Planning Department of Hong Kong. Green Master Plan is the third Edition by the Civil Engineering and Development Department of Hong Kong. Urban Renewal Strategy is the version released in 2011 by the Development Bureau. Sustainable Building Design Guidelines is the version of 2016 by the Buildings Department.

\subsubsection{Weight and score}

This section describes the specific criteria selected from the documents specified above and estimates the scores the Form-Based Code can achieve under these criteria. There are two criteria types, including the qualitative description and quantitative description, in the weighting system. For example, the criterion "Sky-rise greening encompasses all greening on buildings or other structures beyond the ground level, including roof greening, vertical greening, sky gardens and terrace planting" is a qualitative description as it does not contain specific values or value ranges. The criterion "Local open space (at least $500 \mathrm{~m}^{2}$ in urban areas and a maximum building site coverage of $5 \%$ fulfil the standard that 10 ha per 100,000 persons (i.e. $1 \mathrm{~m}^{2}$ per person)" is a quantitative description with specific parameters.

Weighting and scoring the Form-Based Code provides an evaluation of aspects like open space and greenery, raising quality of life and development control. In each aspect, the Form-Based Code is scored in four grades, including None (0), Weak (1), Fair (2), and Good (3). The application range of grades "None" and "Good" contains qualitative and quantitative descriptions as they provide both descriptive and numerical principles. If a criterion only offers "yes" or "no" questions, then "Good" means "yes" and "None" means "no". The code can be scored as " 3 " or " 0 ". All four grades contain descriptive criteria. Qualitative description happens in each grade (Table 52). 


\begin{tabular}{c|c|c|c}
\hline Grades & Description & Application Range & Score \\
\hline None & $\begin{array}{c}\text { Although the standards are related to urban form, they are not } \\
\text { reflected in the code. }\end{array}$ & $\begin{array}{c}\text { Qualitative description } \\
\text { Quantitative description }\end{array}$ & 0 \\
\hline Weak & The standards are weakly reflected in FBC. & Qualitative description & 1 \\
\hline Fair & The standards are fairly reflected in FBC & Qualitative description & 2 \\
\hline Good & The standards are fully reflected in FBC & $\begin{array}{l}\text { Qualitative description } \\
\text { Quantitative description }\end{array}$ & 3 \\
\hline
\end{tabular}

Table 52. Grades and scores of local standards in Hong Kong

\subsubsection{Open space and greenery}

The weights of open space and greenery evaluate the quality of the public area and green space. HKPSG, Green Master Plan and Sustainable Building Design Guidelines function as the weight's resources. According to the selected formrelated criteria, the scoring situation is described in Table 53.

Most weights are potentially fulfilled by the Form-Based Code of Tsim Sha Tsui except for the one principle of the "Jade Necklace" theme for Tsim Sha Tsui area in the Green Master Plan. The established plan indicates the "jewels" are compact large green spaces such as Kowloon Park and Centenary Garden, and the "chains" are greenery along streets. Large-scale green space without buildings or street forms are not in the Form-Based Code's modelling range so this criterion of the Green Master Plan is weakly reflected in the Code.

The average score is 2.5 . This means that Form-Based Code has the capability to create a relatively appropriate urban space in the category of open space and greenery. 


\begin{tabular}{|c|c|c|c|c|}
\hline \multicolumn{3}{|c|}{ Indicators } & Resource & Score \\
\hline \multicolumn{3}{|c|}{$\begin{array}{l}\text { Local open space (at least } 500 \mathrm{~m} 2 \text { in urban areas and a maximum } \\
\text { building site coverage of } 5 \% \text { ) fulfil the standard that } 10 \text { ha per } \\
\qquad 100,000 \text { persons (i.e. } 1 \mathrm{~m} 2 \text { per person). }\end{array}$} & \multirow{4}{*}{$\begin{array}{l}\text { Hong Kong } \\
\text { Planning } \\
\text { Standards } \\
\text { and } \\
\text { Guidelines }\end{array}$} & 3 \\
\hline \multicolumn{3}{|c|}{$\begin{array}{l}\text { For active open space, at least } 20 \% \text { of the land for soft } \\
\text { landscaping, half of which for planting trees; for passive open } \\
\text { space, } 70 \% \text { of the land for soft landscaping, } 60 \% \text { of which for } \\
\text { planting trees. }\end{array}$} & & 3 \\
\hline \multicolumn{3}{|c|}{$\begin{array}{l}\text { Sky-rise greening encompasses all greening on buildings or other } \\
\text { structures beyond the ground level, including roof greening, } \\
\text { vertical greening, sky gardens and terrace planting. }\end{array}$} & & 2 \\
\hline \multicolumn{3}{|c|}{$\begin{array}{l}\text { Encourage provision of open space at ground, podium and roof } \\
\text { levels }\end{array}$} & & 3 \\
\hline \multicolumn{3}{|c|}{$\begin{array}{l}\text { Follow the "Jade Necklace" theme for TST, highlight the linkage } \\
\text { of existing precious green jewels, such as Kowloon Park and } \\
\text { Centenary Garden, by green links along major roads including } \\
\text { Nathan Road and Salisbury Road }\end{array}$} & $\begin{array}{c}\text { Green } \\
\text { Master Plan }\end{array}$ & 1 \\
\hline \multicolumn{3}{|c|}{$\begin{array}{l}\text { In order to improve the environmental quality of the urban space, } \\
\text { particularly at the pedestrian level and to mitigate the heat island } \\
\text { effect, sites with areas of } 1,000 \mathrm{~m} 2 \text { or more should be provided } \\
\text { with greenery areas in accordance with: }\end{array}$} & \multirow{3}{*}{$\begin{array}{l}\text { Sustainable } \\
\text { Building } \\
\text { Design } \\
\text { Guidelines }\end{array}$} & \\
\hline Site Area & \multicolumn{2}{|c|}{ Minimum Site Coverage of Greenery } & & \\
\hline $\begin{array}{l}1,000 \mathrm{~m}^{2}-20,000 \mathrm{~m}^{2} \\
>=20,000 \mathrm{~m}^{2}\end{array}$ & $\begin{array}{l}10 \% \\
15 \% \\
\end{array}$ & \begin{tabular}{|l|}
$20 \%$ \\
$30 \%$ \\
\end{tabular} & & \\
\hline \multicolumn{3}{|c|}{ Average: } & \multicolumn{2}{|l|}{2.5} \\
\hline \multicolumn{3}{|c|}{ Subtotal: } & \multicolumn{2}{|l|}{15.0} \\
\hline
\end{tabular}

Table 53. Open space and greenery scores

\subsubsection{Living environment quality}

The weights of living environment quality measure if Form-Based Code can result in comfort for individuals. The HKPSG provide the weights that relate to living environment quality, such as the railway transportation's noise, 
daylighting, connectivity, and residential density. Table 54 presents the scoring results. The average score is 2.0. This means the weights of living environment quality can be fairly reflected in Form-Based Code.

\begin{tabular}{|c|c|c|}
\hline Indicators & Resource & Score \\
\hline $\begin{array}{l}\text { The residential use avoid areas within } 150 \mathrm{~m} \text { of uncovered MTR } \\
\text { lines, } 85 \mathrm{~m} \text { of KCR lines and } 25 \mathrm{~m} \text { of LRT lines to minimize noise. }\end{array}$ & \multirow{4}{*}{$\begin{array}{l}\text { Hong Kong } \\
\text { Planning } \\
\text { Standards } \\
\text { and } \\
\text { Guidelines }\end{array}$} & 3 \\
\hline $\begin{array}{l}\text { Respect low-rise neighbouring development by lowering building } \\
\text { height. }\end{array}$ & & 1 \\
\hline Provide direct linkages between activity nodes. & & 1 \\
\hline $\begin{array}{l}\text { Maximum domestic plot ratio of R1 residential area is } 7.5 \\
\text { (according to statutory town plans and site class is not relevant); } \\
\text { R2 is } 6 \text { and R3 is } 3.6 \text {. }\end{array}$ & & 3 \\
\hline Average: & 2.0 & \\
\hline Subtotal: & 8.0 & \\
\hline
\end{tabular}

Table 54. Living environment quality scores

\subsubsection{Development control}

Development control provides criteria for the scale, intensity and site requirements of developments as well as the supporting facilities required (Planning Department of Hong Kong, 2016). The criteria of this section are from the HKPSG, the Urban Renewal Strategy and the Sustainable Building Design Guidelines. Form-Based Code has the capability to fulfil most criteria in terms of protecting conservation areas and building setbacks. Because the criteria for creating new conservation areas and government planning are not reflected in the Form-Based Code these two criteria are scored as 0 . Table 55 indicates the criteria system and scores. The average score is 2.0 . This indicates that the Form-Based Code can fairly reflect the weights with respect to development control. 


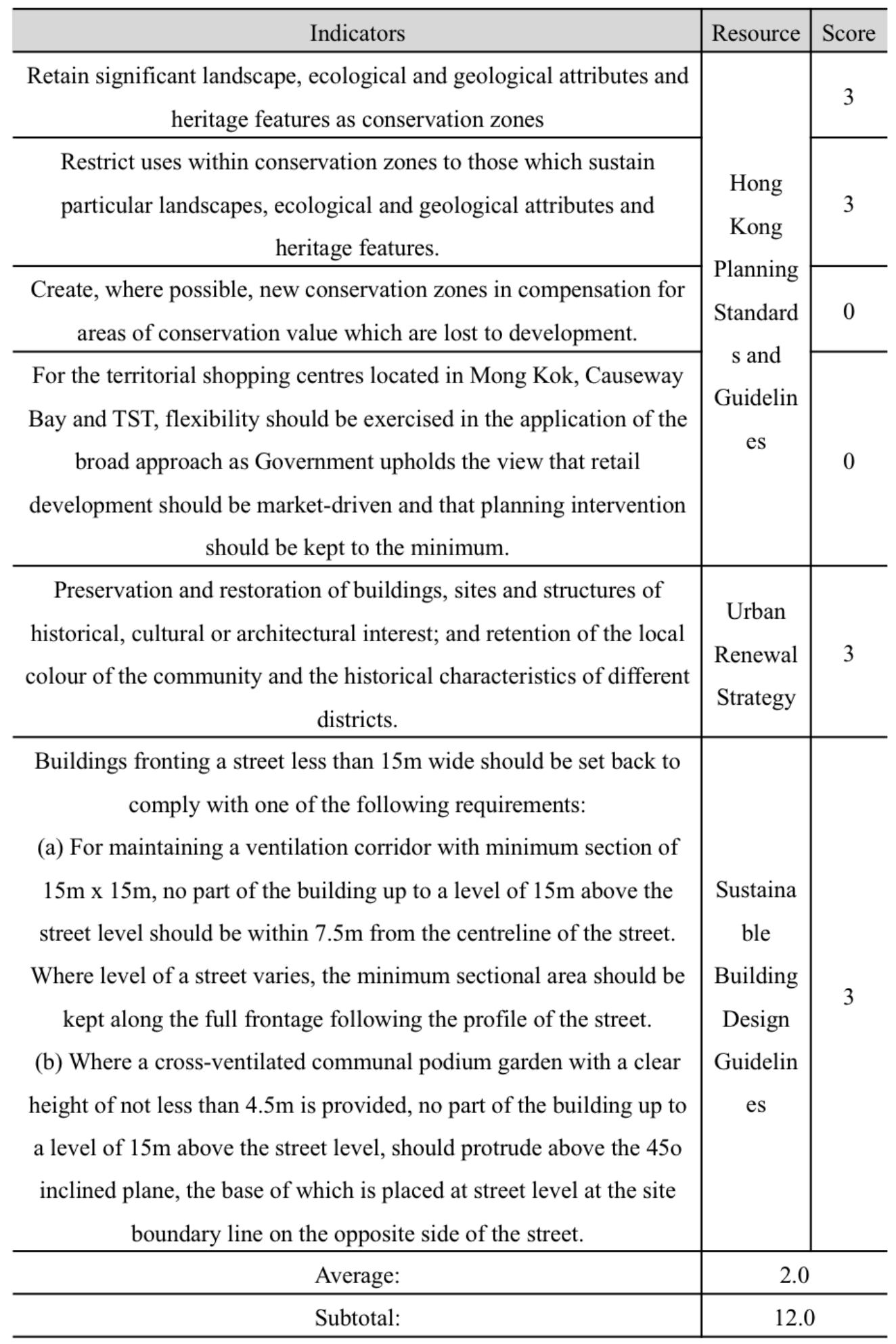

Table 55. Development control scores 


\subsubsection{Findings}

In this weighting system of multiple standards, guidelines and principles, the average score of the Form-Based Code of Tsim Sha Tsui is 2.2. The Form-Based Code is thus concordant with the established planning and urban regulation criteria (Table 56). With the transect-based zoning approach, Form-Based Code has the capability to meet most of the requirements for open space and greenery, living environment quality and development control. Form-Based Code pursues walkable neighbourhoods and comfortable public space in an effectively organised urban morphology. It maintains the urban fabric and serves the revitalisation of traditional blocks. This concept aligns with the established urban regulation of Hong Kong.

\begin{tabular}{c|c|c|c}
\hline Good & Fair & Weak & None \\
\hline & $\sqrt{ }$ & & \\
\hline
\end{tabular}

Table 56. Evaluation of the feasibility in context

The Form-Based Code of Tsim Sha Tsui works as a special code within the existing urban regulation framework of Hong Kong. This manner of application has been tested in Form-Based Code projects from the first adoption by Seaside Florida in the 1980s. This research extends the application to the high-density metropolis in Asia. It is a challenge to embed Form-Based Code into complex urban morphologies with high-density features. Form-Based Code can be incorporated or added to a city's development regulations using a variety of approaches that are not mutually exclusive (Slone, 2008). Conditions of merging Form-Based Code in Hong Kong include:

1. Local government support

2. Clear visions from residents, property owners and developers

3. A technical team of generating a Form-Based Code

4. Predictable benefits for existing urban regulations 
Kim adds that "Form-Based Codes face legal constraints that were not experienced before especially in the application of form-based land development regulations to the built condition. Also, the challenge of an appropriate balance between the prescription for a desired physical result and the amount of discretion necessary were not anticipated when Form-Based Codes were drafted" (Kim, 2010). Implementing Form-Based Code in the existing regulation mechanism needs further research in terms of technology, methodology and management. 


\subsection{Chapter summary}

This chapter utilises a multiple criteria system to evaluate the Form-Based Code of Tsim Sha Tsui in terms of sustainability, code quality and feasibility in context. The zoning and parametric modelling of the Form-Based Code is limited at the conceptual stage in this research. The criteria system provides a guide for further coding within a Form-Based Code framework.

From the perspective of sustainability, the Form-Based Code of Tsim Sha Tsui weakly accords with LEED-ND. Although performing relatively well in the aspect of NPD, Form-Based Code has limited capability to fulfil all requirements of LEED-ND standards. LEED-ND has been applied to examine Form-Based Code projects while rare standards are offered specifically for form-related regulations. LEED-ND emphasises green buildings and energy performance on a community and neighbourhood scale. Evaluated by the sustainability criteria of LEED-ND, the Form-Based Code achieves a "Weak" score according to the weighting and scoring results.

From the perspective of code quality, the Form-Based Code reaches the "good" level according to the scoring results of Smart Scorecard. Smart Scorecard uses a series of principles to test whether a Form-Based Code is well written by. Some principles are highly fulfilled such as density and compactness and diversity of use. Some are outside of Form-Based Code's regulation range, such as diversity of housing and community needs and local development. The FormBased Code of Tsim Sha Tsui has the potential to be a high-quality written code in further generations by using Smart Scorecard principles as a guide.

From the perspective of feasibility in context, the Form-Based Code of Tsim Sha Tsui has "fair" capability to meet the urban regulation standards provided by local planning and management departments. The established urban regulation standards are taken from multiple urban planning documents, 
including the HKPSG, Green Master Plan, Urban Renewal Strategy, and Sustainable Building Design Guidelines. According to the scoring result, the Form-Based Code has the potential to be embedded into the existing urban regulation mechanism of Hong Kong as a special code document for Tsim Sha Tsui area. Form-Based Code has the capability to align with local ordinances and standards. 


\section{Chapter 7. Discussion}

This research demonstrates an alternative approach to urban regulation for the volumetric morphology of high-density cities. It utilises parametric tools to integrate zoning, modelling and coding in one computational system. FormBased Code, a product of New Urbanism ideology, is the approach to urban regulation of this research. The computational system offers an interactive platform for generating and modifying Form-Based Code with visualised scripting procedures and real-time performance feedback.

The aim of this chapter is to further discuss lessons learnt from the research. The discussion provides arguments for implementing the parametric system in urban regulation and practising parametric urban regulation for the future urbanisation of Asian cities. Form complexity, parametric systems, Asian FormBased Code and for that matter any high-density cities around the world, and research contributions are discussed in the following sections. 


\subsection{Form complexity}

Developing urban-peripheral systems in a set area encompasses a series of dynamics influenced by form and land use. These two elements interrelate and interact with each other to shape an artificial environment. Unlike conventional zoning approaches which focus solely on land use, this research argues that urban regulation must embody both form and land use and harmonise these two elements. Land use in urban regulation has been heavily researched along with the wide uptake of conventional zoning. This research looks to improve the functionality, and extend the application, of regulatory practices by using form as the foundation of new approaches to zoning and modelling in urban regulation.

Form complexity reflects the sophistication of human-society systems and the evolution of dynamic morphologies. Form-Based Code uses a novel transect matrix model to describe form complexity. Rooted in Concentric Development Rings, the Valley Section, the Central Place Theory, and the Ecosystem Transection Mode, Form-Based Code abstracts form complexity as a series of sections transforming from natural to urban core zones. It uses microelements, such as floor-area-ratio or building setbacks, and relationships between those microelements to define macro morphology order and law. The form-related subdivision of various zones in the transect matrix model establishes the spatial hierarchy a neighbourhood, community or city.

The transect matrix model employs a pattern forming language, but not the pattern forming language. Very different transects could be conceived for cultures and geographic regions where human settlement patterns, and local ideas of what constitutes natural, rural, suburban and urban characters, have evolved differently (Bohl and Plater-Zyberk, 2006). This research demonstrates that the original zone type subdivisions, including $\mathrm{T} 1, \mathrm{~T} 2, \mathrm{~T} 3, \mathrm{~T} 4, \mathrm{~T} 5$, and $\mathrm{T} 6$, in the standard transect matrix of Form-Based Code have limited capability for 
describing complex urban forms in high-density cities with a volumetric morphology. The standard transect matrix regards form transformation from natural to artificial as a continuous, linear process. High-density cities, however, with their limited land resources and compact populations may contain only a natural zone and an urban core zone. There is no land and space for the general transition described in the standard transect matrix. As a result, the standard transect matrix is inadequate for describing form complexity in high-density cities. Form complexity after urban core zone T6 is highlighted in this research by extending the standard transect matrix to accommodate the high-density situation (Figure 107).

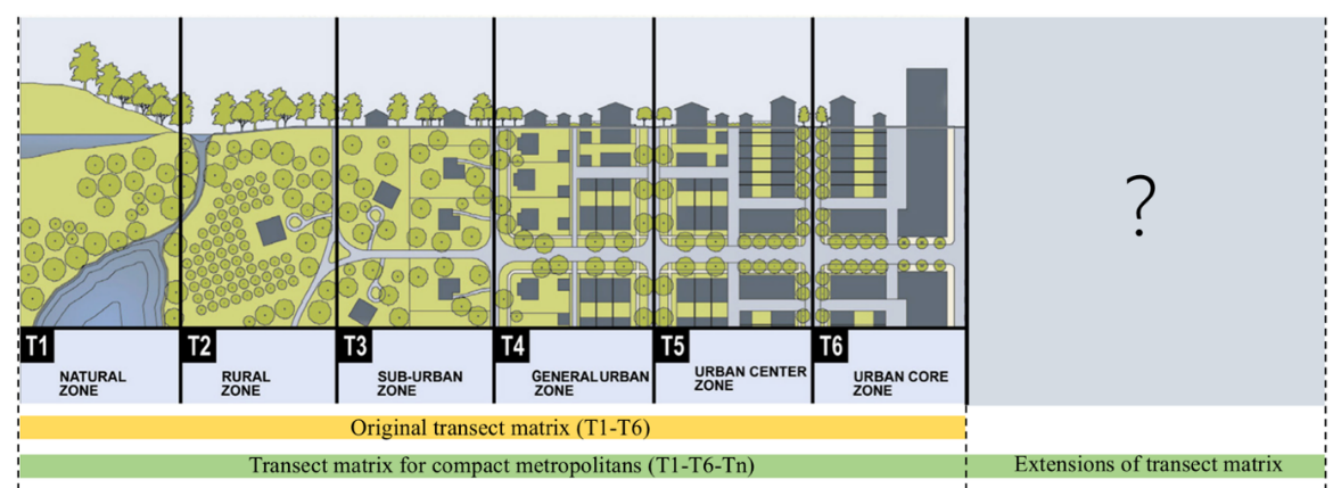

Figure 107. Original transect matrix and the extensions, re-edited by author based on the transect matrix of Form-Based Code, DPZ, 2009

According to the study in former chapters, form complexity in high-density cities is a result of mixed land use, diversified spatial function, and compact public activities. Urban regulation seeks to organise high-density growth and encourage suitable use of space. To do so, it must align with the actuality of a complex urban form by accommodating multiple stratifications. Mapping form complexity onto a transect matrix involves two components:

1. In the horizontal direction, urban core zone $\mathrm{T} 6$ is extended by inserting sub-zone types

2. In the vertical direction, underground and upper ground zones are incorporated into the transect system 
In the horizontal direction, a series of sub-zone types expands the form description of high-density cities; moving beyond using only urban core zone T6 to represent diversified forms in certain areas. Quantitatively analysing urban form formation elements, including floor-area-ratio, pavement width, road hierarchy, infrastructure, depth-to-width ratio, and maximum building height, sub-zone types of urban core zone are classified as T6-1, T6-2, T6-3, T6-4, T6-5, and T6-6 to recreate the transect matrix for the high-density environment. Using the form analysing methodology, other urban zone types, such as general urban zone or urban centre zone, of the transect matrix also can be further divided into sub-zones in future Form-Based Code projects. The transect matrix model can potentially be studied in more depth and applied to existing urban forms by filling or cutting zone types or subtypes according to unique urban development situations. Form complexity results in transect matrix model complexity.

In the vertical direction, this research creatively regards underground and upper ground places as zones. Although these places are not constructed on land, they provide space for human activity, such as transportation, entertainment and commerce. Urban regulation in this research uses form, not land use, as the primary consideration. Underground and upper ground places have their specific forms. Thus, they should be included in the urban regulation system as morphology components. If Form-Based Code can benefit to ground zoning, it can similarly benefit underground and upper ground levels to regulate a whole volumetric urban system. Incorporating volumetric layers into urban regulation, recreates the transect matrix model of Form-Based Code, facilitating ground, underground and upper ground zone types. These volumetric zone types expand the potential implementation of the transect matrix model. They supplement the original system of natural to artificial transformation by describing the complexity of vertical form. 


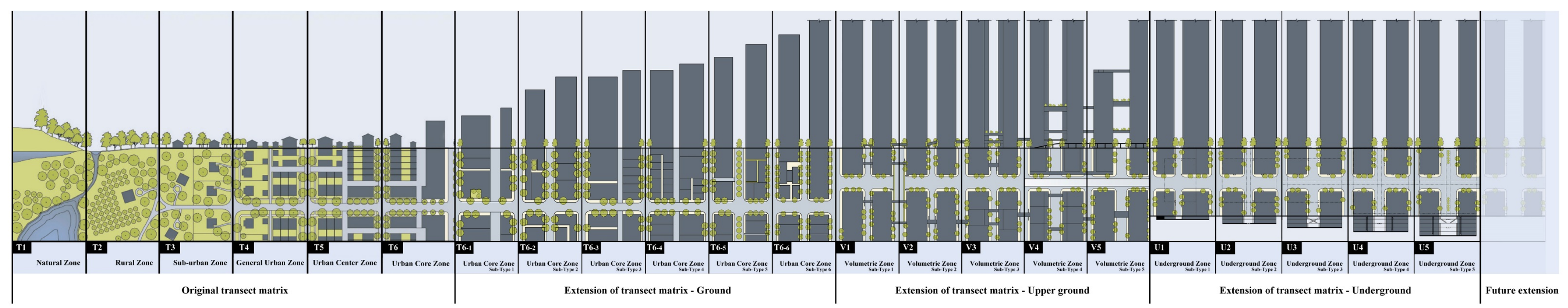

Figure 108. Transect matrix for a volumetric morphology, re-edited by author based on the transect matrix of Form-Based Code, DPZ, 2009 
Form complexity in high-density cities with a volumetric morphology is mapped on a transect matrix model recreated for Form-Based Code (Figure 108). The form-based zoning concept and approach of Form-Based Code are duplicated across multiple spatial layers. Extending zone types and subtypes to volumetric grounds makes Form-Based Code more implementable in terms of complex form description, high-density areas zoning, and urban growth guidance in metropolitan areas. 


\subsection{Parametric system for urban regulation}

The last section discussed form complexity in high-density cities embedding that form complexity into the transect matrix. To effectively describe and examine urban regulation with complex form-based zone types, this research establishes a parametric modelling system to facilitate regulatory intention at a project's conceptual stage. The system integrates mapping zone types, modelling building regulations and modifying scenarios on one platform provided by parametric modelling software. This section further discusses the future implementation of the parametric modelling system in Form-Based Code.

\subsubsection{Workflow}

The coding process of the parametric modelling system created for this research is based on the original phases of Form-Based Code, but not limited to them. Standard Form-Based Code divides the coding process into three phases: Documenting, visioning, and assembling. In the documenting phase, a FormBased Code team leads the work to understand existing urban planning files and the nature of the target site. According to the results of the documenting phase, the Form-Based Code team proposes regulation intentions and strategies to the target community in a visioning phase. With community participation, the visioning phase manifests as an interactive bridge between specialists and the public. After a few rounds of communication, the Form-Based Code team assembles the final code book to implement the Form-Based Code (Figure 109).

The parametric modelling system created in this research supports the generation and description of Form-Based Code in multiple phases. In the documenting phase, the Form-Based Code team proposes variables that influence the formation of urban form. The variable data are collected through established planning standards and field study. By data collection, calculation and normalisation, form-based zone types are addressed to compose a sitespecific transect matrix. In the visioning phase, the Form-Based Code team can 
use the transect matrix to illustrate the intended outcomes of urban regulation to the target community by mapping these zone types on the target site. The workflow above is described as the pre-modelling phase in parametric FormBased Code, which encompasses the documenting and visioning phases of the original Form-Based Code generation process.

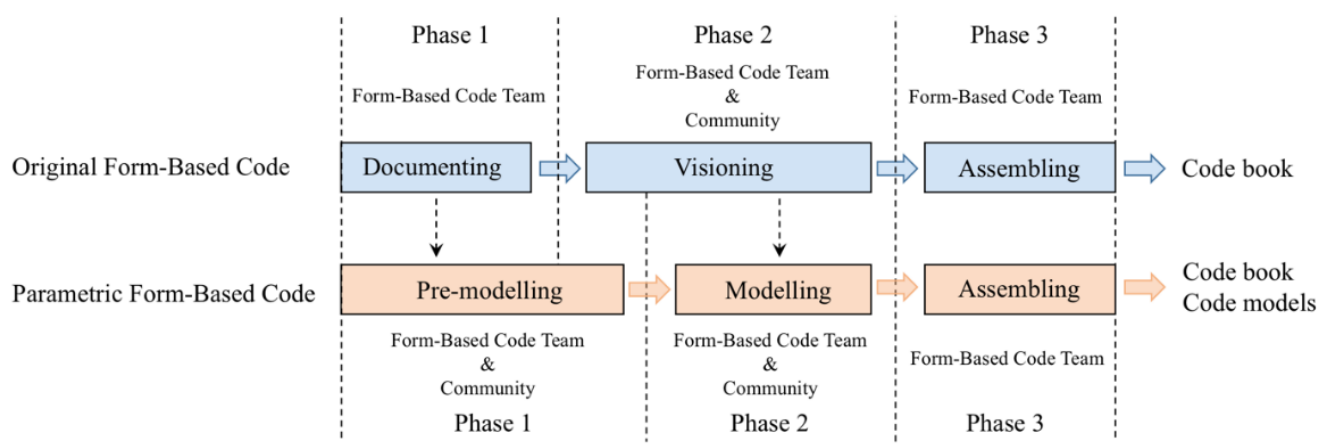

Figure 109. Workflow of the original and parametric Form-Based Code

The modelling phase in parametric Form-Based Code operates to perform urban regulation in a directly visualised manner. Regulation models help members of the target community easily understand what will happen where, and the general scenario of their neighbourhoods in the future. As a result, regulation design is more accessible to the public. The Form-Based Code team can respond to public feedback by describing their intentions through easily read models. Compared with conventional manual drawings, models are much more conveniently modified by changing parameters in scripts. The workflow of creating a parametric modelling system includes locating building coordinates, mapping zones on the target site, modelling buildings through scripts, and attempting multiple scenarios. Parametric modelling software, such as Rhinoceros 3D and Grasshopper 3D, generates scripts in visualised coding processes and provides real-time performance feedback.

Parametric Form-Based Code assembles both a code book and code models. 
Code books describe urban regulations with text-based standards, illustrations and tables. They contain a modality similar to that of the code books of conventional Form-Based Code. Code models describe urban regulations in a digital manner. The models and their scripts are regenerative. Scripts with parameters that control models can be modified to perform new scenarios when urban regulations require amendments. They can also be used as a prototype for Form-Based Code projects in high-density cities with a volumetric morphology. Code books and code models cooperate for smart and logical urban regulation. Due to the novel methodology and workflow, urban regulation designers require training before composing a Form-Based Code Team. The following section discusses the expertise necessary for creating a parametric Form-Based Code.

\subsubsection{Expertise}

Creating a parametric Form-Based Code requires a collaboration of diverse specialists and experts from different disciplines and departments. As a novel approach to urban regulation for most cities, building a Form-Based Code team of trained specialists is necessary for implementing parametric Form-Based Code in real-world projects in the future. The Form-Based Code team is responsible for leading the code procedures and completing the regulation documents for downstream architectural design and construction. In general, a Form-Based Code team consists of three groups of people:

1. Municipal staff team

2. Consultant assistance team

3. Modelling team

The municipal staff team assesses existing urban planning and regulations, organises community participation and drafts Form-Based Code. Relevant departments include urban planning, social development, legal support and public works. The consultant assistance team is comprised of planners, urban 
designers and architects. They provide the theoretical and technical support for generating Form-Based Code. Both the municipal staff and consultant assistance teams require training in the theory, methodology, expression, implementation, and evaluation of Form-Based Code. Original variants of Form-Based Code do not require the work of a modelling team. Parametric Form-Based Code, however, assembles both documents and models. Modelling teams thus work to draft scripts in software, generate parametric models and facilitate regulation intentions. They can be composed of urban designers, planners, architects, as well as digital designers, programmers or information technologists. Conventional Form-Based Code is manual-based and relies on hand drawing or illustrating. It is familiar for most urban designers and architects who are trained with an architecture background. Adding modelling specialists to a Form-Based Code team facilitates the computational methodology used in the regulation design process. The modelling specialists require training about urban planning and regulation, urban design, building laws and common building parameters. They can then use parametric software to describe regulations during the modelling phase.

The Form-Based Code team is the core element to of the entire regulation process. Due to its complexity, the regulation process contains multiple interrelated phases. Team members need to cooperate to achieve a well-written Form-Based Code. For example, the Form-Based Code team decides on the variables of urban form formation. This selection of variables affects zone type subdivisions in the pre-modelling phase and parameter settings in the modelling phase. The outcome is highly dependent on the Form-Based Code team's ability to successfully summarise the sites' spatial characteristics, morphology and potential growth trends.

Introducing parametric instruments to Form-Based Code helps the Form-Based Code team to facilitate the intentions and strategies of regulation through 
visualised models. The following section discusses the parametric modelling system's implementation prospects in urban regulation.

\subsubsection{Implementation prospects}

This research creates a parametric modelling system to facilitate Form-Based Code. The parametric modelling system works in multiple Form-Based Code generation phases conducted by various specialists and experts. The system's implementation prospects are discussed in terms of:

1. Predictable regulation results

2. Regenerative prototype in further urban regulation

3. Scenario modification

4. Usage in future design and research

Implementing the parametric modelling system in urban regulation provides predictable results. Conventional urban regulation uses land use to define zones. Two-dimensional land use-based zoning controls three-dimensional urban growth. Text-based descriptions and manual drawings make regulation procedures complicated due to multiple zone types and functions in cities with a complex morphology. In the parametric modelling system of this research, conversely, the methodology is to use parameters and the relationships between parameters to control three-dimensional urban growth. The parametric modelling system has the capability to simulate regulation outcomes through modelling software. Simulations can be used to assess whether the regulation results meet urban development requirements. Implementing the parametric modelling system created in this research facilities predictable regulation results.

The parametric modelling system relies on prototypes to model urban regulations. A prototype consists of a series of scripts that control building performance in the parametric software's interface. This research uses 
Rhinoceros 3D and Grasshopper 3D to model buildings. In further planning and design, the prototype can be regenerated by modifying components, cooperating with other scripts, or modifying parameter values. For example, by adding energy-related components to the prototype, a group of energy simulating models is generated based on the established massing model. Inserting virtual reality scripts into the prototype achieves virtual reality models to facilitate the regulation design experience. Creating a regenerative prototype is a complex process considering various parameters, algorithms, logic, and preferred performance feedback. It influences the methodology of urban regulation by providing parametric concepts. Executing the prototype and applying it more broadly across urban-scale projects needs further exploration in future urban studies.

Implementing the parametric modelling system enables convenient scenario modification. Urban regulation is a complex process that produces plans, codes and guidance on an urban scale. A convenient modification method contributes to saving time and simplifying manual works. By implementing a parametric modelling system, a Form-Based Code team can modify the parameter values to achieve a series of differentiated scenarios. These scenarios provide threedimensional images for regulation description and further evaluation. Generating and modifying processes becomes easier for the Form-Based Code team.

Urban regulation aims to guide real-world construction. Implementing the parametric modelling system in urban regulation offers a basis for further urban and architectural design. This research explores massing models through parametric software. For more in-depth design projects, additional details can be added to the massing models. For example, designers can use a group of plots and blocks of a specific zone type to continuously conduct urban design according to the established script and parametric model. More buildings and 
public details can be added by changing parameters, scripts or components in Grasshopper 3D. The parametric system has the potential to run through entire urban regulation and design procedures and combine these with the design of plots and buildings.

The parametric modelling system of this research is a novel concept that can facilitate urban regulation in terms of result prediction, expression, modification, and further design. It has the capability to resolve the challenges of conventional urban regulation such as complex form control and manual-based description. It also brings new challenges in terms of embedding new processes into existing regulatory systems, implementing in diversified contexts, and gaining the acceptance of communities. The following section further discusses the challenges of parametric Form-Based Code generation and implementation in Asia. 


\subsection{Asian Form-Based Code}

Form-Based Code has been implemented in various contexts from unconstrained counties to compact metropolitan areas. Much of this implementation is clustered in the USA. In the 1980s, Form-Based Code was created to respond to conventional American zoning and resolve zoning challenges. The original concept of Form-Based Code catered to the contexts and requirements of American cities at that time. Through years of development, Form-Based Code researchers and implementers have attempted to apply FormBased Code to places outside of the USA. Even so, this study of parametric Form-Based Code in high-density cities is the first attempt in Asia. Distinct from American Form-Based Code, Asian Form-Based Code responds to a series of different situations, including:

1. A context of fast urbanisation

2. A tradition of mixed land use

3. Established urban regulation systems

4. A lack of evaluation standards

This research creates Form-Based Code in Asia by using Hong Kong as an experimental site. A parametric modelling system is used to support the generation of Form-Based Code. Multiple evaluation principles and standards are employed to examine the conceptual results of the Form-Based Code. The following sections discuss the urban development contexts and challenges in Asia that Form-Based Code researchers and implementers should consider.

\subsubsection{Fast urbanisation}

Mayhew's Dictionary of Geography (2015) presents urbanisation progress as a curve model with three stages. At the first stage, the rate of urbanisation is low, and the curve gently rises to a rate threshold of $20 \%$. With improved manufacturing and services, the urbanisation rate increases quickly; at which 
point the curve rises sharply until the rate of $75 \%$. After that, the urbanperipheral system comprises a developed region and the urbanisation curve slackens. According to the curve model, many Asian regions are experiencing fast urbanisation. For example, Shenzhen city of China took only three or four decades to grow from a small village into a metropolitan area. Local urban planners, designers and architects are exploring approaches to create efficient urban regulation. The regulation needs the capability to guide and control fast urbanisation development.

A Form-Based Code offers an alternative approach from the perspective of form regulation. Tsim Sha Tsui area of Hong Kong is used as a case study to examine Asian Form-Based Code. Hong Kong experienced fast urbanisation in the last century. Fast urbanisation resulted in limited urban land resources, a sharply increased population, and an intensive urban core zone. The Form-Based Code of Tsim Sha Tsui reorganises zones to use urban space more effectively. It uses form as the zone hierarchy principle. The urban core zone is divided into detailed sub-zones. Each sub-zone of multiple grounds has specific regulation standards to avoid overcrowding or inadequate occupation. The code attempts to create an urban area that contains high-density buildings with a comfortable street atmosphere and sufficient open space.

The Form-Based Code of Tsim Sha Tsui provides an example for other areas of Hong Kong and for other cities in Asia with a compact urban morphology. The workflow of code generation and evaluation can be duplicated or regenerated in other Form-Based Code projects. It supports a rational and logical urban regulation framework by considering form complexity in fast urbanisation areas. Potential adopters can draw lessons from the Form-Based Code of Tsim Sha Tsui and customise their own Form-Based Code according to their actualities. 


\subsubsection{Mixed land use tradition}

Unlike the zoning patterns of American cities, mixed land use is more of an accepted tradition in many Asian cities. It is common for multiple land uses and spatial functions to mix together in Hong Kong, Macau, Taipei, and Shenzhen. The mixed pattern is thus more easily accepted by communities. Because of the high-density building and population, it is recognised that single land use in one area wastes urban space. Form-Based Code encourages mixed land use to control excessive counter-urbanisation. The principle behind the mixed land use of Asian cities is fully functional urban land resources. Although coming from different perspectives to resolve different issues, the two mixed land use regulation concepts are similar. Form-Based Code has the capability to positively impact Asian cities, and benefits from the existing high acceptance of mixed land use by communities and neighbourhoods.

\subsubsection{Established urban regulation systems}

Challenges are foreseeable when further implementing Form-Based Code in Asian cities. Using Hong Kong as an example, the established urban regulation is a relatively mature system controlling land use, zoning and building construction. Form-Based Code is a new concept that needs to be embedded into the existing system and cooperate with other regulatory documents. As an American zoning approach, a way must be found for Form-Based Code to accommodate different development requirements.

This research presents the Form-Based Code of Tsim Sha Tsui as a hybrid code in the established urban regulation system of Hong Kong. It draws lessons from former hybrid Form-Based Code projects in the USA. A Hybrid code combines existing urban regulation, Form-Based Code, and existing design guidelines. In Hong Kong, Tsim Sha Tsui acts as a special area for implementing Form-Based Code under the established standards and guidelines. Compared with mandatory and optional codes, the hybrid code is an appropriate test option. If the 
implementation proves successful, Form-Based Code can be extended to other areas or cities as a mandatory code like the Miami 21 Code example. Embedding Form-Based Code into established urban regulation needs further exploration in future studies, with attention paid to types of hybrid, implementation assessment, and examination in diversified contexts.

\subsubsection{Lack of evaluation principles}

Another challenge for implementing Form-Based Code in Asia is the lack of mature evaluation principles. Using Hong Kong as an example, local evaluation principles are suitable for examining existing urban regulations. Form-Based Code has not been applied in real-world projects so there is no standard to assess if the code is appropriate for resolving issues in context.

This research proposes an evaluation system for the Form-Based Code in Hong Kong. The system consists of LEED-ND, Smart Scorecard and Hong Kong's local regulation evaluation principles. American Form-Based Code has been examined through LEED-ND and Smart Scorecard criteria by previous researchers and implementers. The evaluation methodology is reused for the Form-Based Code of Tsim Sha Tsui. Additionally, local principles are also included in the evaluation system to examine Form-Based Code's implementation capability. According to the analysis in Chapter 6, the FormBased Code of Tsim Sha Tsui is scored as weak in LEED-ND, good in Smart Scorecard and fair in local principles. In general, Form-Based Code does not perform at the excellent level in the evaluation system proposed in this research. It achieved "weak" in sustainability, "good" in code quality and "fair" in feasibility. The evaluation results may be the consequence of two factors. One is that the Form-Based Code itself does not fully meet the requirements of sustainability and feasibility in Hong Kong. It should be further improved. The other is the lack of evaluation standards specifically for Form-Based Code. The evaluation system needs further study. 


\subsection{Contributions}

Form-Based Code for the volumetric morphology of high-density cities has not been studied within a parametric modelling system before this research. This is a significant contribution to the research of both Form-Based Code and urban regulation in high-density cities. For the field of Form-Based Code study, the research contributions include:

1. Extending form recognition and description

2. A technique for processing the generation and modification of FormBased Code

3. Expanding the implementation of Form-Based Code

In the field of urban regulation in high-density cities, the research contributions include:

4. An alternative approach to the urban regulation of high-density cities

5. A strategy to indigenise Form-Based Code in Asia

The research extends form recognition and description in Form-Based Code. Conventional Form-Based Code is reformed by adding sub-zone types into the urban core zone; by incorporating underground and upper ground levels in form hierarchy; and by changing the regulatory context to the volumetric morphology of high-density cities. The original zones describe a general form transformation from natural to artificial. This research linearly extends that description of form transformation from artificial to further artificial. It demonstrates a pattern of urban growth in high-density cities. The pattern expands form description according to further understanding zone structure and morphology. In addition, underground and upper ground are creatively incorporated to provide additional zone types for Form-Based Code. Within the concept of form transformation, 
zones of multiple grounds are described according to their form characteristics. A representative high-density urban core zone works as the context in which to implement the form recognition and description. A redefined transect matrix for Form-Based Code is created to contribute to the understanding, utilisation and regulation of urban forms.

The Parametric modelling system created in this research facilitates FormBased Code's generation and modification. The technical capability of the system supports urban regulation in smart manners. Preceding research mostly uses parametric instruments to support architectural design, urban design or energy simulation. Parametric urban regulation is a novel idea for morphology control on an urban scale. It transforms texts, tables and two-dimensional illustrations to three-dimensional models. At the conceptual stage, the real-time performance feedback in parametric modelling software can directly reflect regulatory intentions and possible regulation results. Urban regulation is more interactive for both code designers and communities. Public participation is more accessible through visualised models rather than expert principles and standards. The parametric modelling system uses computational techniques to integrate the generation and modification of regulation on one platform.

This research broadens the implementation of Form-Based Code. Although Form-Based Code has been applied in hundreds of projects, most of these are for American cities and counties. Asian Form-Based Code is examined in this research to make the Form-Based Code system more relevant both in academia and practice. Form-Based Code in Hong Kong draws lessons from Miami 21 Code in terms of understanding urban forms, zoning high-density communities and establishing code mechanisms. It extends more layers than Miami 21 Code due to the volumetric morphology of the city. Being applicable to high-density cities with a volumetric morphology increases the potential future implementation of Form-Based Code. 
The research also provides an alternative approach to urban regulation in highdensity cities. Hong Kong and other super compact cities can potentially adopt a Form-Based Code approach. Urban regulation in high-density cities needs to resolve spatial, social and cultural challenges created by dense built environments. Regulating urban form instead of land use provides a new concept to support spatial regeneration, mixed land use and appropriate morphology control.

The strategy for Form-Based Code indigenisation in Asia is contributed by this research through assessing possible manners of cooperation and establishing an evaluation system. The potential means of cooperation between Form-Based Code and existing urban regulations include mandatory code, hybrid code and optional code. At the test stage, Form-Based Code can work as a hybrid code within the structure of established urban planning and regulation. If the hybrid code is proved successful, the mandatory code can be used to implement FormBased Code in context. Creating an evaluation system is required to examine in-context customised Form-Based Code. This research demonstrates that parametric Form-Based Code has both the theoretical and technological capability to work in high-density cities with a volumetric morphology towards a predictable urban environment. 


\subsection{Chapter summary}

This chapter further discusses the findings and contributions of the research. A parametric modelling system is created to facilitate urban regulation. Using Form-Based Code as the regulation approach, the first parametric Form-Based Code is developed for the volumetric morphology of high-density cities. The theoretical and technical capability of the parametric Form-Based Code has been demonstrated to support further implementation. The discussion corresponds to a significance part of the introductory chapter:

1. The parametric modelling system allows performable and predictable urban regulation in complex urban morphology through integrating parameters, analysis, modelling and modifying in one platform

2. Original Form-Based Code's challenges are resolved by embedding parametric methodology into the urban regulation process

3. The innovation of parametric urban regulation is extended to the volumetric morphology of high-density cities

Generating a parametric modelling system addresses the methodology objective of this research for improving the design process of Form-Based Code. The system transfers manual drawing regulations to parameters and algorithms to control urban forms. A modelling prototype consisting of a series of scripts is regenerative, so appropriate for further Form-Based Code modelling or other Form-Based Code projects. Designers can reuse the prototype by adding or deleting component parts. The parametric Form-Based Code is much easier to manipulate than the original, especially in complex morphology control. When modifying parameters or relationships between parameters, real-time performance feedback is presented through modelling software. Urban regulation results can be predicted with three-dimensional feedback.

Form-Based Code has been applied by various adopters of this approach. 
Although a novel approach to urban regulation, original Form-Based Code still uses hand drawing and manual modelling to describe codes. Conventional methods cannot fully support Form-Based Code to facilitate regulatory intentions. Parametric instruments are introduced to the Form-Based Code generation process in this research. Parametric modelling software and a visualised coding platform work to present designers' intentions at the conceptual stage of the Form-Based Code.

High-density cities with a volumetric morphology provide a context in which to implement the parametric Form-Based Code developed in this research. It addresses the implementation objective of examining the parametric system in a complex urban core zone. To accommodate the morphological characteristics of the experimental site, the transect matrix of Form-Based Code has been extended by including multiple zone types in different layers. The resulting complex transect matrix contributes to a greater technical capability for FormBased Code implementation and its cooperation with established urban regulation systems. 


\section{Chapter 8. Conclusion}

The research results demonstrate that a parametric modelling system can improve urban regulation schemes by integrating zoning and modelling on one computational platform. Unlike conventional methods, parametric modelling systems allow urban planners, designers and architects to visualise the consequences of parameter variation within regulation results at the conceptual stage of a project. Urban regulation with parametric instruments supports efficient design and communication processes, especially for complex urban development situations.

Using Form-Based Code as the regulation approach, this research proves the feasibility of parametric Form-Based Code in Tsim Sha Tsui area of Hong Kong. For future studies, the conceptual framework can be continually re-examined in new contexts such as other areas of Hong Kong, or other high-density cities with a volumetric morphology. Furthermore, although the parametric concept has been broadly applied, parametric urban regulation is still in its infancy. Educating specialists and establishing an elaborate evaluation mechanism requires more in-depth study towards more practical parametric urban regulation. 


\subsection{Research conclusion}

This research studies two issues in the field of computer-aided urban regulation. One is the creation of a parametric modelling system to facilitate the urban regulation process. Form-Based Code has been chosen as the original urban regulation approach in which the parametric modelling system is implemented. The other is an examination of the parametric Form-Based Code in a context limited to high-density cities with a volumetric morphology. Through addressing both issues, the research indicates the approaches, logic and mechanisms of a parametric modelling system support urban regulation in intricate development situations.

The research question proposed in the introduction chapter has been answered. Parametric Form-Based Code has the capability to be an alternative approach to urban regulation in the volumetric morphology of high-density cities. The research question involves two sub-questions. In response to the first subquestion, a parametric modelling system is developed by identifying form complexity in high-density cities; by embedding form-related parameters into scripting processes; and by generating a prototype to perform and manipulate three-dimensional models with parametric software. In response to the second sub-question, a parametric modelling system is experimentally implemented in an in-context Form-Based Code. Establishing an evaluation system with multiple standards confirms that the parametric modelling system for FormBased Code has positive implications for urban regulation in the volumetric morphology of high-density cities.

Using Tsim Sha Tsui area of Hong Kong as an experimental site, the research demonstrates how a parametric modelling system provides dynamic solutions rather than static layouts for Form-Based Code. Compared with manual sketching and modelling, the parametric modelling system reflects real-time performance feedback through manipulating parameters. This feedback helps 
local planners, designers and architects to describe their regulatory intentions and provide visualised images so the public can easily understand what will happen where. Parametric urban regulation bridges urban regulation specialists and communities. It contributes to the enhancement of Form-Based Code generation and implementation in a high-density environment. The parametric Form-Based Code proposed in this dissertation works to shape the urban form and describes the possible development of morphology. Issues such as land use division, building functions and community mixing are not addressed. The following section concludes with the implications of the parametric modelling system for urban regulation. 


\subsection{Implications for urban regulation}

A parametric modelling system for urban regulation has been experimentally implemented in Form-Based Code in this research. The implementation aligns with Form-Based Code's generation phases in virtual environments. Foreseeable implications for urban regulation are concluded as:

1. Enlarging the range and components of regulation

2. Team reorganisation

3. Reforming local planning mechanisms

One research implication is an expansion of urban regulation's range and components by extending Form-Based Code to the volumetric morphology of high-density cities. The representative urban regulation contains two types, namely land use-based and form-based. Form can be performed by threedimensional models while land use cannot. Thus Form-Based Code is selected as the original regulation approach with which to create directly visualised layouts. Prior to this research, Form-Based Code has been applied mainly in the USA. Generating Form-Based Code in Hong Kong expands the range of this approach to include a new context in Asia. Form transformation in Form-Based Code is described as from natural zone to urban core zone. This research continues that transformation by incorporating forms after the urban core zone. Underground, ground and upper ground regulations with diversified form-based zones are new components added to the original Form-Based Code.

Another research implication is the reorganisation of the urban regulation team. The former regulation team comprises urban planners, designers and architects who are accustomed to conventional design methods. Parametric Form-Based Code teams should include experts with multiple discipline backgrounds, including municipal staff, consultant assistants and three-dimensional modelling specialists. Training is necessary for the team to conduct the new 
approach. The theme of parametric Form-Based Code expertise is expected to be further studied in terms of architecture education, urban regulation training and multi-professional collaboration.

Furthermore, local planning mechanisms must be reformed if implementing parametric Form-Based Code in context. The Parametric Form-Based Code explored in this research provides a novel approach and specialist team for urban regulation. These changes impact the workflow, organisation structure and cooperation between departments. For instance, Hong Kong's urban planning is structured by four grades, including Ordinance, By-law, Statutory order, and Code of practice from top to bottom. Each grade is conducted by specific departments. Embedding parametric Form-Based Code into the mature hierarchy is a challenge for both urban planning and management. This research proposes a mode of embedding parametric Form-Based Code into the planning mechanism. The mode suggests that Form-Based Code works as a special code in Code of practice level at the testing stage. When positive results are received through real-world practice, the code can be improved as Statutory order, Bylaw, even Ordinance, as Miami 21 Code is. The implications for local planning mechanisms is significant for urban development both in academia and practice. 


\subsection{Future studies}

The field of parametric urban regulation is rich for future studies. Implementing parametric modelling systems in Form-Based Code provides opportunities for urban regulation designers to model their intentions at the early stage of a project. A parametric Form-Based Code has potential to facilitate urban regulation in the volumetric morphology of high-density cities. The theoretical and technical capability of parametric Form-Based Code has been proved using Tsim Sha Tsui area of Hong Kong as the experimental site. Yet hitherto, the implementation quality of parametric urban regulation remains unclear. As Beirao et al. (2011) points out, cities are as complex and self-organising as any other open system. Development conditions and contexts vary, especially in the compact metropolis. Parametric urban regulation needs further examination in other areas of Hong Kong or in other high-density cities with a volumetric morphology and high-density context. Whether to replace conventional regulation methods with parametric methods and, if yes, how to replace these methods, must be identified through deeper investigation.

Future applications of the parametric Form-Based Code need further study. Form-Based Code can work as a part of the land-use regulatory system as the former chapters analysed. Its application capability is examined in multiple cities, working as a mandatory code that replace the former land use-based code, or as a hybrid code that specifically regulate one district in land use-based code framework, or an optional code that communities and developers can choose to use. While for the Form-Based Code enhanced by parametric capabilities, the application is very limited up to days. Future studies of the application of parametric Form-Based Code may focus on generating relatively universal parametric scripts that can be reused in different Form-Based Code implementations, or exanimating the feasibility of parametric Form-Based Code in regions with different urban morphologies rather than only in high-density cities, or extending the parametric modelling system to the whole land use- 
based regulatory system rather than only in Form-Based Code framework.

This research generates a parametric system for zoning and modelling in FormBased Code for the first time. The results include example regulating plans for multiple grounds, example code pages, and parametric massing models. The parameters that used in the parametric system in this dissertation are based on the former Form-Based Code applications. There is a research potential to explore more parameter types specific for volumetric morphology of highdensity cities, such as the distance between high-rise buildings or the ratio of urban green land. Specific standards for building, public space, signage, and parking can also potentially be performed through parametric instruments. It may be of interest to establish new parametric modelling components for specific standards to deeper realise smart urban regulation and place this research into a wider range of contexts, even the cities imaged in movie Blade Runner and Metropolis.

Urban regulation is extended to three-dimensional performance. It is interpreted with parametric models rather than through texts and hand drawings. Conventional regulation methods that urban planners, designers and architects are familiar with rely on manual design tools that have been used for a long time. Transferring the accustomed methods to parametric methods may be accomplished by adjusting discipline courses, arranging workshops or organising post-school education. Training parametric Form-Based Code specialists is a significant theme to be further considered.

The parametric modelling system provides differentiated regulation scenarios in real-time, yet there is no mature assessment strategy to evaluate these scenarios. Urban regulation is a complicated process which involves design teams, developers and stakeholders. The uncertainty of cultural, social and economic backgrounds leads to diversified regulation tendencies. This research 
develops an evaluation system customised for a parametric Form-Based Code of Hong Kong. Further research about establishing an elaborate evaluation mechanism in vibrant contexts will significantly contribute towards more practical parametric urban regulation. 


\section{Bibliography}


Agkathidis, A. and Brown, A. (2013). Three-structure canopy: A case study in design and fabrication of complex steel structures using digital tools. International Journal of Architecture Computing, 11, 87-104.

Ahmed, C. F. and Sekar, S. P. (2013). Three-dimensional (3D) volumetric analysis as a tool for urban planning: A case study of Chennai. WIT Transactions on Ecology and the Environment, 179, 731-742.

Aish, R. and Woodbury, R. (2005). Multi-level interaction in parametric design. Frauenworth Cloister: Springer.

Alexander, E. R. (1993). Density measures: A review and analysis. Journal of Architectural and Planning Research, 10, 181-202.

Arbury, J. (2005). From urban sprawl to compact city: An analysis of urban growth management in Auckland. Pennsylvania: CiteSeer.

Arendt, H. (1958). The human condition Chicago. Illinois: University of Chicago Press.

Autodesk Incorporated. (2015). Project Galileo. Retrieved November 24, 2015, from https://labs. autodesk.com/utilities/galileo.

Barnett, J. (2011). City design: Modernist, traditional, green, and systems perspectives. UK: Routledge.

Barnett, J. (2016). City design: Modernist, traditional, green and systems perspectives. Abingdon: Routledge.

Barry, J. M. (2008). Form-based codes: Measured success through both mandatory and optional implementations. Connecticut Law Review, 41, 305-337.

Basiago, A. D. (1998). Economic, social, and environmental sustainability in development theory and urban planning practice. Environmentalist, 19, $145-161$

Bassett, E. M. (1922). Zoning versus private restrictions. Baltimore Municipal Journal, 6, 2. 
Batty, M., et al. (2012) Smart cities of the future. The European Physical Journal Special Topics, 214, 481-518.

Beirão, J. N., et al. (2011). Parametric urban design: An interactive sketching system for shaping neighbourhoods. Proceedings of the 29th Conference on Education and Research in Computer Aided Architectural Assign in Europe, 279-288.

Ben-Joseph, E. (2009). Commentary: Designing codes: Trends in cities, planning and development. Urban Studies, 46, 2691-2702.

Ben-Joseph, E. and Kiefer, M. J. (2005). The code of the city: Standards and the hidden language of place making. Massachusetts: The Massachusetts Institute of Technology press.

Benfield, F. K., et al. (2001). Solving sprawl: Models of smart growth in communities across America. New York: Natural Resources Defence Council.

Benfield, K. (2010). Miami 21 leads the way on zoning reform. Retrieved March 21, 2017, from

https://www.smartcitiesdive.com/ex/sustainablecitiescollective/miami-21leads-way-zoning-reform/7933/.

Bengston, D. N., et al. (2004). Public policies for managing urban growth and protecting open space: Policy instruments and lessons learned in the United States. Landscape and urban planning, 69, 271-286.

Berghauser, P. M. and Haupt, P. A. (2009). Space, density and urban form. Delft: Delft University of Technology.

Bettman, A. (1925). The fact bases of zoning. City Planning, 2, 86-95.

Billings Industrial Revitalization District incorporated. (2014). Tax Increment Financing. Retrieved Auguest 18, 2016, from http://www.billingsbird.com/revitializing-east-billings/.

Black, H. C. (1995). Black's Law Dictionary Second Edition. New Jersey: The Lawbook Exchange Limited. 
Boeing, G., et al. (2014). LEED-ND and Liveability Revisited. Berkeley Planning Journal, 27, 31-55.

Boer, R., et al. (2007). Neighbourhood design and walking trips in ten US metropolitan areas. American Journal of Preventive Medicine, 32, 298304.

Bohl, C. C. and Plater-Zyberk, E. (2006). Building community across the rural-to-urban transect. Places, 18, 4-17.

Bonnes, M., et al. (1990). The city as a multi-place system: An analysis of people - urban environment transactions. Journal of environmental psychology, 10, 37-65.

Borys, H., et al. (2014). Form-Based Codes? You are not alone. Retrieved October 18, 2015, from http://www.placemakers.com/how-weteach/codes-study/.

Brueckner, J. K. (2000). Urban sprawl: Diagnosis and remedies. International Regional Science Review, 23, 160-171.

Bruegmann, R. (2005). Sprawl: A compact history. Chicago: University of Chicago Press.

Building Department of Hong Kong. (2016). Sustainable Building Design Guidelines. Retrieved June 2, 2017, from http:www.bd.gov.hk/English/documents/pnap/APP/APP152.pdf.

Burdett, R., et al. (2011). Cities, health and well-being. Report at the Hong Kong Urban Age Conference, Hong Kong. Retrieved March 20, 2017 from http://downloads0.cloud.1secities.net/downloads/2011/11/2011_chw_hong -kong-newspaper.pdf.

Burdette, J. T. (2004). Form-based codes: A cure for the cancer called Euclidean zoning (Master's dissertation). Virginia Polytechnic Institute and State University, Virginia, USA.

Calthorpe, P. and Fulton, W. (2001). The regional city. Washington D. C.: Island Press. 
Canham, S. and Wu, R. (2008). Portraits from above: Hong Kong's informal rooftop communities. Berlin: Peperoni Books.

Carmona, M. (2009). Design coding and the creative, market and regulatory tyrannies of practice. Urban Studies, 46, 2643-2667.

Carmona, M. and Punter, J. (1997). The design dimension of planning: Theory, content, and best practice for design policies. UK: Taylor and Francis.

CATS (2017). Land use principles. Retrieved November 1, 2017, from https://transect.org/.

Census and Statistics Department of Hong Kong. (2015). Population statistics. Retrieved August 11, 2017, from https://www.censtatd.gov.hk.

Chan, Y. K. (1999). Density, crowding and factors intervening in their relationship: Evidence from a hyperdense metropolis. Social Indicators Research, 48, 103-124.

Cheng, V. (2009). Understanding density and high density. Designing highdensity cities. London: Earthscan.

Chicago Metropolitan Agency for Planning (CMAP). (2012). Annotated agenda. Retrieved September 5, 2015, from http://www.cmap.illinois.gov/documents/10180/84319/FullPacket6-82011.pdf/25f07fb6-4b08-41bb-96e6-0f81ee7c139f.

Churchman, A. (1999). Disentangling the concept of density. Journal of Planning Literature, 13, 389-411.

City of Bellevue. (2014). Form-Based Code of City of Bellevue. Retrieved April 12, 2016, from

https://formbasedcodes.org/content/uploads/2014/08/Bellevue-FormBased-Code_Article-XXI_FBC.pdf.

City of Benicia. (2007). Downtown Mixed Use Master Plan of Benicia.

Retrieved April 14, 2017, from

https://formbasedcodes.org/content/uploads/2014/02/benicia-downtownmixed-use-master-plan.pdf. 
City of Billings. (2014). East Billings Renewal District Code. Retrieved May

21, 2017, from

https://formbasedcodes.org/content/uploads/2014/06/EBURD-

CODE21.pdf.

City of Bradenton. (2011). Web-GIS system of Form-Based Code in

Bradenton, Retrieved November 1, 2016, from

http://cityofbradenton.maps.arcgis.com/apps/OnePane/basicviewer/index.

html?appid=cfe3dd5890c641ad926c402385f26758.

City of California. (2010). California Planning and Development Report.

Retrieved November 1, 2017, from http://www.cp-dr.com/articles/node2770.

City of Cincinnati. (2013). Form-Based Code of City of Cincinnati. Retrieved

March 10, 2016, from https://www.cincinnati-

oh.gov/planning/assets/File/CFBC_1703_FBC_FinalDraft_021513_web( 1).pdf.

City of Clayton, Delaware. (2014). Delaware Code. Retrieved October 29,

2016, from

https://www.completecommunitiesde.org/planning/landuse/zoning/

City of Euclid. (2018). Euclidean zoning historical documents. Retrieved

December 1, 2018, from

http://www.cityofeuclid.com/community/development/PlanningandZonin gDivision/EuclideanZoningHistoricDocuments

City of Flagstaff. (2011). Regulating plan of Flagstaff Downtown Code.

Retrieved November 1, 2017, from

https://www.flagstaff.az.gov/DocumentCenter/View/57155/Zoning-

Map?bidId=.

City of Hammonton. (2011). Regulating plan of Hammonton Form-Based

Code. Retrieved November 1, 2017, from

https://ianlitwin.wordpress.com/master-plans-codes/hammonton-fbc/. City of Los Angeles. (2013). Los Angeles Plan Recode. Retrieved May 15, 
2017, from https://recode.la/updates/news/types-zoning-codes.

City of Miami. (2009). Miami 21 Code. Retrieved June 20, 2016, from

http://www.miami21.org/finalcode.asp.

City of Miami. (2015). Miami 21 Amended Codes. Retrieved September 28,

2016, from http://www.miami21.org/final_code_May2015.asp.

City of Montgomery. (2007). Downtown Montgomery Plan. Retrieved

October 1, 2016, from

https://static1.squarespace.com/static/5612e13ae4b0c37386e86b7e/t/5685

605ad8af102bf3cfa166/1451581530960/Montgomery_low+res.pdf.

City of Montgomery. (2014). SmartCode Montgomery. Retrieved June 20,

2016, from http://www.montgomeryal.gov/home/showdocument?id=129.

City of Nashville, (2017). Downtown Code for Nashville, Tennessee.

Retrieved May 21, 2017, from

https://formbasedcodes.org/content/uploads/2017/04/The-Downtown-

Code.pdf.

City of Virginia Beach. (2017). Ocean Front Resort District Form-Based

Code of City of Virginia Beach. Retrieved November 1, 2017, from

https://www.vbgov.com/government/departments/sga/projects/Pages/Oce anfront-Resort-District-Form-Based-Code.aspx.

Civil Engineering and Development Department of Hong Kong. (2012).

Green Master Plan. Retrieved May 29, 2017, from

http://www.cedd.gov.hk/eng/greening/tst/theme.html.

Clarke, K. C. (1986). Advances in geographic information systems.

Computers, Environment and Urban Systems, 10, 175-184.

Clay, G. (1980). Crossing the American grain with Vesalius, Geddes, and

Jackson: The cross section as a learning tool. In everyday America:

Cultural landscape studies after J.B. Jackson. Chicago: University of

Chicago Press.

CNU. (2015a). The charter of the New Urbanism. Retrieved August 8, 2015, from https://www.cnu.org/who-we-are/charter-new-urbanism. 
CNU. (2015b). Duany's idea from eco-system. Retrieved June 22, 2015, from https://www.cnu.org/resources/tools.

CNU. (2015c). What is New Urbanism. Retrieved August 8, 2015, from https://www.cnu.org/resources/what-new-urbanism.

Crawford, J. H. (2000). Carfree cities. Charlbury: International Books.

Davis, D. (2013). A history of parametric [Blog post]. Retrieved July 18, 2017, from http://www.danieldavis.com/a-history-of-parametric/.

Development Bureau of Hong Kong. (2011). Urban Renewal Strategy. Retrieved March 15, 2016, from https://www.devb.gov.hk/filemanager/en/Content_3/URS_eng_2011.pdf.

Dewolf, C. (2002). Why new urbanism fails. Retrieved June 12, 2016, from https://www.planetizen.com/node/42.

Dover, Kohl and Partners. (2007). Montgomery Downton Plan and Code. Retrieved June 20, 2016, from https://www.doverkohl.com/montgomery/.

DPZ. (2015). Smart Code version 9.2. Retrieved December 2, 2015, from https://transect.org/codes.html.

DPZ. (2009). The transect. Retrieved December 15, 2015, from https://www.cnu.org/publicsquare/transect.

Duany, A. and Talen, E. (2001). Making the good easy: The smart code alternative. Fordham Urban Law Journal, 29, 1445-1468.

Dubos, R. (1965). Man adapting. New Haven: Yale University Press.

Eastman, C. M., et al. (2008). BIM Handbook: A guide to Building Information Modelling for owners, managers, designers, engineers, and contractors. New Jersey: John Wiley \& Sons.

Elliott, D. L., et al. (2012). The rules that shape urban form. Chicago: American Planning Association.

Ellis, C. (2002). The New Urbanism: Critiques and rebuttals. Journal of Urban Design, 7, 261-291.

Emerson, C. D. (2006). Making main street legal again: The SmartCode solution to sprawl. Retrieved April 24, 2017, from 
http://law.bepress.com/expresso/eps/954/.

EPA. (2018). Smart scorecard for development projects. Retrieved May 15, 2016, from https://www.epa.gov/smartgrowth/smart-scorecarddevelopment-projects.

Esther, L. and Li, S. (2014). Kowloon cultural district: An investigation into spatial capabilities in Hong Kong. Hong Kong: MCCM Creations.

Ewing, R. H. (2005). Endangered by sprawl: How runaway development threatens America's wildlife. Washington, DC: National Wildlife Federation.

Faga, B. (2014). Formers versus zoners: How and why communities shift to form-based zoning (Doctoral dissertation). Georgia Institute of Technology, Atlanta, USA.

FBCI. (2014). Transition from rural to downtown. Retrieved June 22, 2014, from http://formbasedcodes.org/content/uploads/2014/08/.

FBCI. (2015a). Form-Based Code definition. Retrieved May 12, 2017, from https://formbasedcodes.org/definition/.

FBCI. (2015b). What are Form-Based Codes? Retrieved November 1, 2017, from https://formbasedcodes.org/.

FBCI. (2015c). Miami 21. Retrieved June 21, 2016, from https://formbasedcodes.org/?s=Miami $+21+$ Code + is + the + most + sophisticat ed+applicatio.

FBCI. (2017). Downtown Code for Nashville, Tennessee. Retrieved February 1, 2018, from https://formbasedcodes.org/codes/downtown-codenashville-tennessee/.

Fleissig, W. and Jacobsen, V. (2002). Smart Scorecard for Development Projects. Retrieved June 16, 2016, from https://www.epa.gov/sites/production/files/201402/documents/scorecard_expfleissigjacobsen.pdf.

Forsyth, A. (2003a). Twentieth-century planning history. Journal of Planning History, 2, 181-184. 
Forsyth, A. (2003b). Measuring density: Working definitions for residential density and building intensity. Design brief, 8, 2-8.

Frampton, A., et al. (2012). Cities without ground: A Hong Kong guidebook. Hong Kong: Oro editions.

Franzman, S. (2010). Hitler's geographer: Walter Christaller and Nazi Academics. Retrieved June 22, 2016, from http://www.jpost.com/Magazine/Features/Article.aspx?id=186068.

Frug, G. E. (1999). City making: Building communities without building walls. Princeton: Princeton University Press.

Frumkin, H. (2004). Urban sprawl and public health: Designing, planning, and building for healthy communities. Washington, DC: Island Press.

Garde, A., et al. (2015). Differences between Miami's form-based code and traditional zoning code in integrating planning principles. Journal of the American Planning Association, 81, 46-66.

Garnett, N. S. (2013). Redeeming Transect Zoning. Brooklyn Law Review, 78, 571-588.

Garvin, E. and Jourdan, D. (2008). Through the looking glass: Analysing the potential legal challenges to Form-Based Codes. Journal of Land Use and Environmental Law, 23, 395-421.

Geller, R. S. (2010). The legality of form-based zoning codes. Journal of Land Use and Environmental Law, 26, 35-91.

Geofabrik. (2017). OpenStreetMap. Retrieved January 21, 2018, from https://www.geofabrik.de/geofabrik/openstreetmap.html.

Gerber, D. (2007). Parametric practices: Models for design exploration in architecture. Cambridge: Harvard University.

Gil, J., et al. (2010). Assessing computational tools for urban design: Towards a city information model. Proceedings of the 28th Education and Research in Computer Aided Architectural Design in Europe (eCAADe) Conference, 361-369.

Glaeser, E. L. and Kahn, M. E. (2003). Sprawl and urban growth. Retrieved 
April 20, 2016, from https://ssrn.com/abstract=412880.

Gonzalez, G. A. (2009). Urban sprawl, global warming, and the empire of capital. Albany: State University of New York Press.

Gunder, M. (2011). Commentary: Is urban design still urban planning? An exploration and response. Journal of Planning Education and Research, 31, 184-195.

Haarhoff, E., et al. (2016). Does higher density housing enhance liveability? Case studies of housing intensification in Auckland. Cogent Social Science, 2, 1243289.

Haas, T. (2008). New Urbanism and beyond: Designing cities for the Future. New York: Rizzoli International Publications.

Hall, P. G. (2002). Cities of tomorrow: An intellectual history of urban planning and design in the twentieth century (3rd ed.). Oxford: Blackwell Publication.

Hansen, G. (2014). Design for healthy communities: The potential of formbased codes to create walkable urban streets. Journal of Urban Design, 19, 151-170.

Hascic, I. (2006). Essays on land use regulation (Doctoral dissertation). Oregon State University, Oregon, USA.

Hascic, I. and Wu, J. (2004). Land use and watershed health in the United States. Land Economics, 82, 214-239.

Hassinger, J. R., et al. (2001). Applications of performance zoning for industrial uses in Hanover County. Retrieved April 19, 2016, from http://www.richmondregional.org/Publications/Reports_and_Documents/ Planning/Hanover/Hanover_Industrial_Zoning.pdf.

Hirt, S. A. (2015). Zoned in the USA: The origins and implications of American land-use regulation. New York: Cornell University Press.

Holistic City Company. (2015). What is CityCAD. Retrieved November 12, 2015, from https://www.holisticcity.co.uk/index.php/citycad.

Holm, I. R. (2006). Ideas and beliefs in architecture and industrial design: 
How attitudes, orientations, and underlying assumptions shape the built environment (Doctoral dissertation). Oslo School of Architecture and Design, Oslo, Norway.

Howard, E. (1898). To-morrow: A Peaceful Path to Real Reform. Bath: Swan Sonnenschein \& Co.

Hudson, R. (2010). Strategies for parametric design in architecture: An application of practice led research. Bath: University of Bath.

Imrie, R. and Street, E. (2006). The attitudes of architects towards planning regulation and control. The Codification and Regulation of Architects' Practices, Kings College London, UK.

Imrie, R. and Street, E. (2009). Regulating design: The practices of architecture, governance and control. Urban Studies, 46, 2507-2518.

Inniss, L. B. (2007). Back to the future: Is Form-Based Code an efficacious tool for shaping modern civic life. University of Pennsylvania Journal of Law and Social Change, 11, 75-103.

Jabi, W., Johnson, B., and Woodbury, R. (2013). Parametric design for architecture. London: Laurence King Publishing.

Jacobs, J. (1961). The death and life of great American cities. New York: Modern Library.

Kan, C. H. (2012). Form-based urban planning code and its implications in Hong Kong (Master's dissertation). The University of Hong Kong, Pokfulam, Hong Kong.

Katz, P. (2004). Form first: The New Urbanist alternative to conventional zoning. Planning, 11, 16-20.

Kayden, J. (2011). The law of urban design. Companion to urban design. New York: Routledge.

Kendig, L., et al. (1980). Performance zoning. Washington, DC: Planners Press. 
Kim, J. B. (2014). Parametric urban regulation models for predicting development performances (Doctoral dissertation). Texas A\&M University, Texas, USA.

Kim, J. B. and Clayton, M. J. (2010). Support Form-Based Codes with Building Information Modelling - The parametric urban model case study. Proceedings of the 30th Association for Computer Aided Design in Architecture (ACADIA) conference, 133-138.

Kim, J. B., et al. (2011). Parametric Form-Based Codes: Incorporation of landuse regulations into building information models. Proceedings of the 31 th Association for Computer Aided Design in Architecture (ACADIA) conference, 217-223.

Kim, K. (2010). The evaluation of the impact of form-based code and conventional zoning on Fort McPherson redevelopment (Master's Dissertation). Georgia Institute of Technology, Atlanta, USA.

Knuth, D. (1969). Semi-numerical algorithms, The art of computer programming. Massachusetts: Addison Wesley.

Kropf, K. (1996). Urban tissue and the character of towns. Urban Design International, 1, 247-263.

Lai, C. (2010). Treating the symptoms - A critical review of urban renewal in Hong Kong. Hong Kong: Civic Exchange.

Lemar, A. S. (2015). Zoning as taxidermy: Neighbourhood conservation districts and the regulation of aesthetics. Indiana Law Journal, 90, 15251590.

Leyhausen, P. (1971). Dominance and territoriality as complemented in Mammalian social structure. Behaviour and Environment. New York: Plenum.

Ligmann-Zielinska, A. (2008). Exploring normative scenarios of land use development decisions with an agent-based simulation laboratory (Doctoral dissertation). University of California, California, USA. Logan, T. (2016). OpenStreetMap Data Component. Retrieved May 15, 2016, 
from https://www.food4rhino.com/app/elk.

Madden, M. E. and Spikowski, B. (2006). Place making with Form-Based Code. Urban Land, 9, 174-178.

Mahendriyani, D. (2016). LEED-ND: The future of urbanism in Asia.

Retrieved June 1, 2017, from

http://www.asiagreenbuildings.com/12953/leed-nd-the-future-of-

urbanism-in-asia/.

Maliene V., et al. (2011). Geographic information system: Old principles with new capabilities. Urban Design International, 16, 1-6.

MAP, (2007). Smart growth tactics. Retrieved June 1, 2017, from https://www.mml.org/pdf/map_article_issue28.pdf.

Marshall, A. (1999). Building New Urbanism: Less filling, but not so tasty. Builder Magazine. Retrieved 1 Nov, 2013 from http://www.alexmarshall.org/2006/08/02/building-new-urbanism-lessfilling-but-not-so-tasty/

Mayhew, S. (2015). A dictionary of geography. Oxford: Oxford University Press.

Merriam-Webster Incorporated. (2018). Merriam-Webster Dictionary. Retrieved December 12, 2018, from https://www.merriamwebster.com/legal/Euclidean\%20zoning

MTR Cooperation Limited. (2013) 2012 Annual Report of MTR Corporation: Sharing our growth. Retrieved May 21, 2017, from http://www.mtr.com.hk/en/corporate/investor/2012frpt.html.

MTR Cooperation Limited. (2017). Map of Tsim Sha Tsui Mass Transit Railway (MTR) Station. Retrieved June 1, 2017, from http://www.mtr.com.hk/en/customer/tourist/index.php

Nagy, D. (2009). Urban magazine: Towards a collective purpose. Publication of the students of Columbia University, Columbia, USA. 
Oliveira, E. A., et al. (2015). Distributed and heterogeneous data analysis for smart urban planning. Proceedings of International Conference on Computer-Aided Architectural Design Futures, 37-54.

Oliveira, V. (2016). Urban morphology: An introduction to the study of the physical form of cities. New York: Springer International Publishing.

OpenStreetMap Foundation. (2017). Screenshot of OSM interface. Retrieved March 21, 2017, from https://www.openstreetmap.org/\#map=13/22.3072/114.1616\&layers=DG.

Parolek, D. G. (2013). Addressing Form-Based Code misconceptions and common mistakes. Zoning Practice, 5.

Parolek, D. G., et al. (2008). Form based codes: a guide for planners, urban designers, municipalities, and developers. New Jersey: John Wiley \& Sons.

Pendall, R. (2000). Local land use regulation and the chain of exclusion. Journal of the American Planning Association, 66, 125-142.

Planning Department of Hong Kong. (2015). Underground Space Development in the Selected Strategic Urban Areas. Retrieved August 29, 2015, from https://www.urbanunderground.gov.hk/main.php?locale=en.

Planning Department of Hong Kong. (2016). The Facts Town Planning. Retrieved March 11, 2018, from https://www.gov.hk/en/about/abouthk/factsheets/docs/town_planning.pdf. Planning Department of Hong Kong. (2017). Underground Space Development in the Selected Strategic Urban Areas. Retrieved May 21, 2017, from http://www.urbanunderground.gov.hk/main.php?locale=en.

Planning Department of Hong Kong. (2018). Hong Kong Planning Standards and Guidelines. Retrieved May 24, 2018, from https://www.pland.gov.hk/pland_en/tech_doc/hkpsg/sum/pdf/sum.pdf. Procedural Incorporated. (2015). Overview of Esri CityEngine. Retrieved November 24, 2015, from https://www.procedural.com/cityengine. 
Purdy, J. R. (2007). Form-based codes - new approach to zoning. Retrieved February 12, 2016, from https://www.mml.org/pdf/map_article_issue28.pdf.

Rangwala, K. (2013). Assessing criticisms of Form-Based Codes. Retrieved July 19, 2017, from https://formbasedcodes.org/articles/assessing-formbased-code-criticisms/.

Rapoport, A. (1975). Toward a redefinition of density. Environment and Behaviour, 7, 133-158.

Reilly C. (2014). What is Grasshopper? Retrieved June 20, 2017, from https://www.lynda.com/Grasshopper-tutorials/WhatGrasshopper/174491/194087-4.html.

Rodrigue, J. (2017). The geography of transport systems. New York: Routledge.

Rogers, H. (1987). Theory of recursive functions and effective computability. Massachusetts: The Massachusetts Institute of Technology press.

Russell, J. S. (1994). Rethinking conventional zoning. Planning Commissioners Journal, 15, 6-9.

Russell, J. S. and Madden, M. (2015). An introduction to Form-Based Code. Retrieved March 2, 2016, from https://formbasedcodes.org/content/uploads/2015/05/FBC-PlannersWebArticle-Dec2014a.pdf.

Salingaros, N. and Mena-Quintero, F. (2010). A brief history of peer-to-peer urbanism. Retrieved October 21, 2018, from http://zeta.math.utsa.edu/ yxk833/abriefhistoryofp2purbanism.pdf

Schumacher, P. (2009). Parametricism - A new global style for architecture and urban design. Architectural Design, 79, 14-23.

Scott, M. L. (2009). Programming language pragmatics. Massachusetts: Morgan Kaufmann Publishers.

Scott, M., et al. (2013). The use of smart growth scorecards/assessment tools to advance sustainable land use practices. Report of Institute for Public 
Administration, University of Delaware. Retrieved May 1, 2017, from udspace.udel.edu/bitstream/handle/19716/21598/smart-growthscorecards-2016.pdf.

Shelton, B., et al. (2011). The making of Hong Kong: From vertical to volumetric. New York: Routledge.

Shigley, P. (2006). In a state known for sprawl, high-rise infill is the surprising new trend. Planning, 72, 44-47.

Singh, S. S. (2010). Form-based codes: An alternative method for development regulation. Institute of Town Planners India Journal, 7, $27-$ 33.

Slone, D. K. (2008). A legal guide to urban and sustainable development for planners, developers, and architects. New Jersey: Wiley.

Smart Growth America's Leadership Institute. (2007). Smart Growth Project Scorecard Version 1.0. Retrieved June 12, 2018, from https://www.smartgrowthamerica.org/app/legacy/documents/scorecard.pd f.

Smith, D. K. and Tardif, M. (2009). Building Information Modelling: A strategic implementation guide for architects, engineers, constructors, and real estate asset managers. New Jersey: John Wiley \& Sons.

Squires, G. D. (2002). Urban sprawl: Causes, consequences and policy responses. Washington, DC: The Urban Institute Press.

Stephenson, B. (2002). The roots of the New Urbanism: John Nolen's garden city ethic. Journal of Planning History, 1, 99-123.

Stokols, D. (1972). On the distinction between density and crowding: Some implications for future research. Psychological Review, 79, 275-277.

Sullivan, J. (2005). Future tense: Trend 12. Builder, December.

Suyoto, W., et al. (2015). Parametric approach as a tool for decision-making in planning and design process. Procedia-Social and Behavioural Sciences, 184, 328-337.

Talen, E. (2002). The social goals of new urbanism. Housing policy debate, 
$13,165-188$.

Talen, E. (2009). Design by the rules: The historical underpinnings of FormBased Codes. Journal of the American Planning Association, 75, 144160.

Talen, E. (2013). Zoning for and against sprawl: The case for form-based code. Journal of Urban Design, 18, 175-200.

Tausworthe, R. C. (1977). Standardized development of computer software part 1 methods. Englewood Cliffs: Prentice-Hall, Inc.

Taylor, R. (1973). Development control systems for group and cluster housing (Unpublished master's dissertation). University of Witwatersrand, Gauteng, South Africa.

Thilakaratne, R. and Lew, V. (2011). Is LEED leading Asia: An analysis of global adaptation and trends? Procedia Engineering, 21, 1136-1144.

Thilakaratne, R. and Schnabel, M. A. (2013). Will LEED survive in Asia? Proceedings of the 47th International Conference of the Architectural Science Association, 385-394.

Tomlinson, R. F. (2003). Thinking about GIS: Geographic Information System planning for managers. California: Esri Press.

Town Planning Board of Hong Kong. (2008). Tsim Sha Tsui Planning in the Town Planning Ordinance. Retrieved May 21, 2017, from https://www.pland.gov.hk/pland_en/info_serv/tp_plan/stat_plan/kozp.htm 1.

USGBC. (2018). LEED Version 4 for Neighbourhood Development. Retrieved September 1, 2017, from https://www.usgbc.org/sites/default/files/LEED\%20v4\%20ND_01.5.18_c urrent.pdf.

Von Thunen, J. H. (1826). The isolated state. Oxford: Pergamum.

Wendell Cox Consultancy. (2016). Demographia World Urban Areas.

Retrieved June 12, 2016, from http://demographia.com/db-worlduaintro.pdf. 
Wickersham, J. (2001). Jane Jacob's critique of zoning: From Euclid to Portland and beyond. Boston College Environmental Affairs Law Review, $28,547-563$.

Woodbury, R. (2010). Elements of parametric design. New York: Routledge.

Woodbury, R., et al. (2006). Parametric modelling as a design representation in architecture: A process account. Proceedings of Canadian Design Engineering Network Conference, 8 pgs.

Woodward, K. A. (2013). Form over use: Form-Based Codes and the challenge of existing development. Notre Dame Law Review, 88, 2627 2654.

World Health Organisation. (2016). Global Health Observation. Retrieved December 10, 2018, from https://www.who.int/gho/urban_health/situation_trends/urban_population _growth_text/en/

Zack, T. and Silverman M. (2007). Using regulation as a tool for better urban management. Discussion document for the Development and Location Government course on urban renewal, South Africa. Retrieved July 27, 2017, from http://www.treasury.gov.za/divisions/bo/ndp/TTRI/TTRI\%20Oct\%20200 7/Day\%204\%20-\%201\%20Nov\%202007/3a\%20Regulations\%20Silverm an\%20\&\%20Zack\%20Presentation.pdf 